AUTARQUIA ASSOCIADA À UNIVERSIDADE DE SÃO PAULO

\title{
DESENVOLVIMENTO E VALIDAÇÃO DE METODOLOGIA PARA DETERMINAÇÃO DE METAIS EM AMOSTRAS DE ÁGUA POR ESPECTROMETRIA DE EMISSÃO ÓPTICA COM PLASMA DE ARGÔNIO (ICP-OES)
}

\author{
MAINARA GENEROSO FAUSTINO
}

Dissertação apresentada como parte dos
requisitos para obtenção do Grau de
Mestre em Ciências na Área
de Tecnologia Nuclear-Materiais

Orientadora:

Profa. Dra. Marycel Elena Barboza Cotrim 
INSTITUTO DE PESQUISAS ENERGÉTICAS E NUCLEARES

Autarquia associada à Universidade de São Paulo

DESENVOLVIMENTO E VALIDAÇÃO DE METODOLOGIA PARA DETERMINAÇÃO DE METAIS EM AMOSTRAS DE ÁGUA POR ESPECTROMETRIA DE EMISSÃO ÓPTICA COM PLASMA DE ARGÔNIO (ICP-OES)

\author{
MAINARA GENEROSO FAUSTINO
}

Dissertação apresentada como parte dos requisitos para obtenção do Grau de Mestre em Ciências na Área de Tecnologia Nuclear - Materiais

Orientadora:

Profa. Dra. Marycel Elena Barboza Cotrim

Versão Corrigida

Versão Original disponível no IPEN

São Paulo

2015 


\section{DEDICATÓRIA}

Aos meus pais, Marla Márcía e joão Francisco, pelo apoío e os ensinamentos da vida e a minha irmã Naomi por sempre estar ao meu lado. 


\section{AGRADECIMENTOS}

A Profa. Dra. Marycel Elena Barboza Cotrim pela oportunidade, orientação, incentivo e confiança

Ao Instituto de Pesquisas Energéticas e Nucleares (IPEN/CNEN-SP) e ao Centro de Química e Meio Ambiente (CQMA) pela disponibilização da infraestrutura para a realização deste trabalho.

A Dra. Elizabeth S. K. Dantas por ter me aceito no programa de iniciação cientifica, que foi o maior incentivador para eu ter ingressado a Pós Graduação - Mestrado.

Ao CNPq - pelo apoio financeiro concedido, processo $n^{\circ}$ 134537/2013-0.

À FAPESP - Fundação de Amparo à Pesquisa do Estado de São Paulo, pelo apoio financeiro concedido ao projeto de pesquisa que este trabalho está inserido (FAPESP $\left.n^{\circ} 2009 / 53898-9\right)$.

Ao Prof. Dr. Carlos Eduardo de Mattos Bicudo e a Profa. Dra. Denise de Mattos Bicudo do Instituto de Botânica, coordenadores do projeto temático FAPESP juntamente com a Profa. Dra. Maria Aparecida Faustino Pires do IPEN. Além da Companhia de Saneamento Básico do Estado de São Paulo (SABESP) pela parceria e o auxílio nas coletas das amostras de água e apoio logístico de campo.

A Dra. Elâine Arantes Jardim Martins e Dr. Hélio Akira Furusawa pelo auxílio nos dados estatísticos.

A MSc.a Lucilena Rebelo Monteiro pelo auxilio nas pesquisas, nos cálculos estatísticos e principalmente pela amizade, carinho e incentivo.

Ao Dr. Olívio Pereira de Oliveira Junior pelos ensinamentos.

As minhas companheiras de laboratório: Thamiris B. Stellato, Sabrina M. V. Soares, Tatiane B. S. C. Silva e Joyce R. Marques pelo incentivo. E não mesmo importante o Douglas B. da Silva que me ajudou muito nas pesquisas sobre a Guarapiranga. 
Ao Elias Silveira e a Sabine Neusatz Guilhen que me animaram muito, quando estava no laboratório analisando as amostras.

Aos meus queridos pais que sempre estão me ensinando, incentivando e me dando muito amor e carinho quando eu mais preciso e a minha irmã que tenho um carinho muito especial.

Agradeço a todos que contribuíram para a realização deste trabalho.

Obrigada! 


\section{EPÍGRAFE}

"O homem não pode viver isolado. Lembre-se de que cada companheiro de jornada é um amigo que o ajuda e a quem você precisa também ajudar. Cooperação existe entre todas as coisas criadas. Procure você também cooperação com tudo e com todos, em benefício da própria Terra, em que o acolhe bondosamente, permitindo a sua evolução. Ajude sempre, e jamais desanime”.

C. Torres Pastorino. 


\title{
DESENVOLVIMENTO E VALIDAÇÃO DE METODOLOGIA PARA DETERMINAÇÃO DE METAIS EM AMOSTRAS DE ÁGUA POR ESPECTROMETRIA DE EMISSÃO ÓPTICA COM PLASMA DE ARGÔNIO (ICP-OES)
}

\author{
Mainara Generoso Faustino
}

\begin{abstract}
RESUMO
Para atender a legislação ambiental do Conselho Nacional do Meio Ambiente (CONAMA), a Resolução CONAMA 357/2005, é necessário desenvolver metodologias que se aplicam na medição analítica de forma correta e para um controle de qualidade é necessário a aplicação da validação de metodologia. Para atender as exigências legais, o presente trabalho desenvolveu uma metodologia para a identificação de 12 elementos metálicos, tais como: $\mathrm{Al}, \mathrm{Ba}, \mathrm{Ca}, \mathrm{Cd}, \mathrm{Cr}, \mathrm{Cu}, \mathrm{Fe}, \mathrm{K}, \mathrm{Mg}, \mathrm{Mn}, \mathrm{Na}$ e Ni em águas, avaliando 14 pontos, sendo eles GU000-01 (23॰46'49.6”S-4647'22”0W), GU000-02 (2345'29.5”S-4646'18.7”W), GU000-03 (2344'52.2”S-4646'13.6”W), GU106-04 (2344'44.6”S-46²5'25.8”'W),

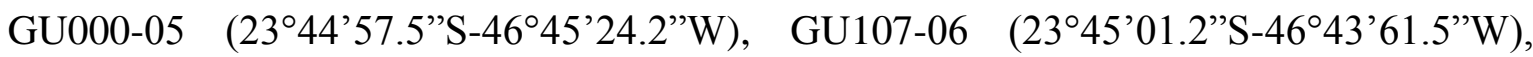
GU108-07 (2343'64.7’S-4643'42.3”W), GU000-08 (2342'96.9”S-4643'61.2”W), GU109-09 (2343'04.6”S-4643'34.0”W), GU105-10 (2342'89.9”S-4644'68.7’W), GU108-11 (2342'53.4”S-4643'44.9”W), GU103-12 (2341'88.5”S-4644'67.3”W), GU102-13 (2341'58.0”S-4643'57.3”W), GU000-14 (2340'78.2”S-4643'55.0”W), distribuídos pela Represa Guarapiranga, situada no Estado de São Paulo, aplicando a metodologia validade, realizada com base no guia do Instituto Nacional de Metrologia, Qualidade e Tecnologia (INMETRO), “Orientação sobre Validação de Métodos Analíticos - DOQ-CGCE-008". Foram avaliados os parâmetros: seletividade, faixa de trabalho/linearidade, limites de detecção e quantificação, tendência/recuperação, precisão, robustez e incerteza de medição. Foi utilizado a técnica de espectrometria de Emissão Óptica com Plasma de Argônio (ICP-OES). O teste de seletividade comprovou que a matriz não interfere nas curvas analíticas elaborada; a faixa de trabalho apresentou um comportamento linear, para as amostras com e sem a matriz de interesse, com um coeficiente de correlação (r), entre 0,9965 a 1,0; os limites de detecção e quantificação do método atendem aos valores máximos permitidos pela Resolução CONAMA 357/2005; com os testes de repetitividade e
\end{abstract}


de recuperação o método demonstrou ser preciso e exato, além de robusto. Posteriormente foi estimado uma incerteza de medição do método. A incerteza expandida estimada variou entre 3 e $18 \%$ da concentração encontrada. A validação da metodologia permitiu a sua aplicação para a avaliação da distribuição dos 12 elementos, nas águas da represa Guarapiranga. Foram observados valores altos para $\mathrm{Ca}$, $\mathrm{Na}$ e $\mathrm{K}$, em todos os pontos de coletas analisados, evidenciando que são os elementos que fazem parte da característica geológica da área. Os elementos Fe e Al obtiveram valores acima da legislação nos pontos da Represa (G000-01, G000-02 e G000-03). Com os testes dos parâmetros para a validação, com os cálculos estatísticos aplicados, foi possível desenvolver e aplicar uma metodologia adequada para o uso pretendido. 


\title{
DEVELOPMENT AND VALIDATION OF METHODOLOGY FOR DETERMINATION OF METALS IN WATER SAMPLES BY OPTICAL EMISSION WITH ARGON PLASMA SPECTROMETRY (ICP-OES)
}

\author{
Mainara Generoso Faustino
}

\begin{abstract}
To attend the environmental legislation of the National Environmental Council (CONAMA) CONAMA's Resolution 357/2005, it is necessary to develop methodologies that apply the analytical measurement correctly and to a quality control application of the methodology validation is required. To attend legal requirements, this study developed a methodology for identifying 12 metals, such as: $\mathrm{Al}, \mathrm{Ba}, \mathrm{Ca}, \mathrm{Cd}, \mathrm{Cr}, \mathrm{Cu}, \mathrm{Fe}, \mathrm{K}, \mathrm{Mg}, \mathrm{Mn}, \mathrm{Na}$ and $\mathrm{Ni}$ in water in 14 points, being them GU000-01 (2346'49.6”S-4647'22”0W), GU000-02 (2345'29.5”S-4646'18.7”W), GU000-03 (2344'52.2”S-4646'13.6”W), GU106-04 (2344'44.6”S-4645'25.8”W), GU000-05 (2344'57.5”S-4645'24.2”W), GU107-06 (2345'01.2”S-4643'61.5”W), GU108-07 (2343'64.7'S-4643'42.3”W), GU000-08 (2342'96.9”S-4643'61.2”W), GU109-09 (2343'04.6”S-4643'34.0”W), GU105-10 (2342'89.9”S-4644'68.7’'W), GU108-11 (2342'53.4”S-4643'44.9”W), GU103-12 (2341'88.5”S-4644'67.3”W), GU102-13 (2341'58.0”S-4643'57.3”W), GU000-14 $\left(23^{\circ} 40^{\prime} 78.2^{\prime}\right.$ S- $\left.46^{\circ} 43^{\prime} 55.0^{\prime} \mathrm{W}\right)$ distributed by Guarapiranga dam, in the State of São Paulo, applying the methodology of validation based on the National Institute of Metrology, Quality and Technology (INMETRO) guide, "Guidance on Analytical Methods Validation - DOQCGCE-008". The parameters analyzed were: selectivity, working range/linearity, limits of detection and quantification, tendency/recovery, accuracy, robustness and measurement uncertainty. Was used the optical emission with argon plasma spectrometry (ICP-OES) technique. The selectivity test proved that the matrix does not interfere with elaborate analytical curves; the elaborate working range obtained demonstrate a linear behavior for samples with and without the matrix of interest, with a coefficient of correlation ( $r$ ) between 0,9965 and 1,0; limits of detection and quantification of this method meet the maximum values allowed by CONAMA Resolution 357/2005; with repeatability of tests and recovery method proved to be precise and accurate, and robust. It was subsequently estimated uncertainty of measurement method. The estimated expanded uncertainty varied between 3
\end{abstract}


and $18 \%$ of the concentration found. The validation of the methodology allowed the application for the evaluation of the distribution of 12 elements in Guarapiranga dam waters. Were observed high values for $\mathrm{Ca}, \mathrm{Na}$ and $\mathrm{K}$, at every point analyzed collections, showing, which are, the elements that are part of the geological characteristic of the area. The iron and aluminum elements obtained values above the law in points Dam (G000-01, G000-02 and G000-03). With the parameters for the validation tests, with the statistical calculations applied, it was possible to develop and apply a methodology appropriate for the intended use. 


\section{SUMÁRIO}

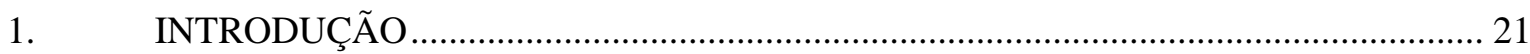

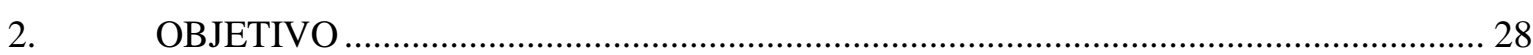

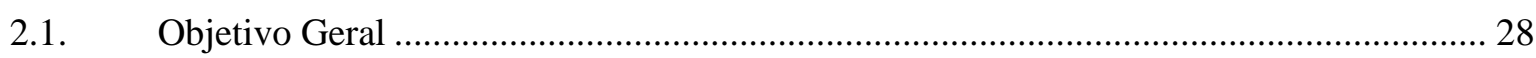

2.2. Objetivos Específicos …………………………………………………….... 28

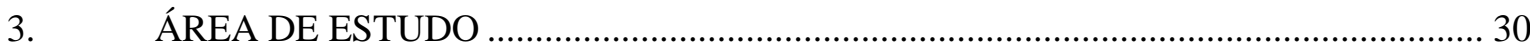

3.1. Histórico da represa Guarapiranga ........................................................................ 30

3.2. Carga Poluidora nas Águas do Guarapiranga ............................................................... 33

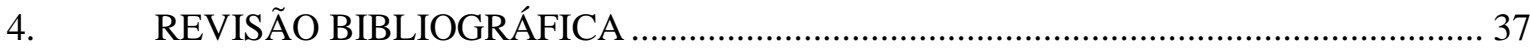

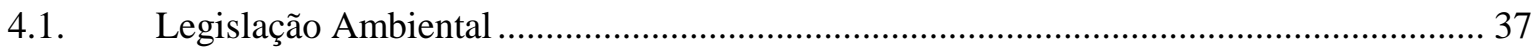

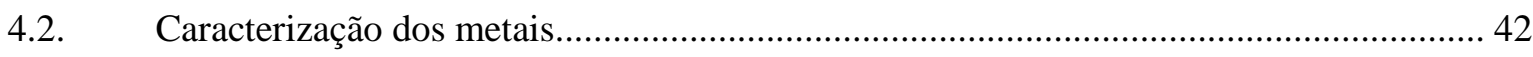

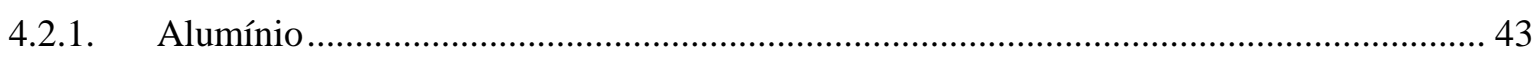

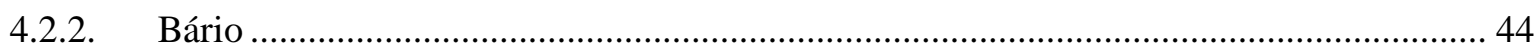

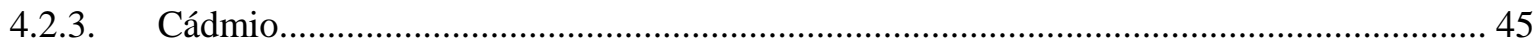

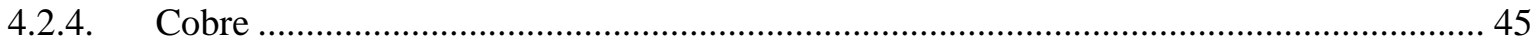

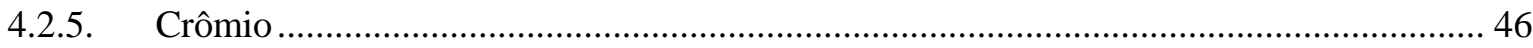

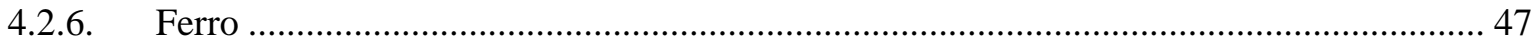

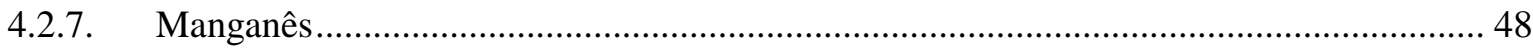

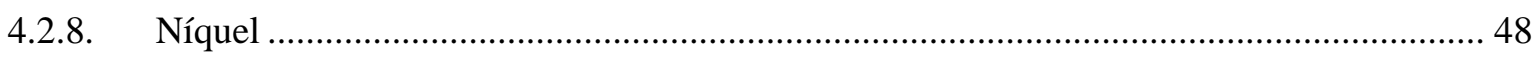

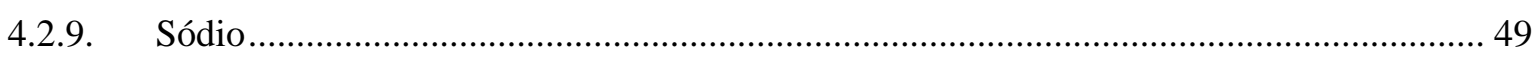

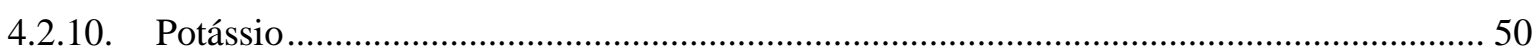

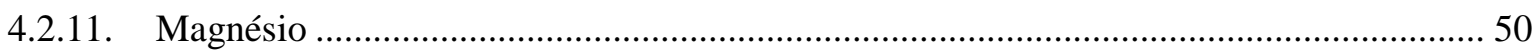

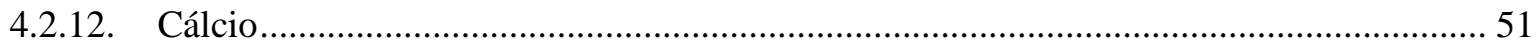

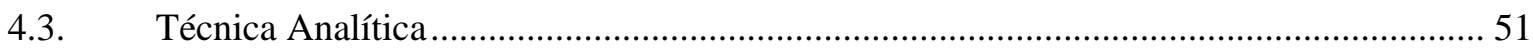

4.3.1. Espectrometria de emissão óptica por plasma de argônio - ICP-OES …………………... 52

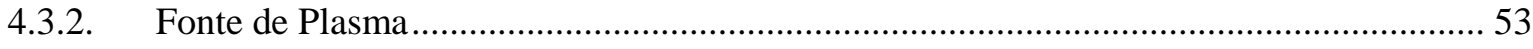

4.3.3. Configuração do Plasma …………………………………………………………..... 55

4.3.4. Instrumentação no ICP-OES......................................................................................... 56

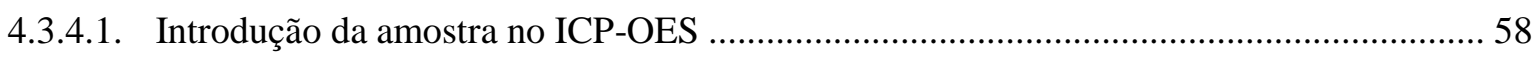

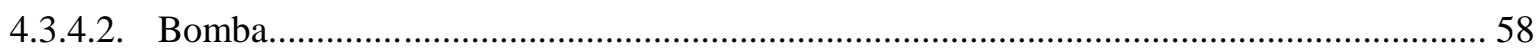

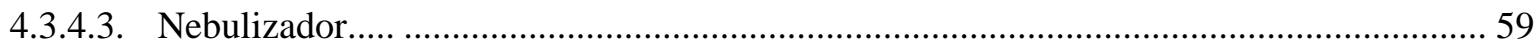

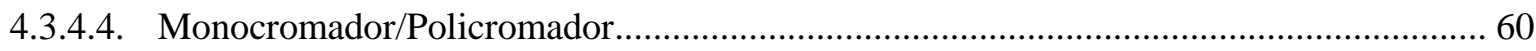

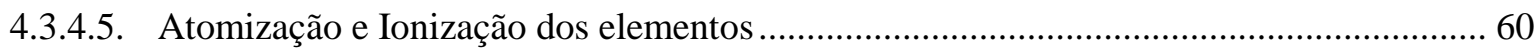

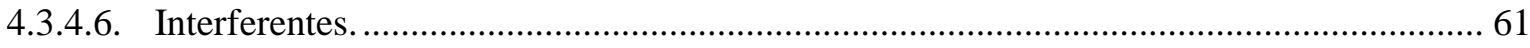




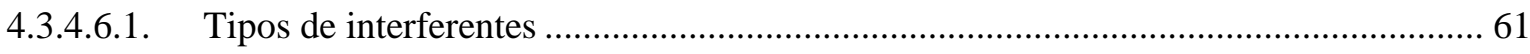

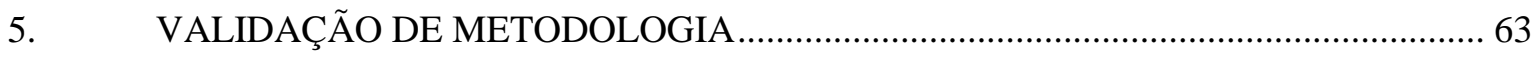

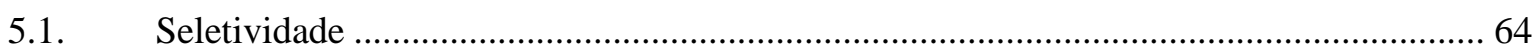

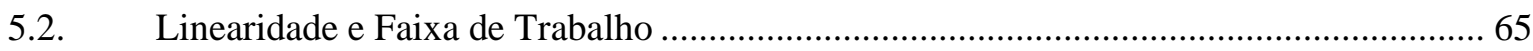

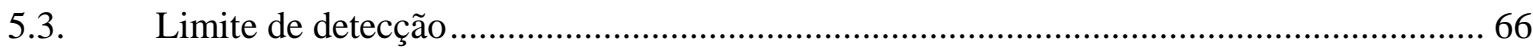

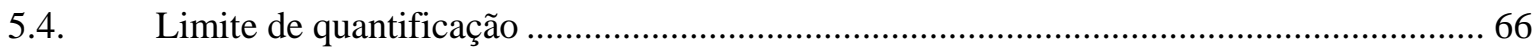

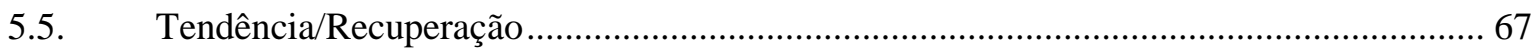

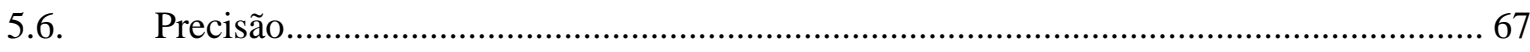

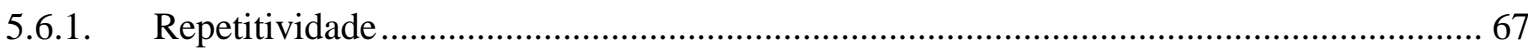

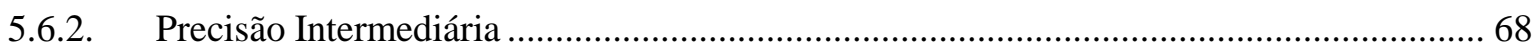

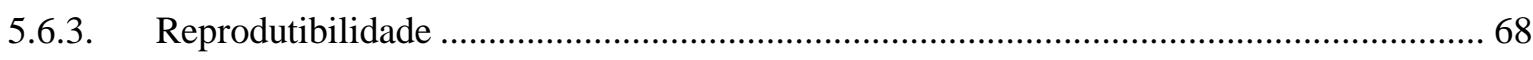

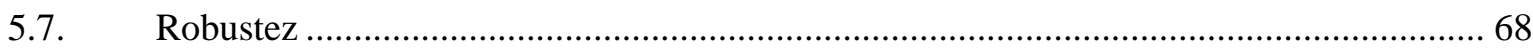

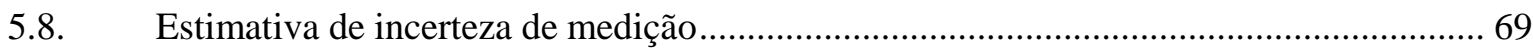

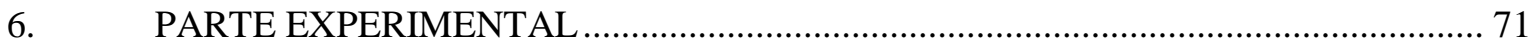

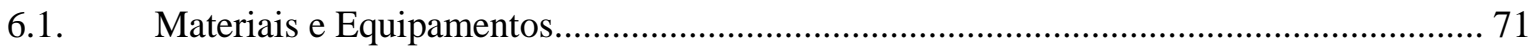

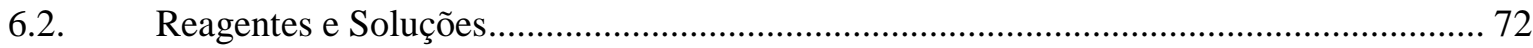

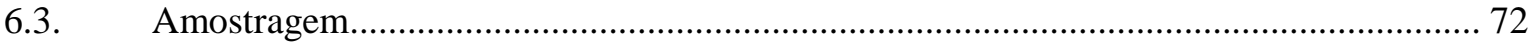

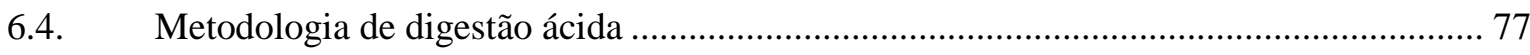

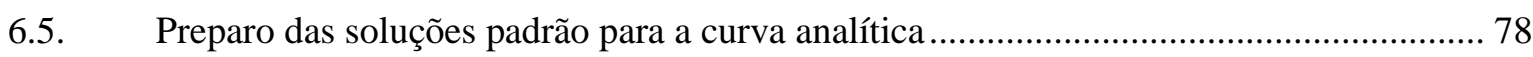

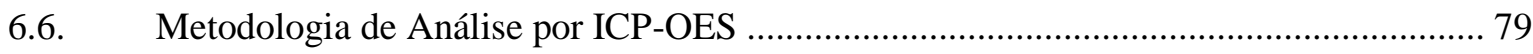

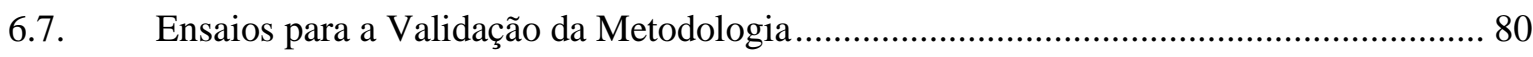

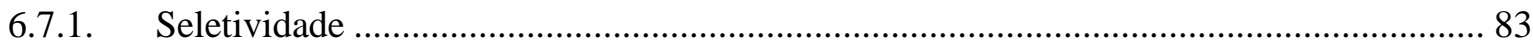

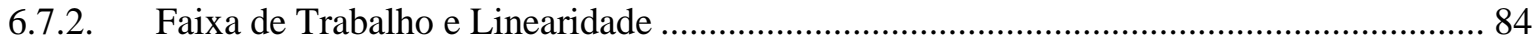

6.7.3. Limite de detecção do método (LDM) e Limite de Quantificação do método (LQM) .... 85

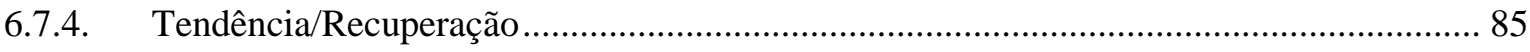

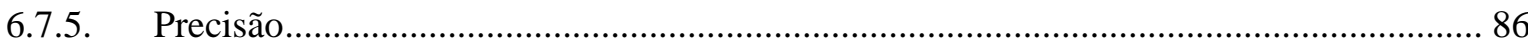

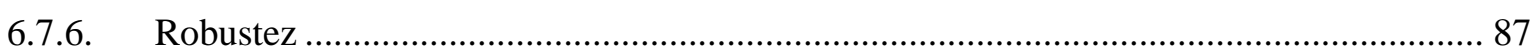

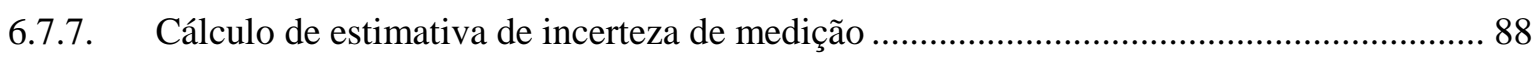

6.7.7.1. Incerteza de medição associada a digestão ácida em micro-ondas..................................... 90

6.7.7.2. Incerteza de medição associada ao preparo da curva analítica ......................................... 91

6.7.7.3. Incerteza de medição associada a curva analítica ................................................................. 93

6.7.7.4. Incerteza de medição associada a repetitividade do método ............................................ 94

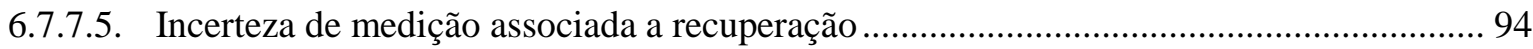

6.7.7.6. Incerteza de medição combinada e expandida..................................................................... 95

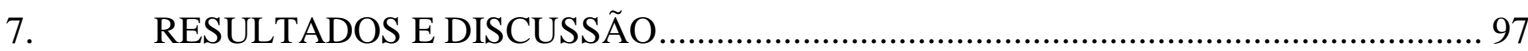




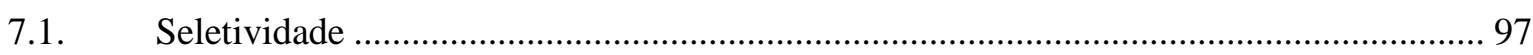

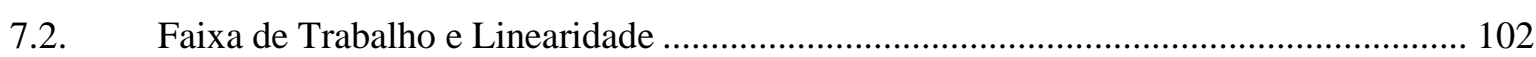

7.3. Limite de detecção do Método (LDM) e quantificação do Método (LQM) .................... 110

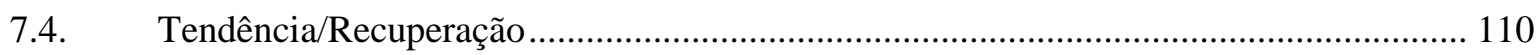

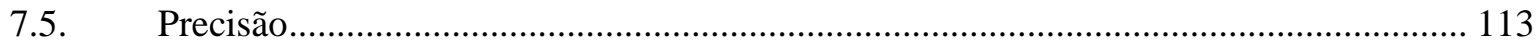

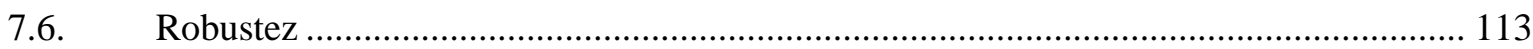

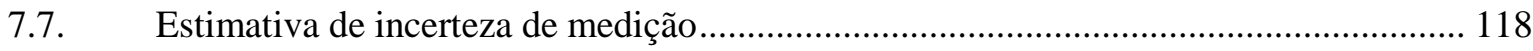

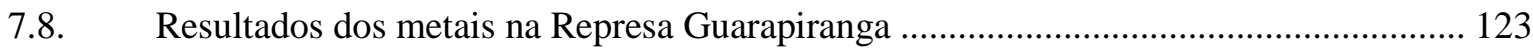

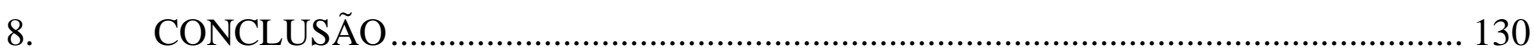

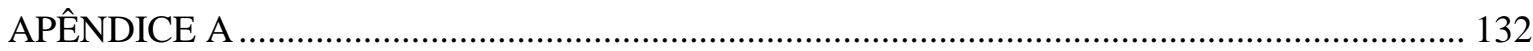

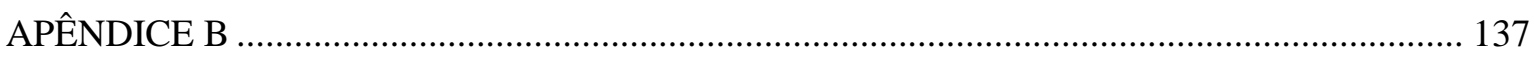

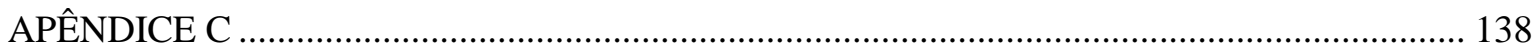

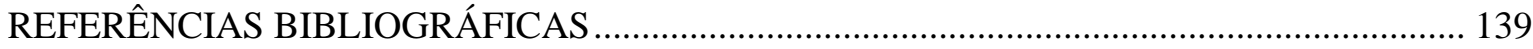




\section{LISTA DE FIGURAS}

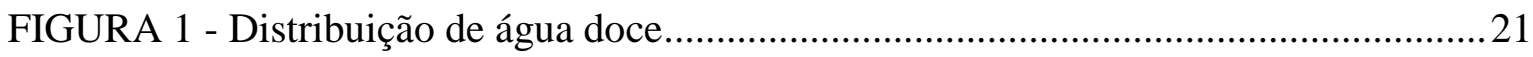

FIGURA 2 - Esquema de fontes de poluição pontual e difusa ............................................2 23

FIGURA 3 - Região Metropolitana de São Paulo (RMSP) com destaque para a Represa de

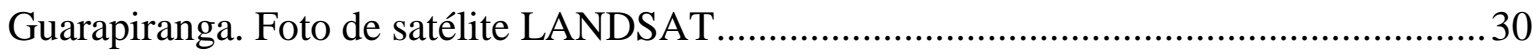

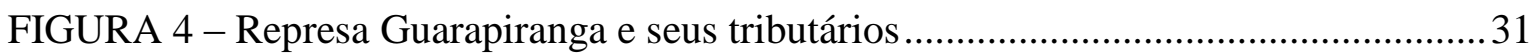

FIGURA 5 - Transferência de águas do Taquacetuba/Billings para o Guarapiranga ..........32 FIGURA 6 - Mapa temático da concentração de Ferro - Fe (a) e concentração de Fosforo P (b) na água do Represa; Mapa temático com as razões de Fe-P nos sedimentos coletados

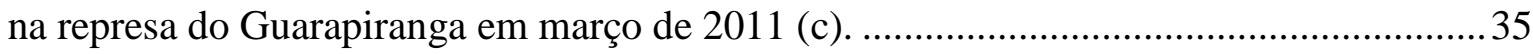

FIGURA 7 - Sistema de Saneamento da Bacia Guarapiranga............................................... 36

FIGURA 8 - Legislações Aplicáveis a Bacia Hidrográfica do Guarapiranga ....................... 41 FIGURA 9 - Representação esquemática do princípio de energia de excitação e emissão dos átomos em um ICP-OES, onde a e b representa o estado de excitação; $\mathbf{c}$ é a ionização; $\mathbf{d}$ é ionização/excitação; e é a emissão do íon; f, $\mathbf{g}$ e $\mathbf{h}$ são as emissões do átomo. $\boldsymbol{\lambda}=$

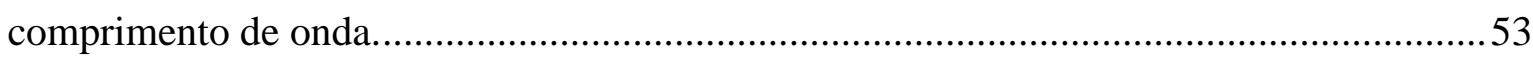

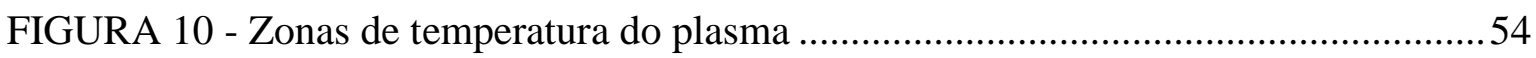

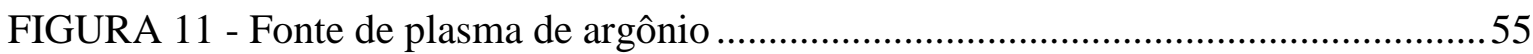

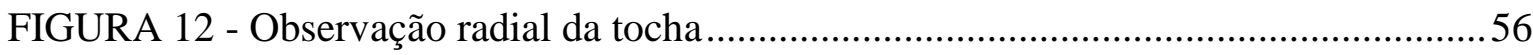

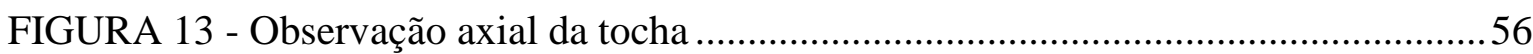

FIGURA 14 - Representação esquemática dos componentes em um ICP-OES ..................57

FIGURA 15 - Diagrama de blocos com processo que levam a produção de átomos, moléculas e íons em um sistema contínuo de introdução de amostras em um plasma ou chama

FIGURA 16 - Diagrama de blocos com o processo de introdução de uma amostra em um ICP-OES

FIGURA 17 - Representação de uma bomba peristáltica utilizada na técnica de ICP-OES59

FIGURA 18 - Nebulizador Meinhard

FIGURA 19 - Representação do processo quando uma amostra é inserida em um ICP-OES

FIGURA 20 - Espectrômetro de Emissão Óptica com Plasma de Argônio (ICP-OES) 
(SPECTRO ARCOS)

FIGURA 21 - Forno Micro-ondas MDS-2000 (CEM). 72

FIGURA 22 - Garrafa de van Dorn utilizada para a coleta de água. .74

FIGURA 23 - Distribuição dos pontos de coleta da represa Guarapiranga e seus tributários

FIGURA 24 - Esquema do processo de digestão ácida e micro-ondas. 77

FIGURA 25 - Fluxograma para a Validação de Método 82

FIGURA 26 - Diagrama de Ishikawa para o cálculo de estimativa de incerteza de medição

FIGURA 27 - Espectros de emissão das soluções-padrão (linha-vermelha) e de uma das soluções das amostras de matriz digerida (linha verde/azul) na região próxima ao $\lambda$ de emissão dos elementos estudados

FIGURA 28 - Representação Gráfica da comparação das curvas analíticas com e sem matriz dos elementos alumínio, cádmio, crômio, cobre, manganês e níquel. 101

FIGURA 29 - Representação Gráfica da comparação das curvas analíticas com e sem matriz dos elementos bário, cálcio, ferro, potássio, magnésio e sódio. 102

FIGURA 30 - Representação gráfica da curva de calibração analítica, para alumínio, cádmio, crômio, cobre, manganês e níquel - Sem Matriz

FIGURA 31 - Representação gráfica da curva de calibração analítica, para bário, cálcio, sódio, magnésio, ferro e potássio - Sem Matriz. 105

FIGURA 32 - Avaliação da normalidade e da linearidade dos dados da curva empregando a análise de resíduos - Sem matriz. 108

FIGURA 33 - Representação gráfica do teste de recuperação com os dados da média de recuperação de cada elemento para verificar a exatidão do método. 111

FIGURA 34 - Representação gráfica dos elementos com os dados de recuperação das sete replicatas para verificar a exatidão do método 112 FIGURA 35 - Representação gráfica do cálculo do Desvio Padrão Relativo (DPR\%), para observar a precisão do método, utilizando o teste de repetitividade* 113 FIGURA 36 - Representação gráfica dos elementos alumínio, sódio, magnésio, potássio e cádmio com os dados de meia normal (Rankit) e probabilidade normal. .114 FIGURA 37 - Representação gráfica dos elementos crômio, manganês, ferro, níquel e cobre com os dados de meia normal (Rankit) e probabilidade normal 
FIGURA 38 - Representação gráfica dos elementos cálcio e bário com os dados de meia normal (Rankit) e probabilidade normal 116

FIGURA 39 - Representação gráfica do teste de significância dos efeitos para avaliar o comportamento dos elementos alumínio, sódio, magnésio e potássio no ensaio de robustez

FIGURA 40 - Representação gráfica do teste de significância dos efeitos para avaliar o comportamento dos elementos crômio, manganês, ferro, níquel, cobre, cádmio, bário e cálcio no ensaio de robustez 118

FIGURA 41 - Contribuição de cada fonte na estimativa da incerteza combinada para os elementos alumínio, bário, cálcio e cádmio.

FIGURA 42 - Contribuição de cada fonte na estimativa da incerteza combinada para os elementos crômio, cobre, ferro, potássio, magnésio, manganês, sódio e níquel 122 FIGURA 43 - Resultados de $\mathrm{Na}, \mathrm{Mg}, \mathrm{K}$ e Ca nas amostras de água, nas profundidades subsuperficie (S), zona média (M) e $1 \mathrm{~m}$ acima do fundo (F) na Represa Guarapiranga, nos dias 07 e 09 de outubro de 2014, com suas respectivas incertezas de medição. 123 FIGURA 44 - Resultados de Al e Fe em água, nos pontos coletados, nas profundidades subsuperficie (S), zona média (M) e $1 \mathrm{~m}$ acima do fundo (F), da Represa Guarapiranga, nos dia 07 e 09 de outubro de 2014, com os VMP (Valores Máximos permitidos) pela Resolução CONAMA 357/2005 e suas respectivas incertezas de medição. 124 FIGURA 45 - Resultado de $\mathrm{Cu}$ em água, nos pontos coletados, nas profundidades subsuperficie (S), zona média (M) e $1 \mathrm{~m}$ acima do fundo (F) da Represa Guarapiranga, nos dia 07 e 09 de outubro de 2014, com os VMP (Valores Máximos permitidos) pela Resolução CONAMA 357/2005 e suas respectivas incertezas de medição.

FIGURA 46 - Comparação dos resultados em função das profundidades coletadas elementos $\mathrm{Ca}, \mathrm{K}, \mathrm{Mg}$ e $\mathrm{Na}$.

FIGURA 47 - Comparação dos resultados em função das profundidades coletadas elementos $\mathrm{Ba}, \mathrm{Cu}$ e $\mathrm{Mn}$. 128

FIGURA 48 - Comparação dos resultados em função das profundidades coletadas elementos Fe e Al. 


\section{LISTA DE TABELAS}

TABELA 1- Estimativa da população residente nos municípios que estão no entorno da Bacia Guarapiranga, dados de 2014 33

TABELA 2 - População residente no entorno da represa Guarapiranga por bairros de São Paulo, em 2010

TABELA 3 - Valores Máximos Permitidos (VMP) dos elementos analisados que podem ser

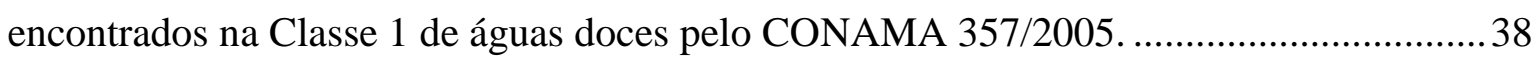

TABELA 4 - Vantagens e Desvantagens do Instrumento de Comando e Controle ..............39

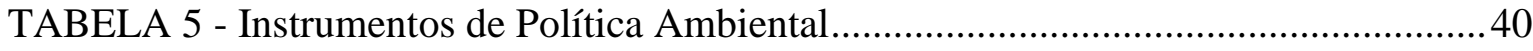

TABELA 6 - Níveis de níquel no meio ambiente ............................................................... 49

TABELA 7 - Classificação dos métodos espectroscópicos atômicos ..................................52

TABELA 8 - Lista de elementos que podem ser determinados por ICP-OES ....................52

TABELA 9 - Parâmetros de validação conforme o tipo de ensaio......................................... 64

TABELA 10 - Coordenadas Geográfica dos 14 pontos de coleta da represa Guarapiranga73 TABELA 11 - As três divisões de coleta nos pontos, o $\mathrm{pH}$ de cada profundidade e a profundidade máxima dos pontos coletados .................................................................... 75

TABELA 12 - Condições de análise da digestão ácida em forno de micro-ondas................77

TABELA 13 - Concentração da solução estoque ............................................................ 78

TABELA 14 - Concentração da solução-padrão multielementar, realizada a partir das

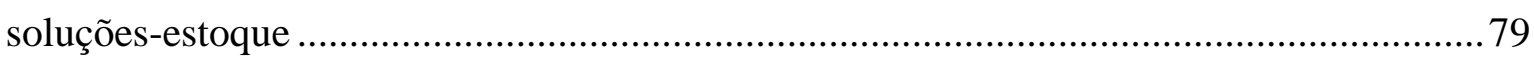

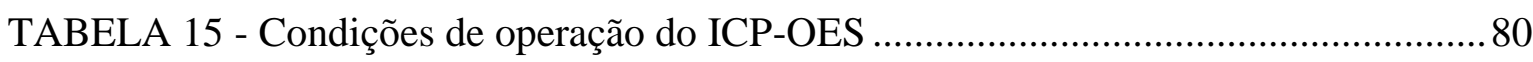

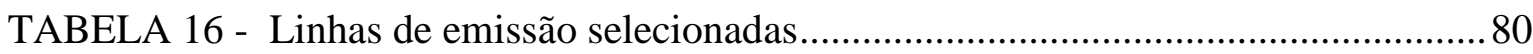

TABELA 17 - Concentração utilizada para a determinação dos espectros no teste de seletividade 83

TABELA 18 - Modificações de análise para o teste de robustez 87

TABELA 19 - Matriz dos fatores para a determinação da robustez do método. 87

TABELA 20 - Análise do teste F - Snedecor* e teste t de Student ${ }^{* *}$ para avaliar o efeito da matriz na curva analítica

TABELA 21 - Concentrações (mg.L $\left.{ }^{-1}\right)$ das soluções-padrão multielementares para construção das curvas de calibração 103

TABELA 22 - Dados dos coeficientes de correlação (r) e determinação $\left(r^{2}\right)$ e os 
comprimentos de onda $(\lambda)$ de cada elemento analisado. 103

TABELA 23 - Valores do Teste t de Student para cada ponto da curva analítica de cada composto 106

TABELA 24 - Resumo dos resultados da análise de variância (ANOVA) para os elementos sem matriz

TABELA 25- Limite de Detecção e Quantificação. 110

TABELA 26 - Grandeza utilizada na recuperação, na concentração da curva analítica e no volume final de amostra para a estimativa de incerteza de medição. 119

TABELA 27 - Resultados do cálculo de estimativa de incerteza de medição para os 12 elementos avaliados 120

TABELA 28 - Análise de variância (ANOVA) para o alumínio, sem matriz. 132

TABELA 29 - Análise de variância (ANOVA) para o cádmio, sem matriz. 132

TABELA 30 - Análise de variância (ANOVA) para o crômio, sem matriz. 133

TABELA 31 - Análise de variância (ANOVA) para o cobre, sem matriz. 133

TABELA 32 - Análise de variância (ANOVA) para o manganês, sem matriz. 133

TABELA 33 - Análise de variância (ANOVA) para o níquel, sem matriz. 134

TABELA 34 - Análise de variância (ANOVA) para o bário, sem matriz. 134

TABELA 35 - Análise de variância (ANOVA) para o ferro, sem matriz. 134

TABELA 36 - Análise de variância (ANOVA) para o magnésio, sem matriz. 135

TABELA 37 - Análise de variância (ANOVA) para o cálcio, sem matriz. 135

TABELA 38 - Análise de variância (ANOVA) para o potássio, sem matriz. 135

TABELA 39 - Análise de variância (ANOVA) para o sódio, sem matriz. 136

TABELA 40 - Resultado da concentração dos 12 elementos avaliados nesse trabalho em cada ponto analisado da represa Guarapiranga

TABELA 41 - Controle de qualidade dos grupos de análises da digestão ácida em microondas das águas na Represa Guarapiranga 


\section{LISTA DE ABREVIATURAS}

ANA: Agência Nacional das Águas.

ANOVA: Análise de Variância.

ANVISA: Agência Nacional de Vigilância Sanitária.

CCD: Dispositivo de Carga Acoplada.

CETESB: Companhia Ambiental do Estado de São Paulo.

CONAMA: Conselho Nacional do Meio Ambiente.

CPS: Contagens por Segundo (Intensidade).

CV: Coeficiente de Variação.

DP: Desvio Padrão Absoluto.

DPR\%: Desvio Padrão Relativo.

GUM: Guia para a Expressão de Incerteza de Medição.

ICP-OES: Espectrometria de Emissão Óptica com Plasma de Argônio.

INMETRO: Instituto Nacional de Metrologia, Qualidade e Tecnologia.

IPEN: Instituto de Pesquisas Energéticas e Nucleares.

IRC: Insuficiência Renal Crônica.

LD: Limite de Detecção.

LDM: Limite de Detecção do Método.

LQ: Limite de Quantificação.

LQM: Limite de Quantificação do Método.

ME: Margin of Error (margem de erro).

MRC: Material de Referência Certificado.

P.A.: Pureza Analítica.

r: Coeficiente de Correlação.

$r^{2}$ : Coeficiente de Determinação.

RF: Radiofrequência.

RMSP: Região Metropolitana de São Paulo.

SABESP: Companhia de Saneamento Básico do Estado de São Paulo.

SE: Solução Estoque.

SMA: Secretaria do Meio Ambiente.

SME: Simultaneous Margin of Error. 
SP: São Paulo.

USEPA: United States Environmental Protection Agency.

VIM: Vocabulário Internacional de Metrologia.

VMP: Valores Máximos Permitidos. 


\section{INTRODUÇÃO}

A água é primordial aos organismos vivos e é o recurso mais abundante do planeta Terra. Além disso, é um grande regulador do meio ambiente. Os ecossistemas aquáticos podem ser divididos em dois tipos: água doce e água salgada. É considerada água doce quando a concentração de sais dissolvidos é de até $0,5 \mathrm{~g} . \mathrm{L}^{-1}$, enquanto para águas salgada a concentração média é em torno de 35 g.L.-1 (BRAGA, et al., 2005).

A Terra é formada por $3 / 4$ de água (doce e salgada) e somente $1 / 4$ de terra (continentes e ilhas). A água doce é apropriada para o consumo humano e só representa 2,5\% do total de águas do mundo, o restante, 97,5\%, são de água salgada, a distribuição de água doce na Terra está apresentada na FIG.1 (CIA SANEAMENTO BÁSICO DO ESTADO DE SÃO PAULO, 2015).

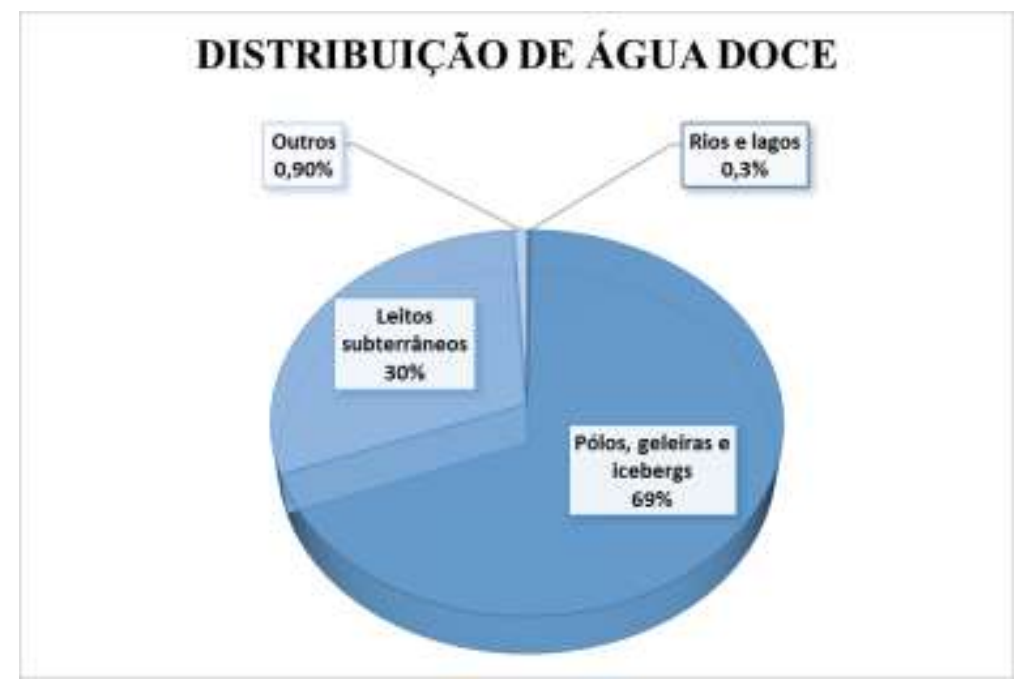

FIGURA 1 - Distribuição de água doce

Fonte: CIA SANEAMENTO BÁSICO DO ESTADO DE SÃO PAULO, 2015.

O ecossistema de água doce pode ser divido em dois grupos, lênticos (lagos e pântanos) e lóticos (rios, nascente e corredeiras). A vida nesse ecossistema é composta por algas, moluscos, insetos aquáticos, crustáceos e peixes, além de bactérias e fungos, que têm a função de decomposição da matéria orgânica (BRAGA, et al., 2005).

A água doce é um dos recursos naturais mais utilizados, por ser fundamental para a existência e a manutenção da vida. Dentre os vários usos da água, o abastecimento público, é considerado o mais prioritário, e deve apresentar características sanitária e 
toxicológicas adequadas, tais como ausência de sustâncias tóxicas (orgânicas e inorgânicas) e organismos patogênico (vírus, protozoários, fungos e bactérias), para a prevenção de danos à saúde (BRAGA, et al., 2005).

Os mananciais são reservas hídricas ou fontes, de água doce superficial ou subterrânea, utilizadas para o abastecimento público de água ou desenvolvimento de atividades econômicas, deste modo essas áreas necessitam de uma atenção específica, sendo contemplados por aspectos legais e gerencias (BRASIL, 2015).

Com o aumento da demanda por água, causado pelo crescimento populacional, as pressões sobre os mananciais aumentam. As degradações que podem ocorrer nessas áreas são: ocupação desordenada do solo, praticas inadequadas de uso do solo e d'água, falta de infraestrutura de saneamento básico, atividades industriais que não seguem as legislações ambientais e descartam seus efluentes sem o devido tratamento, entre outros. Se as degradações se mantiverem podem resultar na baixa qualidade da água distribuída, expondo a população a doenças (BRASIL, 2015).

As bacias hidrográficas que destinam-se ao abastecimento público necessitam constantemente de monitoramento e controle, pois a qualidade da água bruta depende diretamente do modo que a bacia está sendo manejada (BRASIL, 2015).

As fontes de poluentes podem ser classificadas como pontuais e difusas, conforme apresentado na FIG.2. Os poluentes pontuais são lançamentos de esgoto doméstico ou industrial, efluentes gasosos industriais e aterro sanitário de lixo urbano; e difusas são agrotóxicos aplicados na agricultura e dispersos no ar, carregados pelas chuvas para os rios ou para o lençol freático e gases dos escapamentos dos automóveis. As fontes pontuais podem ser detectadas e controladas com mais facilidade que as difusas.

Além dos processos antrópicos (pontuais e difusas), as contaminações de corpos d'água podem ocorrer por processos naturais, tais como: formação geológicas, ação vulcânica, atividades hidrotérmicas e longos períodos chuvosos (ROCHA, et al., 2009). 


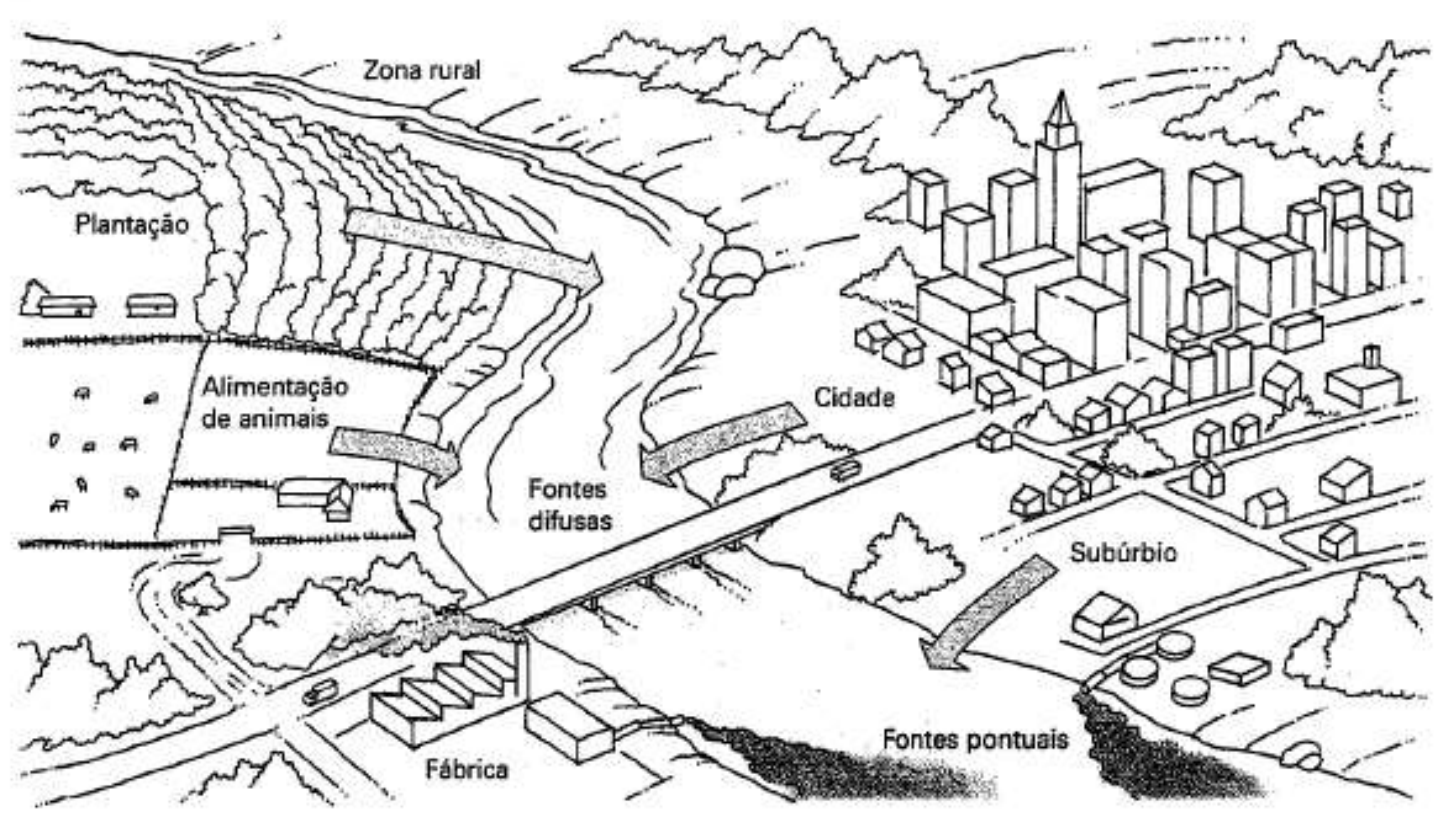

FIGURA 2 - Esquema de fontes de poluição pontual e difusa Fonte: BRAGA, 2005.

A Região Metropolitana de São Paulo (RMSP) importa água de abastecimento por meio do Sistema Cantareira, composta pelas represas Jaguari/Jacareí, Cachoeira, Atibainha, Paiva Castro e Águas Claras. O restante utilizado é fornecido por mananciais, sendo eles a Billings, Guarapiranga, Alto e Baixo Cotia, Alto Tietê, Rio Claro, Rio Grande, Ribeirão da Estiva e Embú-Guaçu, onde essas regiões vêm sofrendo excessivo processo de ocupação (SMA/CEA, 2008; CIA SANEAMENTO BÁSICO DO ESTADO DE SÃO PAULO, 2015).

A falta de planejamento urbano e a ocupação intensa desordenada nas áreas de preservação ambiental acabou por comprometer a qualidade e a quantidade da água na RMSP, pois as áreas ocupadas não possuem serviços públicos de qualidade, como transporte, educação, saúde e o saneamento básico, além disso, o desmatamento e o uso inadequado dos recursos naturais, em particular o da água, prejudica todo o sistema ambiental da cidade (SMA/CEA, 2008). A represa do Guarapiranga, área de estudo deste trabalho, segundo a Prefeitura de São Paulo (2013), possui um alto potencial hídrico, um dos motivos para que em 1928 começasse a ser utilizada para o abastecimento de água da capital paulista e em 1929 foi inaugurado o Sistema de Abastecimento do Guarapiranga (SÃO PAULO, 2013). 
Desde década de 1950 houve uma ocupação irregular e desordenada em torno de sua região. Entre 1977 a 1989, da água do reservatório apresentou valores acima da legislação, agravando a qualidade da água, a principal causa foi o despejo de esgoto, diretamente, nos corpos d'agua, que além de ameaçar o abastecimento público, o manancial começou a apresentar problemas ambientais (SANTORO, et al., 2009). Para resolver esses problemas o Governo do Estado na década de 1990, começou a implantar medidas como o Programa de Saneamento Ambiental da Bacia do Guarapiranga (SÃO PAULO, 2013). Foram implementadas ações corretivas e preventivas, com a criação da Lei ${ }^{\circ} 12.233$, de 16 de janeiro de 2006. Essa lei "define a Área de Proteção e Recuperação dos Mananciais da Bacia Hidrográfica do Guarapiranga, e dá outras providências correlatas" (SÃO PAULO, 2006).

As poluições difusas e pontuais que podem contaminar o corpo hídrico por metais, constituem as principais fontes de poluição da Represa Guarapiranga, e têm íntima ligação com a deficiência dos serviços de saneamento, em especial de rede de coleta, afastamento e tratamento de esgoto produzido pela população da Represa (SMA/CEA, 2008). A presença de metais-traço (metais com concentração inferior a mg. $\mathrm{L}^{-1}$ ), e a concentração de nutrientes no sedimento e nas águas do reservatório indicam que há uma contaminação antrópica na região, em virtude disso, nesse trabalho serão avaliados os metais-traço, tais como: alumínio, bário, cálcio, cobre, cádmio, crômio, ferro, magnésio, manganês, níquel, potássio e sódio, que podem estar presentes na Represa de Guarapiranga (MOZETO, et al., 2003; RICHTER, et al., 2007).

Em água natural os metais podem ser encontrados dissolvidos, coloidais ou em forma de partículas, isso irá depender do potencial de oxido-redução; a presença de sulfeto ou carbonatos, que podem formar íons metálicos; os componentes de sedimento de fundo e em suspensão; e a característica química da água. A mobilidade dos metais em água pode ocorrer através da solubilidade e a tendência de deslocamento das partículas de metais do sedimento para a água (WEINER, 2007).

Segundo Weiner (2007), as formas dissolvidas de metais movem-se com a água superficial e fluxos de água subterrânea; metais em forma de partículas podem ser transportados com o sedimento pelo vento e a movimentação da água. Ambos os metais 
dissolvidos e as formas de partículas podem absorver sólidos orgânicos do solo, no qual podem ser imobilizadas ou transportadas ao longo da erosão do solo; e metais apresentam os maiores riscos ambientais quando estão particulados e deparam com condições ambientais que aumentam sua solubilidade (WEINER, 2007).

Para que tenha um controle sobre esses poluentes as legislações ambientais definem parâmetros com Valores Máximos Permitidos (VMP) que substâncias químicas e elementos químicos podem ser encontradas no corpo hídrico (BRAGA, et al., 2005). O Conselho Nacional do Meio Ambiente (CONAMA), mediante da Resolução CONAMA 357, de 17 de março de 2005, estabelece condições de qualidade para o enquadramento dos corpos hídricos em território nacional, de acordo com os seus usos preponderantes. Essa resolução, como instrumento jurídico, fixou limites para diversas variáveis em sistemas de água doce, salobra e salina (BRASIL, 2005), (CUNHA, et al., 2013).

Nas definições de condições e padrões de qualidade das águas, na Resolução CONAMA 357/2005, no Art. $8^{\circ}$ expressa que os parâmetros devem ser monitorados para que não haja suspeita de sua presença ou não conformidade, além disso, os resultados devem ser analisados estatisticamente levando em consideração as devidas incertezas de medição. No Art. $9^{\circ}$ exprimi que os laboratórios que irão realizar as análises e as avaliações devem ter estruturas adequadas, além de possuir um controle de qualidade analítico para atenderem a Resolução (BRASIL, 2005).

Para atender a legislação ambiental, é necessária a utilização de metodologias analíticas, sendo imprescindível demonstrar a qualidade das medições químicas. Dados analíticos que não apresentam confiabilidade podem acarretar decisões desastrosas e a prejuízos financeiros irreparáveis. Para assegurar que um novo método analítico gere informações confiáveis e interpretáveis sobre uma amostra, a metodologia deve passar por uma avaliação denominada validação. A validação de um método é um processo contínuo. Ao validar uma metodologia, o laboratório demonstra que o método analítico desenvolvido está capacitado a emitir resultados confiáveis. Além disso, aumenta a credibilidade e a confiança no uso rotineiro da metodologia validada. Assim sendo, um processo de validação bem definido e documentado oferece as agências reguladoras evidência objetivas de que os métodos são adequados para o uso desejado (RIBANI, et al., 2004) (BRASIL, 2013). 
Segundo Ribani (2004), dentro do âmbito geral de validação de métodos é possível distinguir dois tipos, a validação no laboratório (“in house validation”) e a validação completa ("full validation").

A validação no laboratório, consiste de etapas de validação dentro de um único laboratório, como por exemplo validar um método novo desenvolvido localmente ou na verificação de um método adotado de outras fontes está aplicado corretamente. Essa etapa pode ser considerada como uma etapa preliminar a validação completa ("full validation") (RIBANI, et al., 2004).

A validação completa, abrange todas as características de desempenho e um estudo interlaboratorial, que verifica como a metodologia se comporta em uma determinada matriz em vários laboratórios, no qual demonstra a reprodutibilidade da metodologia e a incerteza expandida associada à metodologia como um todo. Somente assim a metodologia pode ser aceita como oficial para a determinação do uso pretendido. Os protocolos aceitos internacionalmente para uma validação completa são o Protocolo Harmonizado Internacional e o procedimento ISO (Internacional Standard Organization) (RIBANI, et al., 2004).

O Instituto Nacional de Metrologia, Qualidade e Tecnologia (INMETRO) possui um documento orientativo que auxilia os laboratórios a implantarem boas práticas, como o guia “Orientação sobre Validação de Métodos Analíticos - DOQ-CGCE-008” (INSTITUTO NACIONAL DE METROLOGIA, NORMALIZAÇÃO E QUALIDADE INDUSTRIAL, 2011). O documento orienta sobre a validação de métodos analíticos, para a identificação dos elementos de interesse de forma correta e com a devida qualidade que os laboratórios analíticos devem apresentar. Além disso, esse documento visa atender aos requisitos da ABNT NBR ISO/IEC 17025 (Acreditação de laboratório), aplicável a laboratórios de calibração e de ensaio.

Os parâmetros aplicáveis a validação depende do tipo de ensaio que será aplicado, como por exemplo, ensaios que envolvem análise de elementos menores e traços, ou seja, com menor teor de concentrações entre 0,01 a $1 \%$ e elementos traços, os elementos em concentrações abaixo de $0,01 \%$, devem realizar os parâmetros de seletividade, precisão, tendência/recuperação, robustez, sensibilidade/linearidade/faixa de trabalho, limite de 
detecção, limite de quantificação e incerteza de medição (INSTITUTO NACIONAL DE METROLOGIA, NORMALIZAÇÃO E QUALIDADE INDUSTRIAL, 2011).

Para a determinação dos elementos químicos inorgânicos foi utilizada a técnica de Espectrometria de Emissão Óptica com Plasma de Argônio (ICP-OES), que é amplamente utilizada para análises ambientais por apresentar uma série de características, tais como: análise multielementar, que permite a determinação simultânea dos metais menores e traço; além de baixa vulnerabilidade para interferentes inter-elementares (LEMES, 2001).

Assim, o presente trabalho realizou a avaliação da distribuição de metais em água da represa Guarapiranga, localizada no Estado de São Paulo. Para essa avaliação, foi implantada e validada metodologia analítica baseado no guia do INMETRO DOC-CGCE008, atendendo desta forma o preconizado pela Resolução CONAMA 357/2005. 


\section{OBJETIVO}

\subsection{Objetivo Geral}

O objetivo desse trabalho foi desenvolver, validar e avaliar uma metodologia analítica para determinar os elementos químicos inorgânicos, alumínio, bário, cálcio, cobre, cádmio, crômio, ferro, magnésio, manganês, níquel, potássio e sódio, em amostras e água, utilizando a técnica de Espectrometria de Emissão Óptica com Plasma de Argônio (ICPOES), avaliando a distribuição desses elementos na Represa do Guarapiranga - SP.

\subsection{Objetivos Específicos}

a) Desenvolver e validar metodologia analítica para a determinação de metais em água, utilizando a técnica de Espectrometria de Emissão Óptica com Plasma de Argônio (ICP-OES).

b) Utilizar como base o guia DOC-CGCRE-008, de orientação sobre validação de métodos analíticos do INMETRO (INSTITUTO NACIONAL DE METROLOGIA, NORMALIZAÇÃO E QUALIDADE INDUSTRIAL, 2011), avaliando os parâmetros:

\footnotetext{
○ Seletividade

○ Faixa de trabalho e Linearidade da curva de calibração;

○ Os limites de detecção (LD);

○ Os limites de quantificação (LQ);

○ Precisão (repetitividade);

○ Tendência/Recuperação;

○ Robustez

○ Incertezas de medição;
}

c) Avaliar as informações técnicas e científicas disponíveis relacionadas ao comportamento dos elementos alumínio, bário, cálcio, cobre, cádmio, crômio, ferro, magnésio, manganês, níquel, potássio e sódio em amostras ambientais de água coletada na região da Represa Guarapiranga.

d) Certificar a eficácia da validação de metodologia de análise das amostras coletadas, nos 14 pontos que abrangem toda a Represa Guarapiranga. 
e) Avaliação dos parâmetros conforme a legislação ambiental do CONAMA pela Resolução 357/2005. 


\section{3. ÁREA DE ESTUDO}

\subsection{Histórico da represa Guarapiranga}

Formada em 1906, pela empresa The São Paulo Light \& Power Co, como um lago artificial, é conhecida hoje como a Represa de Guarapiranga, situada na região de Santo Amaro, possui uma área de aproximadamente $630 \mathrm{Km}^{2}$ e localiza-se a sudoeste da Região Metropolitana de São Paulo (RMSP) (FIG.3). Os municípios que fazem parte da bacia são os municípios de Cotia, Embu (Embu das Artes), Itapecerica da Serra, Juquitiba, São Lourenço da Serra, Embu-Guaçu e São Paulo. O mapa da represa Guarapiranga e seus tributários estão apresentados na FIG.4.

A constituição da represa Guarapiranga teve um primeiro propósito de aumentar a geração de energia elétrica da cidade de São Paulo, com a regularização da vazão do Rio Tietê e aumentar a capacidade de geração de energia na Usina de Santana de Parnaíba, em 1901, devido a produção prejudicada em épocas de estiagem (CIA SANEAMENTO BÁSICO DO ESTADO DE SÃO PAULO, 2008), assim como os serviços de iluminação e transporte coletivo.

Depois das obras concluídas a empresa operante descobriu seu grande potencial recreativo e criou linhas de bondes especiais para visitação
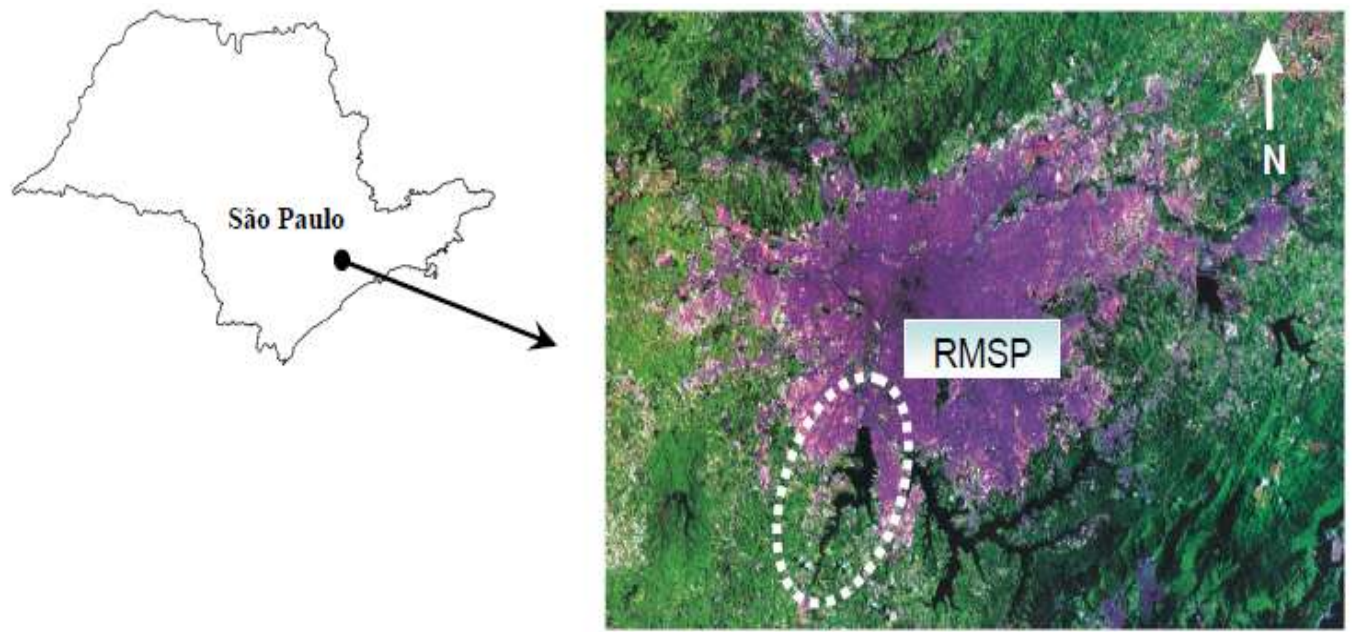

FIGURA 3 - Região Metropolitana de São Paulo (RMSP) com destaque para a Represa de Guarapiranga. Foto de satélite LANDSAT

Fonte: ACQUASED, 2012. 


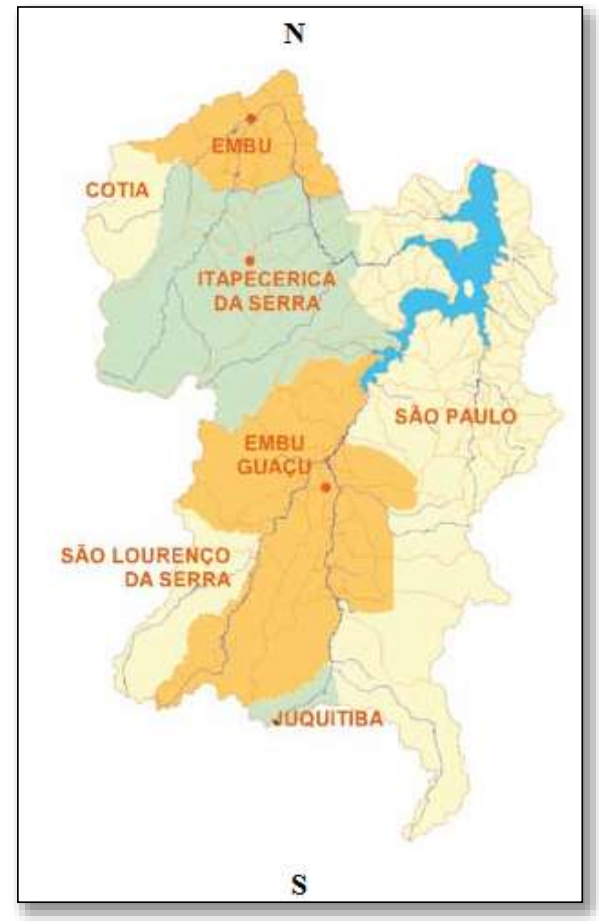

FIGURA 4 - Represa Guarapiranga e seus tributários Fonte: Adaptação de SMA/CEA, 2008.

A partir de 1928 a represa Guarapiranga tornou-se um manancial para abastecimento de água para capital de São Paulo. A represa fornecia 86,4 milhões de litros de água por dia (vazão média de $1 \mathrm{~m}^{3} \cdot \mathrm{s}^{-1}$ ) para a Estação de Tratamento de Água de Teodoro Ramos. Em 1929 foi inaugurado o Sistema de Abastecimento do Guarapiranga, ficando atrás somente do Sistema de Abastecimento da Cantareira (SÃO PAUO, 2013; WHATELY, et al, 2006).

Em 1958, com a construção da estação de tratamento de água do Alto de Boa Vista, a represa aumento o fornecimento para $9,5 \mathrm{~m}^{3} \cdot \mathrm{s}^{-1}$, tornando obrigatória a elevação o nível da lâmina d'agua. Quando havia chuvas excessivas, eram utilizados os descarregadores de fundo, túneis que ligam a represa ao canal rio Pinheiros.

A ocupação entorno da represa Guarapiranga foi marcada, em 1920, com edifícios residenciais e clubes, que eram atraídos por ofertas de lazer e pela qualidade da paisagem. Nos anos 1930 e 1940 começaram a se formar os loteamentos, mas nos anos 1950 e 1960 as ofertas de loteamentos residenciais aumentaram.

Os sinais iniciais de degradação da qualidade de água e da região apareceram na 
década de 50, quando a Sociedade Amigos de Interlagos começou a pedir a construção de um coletor de esgotos na margem direita.

Em 1990 o governo criou um programa de recuperação ambiental da região e contou com auxílio financeiro do Banco Mundial, investindo mais de US\$ 300 milhões na região, em particular em redes de esgotos e reurbanização de favelas. Contudo esses investimentos não foram suficientes, pois a qualidade da água piorou ao longo dos anos e a quantidade de água disponível encontra-se cada vez mais comprometida.

Como a represa Guarapiranga já vinha sendo explorada acima de sua capacidade ao longo dos anos, para regularizar sua vazão, foi construído a interligação do braço Taquacetuba da represa Billings com o rio Parelheiros, afluente da margem direita da Guarapiranga, em 2000, como apresentado na FIG.5 (WHATELY, et al., 2006).

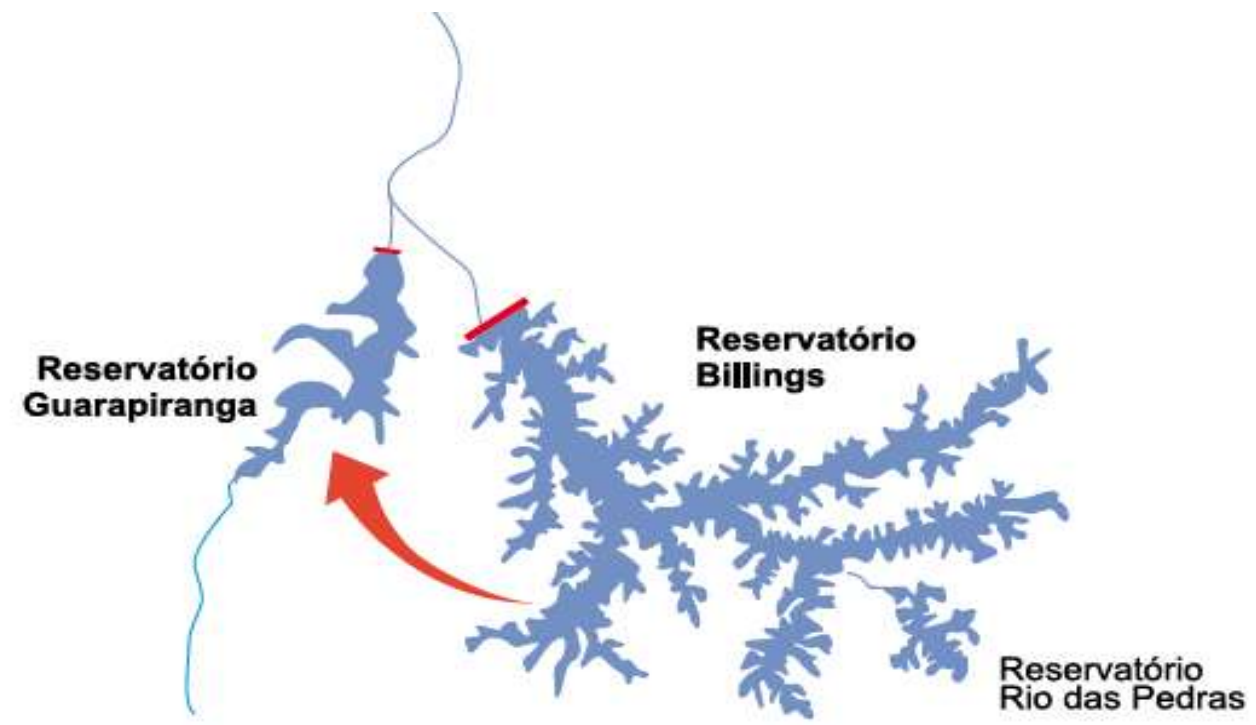

FIGURA 5 - Transferência de águas do Taquacetuba/Billings para o Guarapiranga Fonte: SMA/CEA, 2008.

Atualmente a represa Guarapiranga constitui o segundo maior manancial de abastecimento da RMSP. Os principais contribuintes da represa são os rios Embu-Mirim, Embu-Guaçu e Parelheiros, além de vários córregos e pequenos cursos d'agua (WHATELY, et al., 2006). Segundo Italiani, et al (2014), a Guarapiranga é sete vezes menor que todo o Sistema Cantareira e está produzindo quase a mesma quantidade de água que o maior manancial do Estado. O fornecimento de água, em 2014, foi de 15 mil litros por segundo 
para abastecer 5,2 milhões de pessoas (ITALIANI, et al., 2014).

A estimativa de habitantes no entorno da região em 2014, apresentada na TAB.1, é de 762 mil habitantes, totalizando os municípios de Embu das Artes, Embu-Guaçu, Itapecerica da Serra, Juquitiba e São Lourenço da Serra. Na região de São Paulo, que abrange os bairros de Parelheiros, Capela do Socorro e M'Boi Mirim, os dados em 2010 eram de 1.289.418 de habitantes na região. Os dados estão apresentados na TAB.2 (INSTITUTO BRASILEIRO DE GEOGRAFIA E ESTATÍSTICA, 2015).

TABELA 1- Estimativa da população residente nos municípios que estão no entorno da Bacia Guarapiranga, dados de 2014

\begin{tabular}{cc} 
Município & Habitantes \\
\hline Cotia & 225.306 \\
Embu das artes & 259.063 \\
Embu-Guaçu & 66.792 \\
Itapecerica da Serra & 165.327 \\
Juquitiba & 30.443 \\
São Lourenço da Serra & 15.028 \\
Total & $\mathbf{7 6 1 . 9 5 9}$ \\
\hline NSTITUTO BRASILEIRO DE GEOGRAFIA E ESTATÍSTICA, 2015)
\end{tabular}

TABELA 2 - População residente no entorno da represa Guarapiranga por bairros de São Paulo, em 2010

\begin{tabular}{cc} 
Bairros de São Paulo & Habitantes \\
\hline Capela do Socorro & 594.930 \\
M'Boi Mirim & 563.305 \\
Parelheiros & 131.183 \\
Total & $\mathbf{1 . 2 8 9 . 4 1 8}$
\end{tabular}

Fonte: (INSTITUTO BRASILEIRO DE GEOGRAFIA E ESTATÍSTICA, 2015)

\subsection{Carga Poluidora nas Águas do Guarapiranga}

A carga poluidora na represa do Guarapiranga é causada especialmente por despejos de esgotos (provenientes de residências, de comércio, de ruas, de pequenas 
indústrias e de atividades agrícolas, entre outros) e a poluição difusa (resíduo que não são descartados e coletados adequadamente) (SMA/CEA, 2008).

Com o aumento da ocupação irregular no entorno da bacia do Guarapiranga, com a implantação de favelas e loteamentos populares sem infraestrutura, os esgotos gerados por esses indivíduos eram lançados in natura na represa, considerado o maior fator de sua degradação (BALTRUSIS, et al., 2006).

Em decorrência dos lançamentos de esgotos direto na represa, em janeiro de 1991, uma floração extraordinária de algas se formou na Represa Guarapiranga e a Prefeitura de São Paulo, juntamente com a Companhia de Saneamento Básico do Estado de São Paulo (SABESP) criaram um programa de Saneamento e Recuperação Ambiental (BALTRUSIS, et al., 2006).

O programa foi implantado para recuperar a qualidade das águas do manancial. A estrutura do programa consistia em 5 eixos (ou subprogramas) sendo eles: serviços de água e esgoto, coleta e disposição de lixo, recuperação urbana, proteção ambiental e gestão da bacia (BALTRUSIS, et al., 2006).

Devido aos blooms de algas e para se ter um controle da floração dessas algas faz se uso de sulfato de cobre, que por sua vez impactam na captação e o tratamento de água para o abastecimento (SILVA, et al., 2013). Estudos no sedimento do Guarapiranga mostram que a concentração de nutrientes tais como nitrogênio, fósforo e a razão ferrofósforo (FIG.6), permite identificar as regiões mais favoráveis ao crescimento dos microorganismos (SILVA, et al., 2013). Estas fontes de poluição comprometem a qualidade de água e do sedimento de fundo do reservatório, afetando o tratamento de água realizado pela SABESP, passa a ser necessário o aumento da quantidade de reagentes químicos no processo de tratamento de água e, portanto, aumentam os custos envolvidos. 


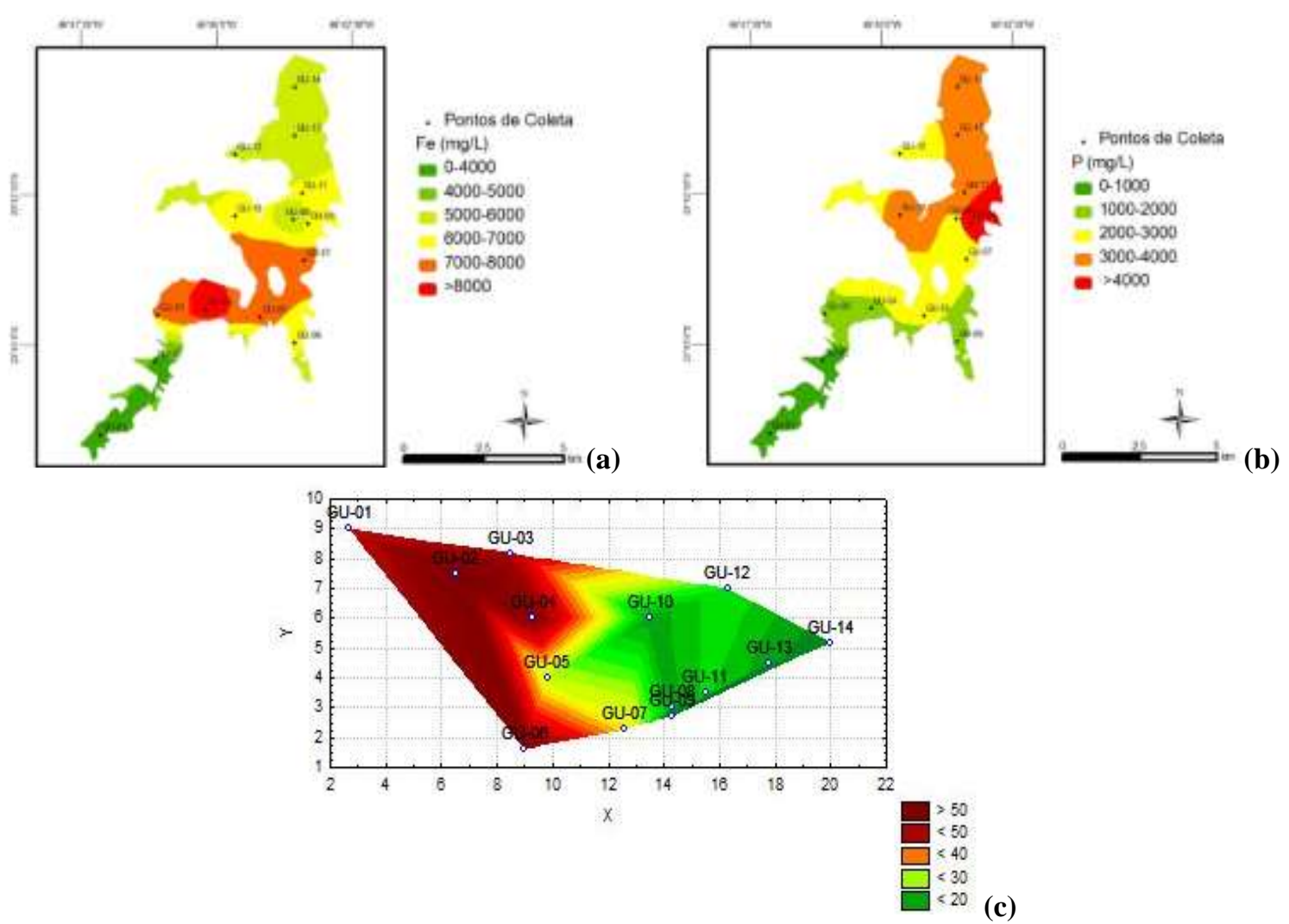

FIGURA 6 - Mapa temático da concentração de Ferro - Fe (a) e concentração de Fosforo $\mathrm{P}$ (b) na água do Represa; Mapa temático com as razões de Fe-P nos sedimentos coletados na represa do Guarapiranga em março de 2011 (c).

Fonte: SILVA, et al., 2013.

Estudos realizados por Richter et al (2007), mostraram que os íons fosfato e amônio apresentam concentrações acima dos máximos permitidos pela legislação, nos córregos Guavirutuba e Itupu, localizados perto do ponto GU103-12 (2341'88.5”S$46^{\circ} 44^{\prime} 67.3$ ' W), o que pode estar relacionado a concentração de uso e ocupação do solo com precária infraestrutura sanitária. Além disso, o metal cobre está presente em altas concentrações, acima da legislação, devido ao seu uso para controle de proliferação de algas (RICHTER, et al., 2007).

Observando os gráficos na a FIG.7 mais de 50\%, de quase 200 mil domicílios, possuem rede de esgoto, mas ainda existem muitos domicílios sem a rede de esgoto, cerca de $30 \%$. A falta de rede de esgoto agrava cada vez mais as condições de qualidade de água. Com um saneamento básico os riscos de contaminação e transmissão de doenças são evitados e também são evitadas as contaminações ambientais (SMA/CEA, 2008).

Em 2003, 59\% do total de água da Bacia do Guarapiranga estava alterado devido 
a atividades antrópicas. Esta parcela está dividida entre usos antrópicos (42\%) e usos urbanos (17\%). As áreas de vegetação remanescente de Mata Atlântica na região estavam em 37\% da área da bacia, em 2003. Estas fisionomias são primordiais para a manutenção da capacidade de produção hídrica e o equilíbrio ambiental (WHATELY, et al., 2006).

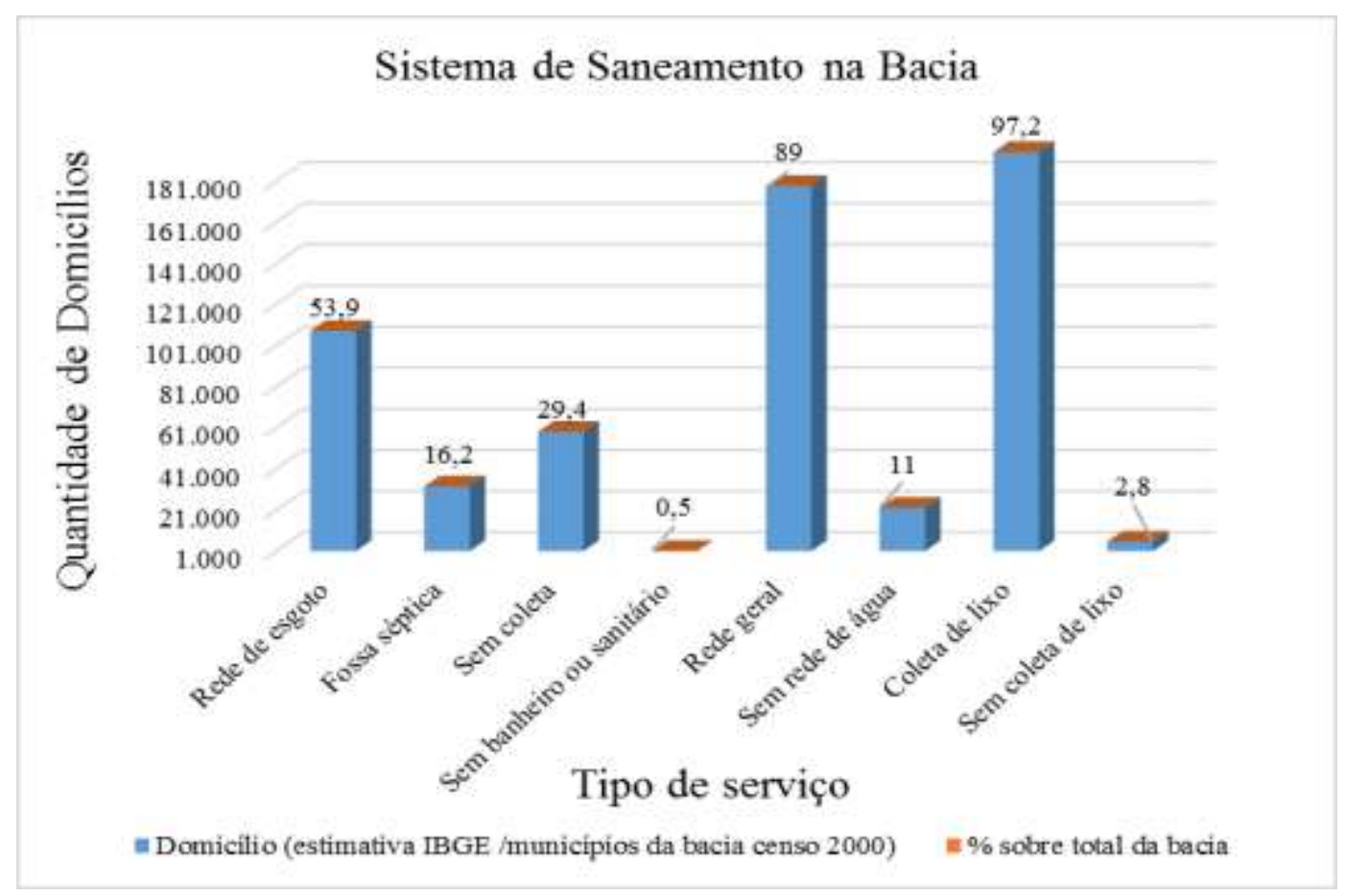

FIGURA 7 - Sistema de Saneamento da Bacia Guarapiranga Fonte: Adaptado da SMA/CEA, 2008. 


\section{REVISÃO BIBLIOGRÁFICA}

\subsection{Legislação Ambiental}

O Conselho Nacional do Meio Ambiente (CONAMA) possui leis para assegurar o uso da água e controlar os parâmetros de qualidade e indicadores específicos, como a Resolução n ${ }^{\circ}$. 357, do CONAMA, de 17 de março de 2005 que tem como propósito:

"Dispor sobre a classificação dos corpos de água e diretrizes ambientais para o seu enquadramento, bem como estabelece as condições e padrões de lançamento de efluentes, e dá outras providências.

Segundo o Art. $2^{\circ}$ dessa resolução os tipos de água controlados são as águas doces (salinidade igual ou inferior a $0,5 \%$ ), águas salobras (salinidade superior a 0,5\% e inferior a 30\%), águas salinas (salinidade igual ou superior a 30\%), ambientes lênticos (água parada, com movimento lento ou estagnado), ambiente lótico (ambiente relativo a águas continentais moventes) e águas para aquicultura (cultivo ou a criação de organismos cujo ciclo de vida depende do meio aquático). Além disso, a Resolução possui padrões de qualidade ou Valores Máximos Permitidos (VMP) para os corpos de água que são classificados, segundo o Art. $3^{\circ}$ dessa Resolução (BRASIL, 2005), em águas doces, salobras e salinas em todo Território Nacional.

As águas da Represa de Guarapiranga, são classificadas em águas doce de classe 1 e possuem VMP que classificam valores para os elementos químicos e para os microorganismos que podem estar presentes nesse tipo de água (UMBUZEIRO, et al., 2009; BRASIL, 2005).

A classificação da represa Guarapiranga foi realizado a partir do DECRETO $\mathrm{n}^{\circ}$ 10.755 de 22 de novembro de 1977 (que tem como finalidade dispor sobre o enquadramento dos corpos de água receptores), para atender o Decreto $\mathrm{n}^{\circ}$ 8.468, de 8 de setembro de 1976, o qual "dispõe sobre a prevenção e o controle da poluição do meio ambiente", a represa Guarapiranga e todos seus afluentes com exceção do Rio Embu-Mirim e seus afluentes até a barragem no Município de São Paulo foi enquadrada nos corpos receptores de águas doce de classe 1 (SÃO PAULO, 1977).

As águas doces de classe 1, são destinadas para: 

simplificado;

“a) ao abastecimento para consumo humano, após tratamento

b) à proteção das comunidades aquáticas;

c) à recreação de contato primário, tais como natação, esqui aquático e mergulho, conforme Resolução CONAMA n²274, de 2000;

d) à irrigação de hortaliças que são consumidas cruas $e$ de frutas que se desenvolvam rentes ao solo e que sejam ingeridas cruas sem remoção de película; Indigenas.

e) à proteção das comunidades aquáticas em Terras

Os valores máximos permitidos pela Resolução CONAMA 357/2005 para os 12 elementos estudados nesse trabalho estão apresentados na TAB.3 (BRASIL, 2005).

TABELA 3 - Valores Máximos Permitidos (VMP) dos elementos analisados que podem ser encontrados na Classe 1 de águas doces pelo CONAMA 357/2005.

\begin{tabular}{|c|c|}
\hline & $\begin{array}{l}\text { CLASS } \\
\text { ÁGUAS DC }\end{array}$ \\
\hline Elementos Químicos & Parâmetros unidade \\
\hline Alumínio (Al) dissolvido ${ }^{* *}$ & 0,1 \\
\hline Bário $(\mathrm{Ba})$ total $^{* * *}$ & 0,7 \\
\hline Cádmio $(\mathrm{Cd})$ total $^{* * *}$ & 0,001 \\
\hline Cobre $(\mathrm{Cu})$ dissolvido ${ }^{* *}$ & 0,009 \\
\hline Crômio $(\mathrm{Cr})$ total $^{* * *}$ & 0,05 \\
\hline Ferro $(\mathrm{Fe})$ dissolvido ${ }^{* *}$ & 0,3 \\
\hline Manganês (Mn) total ${ }^{* * *}$ & 0,1 \\
\hline Níquel (Ni) total ${ }^{* * *}$ & 0,025 \\
\hline Sódio $(\mathrm{Na})^{*}$ & - \\
\hline Potássio $(\mathrm{K})^{*}$ & - \\
\hline Cálcio $(\mathrm{Ca})^{*}$ & - \\
\hline Magnésio $(\mathrm{Mg})^{*}$ & - \\
\hline
\end{tabular}

*Não possuem VMP na Resolução CONAMA 357/2005; ** Dissolvido, amostra coletada, filtrada e analisada; *** Total, amostra coletada, digerida com ácido e analisada.

Fonte: BRASIL, 2005.

Para a determinação desses VMP para uma determinada classe é realizado um estudo para as prováveis substâncias e micro-organismos que podem ser encontrados na água, além disso, leva em consideração o quanto da substância contaminante pode prejudicar a vida dos animais aquáticos, como os peixes, e os seres humanos ao consumir esse tipo de água. Os legisladores ao escolher um valor, sempre escolhem o menor, pois eles podem garantir que o conjunto de usos está sendo abrangido, tanto para os seres humanos, como os 
animais aquáticos (UMBUZEIRO, et al., 2009).

Em 16 de janeiro de 2006, foi criado à lei ${ }^{\circ} 12.233$, especifica para a região da represa do Guarapiranga, que visa "definir a Área de Proteção e Recuperação dos Mananciais da Bacia Hidrográfica do Guarapiranga, e dá outras providências correlatas". E visa também se enquadrar na lei estadual $n^{\circ}$ 9.866, de 28 de novembro de 1997, no qual "Dispõe sobre diretrizes e normas para a proteção e recuperação das bacias hidrográficas dos mananciais de interesse regional do Estado de São Paulo e dá outras providências”, além de declarar a área como abastecimento público (SÃO PAULO, 2006).

As leis são constituídas por instrumentos de planejamento que auxiliam na cobrança pelo o uso da água (instrumentos econômicos) e os regulatórios que comanda/define os níveis de padrões máximos de poluentes que podem ser encontrados na água e controla/fiscaliza esses padrões (instrumentos de comando e controle) (ESCAP, 2003) (BOMFIM, 2011). Porém mesmo existindo esses instrumentos que auxiliam na proteção do uso da água, existem desvantagens. As vantagens e as desvantagens dos instrumentos de comando e controle estão apresentadas na TAB.4.

Segundo PEREIRA, et al., 2007:

"A principal característica da política de comando e controle é que esta, em base legal, trata o poluidor como "ecodelinqüente" e, como tal, não lhe dá a chance de escolha: ele tem de obedecer à regra imposta, caso contrário se sujeita as penalidades em processos judiciais ou administrativos. A aplicação de multas em casos de não-cumprimento da obrigação é bastante usual. " (PEREIRA, et al., 2007).

TABELA 4 - Vantagens e Desvantagens do Instrumento de Comando e Controle

\begin{tabular}{|c|c|}
\hline Vantagens & Desvantagens \\
\hline $\begin{array}{l}\text { - Certeza sobre emissões finais e mais } \\
\text { flexibilidade para regular fenômenos } \\
\text { complexos; } \\
\text { - Facilidade para monitorar e observar o } \\
\text { cumprimento da norma. }\end{array}$ & $\begin{array}{l}\text { - O regulador depende, muitas vezes, } \\
\text { das informações sobre emissões, tecnologias e } \\
\text { custos fornecidos pelo agente impactante; } \\
\text { - Não reflete a forma menos onerosa de } \\
\text { controlar os impactos; não incentiva o agente } \\
\text { impactante à melhoria contínua. }\end{array}$ \\
\hline
\end{tabular}

Fonte: FLORIANO, 2005.

Os limites ambientais, estipulados pelos órgãos ambientais, que são responsáveis pelos instrumentos de comando e controle podem ser diretos e/ou indiretos. Os instrumentos 
diretos estão relacionados as questões ambientais e os indiretos são desenvolvidos para solucionar outros problemas, mas, algumas vezes, acabam colaborando para a solução ou agravamento dos problemas envolvendo o meio ambiente. A característica de cada instrumento está apresentada na TAB.5.

TABELA 5 - Instrumentos de Política Ambiental

\begin{tabular}{|c|c|c|}
\hline & Instrumentos Diretos & Instrumentos Indiretos \\
\hline $\begin{array}{l}\text { Comando } \\
\text { e Controle }\end{array}$ & $\begin{array}{c}>\quad \text { Padrões de emissão; } \\
>\quad \text { Cotas não transferíveis; } \\
>\quad \text { Controle de equipamentos, processos, } \\
\text { insumos e produtos; } \\
>\quad \text { Rodízio de automóveis estadual (SP); } \\
>\text { Zoneamento. }\end{array}$ & $\begin{array}{c}\text { Controle de equipamentos, } \\
\text { processos, insumos e } \\
\text { produtos } \\
\text { Rodízio de automóvel } \\
\text { municipal; }\end{array}$ \\
\hline
\end{tabular}

Fonte: Adaptada de VARELA, 2001.

Além da Lei específica do Guarapiranga e da Resolução CONAMA 357/2005, há outras normas ambientais, sendo elas federais, estaduais e municipais que se aplicam a Bacia. Segundo Whately et al (2006), para a proteção ambiental em geral, a proteção de recursos hídricos e florestais, ao licenciamento de atividades potencialmente prejudiciais ao meio ambiente, ao uso e ocupação do solo e aos crimes ambientais. As legislações aplicáveis a Bacia Hidrográfica do Guarapiranga estão apresentadas na FIG.8 (WHATELY, et al., 2006). 


\section{FEDERAL}

Lei no 12.651 de 2012

Lei $n \circ 6.766$ de 1979

Lei $n$ ㅇ 6.938 de 1981

Resolução Conama no 01 de 1986

Constituição Federal de 1988

Decre to Federal no 750 de 1993

de $\mathrm{R}$

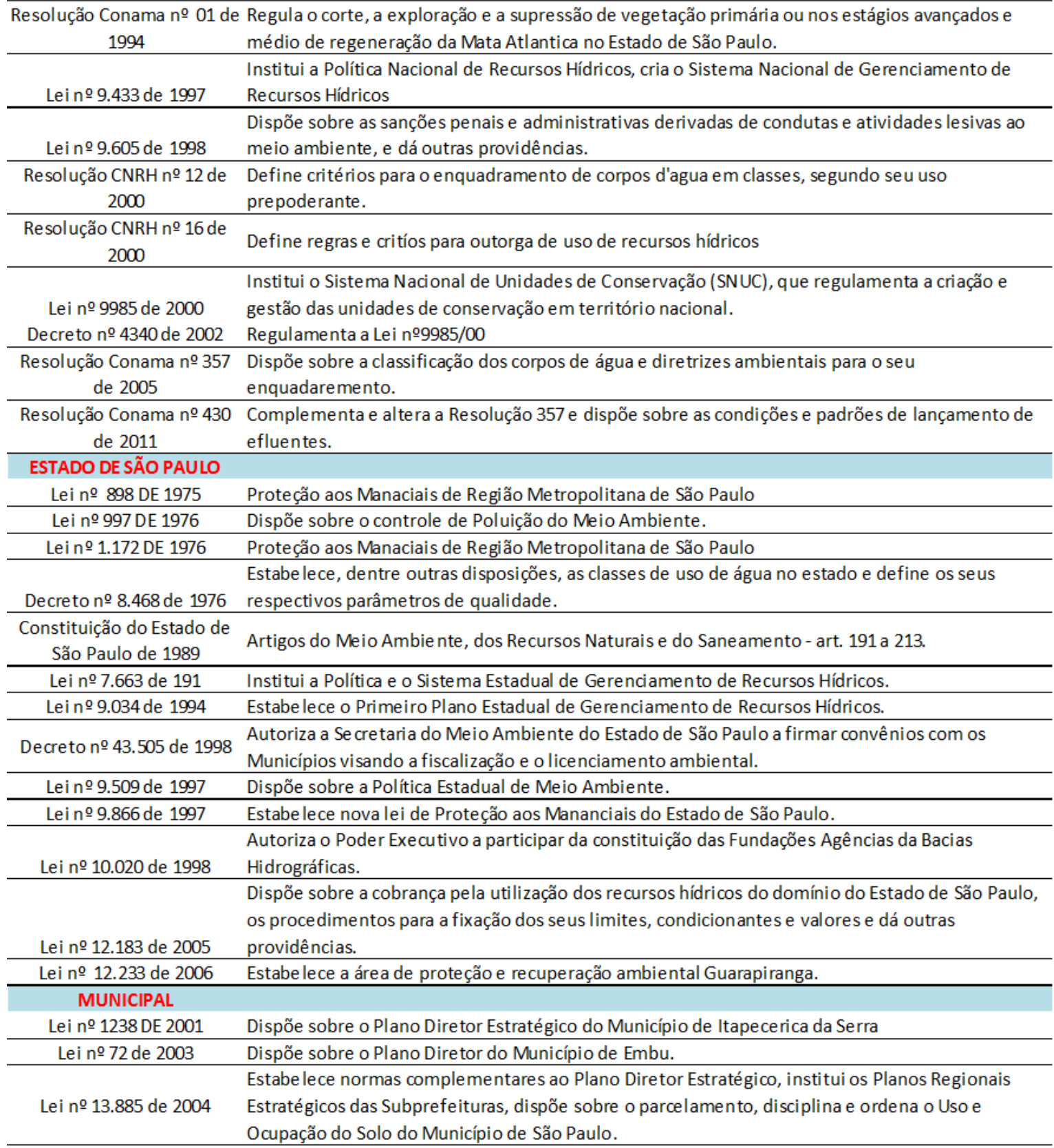

FIGURA 8 - Legislações Aplicáveis a Bacia Hidrográfica do Guarapiranga Fonte: WHATELY, et al., 2006.

Novo Código Florestal - al tera as le is no 6.938/81, 9.393/96e 11.428/06. Regova as Leis 4771/65,

7.754/89, e a Medida Provisória no 2.166-67/01.

Dispõe sobre o Parcelamento do Solo Urbano e dá outras Providências.

Dispõe sobre a criação de Estações Ecológicas, Áreas de Proteção Ambiental e dá outras

Dispõe sobre a Política Nacional do Meio Ambiente, se us fins e mecanismos de formulação e aplicação, e dá outras providências.

Dispõe sobre atividade minérias.

Capítulo de Meio Ambiente - Art. 22, 23, 24 e 225

Dispõe sobre o corte, a exploração e a supressão de vegetação primária ou nos es-tágios Regula o corte, a exploração e a supressão de vegetação primária ou nos estágios avançados e Recursos Hídricos meio ambiente, e dá outras providências. 


\subsection{Caracterização dos metais}

Os metais são definidos como bons condutores de calor e eletricidade, maleável, e dúctil, formam cátions, têm brilho e formam óxidos básicos; e segundo Duffus (2002), o termo metal no uso convencional refere-se ao elemento puro ou uma liga de elementos metálicos.

Os metais estão presentes em diversas áreas do meio ambiente, como na atmosfera, na água, solo, sedimento e nos organismos vivos, e são controlados por processos químicos, físico e biológicos (MORTATTI, et al., 2010).

Os metais podem ser classificados como essenciais, micro-cotaminates ambientais e podem ser simultaneamente essenciais e micro-cotaminantes (AVILACAMPOS, et al., 2015).

Muitos metais são essenciais para o crescimento dos organismos vivos, desde bactérias até os seres humanos, porém em baixas concentrações, sendo eles o sódio, potássio, cálcio, ferro, zinco, cobre, níquel e magnésio; os metais que podem ser micro-contaminantes ambientais, ou seja, ocasionam contaminações ao meio ambiente, podem ser os elementos arsênio, chumbo, cádmio, mercúrio, alumínio, titânio, estanho e tungstênio; já os elementos que podem ser essenciais e ao mesmo tempo micro-contaminantes são o crômio, zinco, ferro, cobalto, manganês e níquel (AVILA-CAMPOS, 2015).

Segundo Braga (2005), os metais tóxicos estão presentes em quantidades diminutas no meio aquático por ação de fenômenos naturais, mas podem ser despejados em quantidades significativas por atividades industriais, agrícolas e de mineração.

O metal dissolvido presente em água natural possui ínfima porção em forma de íon livre, o restante está complexado em ligantes químico orgânicos e inorgânicos, que influenciam a biodisponibilidade, toxicidade e modalidade do metal. As formas que os metais podem ser encontrados são: íon livre hidratado; complexo inorgânico e orgânico dissolvido; espécie metálica na forma de coloide disperso; e metal adsorvido nos coloides ou material em suspensão (VIEIRA, 2000).

A presença de metais-traços, na água ocorre por processos de erosão de materiais 
sólidos e leitos rochosos e pela precipitação atmosférica, no entanto esses processos estão sendo alterados pela ação antrópica (VIEIRA, 2000). A contaminação nos ambientes aquáticos por metais é preocupante devido a sua toxicidade e abundância no meio ambiente, principalmente no meio aquático, no qual há acumulação de metais na flora e fauna, consequentemente entra na cadeia alimentar e pode acarretar efeitos nocivos não só para a fauna, mas também para os seres humanos. Os metais-traços são as principais causas desses efeitos nocivos, onde são provenientes do despejo de efluentes domésticos e industrias no recurso hídrico (COELHO, et al., 2014; VIEIRA, 2000).

\subsubsection{Alumínio}

O elemento mais abundante na crosta terrestre, o alumínio só é menos abundante do que oxigênio e o silício (PEIXOTO, 2001). É um elemento leve e resistente e pode ser utilizado em diversas aplicações, como na fabricação de revestimentos de automóveis, navios e aviões, janelas, latas de refrigerante e cervejas; e entre outros (DO CANTO, 2006). Sua obtenção é proveniente da bauxita $\left(\mathrm{Al}_{2} \mathrm{O}_{3}\right)$, através do processo de redução da alumina. Existem dois processos de extração desse minério, o Processo Bayer e o Processo de Héroult-Hall (DO CANTO, 2006).

O Processo Bayer consiste na purificação da bauxita visando à separação de outras substâncias, em específico o óxido de ferro III $\left(\mathrm{Fe}_{2} \mathrm{O}_{3}\right)$, predominante nesse minério (DO CANTO, 2006).

O Processo de Héroult-Hall utiliza eletrodos de carvão em contato com uma mistura líquida, a criolita-alumina. O calor dissipado pela corrente elétrica é suficiente para manter a mistura fundida. Em um dos eletrodos se forma o alumínio, que estar a uma temperatura maior do que a de seu ponto de fusão, sendo removido em intervalos regulares. No outro eletrodo à formação de gás oxigênio, que reage com o carvão, produzindo gás carbônico e desgastando o eletrodo, na qual é substituído periodicamente (DO CANTO, 2006).

No meio aquático, o alumínio pode ocorrer em diversas formas e é influenciado pelo $\mathrm{pH}$, temperatura e presença de fluoreto, sulfatos, matéria orgânica e outros ligantes. Segunda a CETESB (2009), a solubilidade é baixa em pH entre 5,5 e 6,0. As concentrações 
de alumínio dissolvido em águas com pH neutro variam entre 0,001 a 0,05 mg.L $\mathrm{L}^{-1}$, mas aumentam para 0,5 a $1 \mathrm{mg} . \mathrm{L}^{-1}$ em águas mais ácidas ou ricas em matéria orgânica.

O sulfato de alumínio é muito utilizado no tratamento de água. Na fase inicial do tratamento a fase de clarificação, o sal aglutina toda a matéria em suspensão e forma flocos que ganham densidade e sedimentam. Depois é realizado os processos de coagulação, decantação, filtração, desinfecção correção e fluoretação. Após todos os processos realizados a água pode ser distribuída a rede de abastecimento (CENTRO DE INFORMAÇÃO METAL MECÂNICA, 2008).

Por ser um elemento não essencial ao corpo humano, o alumínio pode ser tóxico e acumulativo, podendo provocar Insuficiência Renal Crônica (IRC) (GARCIA, et al., 1996).

\subsubsection{Bário}

É o metal estável alcalino mais pesado da Terra, se oxida facilmente em contato com o ar úmido e reage com água ou com ácidos diluídos. Não possui cor e é um íon positivo bivalente (CORNELIS, et al., 2005).

Segundo Cornelis, et al. (2005) o bário constitui em aproximadamente 0,04\% da crosta terrestre e está presente no meio ambiente em concentrações relativamente altas. É encontrado na natureza somente na forma combinada e as principais são a barita (sulfato de bário) e a witherita (carbonato de bário). A barita é a principal fonte de obtenção de bário metálico (COMPANHIA AMBIENTAL DO ESTADO DE SÃO PAULO, 2012).

Devido a emissões industriais, como combustão de carvão/óleo diesel e incineração de resíduos o bário é encontrado no ar atmosférico; na maioria das águas superficiais a sua concentração depende da lixiviação das rochas, estudos realizados mostram que as concentrações em água superficiais e na maioria das águas subterrâneas, o bário é encontrado na forma de traço, ou seja, abaixo de mg.L - $^{-1}$ (WEINER, 2007; COMPANHIA AMBIENTAL DO ESTADO DE SÃO PAULO, 2012).

Os compostos solúveis são mais tóxicos do que os insolúveis, como o sulfato de 
bário. A exposição através de ingestão de água e alimentos é a principal via de acesso desse composto. Mesmo pequenas quantidades, em $\mu \mathrm{g} . \mathrm{L}^{-1}$, ingeridas desse composto, em curto período de tempo, podem provocar vômitos, cólicas estomacais, diarreia, dificuldade respiratória, debilidade muscular, alteração da pressão sanguínea e adormecia da face (WEINER, 2007; COMPANHIA AMBIENTAL DO ESTADO DE SÃO PAULO, 2012).

\subsubsection{Cádmio}

O cádmio $(\mathrm{Cd})$ é um elemento traço encontrado na natureza associado a minérios de cádmio, chumbo e sendo encontrado como subproduto da fusão do zinco, já que os dois metais ocorrem usualmente juntos. (BAIRD, 2002). Na atmosfera suas fontes naturais são através de erosões de rochas sedimentares e fosfáticas, incêndios florestais e atividades vulcânicas. As fontes antropogênicas ocorrem a partir de produção industrial desse metal, consumo, atividade de mineração e produtos que utilizam o cádmio. Podem ser encontrados também a partir das rochas fosfáticas, que é a base para fertilizantes fosfatados. É volátil em temperaturas extremamente altas e sua principal forma na atmosfera é o óxido de cádmio, mas o sal (cloreto de cádmio) pode ocorrer durante o processo de incineração (COMPANHIA AMBIENTAL DO ESTADO DE SÃO PAULO, 2012).

O cádmio é bioacumulativo, podendo-se bioacumular na região aquífera, em animais invertebrados e mamíferos. Pode ser adsorvido na argila e em materiais orgânicos, correndo-se o risco de entrar na cadeia alimentar. Pode ser combinado com o metal zinco, onde esse metal que faz parte de tubulações galvânicas, soldas e acessórios metálicos, pode assim contaminar a água potável que pode passar por essas tubulações. Alguns sais e complexos de cádmio são solúveis e apresentam mobilidade na água, os nãos solúveis ou adsorvidos ao sedimento apresentam pouca mobilidade (COMPANHIA AMBIENTAL DO ESTADO DE SÃO PAULO, 2012).

\subsubsection{Cobre}

Segundo Do Canto (2006), o cobre é um elemento raro na crosta terrestre, com apenas $0,0068 \%$ de sua massa. Há mais de 360 minerais de cobre, mas somente alguns são explorados, como por exemplo, o próprio minério não combinado, $\mathrm{Cu}$, calcopirita $\left(\mathrm{Cu}_{2} \mathrm{~S}\right)$, cuprita $\left(\mathrm{Cu}_{2} \mathrm{O}\right)$, malaquita $\left(\mathrm{CuCO}_{3} \cdot \mathrm{Cu}(\mathrm{OH})_{2}\right)$, atacamita $\mathrm{CuCl}_{2} \cdot 3 \mathrm{Cu}(\mathrm{OH})_{2}$ e a calcosita ou 
calcocita $\left(\mathrm{Cu}_{2} \mathrm{~S}\right)(\mathrm{DO}$ CANTO, 2006).

Para a obtenção do cobre utiliza se alguns processos para sua extração, como exemplo a calcosita, onde utiliza a ustulação para sua extração. No caso desse processo há a formação de um perigoso poluente, que contribui para o aumento da acidez na chuva. Na equação (1) esta apresentada a obtenção do cobre a partir da calcosita (DO CANTO, 2006).

$$
\mathrm{Cu}_{2} \mathrm{~S}+\mathrm{O}_{2} \vec{\Delta} \mathbf{2} \mathrm{Cu}+\mathrm{SO}_{2}
$$

Os compostos de cobre são utilizados em preparação que são utilizadas para pulverizar plantas a fim de protege-las contra micro-organismos. Por exemplo, o sulfato de cobre é adicionado à água com objetivo de deter a proliferação de algas e fungos (RODRIGUES, et al., 2012).

Nos seres vivos, o íon Cobre (II) é um elemento traço essencial, sendo o mais abundante em humanos, depois do ferro e do zinco, que necessitam de uma ingestão diária de 2 a $5 \mathrm{mg}$ de cobre por dia (RODRIGUES, et al., 2012).

\subsubsection{Crômio}

Há pouca quantidade de crômio na crosta terrestre, 0,0012\% de massa. É um metal muito resistente à corrosão e os mais comuns são o crômio (II), (III) e (VI). O minério mais típico e abundante é a cromita $\left(\mathrm{FeO} . \mathrm{Cr}_{2} \mathrm{O}_{3}\right)$, contendo cerca de 40 a $50 \%$ do metal. Para a obtenção desse metal pode-se reduzir o oxido de crômio III $\left(\mathrm{Cr}_{2} \mathrm{O}_{3}\right)$ com o carbono, como apresentado na equação (2) ou com a aluminotermia, apresentada na equação (3) (COMPANHIA AMBIENTAL DO ESTADO DE SÃO PAULO, 2012) (DO CANTO, 2006).

$$
\begin{gathered}
\mathrm{Cr}_{2} \mathrm{O}_{3}+3 \mathrm{C} \vec{\Delta} \mathbf{2 C r}+3 \mathrm{CO} \\
\mathrm{Cr}_{2} \mathrm{O}_{3}+3 \mathrm{Al} \vec{\Delta} \mathbf{2 C r}+\mathrm{Al}_{2} \mathrm{O}_{3}
\end{gathered}
$$

Os compostos de crômio podem ser encontrados na natureza em rochas, solo, poeiras, névoas vulcânicas, água, plantas e animais. Em ambientes não contaminados pela ação antrópica, o teor de crômio é aproximadamente de $1 \mu \mathrm{g} . \mathrm{L}^{-1}$ na água e $0,1 \mu \mathrm{g} \cdot \mathrm{m}^{-3}$ no ar 
(COMPANHIA AMBIENTAL DO ESTADO DE SÃO PAULO, 2012).

As emissões industriais, que são de origem antrópica, ocorrem através da produção da liga ferrocrômio, refino do minério e o seu tratamento químico, são os principais contaminantes do meio ambiente (COMPANHIA AMBIENTAL DO ESTADO DE SÃO PAULO, 2012).

\subsubsection{Ferro}

O ferro é encontrado na crosta terrestre somente na forma combinada com outros elementos como, por exemplo, alguns minérios mais representativos são eles a hematita $\left(\mathrm{Fe}_{2} \mathrm{O}_{3}\right)$, magnetita $\left(\mathrm{Fe}_{3} \mathrm{O}_{4}\right)$, siderita $\left(\mathrm{FeCO}_{3}\right)$ e limonita $\left(2 \mathrm{Fe}_{2} \mathrm{O}_{3} .3 . \mathrm{H}_{2} \mathrm{O}\right)$ (DO CANTO, 2006).

O ferro está presente principalmente em águas subterrâneas devido à dissolução do minério siderita pelo gás carbônico da água. É utilizado no tratamento de água para o abastecimento público, empregado como coagulante a base de ferro (COMPANHIA AMBIENTAL DO ESTADO DE SÃO PAULO, 2009).

Mesmo não sendo considerado tóxico, traz diversos problemas para o abastecimento público de água. Pode modificar a cor e o sabor da água, além de provocar contaminações biológicas na água através do desenvolvimento de depósitos em canalizações e de ferro-bactérias (COMPANHIA AMBIENTAL DO ESTADO DE SÃO PAULO, 2009).

O ferro combinado com outros elementos, como o manganês, crômio, níquel, molibdênio, vanádio ou titânio, têm-se a formação de ligas (DO CANTO, 2006).

O processo de obtenção desse material pode ser descrito em três etapas:

1. Combustão incompleta do carvão na presença de oxigênio molecular, formando monóxido de carbono;

2. Reação do monóxido de carbono com óxido de ferro, por exemplo, $\mathrm{Fe}_{2} \mathrm{O}_{3}$, originando óxido de ferro II (FeO) e dióxido de carbono;

3. E reação do $\mathrm{FeO}$ com monóxido de carbono, formando ferro metálico e dióxido de carbono (MEDEIROS, 2010). 
No corpo humano, a hemoglobina é responsável pelo transporte de oxigênio dos pulmões para os tecidos celulares, onde a queima de glicose acontece (na presença de $\mathrm{O}_{2}$ ). Esse transporte acontece pela presença de íons de $\mathrm{Fe}^{2+}$ da hemoglobina, que se liga ao $\mathrm{O}_{2}$ (MEDEIROS, 2010).

\subsubsection{Manganês}

Um metal que possui cerca de $0,11 \%$ da massa da crosta terrestre e seu principal minério é a pirolusita (MnO2). Para a formação do manganês (Mn) ocorre o aquecimento do minério que reage com o carbono e resulta em um manganês metálico, apresentado na equação (4) (DO CANTO, 2006).

$$
\mathrm{MnO}_{2}+2 \mathrm{C} \vec{\Delta} \boldsymbol{M n}+2 \mathrm{CO}
$$

Na água esse elemento é encontrado na forma dissolvida e suspensa, que podem variar conforme $\mathrm{pH}$ e potencial redox. Nas águas subterrâneas anaeróbia na maioria das vezes apresenta o manganês dissolvido, já nos rios é transportado adsorvido a partículas suspensas nos sedimentos (COMPANHIA AMBIENTAL DO ESTADO DE SÃO PAULO, 2012).

Pode se acumular em organismos como algas, moluscos e alguns peixes, mas a bioacumulação do manganês é maior em níveis tróficos, inferiores do que em superiores, por isso não é significativa (COMPANHIA AMBIENTAL DO ESTADO DE SÃO PAULO, 2012).

\subsubsection{Níquel}

Considerado um elemento raro, por existir apenas $0,01 \%$ da massa na crosta terrestre. O minério mais encontrado e mais importante é a pentlandita (FeS.NiS), sua obtenção ocorre através da ustulação do sulfeto de níquel (NiS) e em seguida a redução com o carbono, apresentada na equação (5) (DO CANTO, 2006).

$$
\begin{gathered}
2 \mathrm{NiS}+3 \mathrm{O}_{2} \vec{\Delta} 2 \mathrm{NiO}+2 \mathrm{SO}_{2} \\
2 \mathrm{NiO}+\mathrm{C} \vec{\Delta} 2 \mathrm{Ni}+\mathrm{CO}
\end{gathered}
$$


O níquel é utilizado na fabricação de aço inoxidável, por ser resistente a corrosão de ácidos, sais e álcalis. É usado na produção de ligas, baterias alcalinas, moedas, pigmentos inorgânicos, próteses clínicas e dentárias (COMPANHIA AMBIENTAL DO ESTADO DE SÃO PAULO, 2012).

No solo, água, ar e na biosfera o níquel aparece em concentrações traços, como apresentado na TAB.6. Nos rios, o níquel, transporta-se como partículas precipitadas com material orgânico; nos lagos, a forma iônica é predominantemente, associada com material orgânico. A deposição desse elemento no sedimento pode ocorrer por processos de precipitação, complexação, adsorção em argila e agregado a biota. O níquel não é acumulado em quantidades significativas por organismos aquáticos (COMPANHIA AMBIENTAL DO ESTADO DE SÃO PAULO, 2012).

TABELA 6 - Níveis de níquel no meio ambiente

\begin{tabular}{cc} 
Solos agrícolas & Concentração do níquel \\
Água doce & 3 a $1000 \mathrm{mg} \cdot \mathrm{kg}^{-1}$ \\
Água do mar & 2 a $10 \mu \mathrm{g} . \mathrm{L}^{-1}$ \\
Níveis atmosféricos & 0,2 a $0,7 \mu \mathrm{g} . \mathrm{L}^{-1}$ \\
\hline
\end{tabular}

Fonte: (COMPANHIA AMBIENTAL DO ESTADO DE SÃO PAULO, 2012).

\subsubsection{Sódio}

O minério mais conhecido de sódio é o carbonato de sódio, hoje conhecido como trona. O sódio originou-se da eletrólise da soda cáustica fundida, feita pelo seu descobridor Humphry Davy, em 1807. A sua extração era feita, durante muitos anos, pela redução do carbonato de sódio com o carbono, como apresentada na equação (6), porém com o barateamento da eletricidade o método realizado por Davy retornou, mas com algumas mudanças. Atualmente utiliza-se uma mistura de $\mathrm{NaCl}$ com $\mathrm{Na}_{2} \mathrm{CO}_{3}$ ou $\mathrm{CaCl}_{2}$ (PEIXOTO, 1999).

$$
\mathrm{Na}_{2} \mathrm{CO}_{3}+2 \mathrm{C} \rightarrow \mathbf{2 N a}+3 \mathrm{CO}
$$

Os sais de sódio estão presentes na natureza em abundância. As membranas dos 
seres humanos são controladas pelo equilíbrio dos os íons de sódio em conjunto com íons de potássio. Quando há um desequilíbrio desses elementos pode causar diarreia e desidratação em indivíduos acometidos por certas doenças e distúrbios intestinais (PEIXOTO, 1999).

\subsubsection{Potássio}

O potássio é um metal comum na crosta terrestre, pode ser encontrado em rochas, solos, oceanos e lagos. Oxida-se com o oxigênio do ar e é muito reativo com água. É utilizado na fabricação de fertilizantes, com o hidróxido de potássio $(\mathrm{KOH})$ e na fabricação de vidros com o carbonato de potássio $\left(\mathrm{K}_{2} \mathrm{CO}_{3}\right)$. Além disso, o KOH é utilizado na fabricação de sabão líquido e detergente. $\mathrm{Na}$ forma de liga de sódio e potássio $(\mathrm{NaK})$ é utilizado como fluido de transferência de calor em processos especiais de refrigeração de reatores nucleares (COMPANHIA AMBIENTAL DO ESTADO DE SÃO PAULO, 2012).

Pode ser utilizado como oxidante no tratamento de água com o uso de permanganato de potássio. As concentrações encontradas em água para consumo são baixas e não representa risco a saúde, porém o uso de cloreto de potássio para tratamento de água dura de uso doméstico pode aumentar consideravelmente a exposição (COMPANHIA AMBIENTAL DO ESTADO DE SÃO PAULO, 2012).

\subsubsection{Magnésio}

O magnésio é o oitavo elemento em abundância na crosta terrestre, cerca de 2,5\%. Com uma densidade baixa, cerca de $2 / 3$ da densidade do alumínio, tem uma grande importância na forma de ligas na área aeroespacial. Sua obtenção na área industrial é realizada a partir da eletrólise do cloreto de magnésio $\left(\mathrm{MgCl}_{2}\right)$ fundido; $\mathrm{O} \mathrm{MgCl}_{2}$ é obtido através de jazidas de sais, como $\mathrm{NaCl}$, ou pela água do mar (PEIXOTO, 2000).

Um dos produtos mais conhecidos é o leite de magnésia, que consiste em hidróxido de magnésio em suspenção aquosa. Pode ser utilizado como antiácido e também como laxante. Na natureza esse elemento está presente na clorofila, substância primordial para fotossíntese. Sendo assim, a sua função nas plantas corresponde ao ferro na hemoglobina. É importante na vida animal em geral, participando em uma series de reações enzimáticas, especialmente no metabolismo de açúcares. Ele está presente em todas as 
células, fluidos e nos ossos e músculos do corpo humano (PEIXOTO, 2000).

\subsubsection{Cálcio}

O cálcio é o quinto elemento mais abundante da Terra, cerca de 3,5\% da massa da crosta terrestre e cerca de $8 \%$ da crosta da Lua. Além disso, ele é o elemento metálico mais abundante no corpo humano. Ele é essencial para o crescimento e manutenção dos ossos e dos dentes e ajuda na coagulação do sangue e na contração muscular (PEIXOTO, 2004).

Sendo um metal de baixa dureza, cor prateada, o cálcio reage facilmente com o

oxigênio do ar e com a água. É encontrado na natureza como constituinte de rochas, como calcários, como o mármore $\left(\mathrm{CaCO}_{3}\right)$, gipso $\left(\mathrm{CaSO}_{4} \cdot 2 \mathrm{H}_{2} \mathrm{O}\right)$ e fluorita $\left(\mathrm{CaF}_{2}\right)$ (PEIXOTO, 2004).

Sua obtenção industrial ocorre através da eletrólise ígnea do cloreto de cálcio $\left(\mathrm{CaCl}_{2}\right)$. Possui muitas utilidades na área indústria, por exemplo, como agente redutor na preparação de metais como tório, urânio, zircônio e entre outros. Além disso, pode ser usado como desoxigenador, dessulfurizador e descarbonizador de várias ligas metálicas (PEIXOTO, 2004)

\subsection{Técnica Analítica}

Segundo Harris (2007) na espectrometria atômica, uma substância é decomposta em átomos em uma chama, forno ou plasma (um gás a altas temperaturas para produzir átomos excitadosemitemradiação em comprimentos de ondas característicos de cada elemento). A espectroscopia atômica faz referência a fenômenos que envolvem elétrons de valência, no qual cada elemento pode ser medido através da absorção ou emissão ultravioleta ou radiação visível (HARRIS, 2007). Os métodos utilizados podem detectar partes por milhão a partes por bilhão e, também casos de concentrações ainda menores. Um método espectrométrico é considerado rápido e de alta seletividade, podendo ser espectrometria de massas atômicas e espectrometria atômica óptica. Os elementos são determinados no meio gasoso na forma de íons elementares ou átomos individuais, com uma separação bem seletiva de cada elemento analisado (SKOOG, et al., 1998). 
A primeira etapa para iniciar qualquer método de espectrometria óptica é a atomização da amostra, no qual ocorre o processo de volatilização e decomposição da amostra de interesse produzindo uma fase gasosa de íons e átomos. Essa etapa pode influenciar na sensibilidade, precisão e exatidão do método, considerada uma etapa crítica. Os métodos utilizados para atomização das amostras, apresentados na TAB.7, são as chamas, os atomizadores eletrotérmicos e os de plasmas indutivamente acoplados. Dentre eles as chamas e os atomizadores eletrotérmicos utilizados pela espectrometria de absorção óptica, enquanto os de plasma indutivamente acoplado são utilizados em espectrometria de massas atômica e em emissão óptica, sendo esse último o abordado mais profundamente nesse trabalho (SKOOG, et al., 1998).

TABELA 7 - Classificação dos métodos espectroscópicos atômicos

\begin{tabular}{|c|c|c|c|}
\hline $\begin{array}{l}\text { Métodos de } \\
\text { Atomização }\end{array}$ & $\begin{array}{l}\text { Temperatura } \\
\text { típica de atomização, }{ }^{\circ} \mathrm{C}\end{array}$ & $\begin{array}{l}\text { Tipos } \\
\text { de espectroscopia }\end{array}$ & $\begin{array}{l}\text { Nome comum e } \\
\text { Abreviações }\end{array}$ \\
\hline $\begin{array}{l}\text { Plasma acoplado } \\
\text { indutivamente }\end{array}$ & $6.000-8000$ & $\begin{array}{l}\text { Emissão } \\
\text { Massa }\end{array}$ & $\begin{array}{l}\text { Espectroscopia de emissão em plasma } \\
\text { acoplado indutivamente, ICPAES } \\
\text { Espectroscopia de emissão em plasma } \\
\text { acoplado indutivamente, ICPMS }\end{array}$ \\
\hline Chama & $1.700-3.150$ & $\begin{array}{l}\text { Absorção } \\
\text { Emissão } \\
\text { Fluorescência }\end{array}$ & $\begin{array}{c}\text { Espectroscopia de absorção atômica, EA } \\
\text { Espectroscopia de emissão atômica, EEA } \\
\text { Espectroscopia de Fluorescência } \\
\text { atômica, EFA }\end{array}$ \\
\hline Eletrotérmica & $1.200-3.000$ & $\begin{array}{l}\text { Absorção } \\
\text { Fluorescência }\end{array}$ & $\begin{array}{l}\text { EAA eletrotérmica } \\
\text { EFA eletrotérmica }\end{array}$ \\
\hline $\begin{array}{l}\text { Plasma de corrente } \\
\text { contínua }\end{array}$ & $5.000-10.000$ & Emissão & Espectroscopia de plasma CC, DCP \\
\hline Arco elétrico & $3.000-8000$ & Emissão & $\begin{array}{l}\text { Espectroscopia de emissão com fonte de } \\
\text { arco }\end{array}$ \\
\hline Centelha elétrica & Varia com o tempo e posição & Emissão & $\begin{array}{l}\text { Espectroscopia de emissão com fonte de } \\
\text { centelha } \\
\text { Espectroscopia de emissão com fonte de } \\
\text { centelha }\end{array}$ \\
\hline
\end{tabular}

Fonte: (SKOOG, et al., 1998).

\subsubsection{Espectrometria de emissão óptica por plasma de argônio - ICP-OES}

A espectrometria de emissão óptica com plasma de argônio é uma técnica que não necessita de lâmpadas e é capaz de realizar análises em diversos tipos de amostras, conforme apresentado na TAB.8. É utilizada em diversas áreas, como na indústria mineradora, metalúrgica, agrícola, alimentos, centros de pesquisas e entre outros (HARRIS, 2007; GINÉ ROSIAS, 1998).

TABELA 8 - Lista de elementos que podem ser determinados por ICP-OES

\begin{tabular}{llll}
\hline $\begin{array}{l}\text { Metais alcalinos e } \\
\text { alcalinos terrosos }\end{array}$ & Terras raras & Metal de transição & Outros \\
\hline
\end{tabular}




$\begin{array}{lll} & \mathrm{Sc}, \mathrm{V}, \mathrm{Ti}, \mathrm{Cr}, \mathrm{Mn}, \mathrm{Fe}, \\ \mathrm{Li}, \mathrm{Na}, \mathrm{K}, \mathrm{Rb}, \mathrm{Cs}, \mathrm{Be}, \mathrm{Ce}, \mathrm{Pr}, \mathrm{Nd}, \mathrm{Sm}, \mathrm{Eu}, \mathrm{Gd}, \mathrm{Co}, \mathrm{Ni} \mathrm{Cu}, \mathrm{Zn}, \mathrm{Y}, \mathrm{Nb}, \mathrm{B}, \mathrm{C}, \mathrm{N}, \mathrm{Al}, \mathrm{Si}, \mathrm{P}, \mathrm{S}, \mathrm{Cl}, \\ \mathrm{Tb}, \mathrm{Dy}, \mathrm{Ho}, \mathrm{Er}, \mathrm{Tm}, \mathrm{Yb}, \mathrm{Zr}, \mathrm{Mo}, \mathrm{Ru}, \mathrm{Th}, \mathrm{Pd}, \mathrm{Ag}, \mathrm{Ga}, \mathrm{Ge}, \mathrm{As}, \mathrm{Se}, \mathrm{Br}, \mathrm{In}, \\ \mathrm{Mg}, \mathrm{Cd}, \mathrm{Ba} \\ \mathrm{Lu}, \mathrm{Th}, \mathrm{U}\end{array}$

Fonte: HOU, et al., 2000.

Nessa técnica os átomos do elemento de análise estão no estado fundamental, ou seja, com energia mais baixa, após a aplicação de uma energia os átomos são levados momentaneamente a um estado excitado, ou seja, com uma energia mais alta. Essa energia utilizada pode ser uma energia externa na forma de calor ou energia elétrica, nesse caso a energia é suprida por um plasma (SKOOG, et al., 1998). Um esquema da energia de excitação e emissão em um ICP-OES esta apresentado na FIG.9.
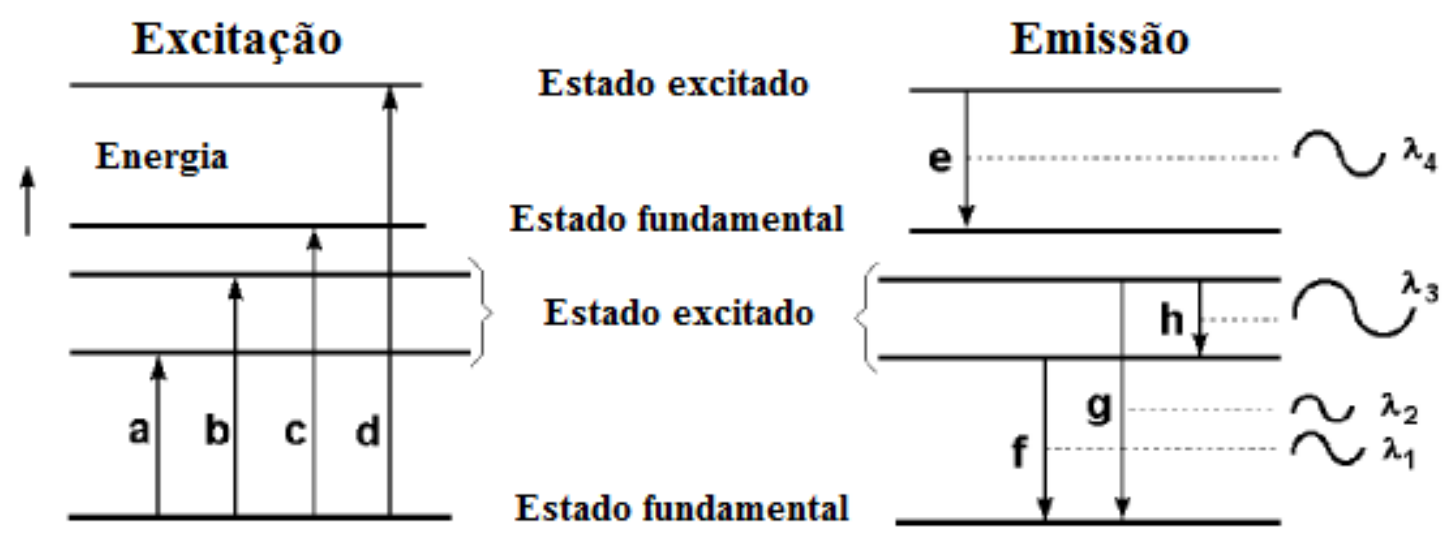

FIGURA 9 - Representação esquemática do princípio de energia de excitação e emissão dos átomos em um ICP-OES, onde a e b representa o estado de excitação; $\mathbf{c}$ é a ionização;

d é ionização/excitação; e é a emissão do íon; f, $\mathbf{g}$ e $\mathbf{h}$ são as emissões do átomo. $\boldsymbol{\lambda}=$ comprimento de onda.

Fonte: Adaptado de BOSS, et al., 1977.

\subsubsection{Fonte de Plasma}

O plasma pode ser definido como descargas elétricas em forma de gases, parcialmente ionizados, no qual há elétrons livres e íons positivos em constante movimento, ocorrendo assim uma transferência de energia, podendo ser por radiação ou condução, entre outros (GINÉ ROSIAS, 1998).

No plasma de argônio empregado na espectrometria óptica, os íons de argônio e os elétrons são as espécies condutoras principais. Os íons de argônio, uma vez formado no 
plasma, são capazes de absorver potência suficiente de uma fonte externa para manter sua temperatura em um determinado nível, de forma que a ionização adicional é capaz de sustentar o plasma indefinidamente (SKOOG, et al., 1998).

Na espectrometria de emissão óptica com fonte de rádio frequência, ou seja, plasma acoplado indutivamente (ICP, do inglês, inductively coupled plasma), segundo Harris (2007), apresenta temperatura duas vezes maior que a combustão por chama. A alta temperatura, a estabilidade e o ar ambiente relativamente inerte no plasma eliminam mais interferências do que a combustão por chama, as zonas de temperatura podem ser vistas na FIG.10. Além disso, a temperatura determina o grau, sendo ele estado fundamental, excitado e ionizado, em que uma amostra se decompõe em átomos. Cada um desses graus influência na intensidade do sinal observado (HARRIS, 2007).

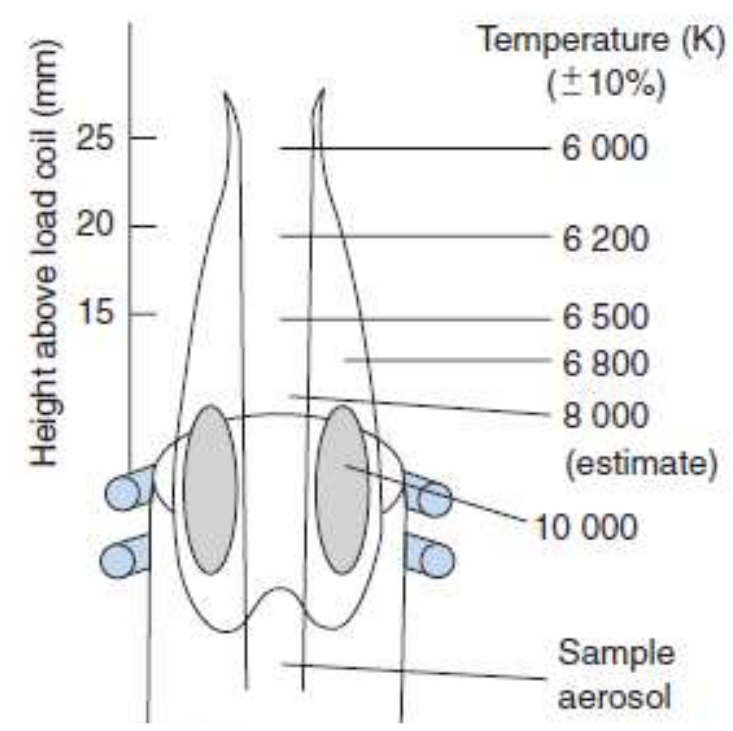

FIGURA 10 - Zonas de temperatura do plasma

Fonte: (HARRIS, 2007)

Devido à alta temperatura o ICP necessita ser isolado termicamente do cilindro de quartzo. Esse isolamento se dá por meio de um fluxo de argônio tangencial as paredes do tubo, como pode ser observado nas setas da FIG.11. O fluxo tangencial resfria as paredes internas do tubo central e centraliza o plasma de forma radial. A temperatura pode atingir a $10.000 \mathrm{~K}$ (Kelvin) (SKOOG, et al., 1998).

O plasma se forma na tocha, que é constituída por três tubos concêntricos de 
quartzo, com entradas separadas para cada seção anular. Dentre esses tubos fluem correntes de argônio a uma vazão total entre 11 e 17 L.min . $^{-1}$ O tubo mais largo possui um diâmetro aproximadamente de $2,5 \mathrm{~cm}$. Envolvendo a parte superior desse tubo encontra-se uma bobina de indução refrigerada a água e alimentada por um gerador de radiofrequência (RF), que tem uma capacidade de produzir cerca de $2 \mathrm{~kW}$ de energia a $27 \mathrm{MHz}$ ou $490 \mathrm{MHz}$. A ionização da corrente de argônio é produzida por uma bobina de Tesla, que é iniciada por uma centelha. A interação dos íons resultantes e seus elétrons associados interagem com o campo magnético oscilante, podem ser observados na FIG.11 (H), que é produzido pela bobina de indução I, também apresentado na FIG.11. Os íons e elétrons no interior da bobina flui em caminhos anelares fechados, devido a essas interações; o aquecimento ôhmico é consequências da sua resistência a este movimento (SKOOG, et al., 1998; GINÉ ROSIAS, 1998).

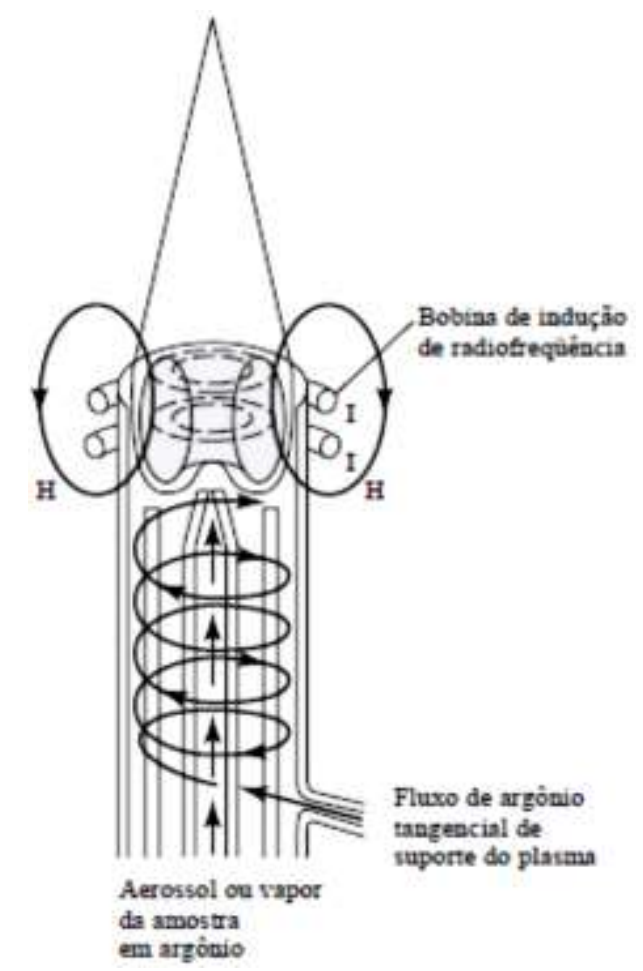

FIGURA 11 - Fonte de plasma de argônio

Fonte: (SKOOG, et al., 1998)

\subsubsection{Configuração do Plasma}

O plasma tem dois tipos de configuração para a observar a emissão no ICP, sendo elas, radial e axial (HOU, et al., 2000). 
Na observação radial o plasma é utilizado em ângulos retos, ou seja, posicionado na posição vertical. Essa observação fornece melhor precisão e estabilidade. É mais utilizada na espectrometria de emissão óptica de ICP, apresentada na FIG.12 (HOU, et al., 2000; SKOOG, et al., 1998).

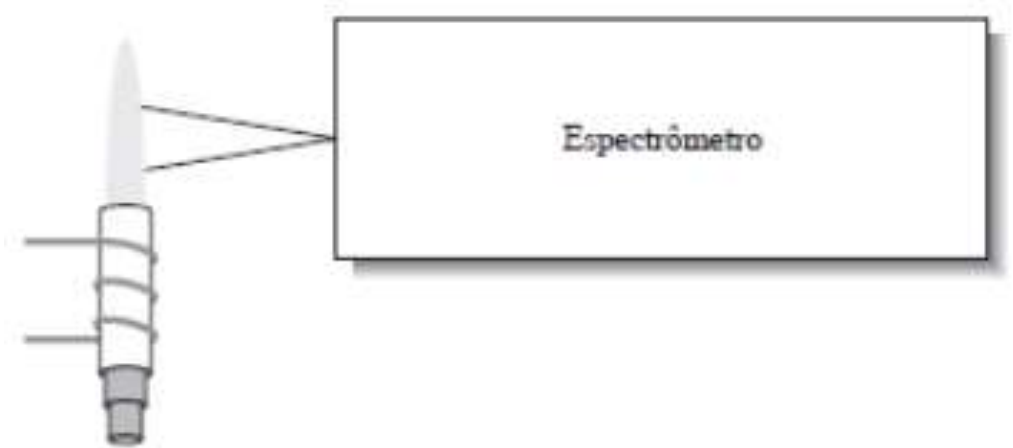

FIGURA 12 - Observação radial da tocha Fonte: SKOOG, et al., 1998.

Na observação axial o plasma é utilizado em $90^{\circ}$, ou seja, é posicionado na posição horizontal, FIG.13. Nessa observação os limites de detecção são melhores do que na observação radial. A única desvantagem é que há um aumento potencial de interferências espectrais e interferências de matrizes. É mais utilizado como fontes de ionização para a espectrometria de massas, pois os íons podem ser extraídos facilmente do topo do plasma para o interior da região de alto vácuo do espectrômetro de massas (HOU, et al., 2000; SKOOG, et al., 1998).

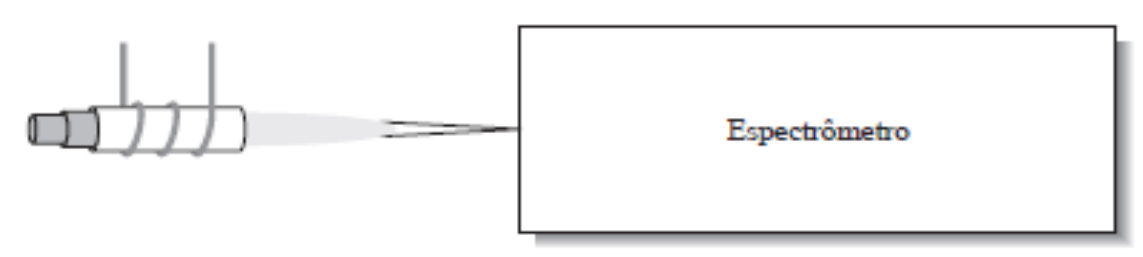

FIGURA 13 - Observação axial da tocha Fonte: SKOOG, et al., 1998.

\subsubsection{Instrumentação no ICP-OES}

A amostra é introduzida no espectrômetro de emissão óptica com plasma de argônio na forma líquida. No espectrômetro a amostra líquida é convertida em aerossol, 
processo chamado nebulização. A amostra é transportada até o plasma onde ocorre o processo de dessolvatação, vaporização, atomização e excitação e/ou ionização. Os átomos excitados e/ou ionizados emitem uma radiação característica. Na FIG.14 esta apresentado uma representação esquemática dos componentes em um típico ICP-OES (BOSS, et al., 1997).

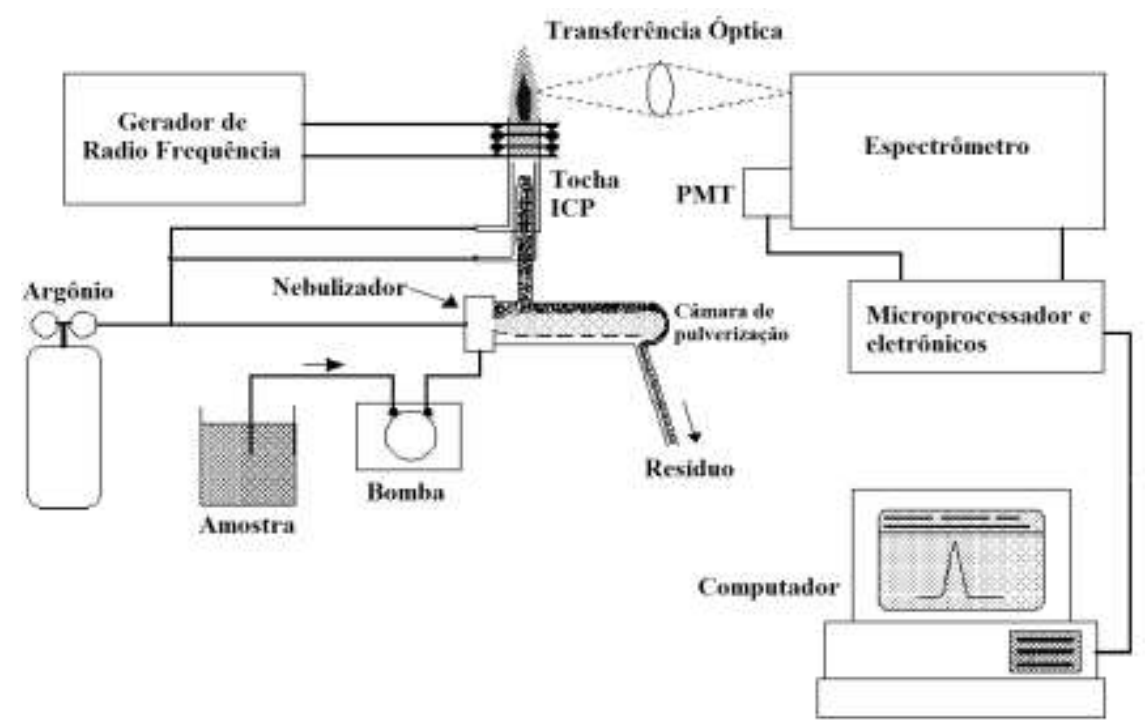

FIGURA 14 - Representação esquemática dos componentes em um ICP-OES Fonte: Adaptado de BOSS, et al., 1977.

As técnicas espectroscópicas ópticas têm que atomizar a amostra, para a conversão da solução da amostra em átomos e íon em fase gasosa. O dispositivo de atomização deve realizar uma tarefa complexa de converter os elementos de análise em soluções de átomos ou íons elementares, ou ambos, na fase gasosa (SKOOG, et al., 1998).

Há duas classes de dispositivos de atomização:

Atomizadores contínuos: plasmas e chamas, as amostras são introduzidas de forma contínua. O processo desse atomizador está apresentado na FIG.15.

Atomizadores discretos: as amostras inseridas através de uma seringa ou um auto-amostrador (SKOOG, et al., 1998). 


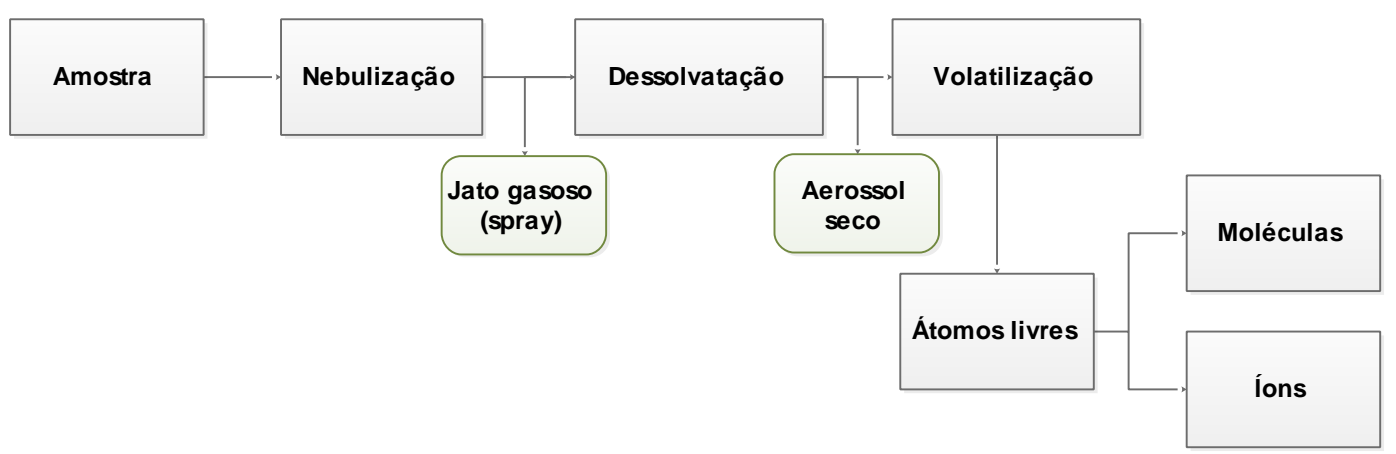

FIGURA 15 - Diagrama de blocos com processo que levam a produção de átomos, moléculas e íons em um sistema contínuo de introdução de amostras em um plasma ou chama

Fonte: Adaptado de SKOOG et al., 1988.

\subsubsection{Introdução da amostra no ICP-OES}

Com a formação do plasma a amostra é introduzida em forma de aerossol, um vapor gerado termicamente ou um pó finamente dividido pelo tubo central de quartzo. Isto causa uma modificação no aspecto do plasma, um escurecimento no canal central e no topo aparece uma chama comprida. Um esquema do sistema de introdução da amostra é apresentado na FIG.16 (SKOOG, et al., 1998; GINÉ ROSIAS, 1998).

É uma técnica que é tolerante a matrizes complexas e tem habilidade de analisar quantidades pequenas de amostra, $<1 \mathrm{~mL}$, para amostras liquidas; e $<50 \mathrm{mg}$, para amostras sólidas (HOU, et al., 2000).

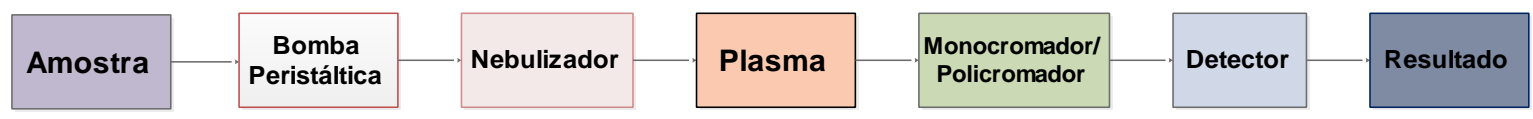

FIGURA 16 - Diagrama de blocos com o processo de introdução de uma amostra em um ICP-OES

\subsubsection{Bomba}

Alguns nebulizadores necessitam que as amostras sejam bombeadas até chegar no nebulizador. A amostra é aspirada pela bomba. Com a solução bombeada, o fluxo de vazão é fixo e não depende dos parâmetros da solução da amostra, como viscosidade ou tensão superficial. Além disso, o fluxo de vazão controlado permite que se faça uma rápida lavagem no nebulizador e na câmera de pulverização (BOSS, et al., 1997).

Uma bomba muito utilizada na técnica de ICP-OES, é a bomba peristáltica. Essa 
bomba utiliza uma serie de rolos que empurram a amostra através de um tubo, processo denominado peristaltismo (BOSS, et al., 1997). Uma representação de uma bomba peristáltica usada no ICP-OES pode ser observada na FIG.17.

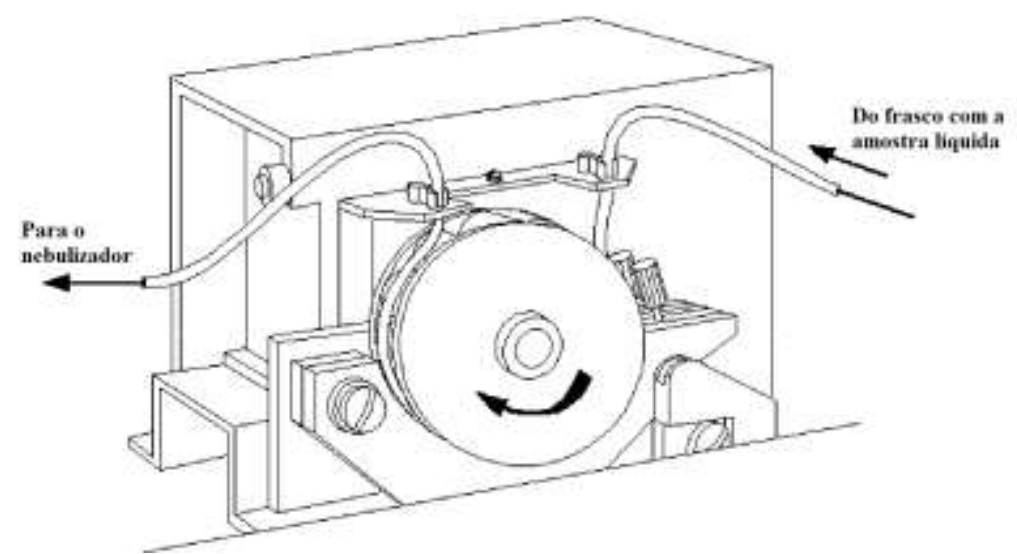

FIGURA 17 - Representação de uma bomba peristáltica utilizada na técnica de ICP-OES Fonte: Adaptado de BOSS, et al., 1977.

\subsubsection{Nebulizador}

Os nebulizadores são dispositivos que convertem amostra liquida em um aerossol que pode ser transportada até o plasma (BOSS, et al., 1997).

A introdução da amostra é feita por meio de um nebulizador concêntrico de vidro, apresentado na FIG.18. O transporte da amostra para o nebulizador é feito pelo efeito Bernoulli. Esse processo é denominado de aspiração. Com a alta velocidade do gás ocorre a dispersão do líquido em gotículas finas de tamanhos variados, as quais são carregadas para o plasma (SKOOG, et al., 1998).

Há outro tipo de nebulizador mais popular que apresenta um desenho de fluxo cruzado. Com esse nebulizador o mesmo efeito de Bernoulli ocorre, mas o gás a alta velocidade flui cruzando um capilar em ângulo reto. É frequente nesse tipo de nebulizador a bombeamento do líquido através do capilar por uma bomba peristáltica. Existem diversos tipos de nebulizadores que estão disponíveis para nebulização de alta eficiência, nebulização de amostra com alto conteúdo de sólido e para produção de névoa ultrafina (SKOOG, et al., 1998). 


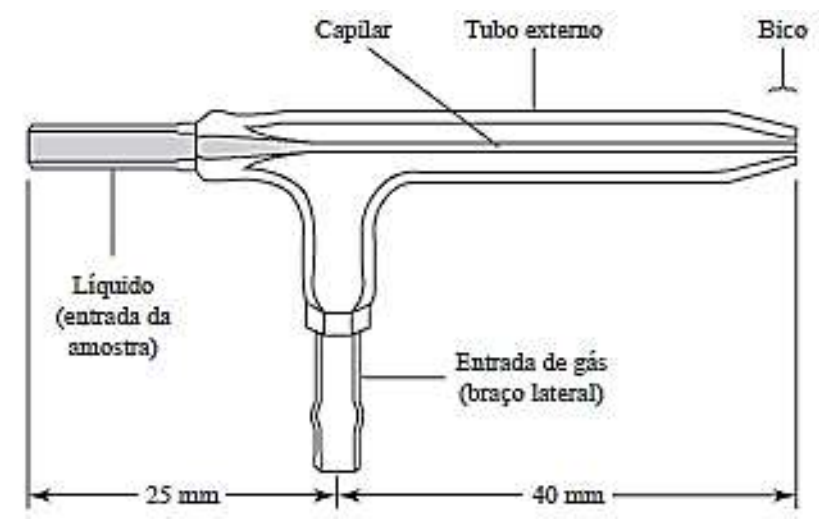

FIGURA 18 - Nebulizador Meinhard Fonte: SKOOG, et al., 1998.

\subsubsection{Monocromador/Policromador}

Monocromadores são instrumentos ópticos que tem a função de selecionar a faixa de espectro de emissão de luz. O monocromador isola a banda de comprimento de onda desejada para que somente essa banda seja detectada e medida. Essa faixa de comprimento de onda é chamada de banda de passagem espectral ou largura de banda efetiva (SKOOG, et al., 1998).

Policromadores são dispositivos que contém múltiplas fendas de saída e múltiplos detectores, permitindo que muitos comprimentos de ondas possam ser medidos simultaneamente, como no caso do ICP-OES, que é uma técnica multielementar (SKOOG, et al., 1998).

\subsubsection{Atomização e Ionização dos elementos}

Com a alta temperatura do plasma a amostra em solução sofre um processo de dessolvatação, que é a remoção do solvente e transformando a solução em um aerossol. Depois esse aerossol sofre uma decomposição, se transformando em um gás de partículas individuais, esse processo de chama vaporização; e essas partículas se dissociam em átomos ou íons, processo chamado de atomização ou ionização, respectivamente. Após a conclusão dos três processos, o plasma pode excitar e/ou ionizar o átomo ou íon (BOSS, et al., 1997). O esquema do processo de atomização e ionização é apresentado na FIG.19.

Os átomos e íons permanecem por cerca de 2 milissegundo no plasma, depois 
eles atingem o ponto de observação no plasma, estando em uma faixa de temperatura de 6.000 a $8.000 \mathrm{~K}$. A etapa de dessolvatação e vaporização são completas e a eficiência de atomização é bastante alta, com isso os efeitos de interferentes na fase de ionização não existem ou são pequenos (SKOOG, et al., 1998).

A atomização em um ICP ocorre em um ambiente inerte, além disso, possui uma temperatura transversal do plasma que é relativamente uniforme. As curvas de calibração são frequentemente lineares. Contudo ele apresenta uma desvantagem quando se analisa solventes orgânicos, não é muito tolerante. Os depósitos de carbono tendem a se formar no tubo de quartzo, o que pode entupir o sistema e causar contaminações (SKOOG, et al., 1998).

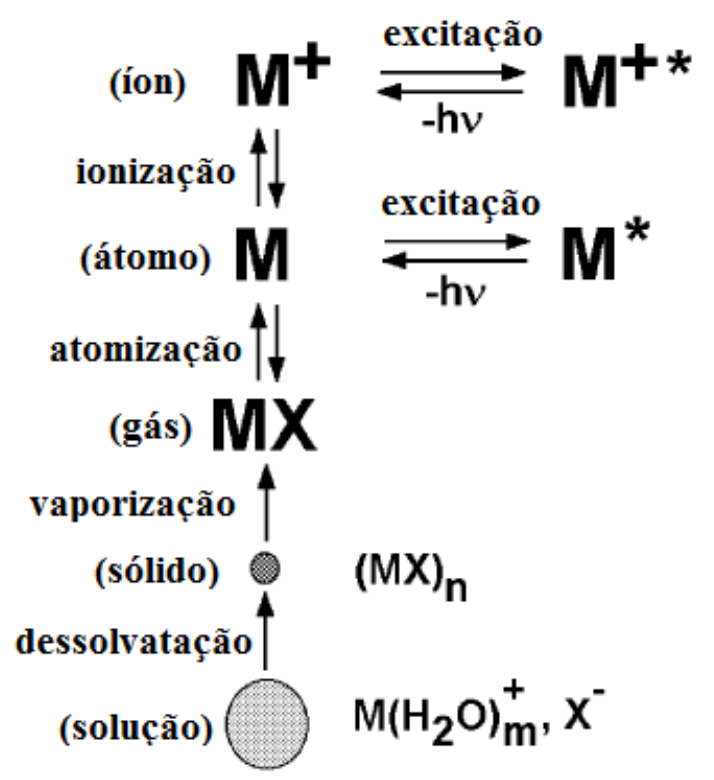

FIGURA 19 - Representação do processo quando uma amostra é inserida em um ICP-OES Fonte: Adaptado de BOSS, et al., 1977.

\subsubsection{Interferentes}

A interferência é qualquer efeito que muda o sinal de concentração do analito e pode ser corrigida removendo a fonte de interferência ou utilizando padrões que mostram as mesmas inferências para poder identificá-la. Porém a técnica de ICP-OES é uma das que possuem poucas interferências, devido ao plasma de argônio (Ar) e a alta temperatura que ajuda a reduzir as interferências químicas (HARRIS, 2007; HOU, et al., 2000).

\subsection{Tipos de interferentes}


As interferências espectrais, ou interferência do branco, produzem efeitos que independem da concentração do analito. Os efeitos podem ser reduzidos ou eliminados com um branco perfeito, ou seja, livre de qualquer analito que posso causar interferência. Na espectrometria de emissão, as linhas espectrais dos elementos analisados podem coincidir totalmente ou parcialmente, devido a sua análise multielementar no plasma. Essa aproximação de linha pode afetar o fundo em um dos extremos da linha de interesse além de aumenta-lo. (SKOOG, et al., 1998) (GINÉ ROSIAS, 1998).

As interferências de matriz alteram a grandeza do sinal do elemento analisado e são interferências de efeitos físicos e químicos. As interferências físicas alteram o processo de aspiração, no processo de nebulização, dessolvatação e de volatilização. As substâncias presentes na amostra, como a viscosidade, podem alterar a vazão e a eficiência do processo de nebulização; as interferências químicas ocorrem após a etapa de dessolvatação, na conversão das partículas sólidas ou fundidas em átomos ou íons elementares. Essa interferência é causada devido os constituintes que influenciam a volatilização das partículas do elemento (SKOOG, et al., 1998).

As interferências de ionização são causadas por substancias que alteram a ionização do elemento. A presença de elementos, como o K, que é facilmente ionizável pode alterar a extensão da ionização de um elemento menos ionizado, como por exemplo o $\mathrm{Ca}$ (SKOOG, et al., 1998). 


\section{VALIDAÇÃO DE METODOLOGIA}

A validação de metodologia, segundo o Vocabulário Internacional de Metrologia (VIM, 2012), é uma verificação na qual os requisitos especificados são adequados para o uso pretendido, ou seja, a validação verifica se a metodologia desenvolvida é adequada para o uso desenvolvido.

Ao desenvolver uma metodologia a aplicação da validação é a parte primordial para assegurar que o método é realmente aplicado para o uso desenvolvido, além de atestar que o método é robusto e confiável (KUBICEK, et al., 2015).

A validação auxilia os laboratórios de análises a demonstrarem corretamente os métodos analíticos aplicados, aumentando a credibilidade e a confiança no uso rotineiro da técnica para emissão dos resultados (INSTITUTO NACIONAL DE METROLOGIA, NORMALIZAÇÃO E QUALIDADE INDUSTRIAL, 2011). No Brasil, há duas agências credenciadoras para verificar a competência de laboratórios de ensaios a Agência Nacional de Vigilância Sanitária (ANVISA) e o INMETRO. A ANVISA possui o "Guia para Validação de Métodos Analíticos e Bioanalíticos - Resolução RE n 899, de 29 de maio de 2003” (AGÊNCIA NACIONAL DE VIGILÂNCIA SANITÁRIA, 2003) e o INMETRO possui o guia “Orientação sobre Validação de Métodos Analíticos - DOQ-CGCE-008”, de julho de 2011. (INSTITUTO NACIONAL DE METROLOGIA, NORMALIZAÇÃO E QUALIDADE INDUSTRIAL, 2011). Porém, para a elaboração desse trabalho será utilizado o guia do INMETRO, pois a resolução da ANVISA é voltada para análises de bioanalíticos.

O guia do INMETRO orienta os tipos de ensaios, bem como os parâmetros a serem realizados para a realização da validação de metodologia. Os parâmetros e os tipos de ensaios estão apresentados TAB.9. 
TABELA 9 - Parâmetros de validação conforme o tipo de ensaio

$\begin{array}{ccccc}\text { Parâmetros } & \text { Qualitativo } & \begin{array}{c}\text { Teterminação do } \\ \text { componente (ou } \\ \text { analito) e maior } \\ \text { teor }\end{array} & \begin{array}{c}\text { Análise de } \\ \text { elementos } \\ \text { menores e } \\ \text { Traços }\end{array} & \begin{array}{c}\text { Propriedades } \\ \text { Físicas }\end{array} \\ \text { Precisão } & & \checkmark & \checkmark & \checkmark \\ \text { Seletividade } & & \checkmark & \checkmark & \checkmark \\ \text { Tendência/Recuperação } & \checkmark & \checkmark & \checkmark & \checkmark \\ \text { Robustez } & & \checkmark & \checkmark & \checkmark \\ \text { Sensibilidade/linearidade/ } & \checkmark & \checkmark & \checkmark & \checkmark \\ \text { faixa de trabalho } & & & \checkmark & \\ \text { Limite de detecção } & \checkmark & & & \checkmark \\ \text { Limite de quantificação } & & & \end{array}$

Fonte: (INSTITUTO NACIONAL DE METROLOGIA, NORMALIZAÇÃO E QUALIDADE INDUSTRIAL, 2011).

\subsection{Seletividade}

A seletividade é o primeiro processo no desenvolvimento da validação de método e deve ser reavaliada continuamente durante a validação e posteriormente no uso do método (RIBANI, et al., 2004).

A seletividade é realizada para avaliar a influência da matriz na curva analítica. Esse trabalho seguiu as orientações da última versão do documento do INMETRO, o DOCCGCRE-OO8, de julho de 2011 (INSTITUTO NACIONAL DE METROLOGIA, NORMALIZAÇÃO E QUALIDADE INDUSTRIAL, 2011), porém nesse documento não há recomendação de nenhuma forma de cálculo para a determinação da seletividade.

Corresponde o quanto o método responde, exclusivamente, ao analito de interesse na análise, além disso, investiga os efeitos das interferências de outros analitos na análise, usualmente é utilizada adição de interferentes nas amostras de branco e adições padrões nas amostras de interesse ou materiais de referências, amostras com ou sem o analito, observando assim as respostas (EURACHEM/CITAC Guide, 2012), (INSTITUTO NACIONAL DE METROLOGIA, NORMALIZAÇÃO E QUALIDADE INDUSTRIAL, 2011).

Segundo o INMETRO (2011), se a seletividade não for assegurada, a linearidade, a tendência e a precisão estarão seriamente comprometidas. 


\subsection{Linearidade e Faixa de Trabalho}

A linearidade corresponde a capacidade do método em fornecer resultados diretamente proporcionais à concentração do elemento analisado, dentro de uma determinada faixa de aplicação, além de verificar até que ponto a faixa de concentração do analito coincide com a faixa dinâmica linear, e certificar que não ocorra nenhuma interferência na resposta do analito (RIBANI, et al., 2004) (INSTITUTO NACIONAL DE METROLOGIA, NORMALIZAÇÃO E QUALIDADE INDUSTRIAL, 2011).

A correlação entre o sinal medido e a massa ou concentração de um elemento a ser quantificado muito esporadicamente é conhecido antes da análise, neste caso, faz necessário o uso de uma relação matemática entre o sinal e a concentração do elemento a ser quantificado. Essa relação matemática chama-se curva analítica, conforme apresentado na equação (7) (RIBANI, et al., 2004) (INSTITUTO NACIONAL DE METROLOGIA, NORMALIZAÇÃO E QUALIDADE INDUSTRIAL, 2011).

Sendo:

$$
y=a+b x
$$

y = resposta medida (intensidade, absorbância, área e etc.);

$\mathrm{x}=$ concentração;

$\mathrm{a}=$ interseção com eixo $\mathrm{y}$, quando $\mathrm{x}=0$

$\mathrm{b}=$ inclinação da curva analítica $=$ sensibilidade

Quanto mais sensível, maior é a variação na resposta, ou seja, maior inclinação (b). Mas para se encontrar a linearidade necessita-se de no mínimo cinco pontos de concentração para a curva analítica e o número de replicatas deve ser o mais próximo do praticado na rotina do laboratório (INSTITUTO NACIONAL DE METROLOGIA, NORMALIZAÇÃO E QUALIDADE INDUSTRIAL, 2011).

Além do cálculo para encontrar os coeficientes de regressão $a$ (interseção) e $b$ (inclinação) da curva analítica, também é possível calcular o coeficiente de correlação (r), o qual permite estimar uma qualidade da curva obtida, pois quanto mais próximo de 1,0 menor a dispersão no conjunto de pontos da curva analítica. Um coeficiente de correlação maior que 0,999 demonstra um ajuste ideal dos dados da linha de regressão. Para o INMETRO um 
coeficiente de correlação acima de 0,90 é considerado ideal (RIBANI, et al., 2004).

A linearidade é observada a partir de um gráfico de intensidade em função da concentração do elemento, deve-se verificar a ausência de valores discrepantes para cada nível de concentração e a homocedasticidade dos dados, depois verificação pela equação da regressão linear, determinada pelo método dos mínimos quadrados (INSTITUTO NACIONAL DE METROLOGIA, NORMALIZAÇÃO E QUALIDADE INDUSTRIAL, 2011).

Qualquer método analítico quantitativo possui uma faixa de concentração para cada analito analisado ou valores que o analito em uma determinada matriz pode ser determinado. Primeiramente é escolhida uma faixa preliminar, depois essa faixa de trabalho deve cobrir a faixa de aplicação do método escolhido e a concentração esperada da amostra, sempre que possível, deve se posicionar no centro da faixa de trabalho (INSTITUTO NACIONAL DE METROLOGIA, NORMALIZAÇÃO E QUALIDADE INDUSTRIAL, 2011).

\subsection{Limite de detecção}

O limite de detecção (LD) é utilizado, durante a validação, para estabelecer o limite inferior da faixa de operação prática do método (EURACHEM/CITAC Guide, 2012). O limite de detecção pode variar conforme o tipo de amostra, devido a isso é de grande importância assegurar que todas as etapas do procedimento do método analítico sejam inclusas na determinação desse limite de detecção. Ao realizar uma validação de método analítico é fundamental distinguir a detecção do analito do sinal do branco ou ruído (INSTITUTO NACIONAL DE METROLOGIA, NORMALIZAÇÃO E QUALIDADE INDUSTRIAL, 2011).

\subsection{Limite de quantificação}

O limite de quantificação (LQ) é a quantidade mínima de um analito que é quantificada com um nível aceitável de precisão e exatidão no método desenvolvido. Equivale normalmente ao padrão de calibração de menor concentração, sem considerar o branco. Ao determinar o limite de quantificação o mesmo deve ser testado com amostras 
independentes, para certificar se a precisão e a tendência encontradas são satisfatórias (INSTITUTO NACIONAL DE METROLOGIA, NORMALIZAÇÃO E QUALIDADE INDUSTRIAL, 2011).

\subsection{Tendência/Recuperação}

Para a avaliação da tendência/recuperação é utilizado estudos com materiais de referências certificados (MRC) ou por adições padrões certificados (spikes), além de participações em comparações interlaboratoriais e realizações de ensaios de recuperação (EURACHEM/CITAC Guide, 2012). Com a utilização de valores de referências apropriados para determinar a tendência faz com que se estabeleça uma rastreabilidade aos padrões reconhecidos (INSTITUTO NACIONAL DE METROLOGIA, NORMALIZAÇÃO E QUALIDADE INDUSTRIAL, 2011).

\subsection{Precisão}

A precisão consiste da dispersão de valores em um método, no qual se observa a concordância entre os resultados de medição sucessivas de um mesmo método. A precisão é avaliada pelo desvio padrão absoluto (DP) ou pelo desvio padrão relativo (DPR\%), também conhecido como coeficiente de variação (CV). Os testes que podem ser realizados para avaliar a precisão são a reprodutibilidade, precisão intermediária e a repetitividade (VOCABULÁRIO INTERNACIONAL DE METROLOGIA, 2012; INSTITUTO NACIONAL DE METROLOGIA, NORMALIZAÇÃO E QUALIDADE INDUSTRIAL, 2011; RIBANI, et al., 2004).

\subsubsection{Repetitividade}

O objetivo da repetitividade é observar a concordância entre os resultados de medição sucessivas de um mesmo método, em diferentes preparações e é, algumas vezes, denominada previsão intra-ensaio ou intra-corrida e pode ser expressa pela estimativa do desvio padrão relativo (DPR\%) (INSTITUTO NACIONAL DE METROLOGIA, NORMALIZAÇÃO E QUALIDADE INDUSTRIAL, 2011; RIBANI, et al., 2004).

Segundo o INMETRO (2011), as condições de repetitividade devem-se seguir 
as seguintes premissas: mesmo procedimento de medição; mesmo observador; mesmo instrumento usado sob mesmas condições; mesmo local e repetições no menor espaço de tempo possível, além de recomendar sete ou mais repetições para o cálculo da estimativa do desvio padrão.

\subsubsection{Precisão Intermediária}

O propósito da precisão intermediária é avaliar o laboratório sob o efeito de variações, no qual avalia-se a mesma amostra ou os mesmos padrões, o mesmo método no mesmo laboratório, mas variando algumas condições, podendo ser diferentes analistas; diferentes equipamentos e diferentes tempos de análise (INSTITUTO NACIONAL DE METROLOGIA, NORMALIZAÇÃO E QUALIDADE INDUSTRIAL, 2011). Com os dados de precisão intermediária pode-se verificar que no mesmo laboratório de análise o método fornece os mesmos resultados. O cálculo pode ser feito a partir da estimativa do desvio padrão relativo (RSD) (RIBANI, et al., 2004).

\subsubsection{Reprodutibilidade}

A reprodutibilidade utiliza as mesmas amostras ou padrões, semelhante à precisão intermediária, porém as análises devem ser feitas com analistas, equipamentos e laboratórios diferentes. Neste caso utiliza-se o desempenho do laboratório em programas de ensaios de comparação interlaboratorial. Com o desvio padrão obtido nesses programas, sob condições de reprodutibilidade, é possível calcular o limite de reprodutibilidade (R), e é possível decidir se a diferença entre os valores das replicatas sob condição de reprodutibilidade é significativo ou não (INSTITUTO NACIONAL DE METROLOGIA, NORMALIZAÇÃO E QUALIDADE INDUSTRIAL, 2011).

\subsection{Robustez}

A robustez é um parâmetro que investiga a sensibilidade do método através de parâmetros específicos. Através do efeito das mudanças de um ou mais parâmetros de análise são observados. Se houver significância faz-se um estudo mais detalhado para medir o tamanho dos efeitos e permitir uma seleção de operação aceitável (EURACHEM/CITAC Guide, 2012). 
Para a determinação da robustez pode-se utilizar o teste de Youden, o qual permite avaliar a robustez do método, além de ordenar a influência da cada variação no resultado final (SILVA, et al., 2006) .

\subsection{Estimativa de incerteza de medição}

A incerteza de medição segundo o VIM (2012), é todo "parâmetro não negativo que caracteriza a dispersão dos valores atribuídos a um mensurando, com base nas informações utilizadas", dessa forma pode-se dizer que a incerteza de medição é uma estimativa dos resultados utilizando os respectivos desvios padrões.

Segundo o Guia para a Expressão de Incerteza de Medição (GUM, 2008), a incerteza do resultado de uma medição reflete a falta de conhecimento exato do valor do mensurando. A partir da correção dos efeitos sistemáticos reconhecidos, o resultado de uma medição é somente uma estimativa do valor do mensurando originário da incerteza proveniente dos efeitos aleatórios e das correções imperfeitas do resultado para efeitos sistemáticos (INMETRO/CICMA/SEPIN, 2012).

O resultado de uma medição, após a correção pode estar muito próximo do valor do mensurando, e, mesmo assim, ter um erro desprezível, muito embora possa ter uma incerteza grande. Porém, não se deve confundir a incerteza do resultado de medição com o erro desconhecido remanescente (INMETRO/CICMA/SEPIN, 2012).

A incerteza de medição pode ser estimada a partir de duas avaliações, a do Tipo A e Tipo B. A avaliação do Tipo A utiliza a distribuição estatística dos valores resultantes de uma series de medições e podem ser caracterizados por desvios-padrão, como por exemplo a utilização dos testes de repetitividade, precisão intermediaria ou reprodutibilidade; a avaliação do Tipo B, pode também ser caracterizada por desvios-padrão estimados a partir de funções de densidade de probabilidade baseadas na experiência ou em outras informações, como por exemplo informações associadas a materiais de referência certificado, certificados de calibração, valores publicados por autoridade competente e entre outros (VOCABULÁRIO INTERNACIONAL DE METROLOGIA, 2012).

O guia EURACHEM/CITAC (2012) resume em quatro etapas para ser 
executado a incerteza de medição:

Etapa 1. Especificação do mensurando: declarar com clareza o que está sendo medido, com a inclusão entre o mensurando e suas grandezas de entrada, das quais ele depende (EURACHEM/CITAC Guide, 2012);

Etapa 2. Identificação das fontes de incerteza: a inclusão das fontes que irá contribuir para a incerteza dos parâmetros em relação a etapa 1, mas pode-se incluir outras fontes e também incluir fontes decorrentes de pressuposições químicas (EURACHEM/CITAC Guide, 2012);

Etapa 3. Quantificação dos componentes de incerteza: medir ou estimar as dimensões dos componentes de incerteza associados a cada fonte potencial de incerteza identificada (EURACHEM/CITAC Guide, 2012);

Etapa 4. Cálculo da incerteza combinada: com as informações obtidas na etapa 3 irá contribuir para a quantificação da incerteza total, sejam associadas as fontes individuais ou aos efeitos combinados de diversas fontes. As contribuições devem ser expressas como desvios padrões e combinados conforme as regras apropriadas, para a incerteza padronizada combinada. $\mathrm{O}$ fator de abrangência apropriado deve ser aplicado para se chegar a uma incerteza expandida (EURACHEM/CITAC Guide, 2012). 


\section{PARTE EXPERIMENTAL}

\subsection{Materiais e Equipamentos}

Para o desenvolvimento deste trabalho foram utilizados os seguintes equipamentos:

Espectrômetro de Emissão Óptica com Plasma de Argônio (ICP-OES), ARCOS da Spectro $^{\circledR}$, com tocha axial, nebulizador Meinhard ${ }^{\circledR}$, acoplado a câmera de nebulização ciclônica e sistema de detecção baseada em dispositivos de carga acoplada (CCD), conforme apresentado na FIG.20;

> Forno Micro-ondas, MDS-2000 CEM ${ }^{\circledR}$, conforme apresentado na FIG.21;

$>\quad$ Balões volumétricos;

$>\quad$ Pipeta volumétrica (Modelo- Wheaton, Socorex ${ }^{\circledR}$ );

$>\quad$ Pipeta de vidro;

$>\quad$ Balança analítica $\left(\right.$ Gehaka $\left.^{\circledR}, \mathrm{BG} 400\right)$;

$>\quad$ Termômetro de líquido em vidro com escala interna (Rivaterm ${ }^{\circledR}$ ) calibrado;

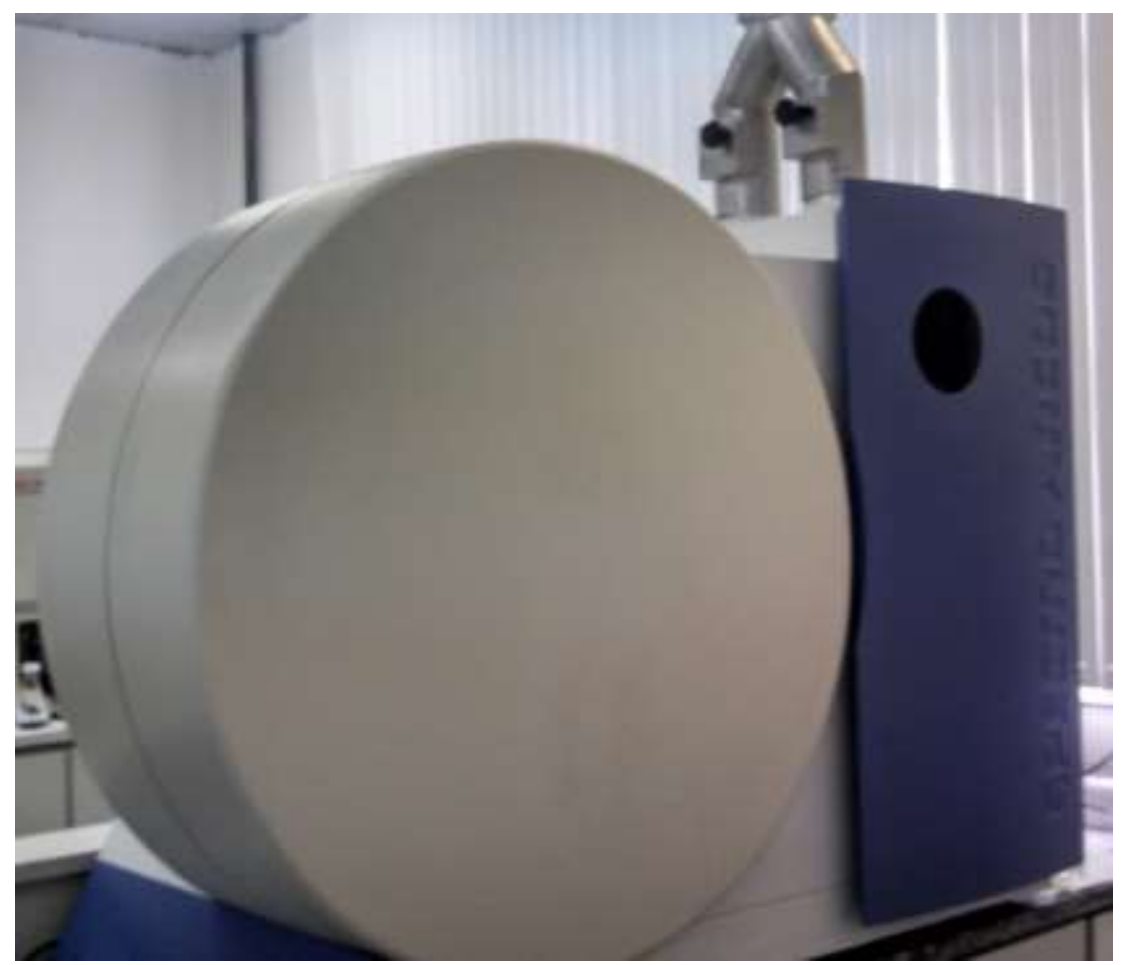

FIGURA 20 - Espectrômetro de Emissão Óptica com Plasma de Argônio (ICP-OES) (SPECTRO ARCOS) 


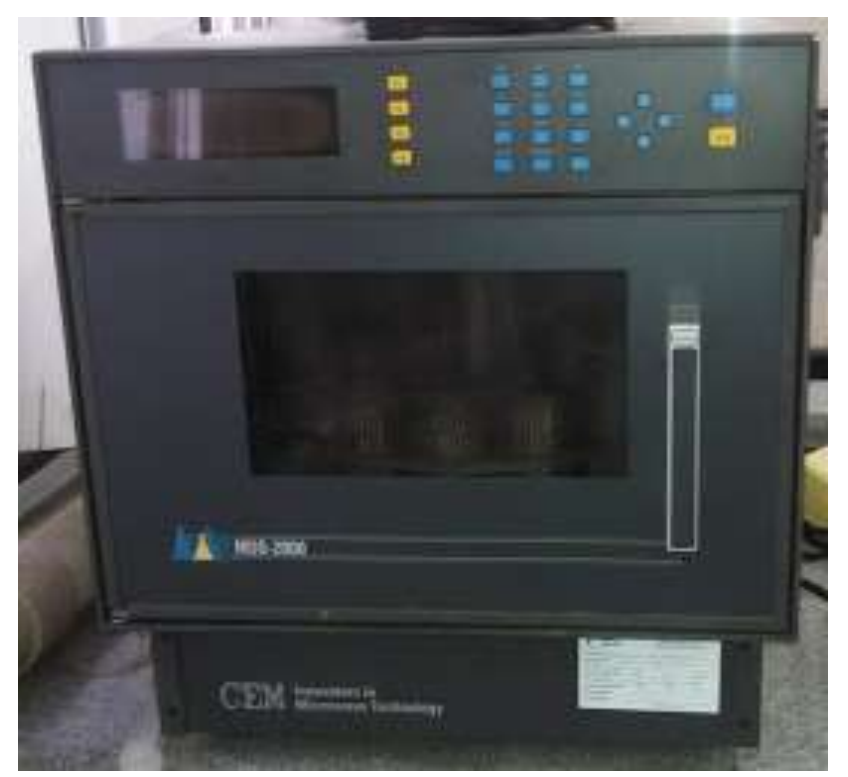

FIGURA 21 - Forno Micro-ondas MDS-2000 (CEM)

\subsection{Reagentes e Soluções}

Todos os reagentes químicos utilizados no trabalho foram de alto grau analítico. As soluções padrão utilizadas para confecção das curvas de calibração e as soluções controle apresentavam certificado de calibração. Foram utilizados padrões, para ICP, monoelementares da Merck $^{\circledR}$, rastreáveis ao NIST. Para o preparo de soluções e diluições foi utilizada água padrão ultrapuro (Elix Millipore®, 18,2 $\mu \mathrm{S} . \mathrm{cm}^{-1}$ ).

\subsection{Amostragem}

A seleção dos pontos de coleta de amostras de água na repesa Guarapiranga ocorreu visando a influência dos seus tributários e das sub-bacias na qualidade da água. A seleção foi realizada com a participação dos representantes do Instituto de Botânica - SP, Instituto de Pesquisas Energéticas e Nucleares (IPEN) e do Centro de Integração e Gerenciamento de Informações da Coordenadoria de Planejamento Ambiental da Secretaria do Meio Ambiente (SMA). Selecionaram 14 pontos, sendo 3 pontos de monitoramento da SABESP (SHIHOMATSU, 2015). As coordenadas geográficas dos pontos de amostragem são apresentadas na TAB.10 e o mapa com os 14 pontos de coleta está apresentado na FIG.23.

Os principais locais de coleta, pontos GU000-01, GU000-02, GU107-06, 
GU108-07, GU105-10 e GU103-12 foram escolhidos estrategicamente na avaliação dos tributários na contaminação das águas da represa Guarapiranga.

GU000-01: recebe águas do rio Embu-Guaçu, sendo o maior dos tributários da represa, com uma área de drenagem de $272 \mathrm{~km}^{2}$. A região deste ponto abrange o município de Embu-Guaçu, extremo sul do município de São Paulo, Itapecerica da Serra e uma ínfima parcela do município de Juquitiba e São Lourenço da Serra; GU000-02: recebe águas do córrego Mombaça, além de estar localizado na passagem do Rodoanel; GU107-06: recebe águas do rio Parelheiros, no qual recebe águas da transposição do braço Taquacetuba da represa Billings; GU108-07: recebe águas do córrego Tanquinho e córrego São José; GU105-09: recebe águas dos rios Pedras e Bonito; GU105-10: recebe águas do rio EmbuMirim; GU103-12: recebe águas do córrego Itupu e ribeirão Guavirutuba (SHIHOMATSU, 2015).

TABELA 10 - Coordenadas Geográfica dos 14 pontos de coleta da represa Guarapiranga

\begin{tabular}{|c|c|c|}
\hline \multirow{2}{*}{ Local de amostragem } & \multicolumn{2}{|c|}{ Coordenada geográfica } \\
\hline & Latitude Sul - S & Longitude Oeste - W \\
\hline GU000-01 & $23^{\circ} 46^{\prime} 49.6^{\prime \prime}$ & $46^{\circ} 47^{\prime} 22.0^{\prime \prime}$ \\
\hline GU000-02 & $23^{\circ} 45^{\prime} 29.5^{\prime \prime}$ & $46^{\circ} 46^{\prime} 18.7^{\prime \prime}$ \\
\hline GU000-03 & $23^{\circ} 44^{\prime} 52.2^{\prime \prime}$ & $46^{\circ} 46^{\prime} 13.6^{\prime \prime}$ \\
\hline GU106-04 & $23^{\circ} 44^{\prime} 44.6^{\prime \prime}$ & $46^{\circ} 45^{\prime} 25.8^{\prime \prime}$ \\
\hline GU000-05 & $23^{\circ} 44^{\prime} 57.5^{\prime \prime}$ & $46^{\circ} 44^{\prime} 24.2^{\prime \prime}$ \\
\hline GU107-06 & $23^{\circ} 45^{\prime} 01.2^{\prime \prime}$ & $46^{\circ} 43^{\prime} 61.5^{\prime \prime}$ \\
\hline GU108-07 & $23^{\circ} 43^{\prime} 64.7^{\prime \prime}$ & $46^{\circ} 43^{\prime} 42.3^{\prime \prime}$ \\
\hline GU000-08 & $23^{\circ} 42^{\prime} 96.9^{\prime \prime}$ & $46^{\circ} 43^{\prime} 61.2^{\prime \prime}$ \\
\hline GU109-09 & $23^{\circ} 43^{\prime} 04.6^{\prime \prime}$ & $46^{\circ} 43^{\prime} 34.0 \prime$ \\
\hline GU105-10 & $23^{\circ} 42^{\prime} 89.9^{\prime \prime}$ & $46^{\circ} 44^{\prime} 68.7^{\prime \prime}$ \\
\hline GU108-11 & $23^{\circ} 42^{\prime} 53.4^{\prime \prime}$ & $46^{\circ} 43^{\prime} 44.9^{\prime \prime}$ \\
\hline GU103-12 & $23^{\circ} 41^{\prime} 88.5^{\prime \prime}$ & $46^{\circ} 44^{\prime} 67.3{ }^{\prime \prime}$ \\
\hline GU102-13 & $23^{\circ} 41^{\prime} 58.0^{\prime \prime}$ & $46^{\circ} 43^{\prime} 57.3^{\prime \prime}$ \\
\hline GU000-14 & $23^{\circ} 40^{\prime} 78.2^{\prime \prime}$ & $46^{\circ} 43^{\prime} 55.0^{\prime \prime}$ \\
\hline
\end{tabular}

As amostras de água foram coletadas nos dias 07 e 09 de outubro de 2014 . No 
dia 07/10/2014 foram coletados os pontos GU000-01, GU000-02, GU000-03, GU106-04, GU000-05, GU107-06 e GU108-07; no dia 09/10/2014 foram coletados os pontos GU00008, GU109-09, GU105-10, GU108-11, GU103-12, GU102-13, GU000-14. Os procedimentos de coleta e amostragem foram realizados conforme os procedimentos descritos no "Guia Nacional de Coleta e Preservação de Amostras" da Agência Nacional das Águas (ANA)/Companhia Ambiental do Estado de São Paulo (CETESB) (AGÊNCIA NACIONAL DAS ÁGUAS; CIA SANEAMENTO DO ESTADO DE SÃO PAULO, 2011) e Standard Methods for the Examination of Water and Wastewater (APHA AWWA WPCF, 2005).

As amostras de água foram coletadas com uma garrafa de Van Dorn, conforme apresentado na FIG.22, em três profundidades, sub-superfície, zona média e $1 \mathrm{~m}$ acima do fundo e foram armazenadas em frascos de polietileno com capacidade de $250 \mathrm{~mL}$.

Devido aos problemas ocorridos pela falta de água nos reservatórios da represa Guarapiranga, em 2014, alguns pontos não puderam ser coletados nas três profundidades que normalmente são coletados no Projeto AcquaSed, devida a baixa profundidade de alguns pontos. Na TAB.11 está apresentado a profundidade dos pontos de coleta e quais pontos tiveram coletas e os que não tiveram nas três profundidades.

Em laboratório as amostras de água coletadas foram acidificadas com $\mathrm{HNO}_{3} \mathrm{em}$ $\mathrm{pH}$ abaixo de 2 e preservadas sob refrigeração a $4^{\circ} \mathrm{C}$.

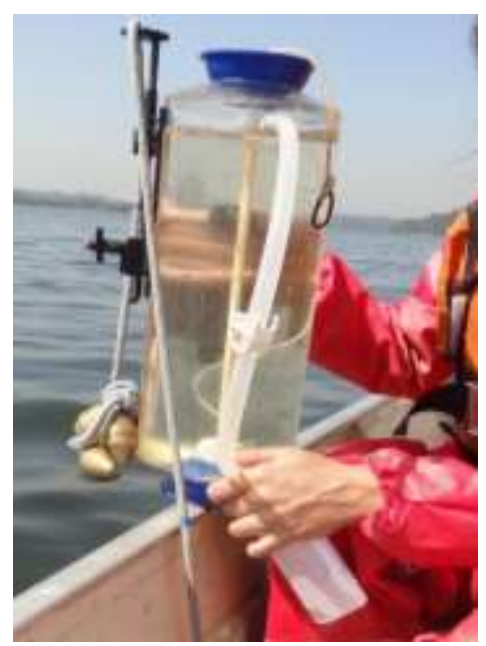

FIGURA 22 - Garrafa de van Dorn utilizada para a coleta de água Fonte: Autor - Dia 09/outubro/2014. 
TABELA 11 - As três divisões de coleta nos pontos, o pH de cada profundidade e a profundidade máxima dos pontos coletados

\begin{tabular}{|c|c|c|c|c|}
\hline \multirow{2}{*}{$\begin{array}{c}\text { Local de } \\
\text { amostragem }\end{array}$} & \multicolumn{3}{|c|}{ Profundidades de Coleta } & \multirow{2}{*}{$\begin{array}{l}\text { Profundidade máxima } \\
\text { dos pontos }(\mathbf{m}) *\end{array}$} \\
\hline & $\begin{array}{c}\text { Sub- } \\
\text { superfície }\end{array}$ & Zona média & $\begin{array}{c}1 \mathrm{~m} \text { acima do } \\
\text { Fundo }\end{array}$ & \\
\hline GU000-01 & Coletado & Não coletado & Não coletado & 0.6 \\
\hline pH & 6,84 & - & - & \\
\hline GU000-02 & Coletado & Não coletado & Não coletado & 2,0 \\
\hline pH & 6,90 & - & - & \\
\hline GU000-03 & Coletado & Não coletado & Não coletado & 2,0 \\
\hline pH & 8,62 & - & - & \\
\hline GU106-04 & Coletado & Não coletado & Não coletado & 2,7 \\
\hline $\mathbf{p H}$ & 8,76 & - & - & \\
\hline GU000-05 & Coletado & Não coletado & Coletado & 4.8 \\
\hline pH & 7,93 & - & 8,66 & \\
\hline GU107-06 & Coletado & Não coletado & Não coletado & 1,4 \\
\hline pH & 8,32 & - & - & \\
\hline GU108-07 & Coletado & Não coletado & Coletado & 3,1 \\
\hline pH & 8,18 & - & 8,18 & \\
\hline GU000-08 & Coletado & Coletado & Coletado & 6,6 \\
\hline pH & 7,94 & 8,51 & 8,51 & \\
\hline GU109-09 & Coletado & Não coletado & Coletado & 3,7 \\
\hline pH & 8,58 & - & 8,60 & \\
\hline GU105-10 & Coletado & Não coletado & Coletado & 3,9 \\
\hline pH & 8,80 & - & 9,91 & \\
\hline GU108-11 & Coletado & Coletado & Coletado & 7,3 \\
\hline pH & 8,15 & - & 9,58 & \\
\hline GU103-12 & Coletado & Não coletado & Não coletado & 1,3 \\
\hline pH & 9,69 & - & - & \\
\hline GU102-13 & Coletado & Coletado & Coletado & 8,2 \\
\hline pH & 8,12 & 9,20 & 10,20 & \\
\hline GU000-14 & Coletado & Coletado & Coletado & 7,8 \\
\hline pH & 8,69 & 9,72 & 10,22 & \\
\hline
\end{tabular}

* Coleta realizada em 07 e 09 de outubro de 2014. 


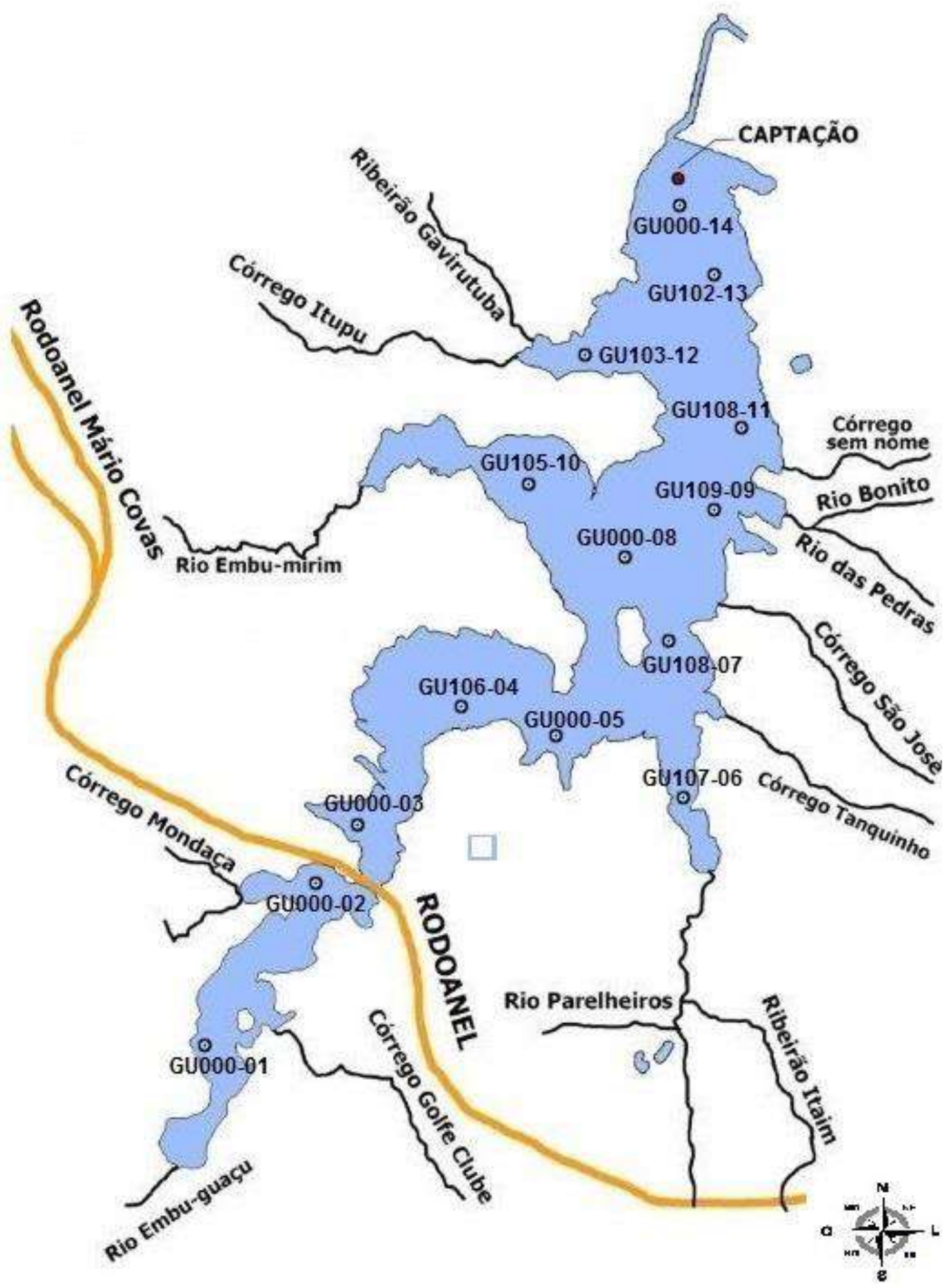

FIGURA 23 - Distribuição dos pontos de coleta da represa Guarapiranga e seus tributários Fonte: (SHIHOMATSU, 2015) 


\subsection{Metodologia de digestão ácida}

Para a determinação dos metais totais foi utilizado o método USEPA 3015 (2007). Esse método baseia-se na extração dos metais em soluções aquosas usando o calor emitido pelo micro-ondas com adição de ácido nítrico $\left(\mathrm{HNO}_{3}\right)$ ou a combinação de adição do ácido nítrico com o ácido clorídrico (HCl) (US ENVIRONMETAL PROTECTION AGENCY, 2007).

As amostras foram inseridas no forno micro-ondas, MDS-2000 CEM ${ }^{\circledR}$ (FIG.21) utilizando as condições de medição sugeridas pelo método EPA 3015 (2007), conforme apresentado na TAB.12, e foi utilizado a adição de $4 \mathrm{~mL}$ de ácido nítrico e $1 \mathrm{~mL}$ de ácido clorídrico, ambos P.A. (Pureza Analítica) O processo de digestão esta apresentado na FIG. 24.

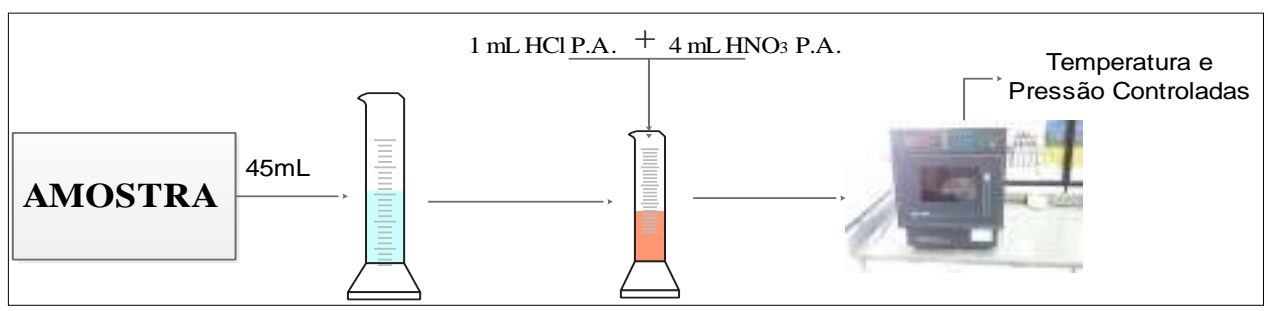

FIGURA 24 - Esquema do processo de digestão ácida e micro-ondas.

TABELA 12 - Condições de análise da digestão ácida em forno de micro-ondas

\begin{tabular}{cc} 
Parâmetros & Condições de análise \\
Potência & $100 \%$ \\
Pressão & $85 \mathrm{~atm}$ \\
Tempo de análise & $20: 00 \mathrm{~min}$ \\
Tempo de Pressurização & $10: 00 \mathrm{~min}$ \\
Temperatura & $165^{\circ} \mathrm{C}$ \\
\hline
\end{tabular}

O forno de micro-ondas comporta apenas 12 frascos, sendo assim, cada lote de amostras digeridas foram acompanhadas de amostras para controle, sendo um branco, uma duplicata e uma adição de padrão. Após a digestão as amostras foram analisadas por ICPOES. Os valores dos brancos e das adições, do controle de qualidade estão apresentados no APÊNDICE C. 


\subsection{Preparo das soluções padrão para a curva analítica}

Conforme mencionado no item 6.2, todos os padrões utilizados nesse trabalho são monoelementares da Merck®. Para o preparo dos padrões foi utilizado água ultrapura e também a matriz de interesse para os testes de validação.

Inicialmente foram preparadas três soluções-estoque multielemetares, conforme apresentado na TAB.13, a partir de soluções padrão para ICP certificadas, monoelementares, rastreáveis ao NIST.

TABELA 13 - Concentração da solução estoque

\begin{tabular}{cc} 
Elementos & Concentração $\left(\mathbf{m g . L}^{-1}\right)$ \\
\hline $\mathrm{Al}, \mathrm{Cd}, \mathrm{Cr}, \mathrm{Cu}, \mathbf{N i}, \mathrm{Mn}$ & 50 \\
$\mathrm{Ba}, \mathbf{M g}, \mathbf{F e}$ & 50 \\
$\mathrm{Na}, \mathrm{Ca}, \mathrm{K}$ & 100
\end{tabular}

Posteriormente foram preparadas as soluções-padrão, para cada ponto da curva analítica, a partir das soluções-estoques, conforme apresentado na TAB.14, e para um controle desses padrões foram preparados em conjunto uma solução branco (água ultrapura e ácido nítrico [1\%]) e para os testes com a matriz foi preparado uma solução com a matriz de interesse e ácido nítrico (1\%).

Após o preparo dos padrões foram obtidos as curvas analíticas no ICP-OES e realizados os testes de validação. 
TABELA 14 - Concentração da solução-padrão multielementar, realizada a partir das soluções-estoque

\begin{tabular}{cccccc}
\hline \multirow{2}{*}{ Elementos } & \multicolumn{5}{c}{ Concentração $\mathbf{( m g . L}^{-\mathbf{1}}$ ) } \\
\cline { 2 - 4 } Al & Padrão 1 & Padrão 2 & Padrão 3 & Padrão 4 & Padrão 5 \\
Cd & 1,0 & 0,5 & 0,1 & 0,05 & 0,01 \\
Cr & 1,0 & 0,5 & 0,1 & 0,05 & 0,01 \\
Cu & 1,0 & 0,5 & 0,1 & 0,05 & 0,01 \\
Mn & 1,0 & 0,5 & 0,1 & 0,05 & 0,01 \\
Ni & 1,0 & 0,5 & 0,1 & 0,05 & 0,01 \\
Fe & 1,0 & 0,5 & 0,1 & 0,05 & 0,01 \\
Ba & 10 & 5 & 1 & 0,5 & 0,1 \\
Mg & 10 & 5 & 1 & 0,5 & 0,1 \\
Ca & 50 & 5 & 1 & 0,5 & 0,1 \\
Na & 50 & 25 & 5 & 2,5 & 0,5 \\
K & 50 & 25 & 5 & 2,5 & 0,5 \\
& & 25 & 5 & 2,5 & 0,5
\end{tabular}

\subsection{Metodologia de Análise por ICP-OES}

Para análise de metais em água por ICP-OES adotou-se a metodologia USEPA 6010C (2007). Esse método baseia-se na determinação de elementos traços em solução aquosa, devidamente acidificadas e/ou digeridas em micro-ondas.

Foram elaborados programas analíticos para a determinação de todos os elementos de interesse. Utilizou-se o método da curva analítica na determinação dos elementos, através do uso de soluções-padrão multielementares. As condições de operação do equipamento, são apresentadas na TAB.15. 
TABELA 15 - Condições de operação do ICP-OES

Parâmetros

\begin{tabular}{cl} 
Potência Plasma & $1400 \mathrm{~W}$ \\
Velocidade da Bomba & $30 \mathrm{rpm}$ \\
Vazão de gás refrigerante & $12,00 \mathrm{~L} \cdot \mathrm{min}^{-1}$ \\
Vazão Auxiliar de gás & $1,0 \mathrm{~L} \cdot \mathrm{min}^{-1}$ \\
Vazão de gás do Nebulizador & $1,0 \mathrm{~L} \cdot \mathrm{min}^{-1}$ \\
\hline
\end{tabular}

As linhas espectrais foram selecionadas para cada um dos 12 elementos, estudados nesse trabalho, avaliando possíveis interferências espectrais, conforme está apresentado na TAB.16.

TABELA 16 - Linhas de emissão selecionadas

\begin{tabular}{cc}
\hline Elementos & Linhas $(\boldsymbol{\lambda} \mathbf{~ m m})$ \\
\hline $\mathbf{A l}$ & 167,078 \\
$\mathbf{B a}$ & 455,404 \\
$\mathbf{C a}$ & 317,933 \\
$\mathbf{C d}$ & 214,438 \\
$\mathbf{C r}$ & 267,716 \\
$\mathbf{C u}$ & 324,754 \\
$\mathbf{F e}$ & 259,941 \\
$\mathbf{K}$ & 766,491 \\
$\mathbf{M g}$ & 276,553 \\
$\mathbf{M n}$ & 279,611 \\
$\mathbf{N a}$ & 589,592 \\
$\mathbf{N i}$ & 231,604
\end{tabular}

\subsection{Ensaios para a Validação da Metodologia}

Os elementos químicos metálicos estudados nesse trabalho possuem concentrações com Valores Máximos Permitidos (VMP), pela legislação CONAMA 357/2005, relativamente baixos, devido a isso foram utilizados os parâmetros de validação para ensaios de elementos menores e traços que se encontra no guia do INMETRO (2011).

Os parâmetros são: seletividade, linearidade, faixa de trabalho/faixa linear, limite de detecção, limite de quantificação, recuperação, precisão (repetitividade), robustez 
e incerteza de medição (INSTITUTO NACIONAL DE METROLOGIA, NORMALIZAÇÃO E QUALIDADE INDUSTRIAL, 2011).

Com base no guia do INMETRO (2011) foi elaborado um fluxograma, para melhor visualização das etapas que devem ser realizadas para a validação de metodologia. O fluxograma é apresentado na FIG.25. 


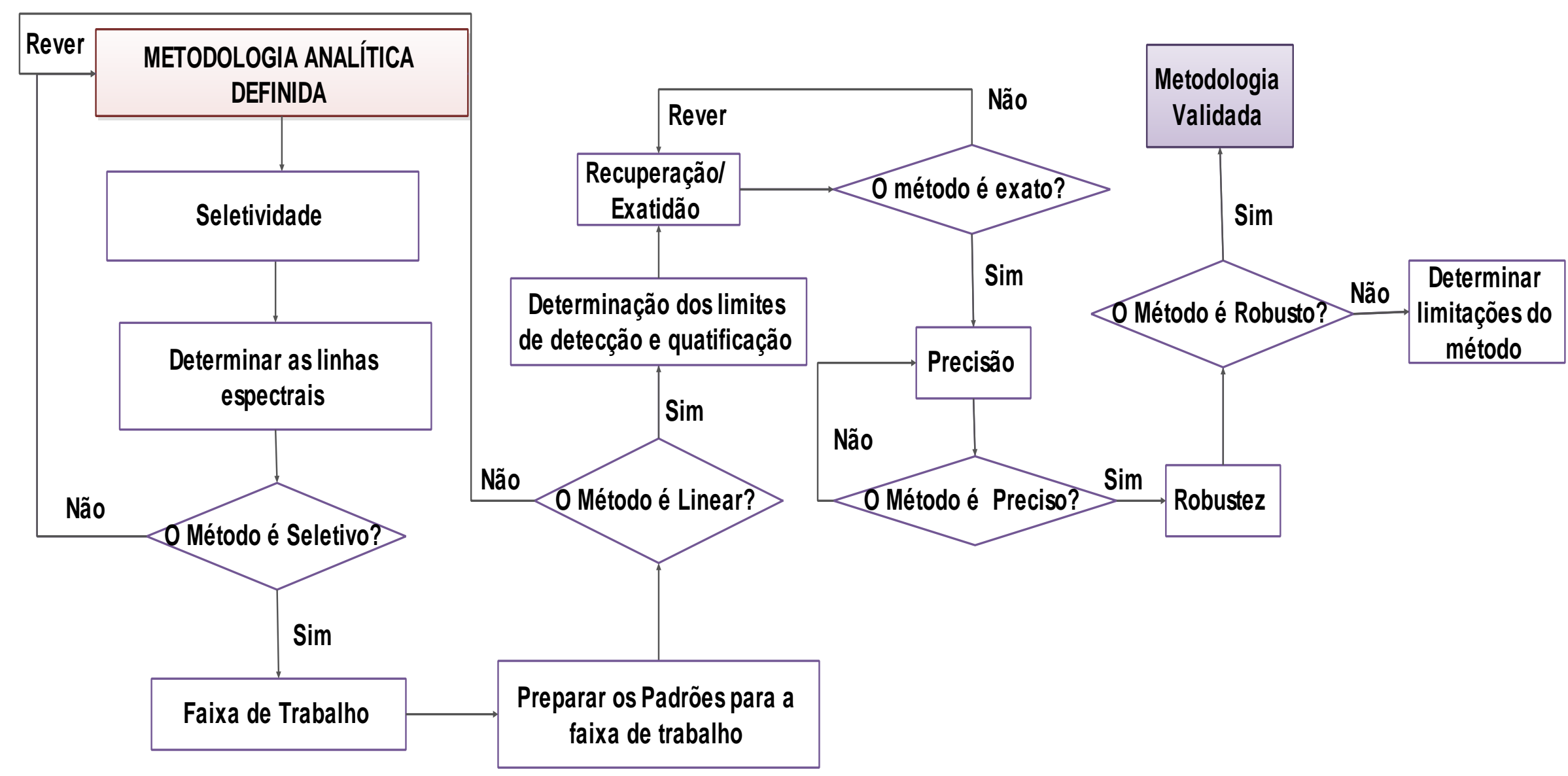

FIGURA 25 - Fluxograma para a Validação de Método Fonte: Adaptação INMETRO (2011) 


\subsubsection{Seletividade}

Foram empregados os cálculos estatísticos da segunda revisão desse documento de Julho/2007 (INSTITUTO NACIONAL DE METROLOGIA, NORMALIZAÇÃO E QUALIDADE INDUSTRIAL, 2007), que recomenda o cálculo através da razão entre as variâncias (teste $\mathrm{F}$ - Snedecor) dos dados obtidos com e sem matriz e o cálculo do teste significância da diferença das médias (teste $t$ de student).

Para os ensaios com a matriz foi preparada uma amostra composta, coletando $50 \mathrm{~mL}$ de cada ponto de coleta da represa Guarapiranga, (sub-superfície, zona média e $1 \mathrm{~m}$ acima do fundo). Para os ensaios sem a matriz foram utilizados somente soluções-padrão multielementares.

Para verificar a seletividade do método, foram levantados os espectros das amostras e dos padrões, nas regiões dos comprimentos de onda $(\lambda)$ de emissão para cada elemento. A concentração da solução-padrão multielementar para a determinação dos espectros, estão apresentados na TAB.17.

TABELA 17 - Concentração utilizada para a determinação dos espectros no teste de seletividade

\begin{tabular}{cc} 
Elementos & Concentração do padrão $\left(\right.$ mg.L $\left.^{-1}\right)$ \\
\hline Al, Cd, Cu, Cr, Mn, Ni & 1,0 \\
Ba, Fe, $\mathbf{M g}$ & 10,0 \\
Ca, $\mathbf{N a}, \mathbf{K}$ & 50,0
\end{tabular}

A equação (8) demonstra o cálculo do teste F - Snedecor e a equação (9) demonstra o cálculo do t de Student.

$$
F=\frac{S_{1}^{2}}{S_{2}^{2}}
$$

Sendo:

$\mathrm{S}_{1}^{2}$ e $\mathrm{S}_{2}^{2}=$ são as variâncias de cada amostra, com a maior variância no numerador. 


$$
t_{\text {calculado }}=\frac{\left|\bar{x}_{1}-\bar{x}_{2}\right|}{\sqrt{s^{2\left(\frac{1}{n_{1}}+\frac{1}{n_{2}}\right)}}}
$$

Sendo:

$S^{2}=$ variância, utilizando o cálculo: $S^{2}=\frac{\left(n_{1}-1\right) s_{1}^{2}+\left(n_{2}-1\right) s_{2}^{2}}{n_{1}+n_{2}-2}$

$\bar{X}_{1}-\bar{X}_{2}=$ Médias das respostas dos analitos em amostras com matriz e sem matriz na mesma faixa de concentrações.

Além disso, avaliou-se o comportamento das curvas analíticas obtidas com matriz e sem matriz para cada elemento analisado.

\subsubsection{Faixa de Trabalho e Linearidade}

Para a determinação dos pontos de calibração da curva analítica de cada elemento estudado nesse trabalho, foi utilizado o histórico de análises, desses elementos, nos quatorze pontos estudados no Projeto ACQUASED da represa Guarapiranga.

Para os cálculos estatísticos, para a determinação da faixa de trabalho e a linearidade, foram utilizados os coeficientes de correlação (r) e os coeficientes de determinação $\left(\mathrm{r}^{2}\right)$, obtidos pela regressão linear de cada elemento e para os cálculos estatísticos foram utilizados a análise de resíduos através do teste t de Student, para a verificação da dispersão de cada ponto na faixa de trabalho, utilizando replicatas com $n=10$,

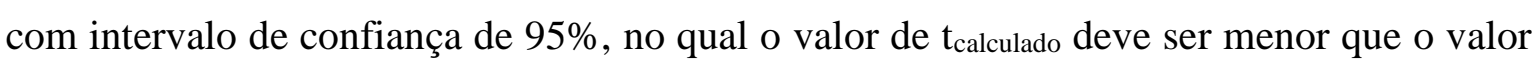
do $t_{\text {crítico }}$ para que o ponto analisado possa estatisticamente pertence a curva analítica.

Além disso, foi realizado a Análise de Variância (ANOVA), que tem como principal propósito verificar se há diferenças significativas entre as médias e se os fatores exercem influência em alguma variável independente. Para o cálculo da ANOVA foram utilizados o teste F, para regressão linear e para o teste da falta de ajuste.

Para a verificação do comportamento linear foram avaliados os gráficos de distribuição espacial dos resíduos absolutos em função da concentração e a em função da probabilidade normalizada de cada resíduo. Com esses resultados obtidos foram avaliados 
por cálculos na tabela ANOVA. Para o cálculo foi utilizado a equação (10).

$$
t_{\text {calculado }}=\frac{r e s i ́ d u o}{S_{r} / \sqrt{n}}
$$

Sendo:

$$
\begin{aligned}
& \text { Resíduo }=\left|\mathrm{X}_{\text {medido }}-\mathrm{X}_{\text {calculado }}\right| \\
& \mathrm{Sr}=\text { desvio padrão dos resíduos } \\
& \mathrm{n}=\text { número de pontos }
\end{aligned}
$$

\subsubsection{Limite de detecção do método (LDM) e Limite de Quantificação do método} (LQM)

Para o cálculo do LDM e o LQM foi utilizado o guia do INMETRO (2011), O DOC-CG-CRE-008. Para a determinação do LDM foi utilizado o branco da amostra com adição da menor concentração aceitável do analito, com $n=10,9$ graus de liberdade ( $\mathrm{n}-1)$ e com um intervalo de $95 \%$ de confiança. Foi utilizado a equação (11) para o cálculo.

$$
L D=t_{(n-1,1-\alpha)} \cdot S
$$

Sendo:

$\mathrm{t}=$ unilateral, dependente do tamanho da amostra e do grau de confiança;

$\mathrm{s}=$ desvio padrão amostral dos brancos da amostra, com adição.

Para a determinação do LQM foi utilizado o valor do branco da amostra, no qual foi analisado 10 replicatas e utilizando 10 vezes o desvio padrão amostral. Foi utilizado a equação (12) para o cálculo.

$$
L Q=\bar{x}+(10) \cdot s
$$

Sendo:

$\bar{x}=$ média dos valores dos brancos;

$\mathrm{s}=$ desvio padrão amostral dos brancos.

\subsubsection{Tendência/Recuperação}

Segundo o INMETRO (2011), para avaliar a tendência de um método pode-se utilizar alguns parâmetros, como por exemplo o uso de materiais de referência certificados 
(MRC), participações em comparações interlaboratoriais e a realização de ensaios de recuperação (INSTITUTO NACIONAL DE METROLOGIA, NORMALIZAÇÃO E QUALIDADE INDUSTRIAL, 2011).

Para esse trabalho foi empregado o uso de ensaios de recuperação. A recuperação foi avaliada através de testes com adição padrão na matriz. Foi realizado em sete replicatas independes, com n=10. A faixa de aceitação foi baseada no método USEPA 6010C, no qual especifica que o limite de recuperação deve ser $\pm 20 \%$, ou seja, entre 80 a $120 \%$ (US ENVIRONMETAL PROTECTION AGENCY, 2007). A recuperação foi realizada com adição padrão na matriz sem o analito. Foi realizado em sete replicatas independes, com n=10. Foi utilizado equação (13) para o cálculo.

$$
\text { Recuperação }(\%)=\left(\frac{C_{1}-C_{2}}{C_{3}}\right) \times 100
$$

Sendo:

$C_{1}=$ Concentração do analito na amostra fortificada;

$C_{2}=$ Concentração do analito na amostra não fortificada;

$C_{3}=$ Concentração do analito adicionada à amostra fortificada.

\subsubsection{Precisão}

Para a avaliação da precisão foi realizado o teste de repetitividade. As condições de repetitividade seguiram as seguintes premissas: mesmo procedimento de medição; mesmo observador; mesmo instrumento usado sob mesmas condições; mesmo local e repetições no menor espaço de tempo possível (INSTITUTO NACIONAL DE METROLOGIA, NORMALIZAÇÃO E QUALIDADE INDUSTRIAL, 2011).

Para o cálculo estatístico foi utilizado o cálculo do desvio padrão relativo (DPR\%) das medições de cada elemento e para avaliação foi seguido o valor de Horwitz, no qual segundo o INMETRO (2011), é um valor que independe da matriz/analito, e sim da concentração medida. As medições realizadas nesse trabalho são em escala de mg.L $\mathrm{L}^{-1}$, nesse caso o valor padrão do DPR será de $16 \%$. Os valores das medições de repetitividade não poderão passar de $16 \%$. 


\subsubsection{Robustez}

Para determinação da robustez foi aplicado o teste de planejamento fracionário saturado, no qual os resultados são avaliados através da estimativa do erro da distribuição dos efeitos utilizando o algoritmo de Dong. Foi utilizado sete fatores variáveis com oito experimentos, baseado na metodologia proposta por Heyden et al. (2001) e para a determinação estatística foi utilizada a planilha elaborada por Furusawa (2007), no qual se baseia na metodologia do INMETRO (2003) e na de Heyden et, al (2001). Na TAB.18 está apresentado os parâmetros escolhidos para o teste de robustez e na TAB.19 está apresentado matriz dos fatores para a determinação da robustez do método.

TABELA 18 - Modificações de análise para o teste de robustez

\begin{tabular}{ccc} 
Fator & Nominal & Variação \\
\hline Ácido nítrico $\left(\mathrm{HNO}_{3}\right)$, P.A. & 4 & 2 \\
Ácido clorídrico $(\mathrm{HCl})$, P.A. & 1 & 0,5 \\
Água do Preparo da Curva Analítica & Ultrapura & Tipo II, baixa pureza \\
Potência do Plasma, W & 1400 & 1200 \\
Velocidade da Bomba, rpm & 30 & 40 \\
Vazão Nebulizador, L/min & 1 & 0,80 \\
Temperatura Ambiente, ${ }^{\circ} \mathrm{C}$ & 20 & 25 \\
\hline
\end{tabular}

TABELA 19 - Matriz dos fatores para a determinação da robustez do método

\begin{tabular}{|c|c|c|c|c|c|c|c|c|}
\hline Valor do fator & \multicolumn{8}{|c|}{ Combinação ensaiada } \\
\hline & 1 & 2 & 3 & 4 & 5 & 6 & 7 & 8 \\
\hline A ou a & A & A & A & A & $\mathrm{a}$ & $\mathrm{a}$ & $\mathrm{a}$ & $\mathrm{a}$ \\
\hline B ou b & B & B & $\mathrm{b}$ & $\mathrm{b}$ & B & B & $b$ & $b$ \\
\hline C ou c & $\mathrm{C}$ & $\mathrm{c}$ & $\mathrm{C}$ & $\mathrm{c}$ & $\mathrm{C}$ & $\mathrm{c}$ & $\mathrm{C}$ & $\mathrm{c}$ \\
\hline D ou d & $\mathrm{D}$ & $\mathrm{D}$ & d & d & d & d & $\mathrm{D}$ & $\mathrm{D}$ \\
\hline E ou e & $\mathrm{E}$ & e & $\mathrm{E}$ & $\mathrm{e}$ & $\mathrm{e}$ & $\mathrm{E}$ & $\mathrm{e}$ & $\mathrm{E}$ \\
\hline F ou $f$ & $\mathrm{~F}$ & $\mathrm{f}$ & $\mathrm{f}$ & $\mathrm{F}$ & $\mathrm{F}$ & $\mathrm{f}$ & $\mathrm{f}$ & $\mathrm{F}$ \\
\hline G ou g & $\mathrm{G}$ & $\mathrm{g}$ & $\mathrm{g}$ & G & $\mathrm{g}$ & $\mathrm{G}$ & G & $\mathrm{g}$ \\
\hline Resultado & $\mathbf{S}$ & $\mathbf{t}$ & $\mathbf{u}$ & $\mathbf{v}$ & $\mathbf{w}$ & $\mathbf{x}$ & $\mathbf{y}$ & $\mathbf{z}$ \\
\hline
\end{tabular}

Fonte: (INSTITUTO NACIONAL DE METROLOGIA, NORMALIZAÇÃO E QUALIDADE INDUSTRIAL, 2007) 
Observando a TAB. 19 quando a combinação 1 for ensaiada, o resultado será S. Quando a combinação 2 for ensaiada será t e assim sucessivamente, até todas as 8 combinações terem sido concluídas. Para a determinação do valor do fator, por exemplo sendo o primeiro fator A, foram utilizadas as equações (14) e (15) para o cálculo.

$$
\frac{s+t+u+v}{4} \mathrm{e} \frac{w+x+y+z}{4}
$$

No caso acima, o efeito do fator A/a será:

$$
\text { Efeito } \mathrm{A} / \mathrm{a}=\frac{s+t+u+v}{4}-\frac{w+x+y+z}{4}
$$

\subsubsection{Cálculo de estimativa de incerteza de medição}

Para a identificação da estimativa de incerteza de medição foi utilizado o guia EURACHEM/CITAC (2012), além da planilha eletrônica "estimativa de incerteza em análise química" elaborada por Furusawa (2007). Foram utilizados os dados dos parâmetros obtidos em todo o desenvolvimento da validação, sendo eles: volume, padrão para o preparo da curva, precisão (repetitividade), recuperação e a curva analítica. Além disso, foi utilizado o modelo matemático para a quantificação do mensurando, apresentada na equação (16), no qual apresenta as variáveis que podem influenciar na quantificação da concentração dos metais em água. O diagrama de Ishikawa, apresentado na FIG.26, demonstra as etapas que foram utilizadas para o cálculo de estimativa de incerteza de medição. Além da organização visual de todo o processo do cálculo de incerteza, auxilia para que os efeitos não sejam duplicados.

Sendo:

$$
C=\frac{C_{O} x V_{f}}{V_{i}} \times \frac{1}{R}
$$

$C=$ Concentração do elemento, $\mathrm{mg} \cdot \mathrm{L}^{-1}$;

$C_{O}=$ Concentração do elemento de acordo com a curva analítica, mg. $\mathrm{L}^{-1}$;

$V_{f}=$ Volume final da amostra após a digestão, $50 \mathrm{~mL}$;

$V_{i}=$ Volume inicial da amostra, $45 \mathrm{~mL}$;

$R=$ Recuperação do método. 


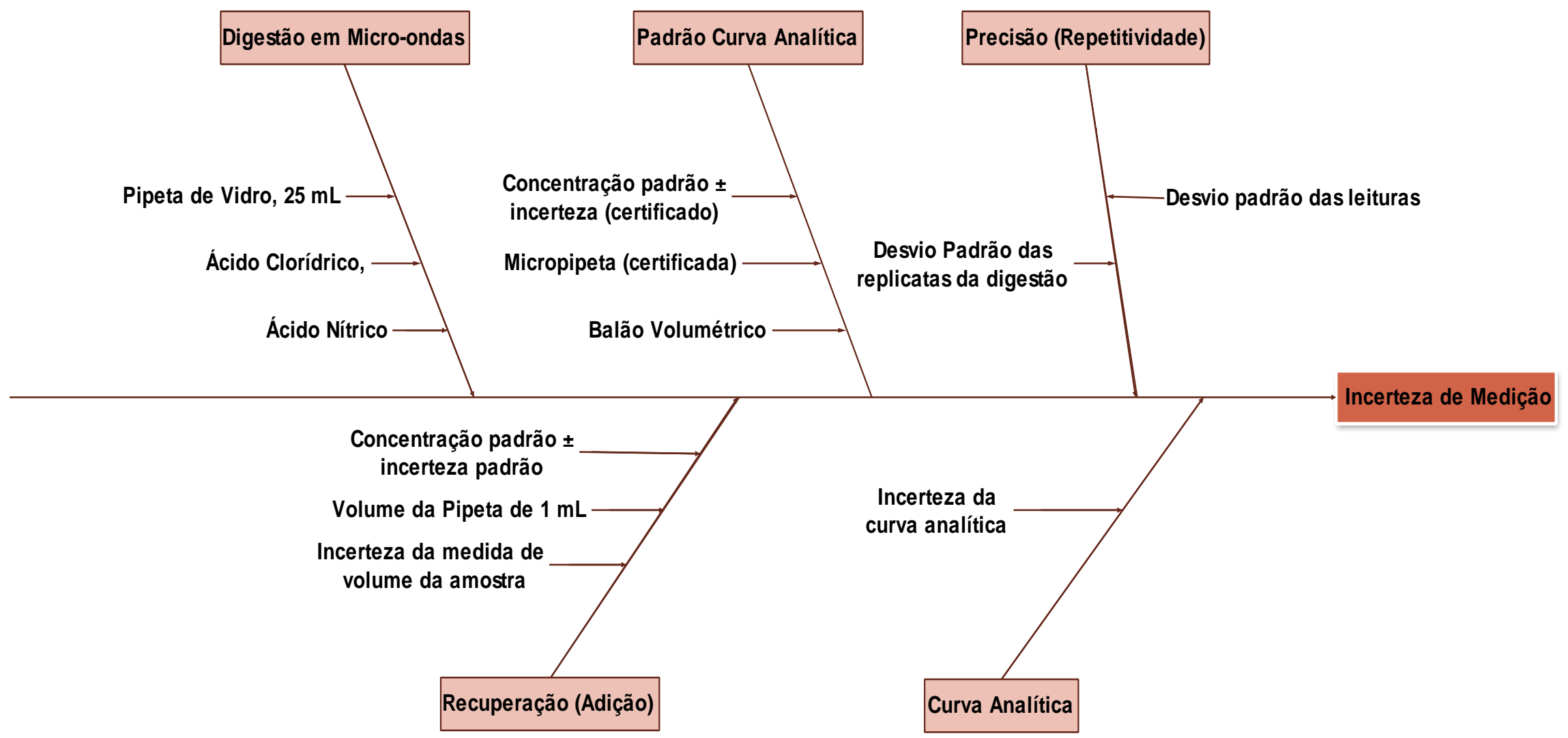

FIGURA 26 - Diagrama de Ishikawa para o cálculo de estimativa de incerteza de medição 


\subsubsection{Incerteza de medição associada a digestão ácida em micro-ondas}

Inicialmente foi identificado as fontes de incerteza da digestão em micro-ondas, na abertura de amostras. As fontes utilizadas foram a pipeta graduada para coletar as amostras e as micropipetas para a coleta do ácido nítrico e ácido clorídrico, além da incerteza associada a repetitividade das pipetas nos volumes utilizados no método (EURACHEM/CITAC Guide, 2012) (FURUSAWA, 2007).

Os cálculos da estimativa de incerteza da repetitividade foram utilizados os dados de desvio-padrão e a quantidade de amostras replicadas, conforme a equação (17).

$$
\mu\left(V_{\text {Repe }}\right)=\frac{D P}{\sqrt{n}}
$$

Sendo:

$\mu\left(V_{\text {Repe }}\right)=$ Incerteza do volume em função da repetitividade, $\mathrm{mL}$;

$D P=$ desvio-padrão;

$n=$ quantidade de amostra replicatas.

Foi utilizado uma distribuição triangular $(\mathrm{k}=\sqrt{ } 6)$, considerando o limite de erro do certificado das pipetas para a coleta da amostra e dos ácidos, conforme a equação (18).

Sendo:

$$
\mu\left(V_{p}\right)=\frac{\text { Limite de Erro }}{k}
$$

$\mu\left(V_{p}\right)=$ Incerteza de medição do volume em função das variações da vidraria e/ou micropipeta, $\mathrm{mL}$;

Limite de Erro = Erro máximo permissível, $\mathrm{mL}$;

$k(\sqrt{6})=$ assumindo uma distribuição triangular.

Depois foi realizado o cálculo de estimativa de incerteza da pipeta graduada e das micropipetas em função da temperatura, para a coleta da amostra e dos ácidos, utilizado uma distribuição retangular. A fórmula matemática utilizada está apresentada na equação (19). 


$$
\mu\left(V_{t}\right)=\frac{V \cdot Q \cdot \Delta T}{\sqrt{3}}
$$

Sendo:

$\mu\left(V_{t}\right)=$ Incerteza de medição do volume da pipeta em função da temperatura, $\mathrm{mL}$;

$Q=$ Coeficiente de dilatação, ${ }^{\circ} \mathrm{C}$;

$\Delta=$ variação temperatura, ${ }^{\circ} \mathrm{C}$;

$V=$ Volume coletado de amostra/ácido, $\mathrm{mL}$;

$\sqrt{3}=$ distribuição retangular.

Para o cálculo da incerteza em função do volume da amostra e o volume dos ácidos foi realizada uma combinação das fontes de incerteza de cada um, apresentada nas equações (20) e (21).

$$
\begin{aligned}
& \mu\left(V_{S}\right)=\sqrt{\mu\left(V_{p}\right)^{2}+\mu\left(V_{t}\right)^{2}+\mu\left(V_{\text {repe }}\right)^{2}} \\
& \mu\left(V_{a}\right)=\sqrt{\mu\left(V_{P}\right)^{2}+\mu\left(V_{t}\right)^{2}+\mu\left(V_{\text {repe }}\right)^{2}}
\end{aligned}
$$

Sendo:

$\mu\left(V_{S}\right)=$ Incerteza do volume de amostra, $\mathrm{mL} ;$

$\mu\left(V_{a}\right)=$ Incerteza do volume do ácido, $\mathrm{mL}$.

Para o cálculo da incerteza combinada associada a digestão ácida em microondas foi utilizado a equação (22).

$$
\mu\left(V_{f}\right)=\sqrt{\mu\left(V_{s}\right)^{2}+\mu\left(V_{a}\right)^{2}}
$$

Sendo:

$\mu\left(V_{f}\right)=$ Incerteza de medição final do volume utilizado na digestão ácida.

\subsubsection{Incerteza de medição associada ao preparo da curva analítica}

Para a estimativa de incerteza do preparo da curva analítica, $\mu(\mathrm{Cpc})$, foi considerado a incerteza dos balões volumétricos e das pipetas micropipetas utilizadas no preparo das soluções estoques e dos padrões monoelementares para a calibração do método, 
além da incerteza associada a repetitividade dos balões utilizados e das concentrações, em mg. $L^{-1}$, dos certificados para cada elemento estudado nesse trabalho (EURACHEM/CITAC Guide, 2012) (FURUSAWA, 2007).

Foi utilizado uma distribuição triangular $(\mathrm{k}=\sqrt{ } 6)$, considerando o limite de erro do certificado das pipetas e dos balões volumétricos. Para o cálculo foi utilizado a equação (18).

Posteriormente foi realizado o cálculo de estimativa de incerteza das micropipetas e dos balões volumétricos em função da temperatura, para a realização do preparo da curva analítica. Para o cálculo foi utilizado a equação (19).

Para o cálculo da incerteza em função do volume do balão volumétrico e o volume das pipetas, foi realizada uma combinação das fontes de incerteza de cada um, apresentada nas equações (23) e (24).

$$
\begin{gathered}
\mu\left(V_{b v}\right)=\left(\sqrt{\mu\left(V_{t}\right)^{2}+\mu\left(V_{p}\right)^{2}+\mu\left(V_{\text {Repe }}\right)^{2}}\right) \\
\mu\left(V_{p}\right)=\left(\sqrt{\mu\left(V_{t}\right)^{2}+\mu\left(V_{p}\right)^{2}+\mu\left(V_{\text {Repe }}\right)^{2}}\right)
\end{gathered}
$$

Sendo:

$$
\begin{aligned}
& \mu\left(V_{b v}\right)=\text { Incerteza do volume do balão volumétrico, } \mathrm{mL} ; \\
& \mu\left(V_{p}\right)=\text { Incerteza do volume da pipeta, } \mathrm{mL} \text {. }
\end{aligned}
$$

Para a combinação da solução-estoque (SE) e dos padrões para cada ponto das curvas analíticas $\left(\mathrm{C}_{\mathrm{PC}}\right)$, foi utilizada a equação (25) para a obtenção da incerteza da soluçãoestoque e a equação (26) para a obtenção da incerteza para cada ponto da curva analítica.

$$
\mu\left(C_{S E}\right)=\left(\sqrt{\left(\frac{\mu V_{p}}{V_{p}}\right)^{2}+\left(\frac{\mu V_{b v}}{V_{b v}}\right)^{2}+\left(\frac{\mu C_{\text {elemento }}}{C_{\text {elemento }}}\right)^{2}}\right) \times C_{S E}
$$

Sendo:

$$
\mu\left(C_{S E}\right)=\text { incerteza da concentração da SE (Solução Estoque); }
$$


$\mu V_{p}=$ incerteza padrão do volume pipetado do padrão certificado;

$V_{p}=$ volume pipetado do padrão;

$\mu V_{b v}=$ incerteza padrão do balão volumétrico;

$V_{b v}=$ volume do balão volumétrico, $\mathrm{mL}$;

$\mu C_{\text {elemento }}=$ incerteza padrão informada no certificado do padrão;

$C_{\text {elemento }}=$ concentração do padrão informada no certificado;

$C_{S E}=$ concentração final do elemento na SE, mg. $\mathrm{L}^{-1}$.

$\mu\left(C_{P C}\right)=\left(\sqrt{\left(\frac{\mu V_{p}}{V_{p}}\right)^{2}+\left(\frac{\mu V_{b v}}{V_{b v}}\right)^{2}+\left(\frac{\mu C_{S E}}{C_{S E}}\right)^{2}}\right) \times C_{P C}$

Sendo:

$\mu\left(C_{P C}\right)=$ Incerteza da concentração de cada Ponto da Curva Analítica (PC);

$\mu V_{p}=$ incerteza padrão do volume pipetado da SE;

$V_{p}=$ volume pipetado da $\mathrm{SE}$;

$\mu V_{b v}=$ incerteza padrão do balão volumétrico;

$V_{b v}=$ volume do balão volumétrico, $\mathrm{mL}$;

$\mu C_{S E}=$ incerteza padrão da SE;

$C_{S E}=$ concentração do elemento na SE;

$C_{P C}=$ concentração final do elemento no ponto.

Com a estimativa de incerteza calculada, para cada ponto da curva analítica, utilizando a solução-estoque preparada, foi considerado a estimativa de incerteza do preparo da curva analítica com o maior valor obtido, transformado em porcentagem para a abrangência da incerteza selecionada em todos os prontos da curva analítica.

\subsubsection{Incerteza de medição associada a curva analítica}

O cálculo de estimativa de incerteza de medição associada a curva analítica, $\mu\left(\mathrm{C}_{0}\right)$, foi realizado utilizando os dados de intensidade (CPS) das curvas analíticas de cada elemento estudo nesse trabalho (EURACHEM/CITAC Guide, 2012) (FURUSAWA, 2007). Para o cálculo foi utilizado a equação (27). 


$$
\mu C_{0}=\frac{S}{B_{1}}\left(\sqrt{\frac{1}{p}+\frac{1}{n}+\frac{\left(C_{0}-\bar{C}\right)^{2}}{S_{x x}}}\right)
$$

Sendo:

$\mu\left(C_{O}\right)=$ Incerteza padrão da curva analítica no ponto $\mathrm{O}$;

$S=$ Desvio-padrão residual;

$B_{1}=$ Coeficiente angular;

$p=$ Número de replicadas;

$n=$ Número total de amostras;

$C_{O}=$ Concentração média da amostra;

$\bar{C}=$ Concentração média das calibrações da curva analítica;

$S_{X X}=\sum_{i=1}^{n}\left(C_{i}-\bar{C}\right)^{2}$, onde $C_{i}=$ Valor de concentração obtida pela curva de calibração.

\subsubsection{Incerteza de medição associada a repetitividade do método}

Para o cálculo da estimativa de incerteza associada a repetitividade do método foi utilizado o cálculo do desvio-padrão relativo (DPR\%) das amostras com adição padrão do ponto intermediário das curvas analíticas de cada elemento estudado nesse trabalho. Para o cálculo foi utilizada a equação (28).

$$
\mu(\text { Repe })=\left(\frac{\text { Máx } D P R}{\sqrt{n}}\right)
$$

Sendo:

Máx $D P R=$ Maior desvio-padrão das replicatas dos valores;

$n=$ número de replicatas.

\subsubsection{Incerteza de medição associada a recuperação}

A estimativa de incerteza associada a recuperação foi obtida a partir dos resultados dos testes de recuperação realizados na validação do método, no qual foram realizadas adições em sete amostras independentes, em dez replicatas, para cada elemento. Posteriormente foi utilizado a média das replicatas para o cálculo da incerteza de medição associada a recuperação conforme a equação (29). 


$$
\mu(\operatorname{Rec})=\left(\frac{\overline{\operatorname{Rec}}}{\sqrt{s}}\right)
$$

Sendo:

$\overline{\operatorname{Rec}}=$ Média da Recuperação do método para o elemento;

$s=$ Desvio padrão da recuperação.

\subsubsection{Incerteza de medição combinada e expandida}

A estimativa de incerteza de medição final do método desenvolvido foi realizada utilizando a combinação de todas as fontes, apresentada na equação (30), e a expansão das mesmas. A estimativa de incerteza expandida foi realizada utilizando um fator de expansão de incerteza de $k=2$, empregando um intervalo de confiança de $95 \%$ dos resultados obtidos, apresentada na equação (31).

$$
=\left(\sqrt{\left(\frac{\mu V}{V}\right)^{2}+\left(\frac{\mu C_{P C}}{100}\right)^{2}+\left(\frac{\mu C_{O}}{C o}\right)^{2}+\left(\frac{\mu R e p e}{100}\right)^{2}+\left(\frac{\mu R e C}{100}\right)^{2}}\right) \cdot C_{\text {Amostra }}
$$

Sendo:

$\mu V=$ Incerteza padrão de volume, $\mathrm{mL}$;

$V=$ volume total, $\mathrm{mL}$;

$\mu P C=$ Maior incerteza padrão dos pontos da curva analítica, \%;

$\mu C_{O}=$ Incerteza padrão do ajuste da curva analítica, mg. $\mathrm{L}^{-1} ;$

$C o=$ Concentração de um ponto da curva analítica, mg. $\mathrm{L}^{-1}$;

$\mu R e p e=$ Incerteza padrão da repetitividade, \%;

$\mu R e c=$ Incerteza padrão da Recuperação, \%;

$C_{\text {Amostra }}=$ Concentração da Amostra, mg. $\mathrm{L}^{-1}$.

$$
\mathrm{U}=\mu\left(C_{\text {Amostra }}\right) x k
$$

Sendo:

$\mathrm{U}=$ incerteza expandida

$\mu\left(C_{\text {Amostra }}\right)=$ incerteza final da concentração da amostra

$k=$ fator de expansão $=2$ 
A avaliação da contribuição de cada fator para o cálculo de estimativa de incerteza foi realizada a partir de uma análise gráfica. 


\section{RESULTADOS E DISCUSSÃO}

\subsection{Seletividade}

Para verificar a seletividade do método, foram traçados os espectros das amostras e padrões, nas regiões dos comprimentos de onda $(\lambda)$ de emissão para cada elemento. Os espectros são apresentados na FIG.27, nos quais pôde-se observar que o perfil dos picos de emissão dos elementos, das soluções das amostras de matriz digerida são idênticos aos respectivos perfis dos picos das soluções-padrão, indicando que não ocorreram interferências espectrais de matriz na determinação dos elementos estudados.

$\mathrm{Na}$ avaliação estatística da seletividade utilizando o teste $\mathrm{F}$ (Snedecor) de homogeneidade das variâncias nas medidas de adição padrão na matriz de interesse e na solução-padrão, para $n=10$ e com um intervalo de $95 \%$ de confiança, com o valor de $\mathrm{F}_{\text {crítico }}$ $=3,18$, os resultados foram satisfatórios. Para que os resultados sejam considerados satisfatório, ou seja, demonstrando que não há interferia de matriz na curva analítica, o valor do $F_{\text {calculado }}$ deve ser menor que o $F_{\text {crítico }}$ e todos os valores calculados foram menores que o

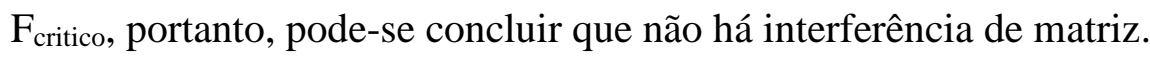

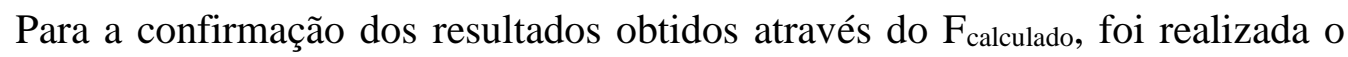
teste $\mathrm{t}$ com o valor crítico de $\mathrm{t}=2,26$. Para que o resultado seja considerado satisfatório o

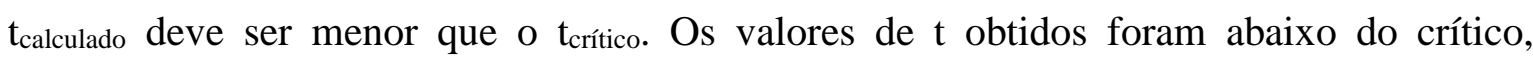
reforçando que não a interferência de matriz. Os dados do teste $\mathrm{F}$ e do teste $\mathrm{t}$ podem ser observados na TAB.20. 


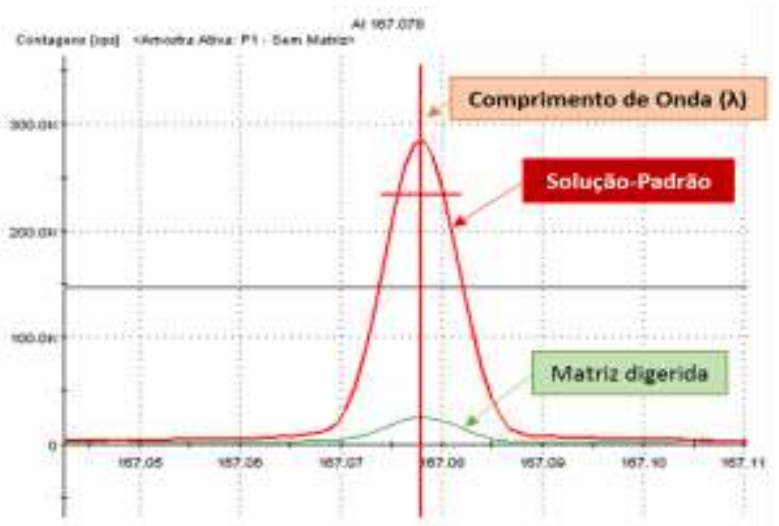

(Alumínio)

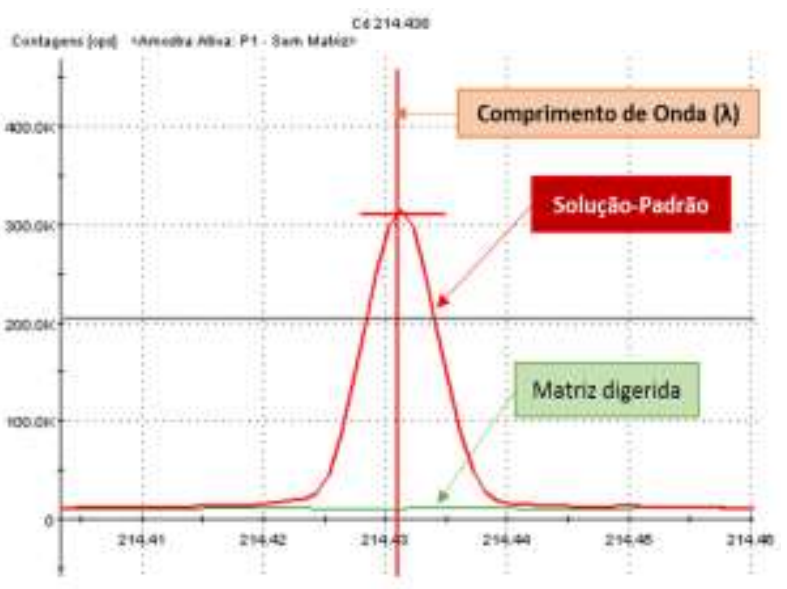

come. Onds phent:

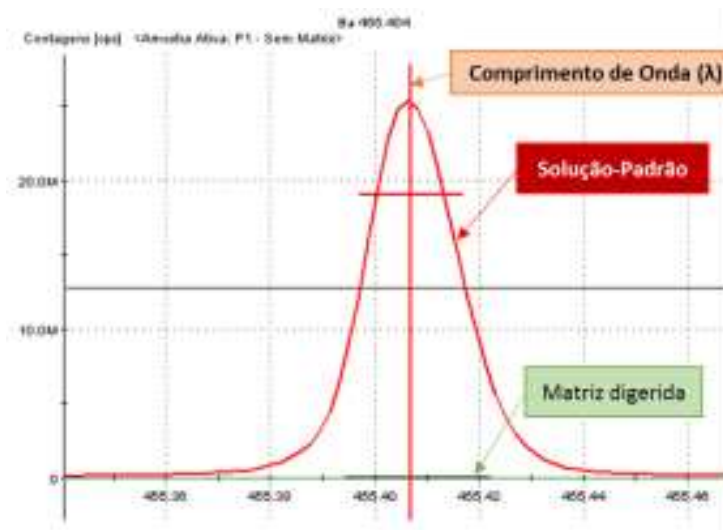

comp ond bor

(Bário)

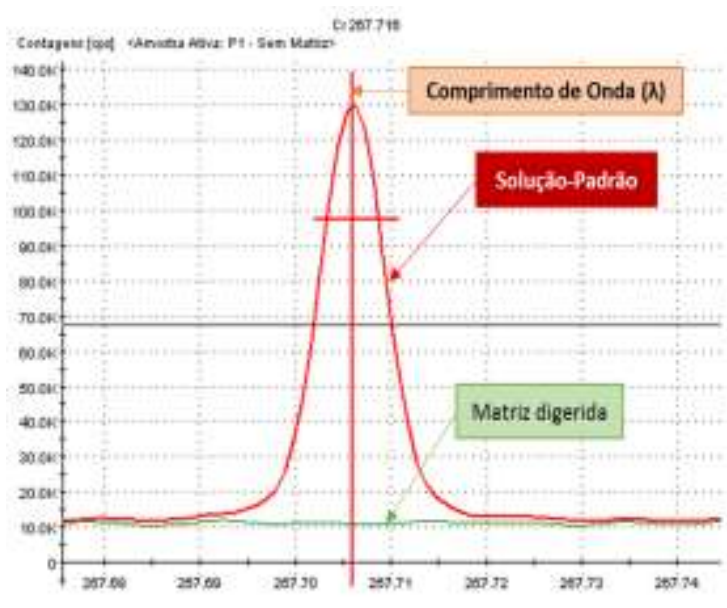

(Crômio)

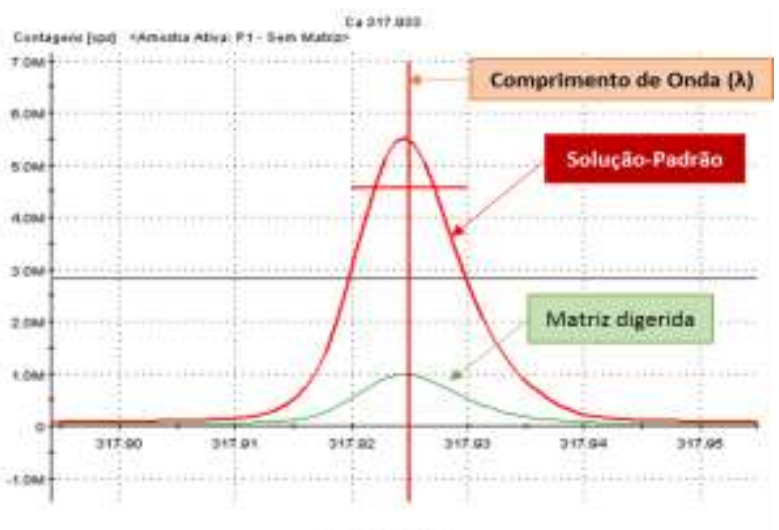

(Cálcio)

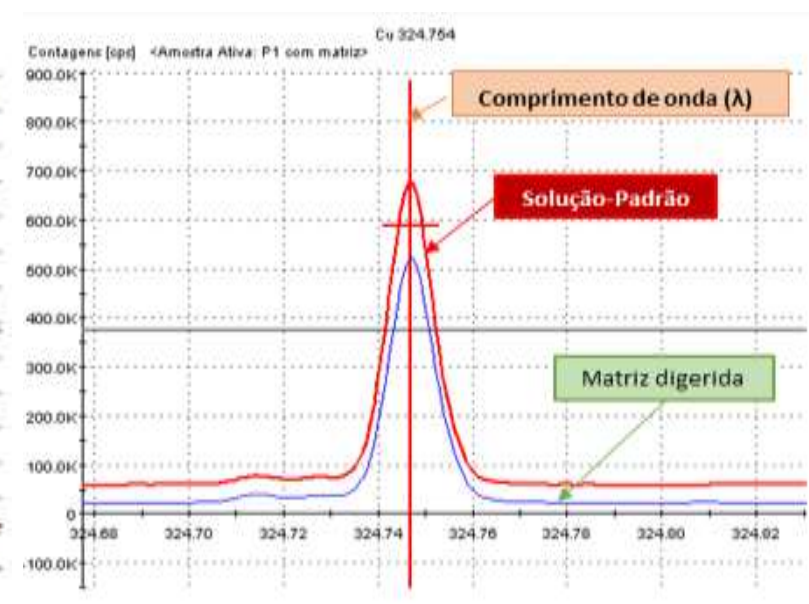

componata nont

Cobre)

FIGURA 27 - Espectros de emissão das soluções-padrão (linha-vermelha) e de uma das soluções das amostras de matriz digerida (linha verde/azul) na região próxima ao $\lambda$ de emissão dos elementos estudados 


\section{Cont. FIGURA 27}

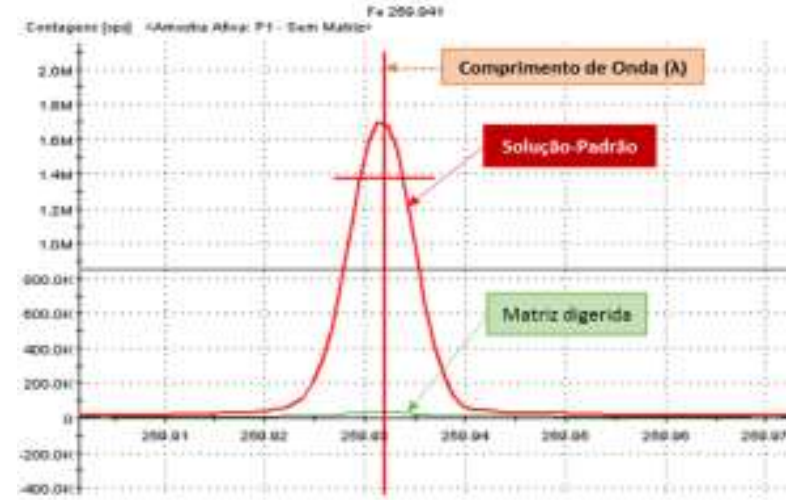

coun ancision

(Ferro)

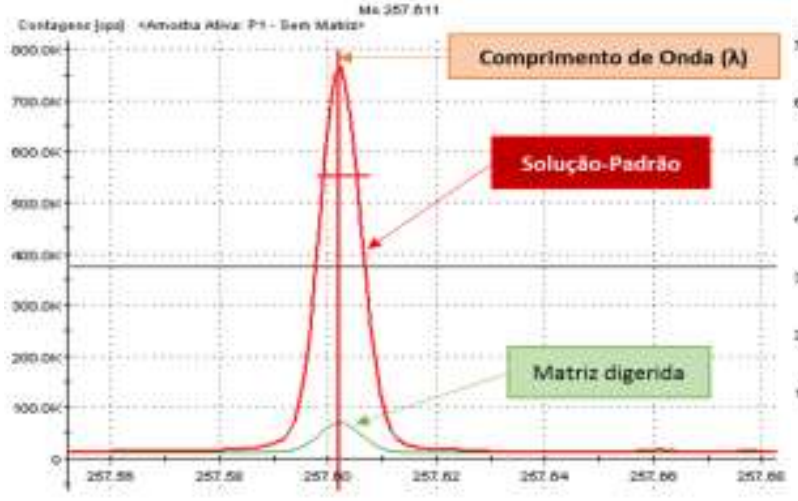

(Manganês)

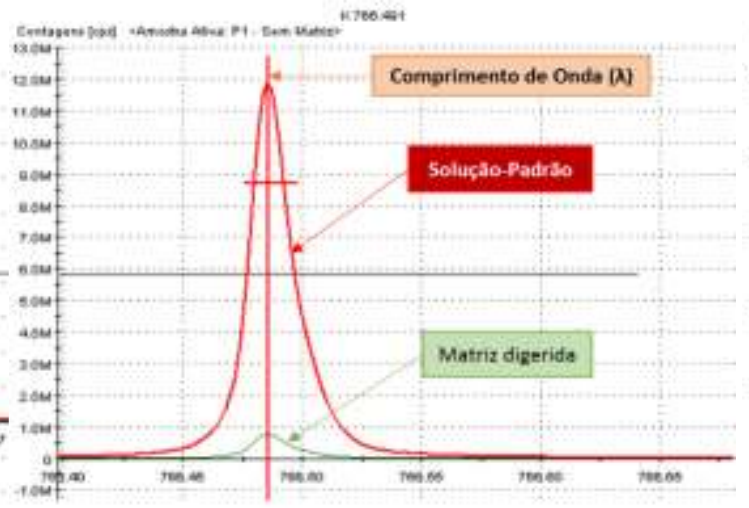

cane osistinal

(Potássio)

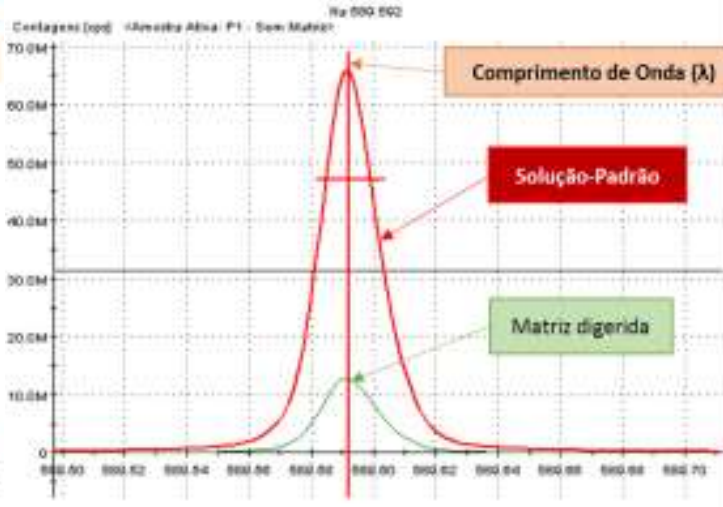

(Sódio)

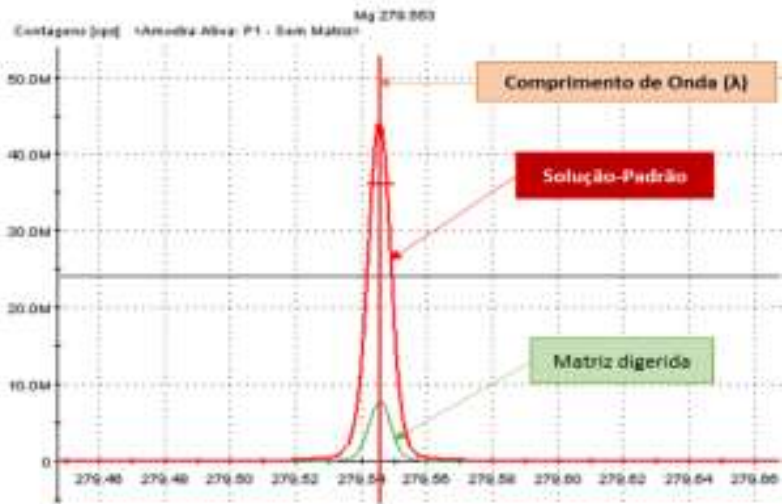

(Magnésio)

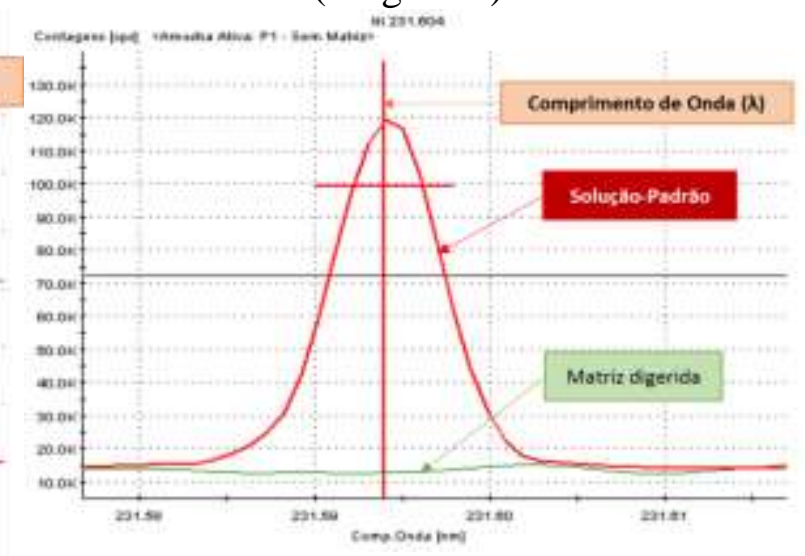

(Níquel)

FIGURA 27 - Espectros de emissão das soluções-padrão (linha-vermelha) e de uma das soluções das amostras de matriz digerida (linha verde/azul) na região próxima ao $\lambda$ de emissão dos elementos estudados 
TABELA 20 - Análise do teste F - Snedecor* e teste t de Student** para avaliar o efeito da matriz na curva analítica

$\begin{array}{ccccc}\text { Elementos } & \text { Variância } & \text { Variância } & & \\ & \text { Sem Matriz } & \text { Com Matriz } & & \mathbf{F}_{\text {calculadado }} \\ \text { Al } & 1,67 \times 10^{+11} & 1,65 \times 10^{+11} & 1,01 & 0,034 \\ \mathbf{B a} & 1,09 \times 10^{+14} & 9,77 \times 10^{+13} & 1,12 & 0,066 \\ \mathbf{C d} & 8,84 \times 10^{+10} & 8,99 \times 10^{+10} & 1,02 & 0,014 \\ \mathbf{C r} & 5,06 \times 10^{+09} & 4,89 \times 10^{+09} & 1,03 & 0,022 \\ \mathbf{C u} & 4,77 \times 10^{+08} & 4,95 \times 10^{+08} & 1,04 & 0,015 \\ \mathbf{F e} & 1,74 \times 10^{+12} & 1,28 \times 10^{+12} & 1,35 & 0,190 \\ \mathbf{M g} & 1,68 \times 10^{+15} & 1,91 \times 10^{+15} & 1,14 & 0,121 \\ \mathbf{M n} & 1,67 \times 10^{+11} & 1,65 \times 10^{+11} & 1,01 & 0,034 \\ \mathbf{N i} & 6,35 \times 10^{+09} & 4,89 \times 10^{+09} & 1,30 & 0,156 \\ \mathbf{K} & 4,26 \times 10^{+12} & 7,25 \times 10^{+12} & 1,70 & 0,256 \\ \mathbf{N a} & 7,25 \times 10^{+14} & 1,24 \times 10^{+15} & 1,71 & 0,262 \\ \mathbf{C a} & 3,79 \times 10^{+12} & 3,22 \times 10^{+12} & 1,18 & 0,109\end{array}$

$* \mathrm{~F}_{\text {crítico }}=3,18 ; * * t_{\text {crítico }}=2,26$

Para observar o comportamento da curva analítica das soluções com e sem matriz foram construídos gráficos com os cinco pontos de concentrações. Os elementos com matriz demonstraram um comportamento semelhante com a curva analítica sem adição em matriz. Os coeficientes de correlação (r) deram entre 0,9965 e 1, para a curva com e sem matriz. A representação gráfica de seletividade, comparando a curva com a adição em matriz e a curva sem adição em matriz é apresentada nas FIG.28 e FIG.29. 

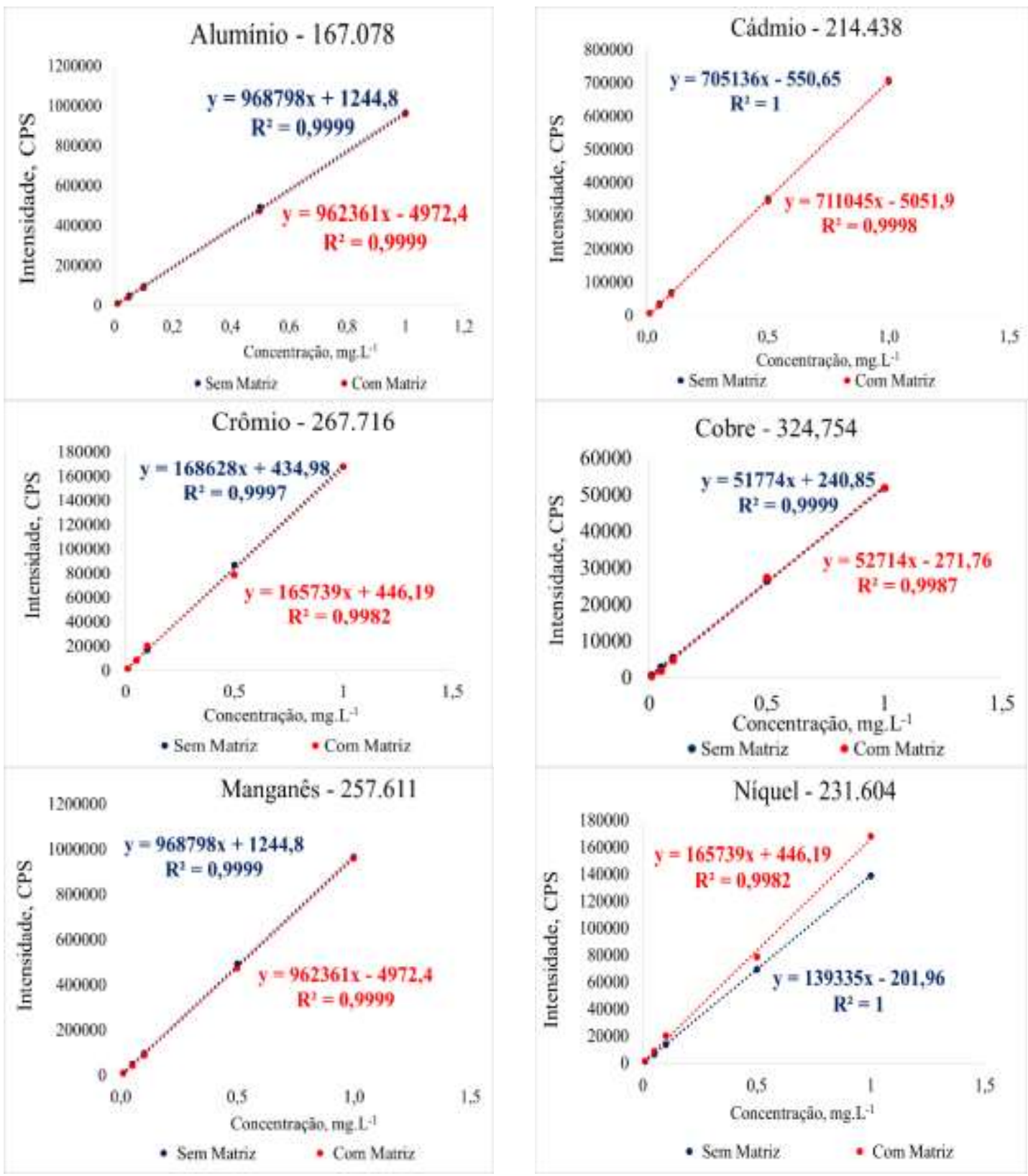

FIGURA 28 - Representação Gráfica da comparação das curvas analíticas com e sem matriz dos elementos alumínio, cádmio, crômio, cobre, manganês e níquel 

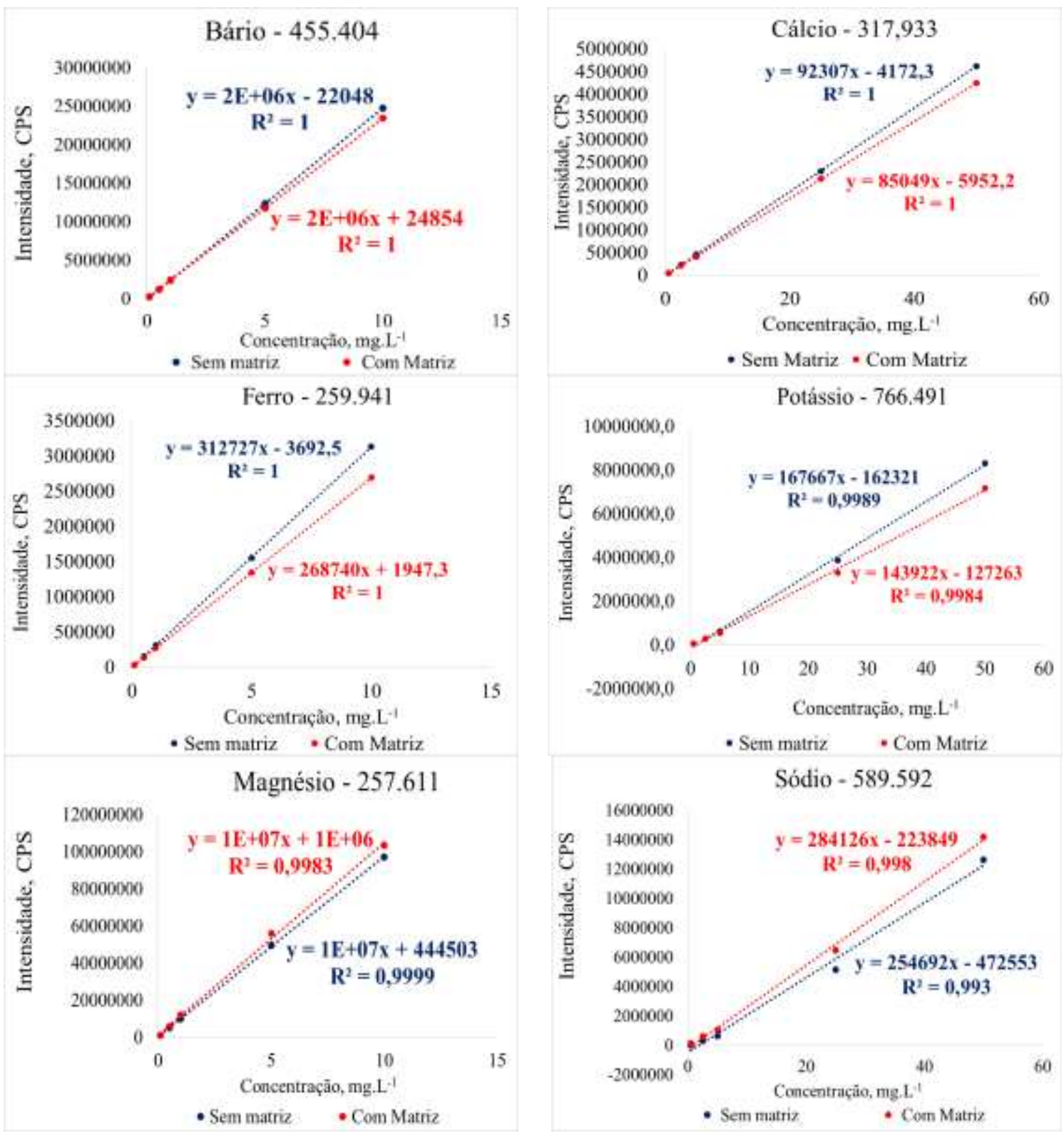

FIGURA 29 - Representação Gráfica da comparação das curvas analíticas com e sem matriz dos elementos bário, cálcio, ferro, potássio, magnésio e sódio.

\subsection{Faixa de Trabalho e Linearidade}

Pelo estudo de seletividade pôde-se verificar que os comportamentos da curva analítica com matriz e sem matriz são semelhantes, dessa forma a curva analítica foi construída, sem a matriz.

Por meio das soluções-padrão, apresentadas na TAB.21, verificou-se a linearidade das faixas de trabalho através da construção das curvas de calibração para cada 
elemento em seu respectivo comprimento de onda $(\lambda)$ de emissão.

TABELA 21 - Concentrações (mg.L $\left.\mathrm{L}^{-1}\right)$ das soluções-padrão multielementares para construção das curvas de calibração

\begin{tabular}{ccccccc}
\hline \multirow{2}{*}{ Elementos } & \multicolumn{5}{c}{ Concentração (mg.L-1) } \\
\cline { 2 - 7 } & Branco & Padrão 5 & Padrão 4 & Padrão 3 & Padrão 2 & Padrão 1 \\
\hline Al, Cd, Cu, & 0,0 & 0,01 & 0,05 & 0,1 & 0,5 & 1,0 \\
Cr, Mn e Ni & 0,0 & 0,1 & 0,5 & 1,0 & 5,0 & 10,0 \\
Ba, Fe e Mg & 0,0 & 0,5 & 2,5 & 5,0 & 25,0 & 50,0 \\
Ca, Na e K & 0,0 & &
\end{tabular}

Para observar o comportamento da curva analítica de calibração dos elementos estudados foram construídos gráficos, sem a matriz. Os coeficientes de correlação (r) foram considerados satisfatórios, pois deram acima de 0,90, recomendado pelo INMETRO. O coeficiente de correlação (r) dos elementos tiveram resultados entre 1 e 0,9965 e o coeficiente de determinação $\left(\mathrm{r}^{2}\right)$ tiveram resultados entre 1 e 0,9933 , utilizando um intervalo de confiança de $95 \%$, portanto pôde-se concluir que a curva analítica é linear e pode ser adotada na quantificação das amostras de interesse. A representação gráfica das curvas analíticas é apresentada na FIG.30 e os coeficientes de correlação (r) e determinação $\left(\mathrm{r}^{2}\right)$ são apresentados na TAB.22.

TABELA 22 - Dados dos coeficientes de correlação (r) e determinação $\left(r^{2}\right)$ e os comprimentos de onda $(\lambda)$ de cada elemento analisado

\begin{tabular}{|c|c|c|c|c|c|c|c|}
\hline & Linhas & & & & Linhas & & \\
\hline Elementos & $(\lambda \mathbf{n m})$ & $\mathbf{r}$ & $\mathbf{r}^{2}$ & Elementos & $(\lambda \mathbf{n m})$ & $\mathbf{r}$ & $\mathbf{r}^{2}$ \\
\hline Al & 167,078 & 0,9999 & 0,9999 & $\mathbf{F e}$ & 259,941 & 1,0000 & 1,0000 \\
\hline $\mathbf{B a}$ & 455,404 & 1,0000 & 1,0000 & Mg & 276,553 & 0,9999 & 0,9999 \\
\hline $\mathrm{Ca}$ & 317,933 & 1,0000 & 1,0000 & Mn & 279,611 & 0,9999 & 0,9999 \\
\hline Cd & 214,438 & 1,0000 & 1,0000 & $\mathbf{N i}$ & 231,604 & 0,9999 & 0,9998 \\
\hline $\mathrm{Cr}$ & 267,716 & 0,9998 & 0,9997 & $\mathrm{Na}$ & 589,592 & 0,9965 & 0,9930 \\
\hline $\mathbf{C u}$ & 324,754 & 0,9999 & 0,9999 & $\mathbf{K}$ & 766,491 & 0,9994 & 0,9989 \\
\hline
\end{tabular}


Os parâmetros de linearidade avaliados foram o coeficiente de determinação, obtidos pela regressão linear de cada elemento, juntamente com a análise de resíduos através do teste $t$ de Student. Os resultados com as curvas de calibração, com os respectivos coeficientes de determinação estão apresentados nas FIG.30 e FIG.31.
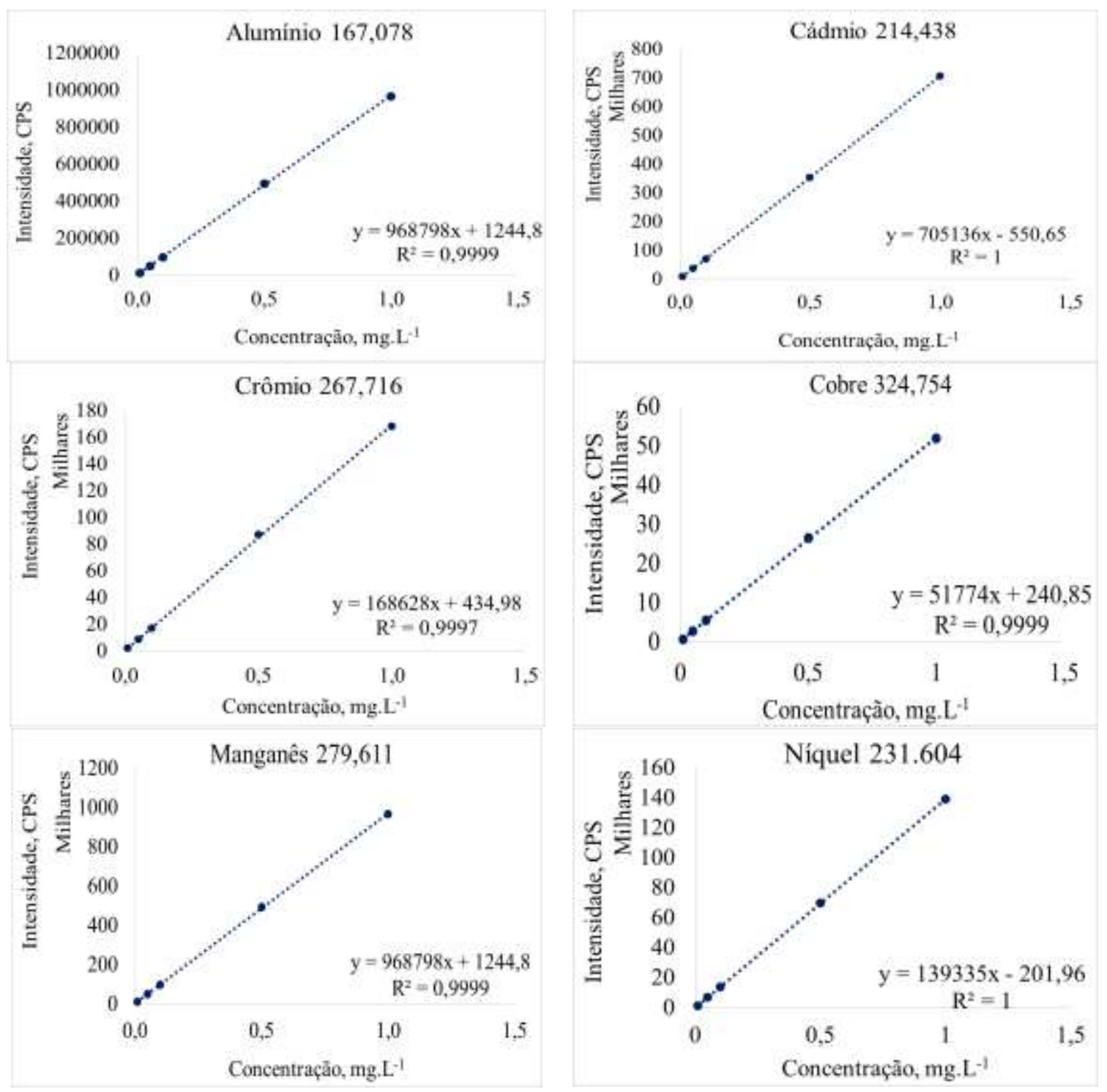

FIGURA 30 - Representação gráfica da curva de calibração analítica, para alumínio, cádmio, crômio, cobre, manganês e níquel - Sem Matriz 

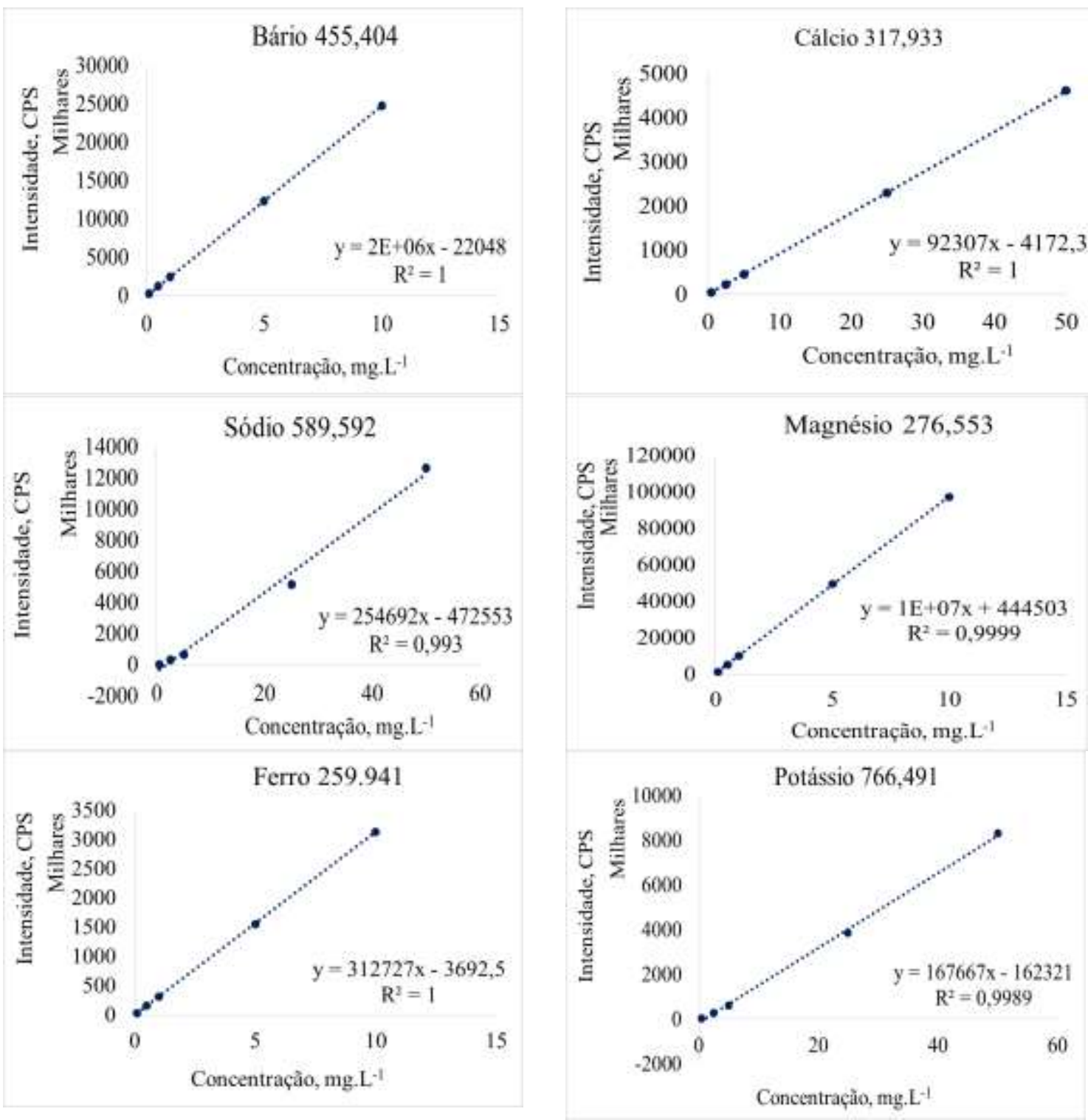

FIGURA 31 - Representação gráfica da curva de calibração analítica, para bário, cálcio, sódio, magnésio, ferro e potássio - Sem Matriz

A partir do cálculo estatístico para a determinação da análise de resíduos foram encontrados os valores do t de Student, para a verificação dos desvios de linearidade para cada ponto da curva analítica, para cada elemento analisado. $\mathrm{O}$ valor de $t_{\text {crítico }}$ para as cinco concentrações foi de $t=2,78$, com $95 \%$ de intervalo de confiança, podendo ser observados na TAB.23. 
TABELA 23 - Valores do Teste t de Student para cada ponto da curva analítica de cada composto

\begin{tabular}{|c|c|c|c|c|c|c|}
\hline Elementos & Al & Cd & $\mathrm{Cr}$ & $\mathrm{Cu}$ & Mn & $\mathbf{N i}$ \\
\hline Padrão em mg.L ${ }^{-1}$ & \multicolumn{6}{|c|}{$\mathrm{t}_{\text {calculado }}$} \\
\hline $\mathbf{0 , 0 1}$ & 0,7 & 1,7 & 0,6 & 1,5 & 0,7 & 2,0 \\
\hline 0,05 & 0,3 & 0,3 & 0,7 & 0,4 & 0,3 & 0,3 \\
\hline $\mathbf{0 , 1}$ & 1,1 & 3,8 & 0,7 & 0,0 & 1,1 & 0,5 \\
\hline 0,5 & 3,9 & 1,0 & 3,9 & 3,8 & 3,9 & 3,5 \\
\hline 1,0 & 1,8 & 0,2 & 1,8 & 1,8 & 18 & 1,8 \\
\hline Elementos & & $\mathbf{B a}$ & $\mathbf{F e}$ & Mg & & \\
\hline Padrão em mg.. ${ }^{-1}$ & \multicolumn{6}{|c|}{$\mathrm{t}_{\text {calculado }}$} \\
\hline 0,1 & & 2,6 & 1,4 & 1,7 & & \\
\hline 0,5 & & 0,8 & 0,9 & 0,2 & & \\
\hline 1,0 & & 2,6 & 0,4 & 0,0 & & \\
\hline 5,0 & & 2,0 & 3,7 & 3,7 & & \\
\hline 10 & & 1,2 & 1,8 & 1,8 & & \\
\hline Elementos & & $\mathbf{N a}$ & $\mathbf{C a}$ & $\mathbf{K}$ & & \\
\hline Padrão em mg.L ${ }^{-1}$ & \multicolumn{6}{|c|}{$\mathrm{t}_{\text {calculado }}$} \\
\hline $\mathbf{0 , 0 5}$ & & 2,0 & 1,1 & 2,8 & & \\
\hline 2,5 & & 0,6 & 0,7 & 0,3 & & \\
\hline 5,0 & & 0,9 & 0,3 & 3,3 & & \\
\hline 25,0 & & 3,5 & 3,9 & 0,9 & & \\
\hline $\mathbf{5 0 , 0}$ & & 1,8 & 1,9 & 0,1 & & \\
\hline
\end{tabular}

Analisado os dados obtidos na TAB.23 pôde-se identificar que alguns pontos o $t_{\text {calculado }}$ estão acima do $t_{\text {tabelado, }}$ indicando que os valores não pertencem a reta de regressão da curva analítica. Contudo, analisando os coeficientes de determinação, apresentados na TAB.22, nos quais se encontram estão satisfatórios, os pontos foram mantidos para a quantificação das amostras. A análise de resíduos foi realizada através dos gráficos na FIG.32, no qual demonstra a distribuição dos resíduos absolutos pela concentração e pela variável normalizada. 

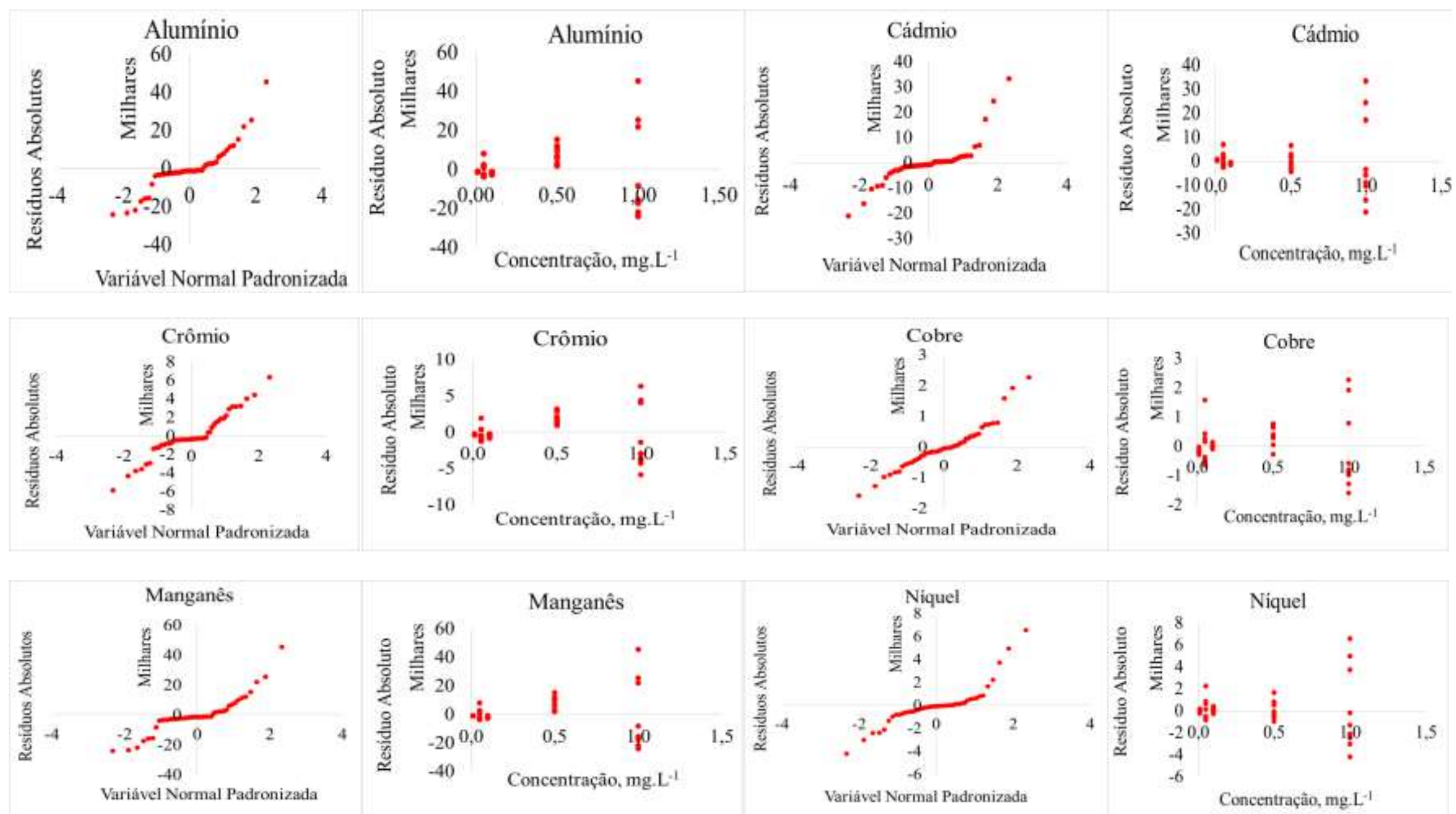

FIGURA 32 - Avaliação da normalidade e da linearidade dos dados da curva empregando a análise de resíduos - Sem Matriz 
Cont. FIGURA 32

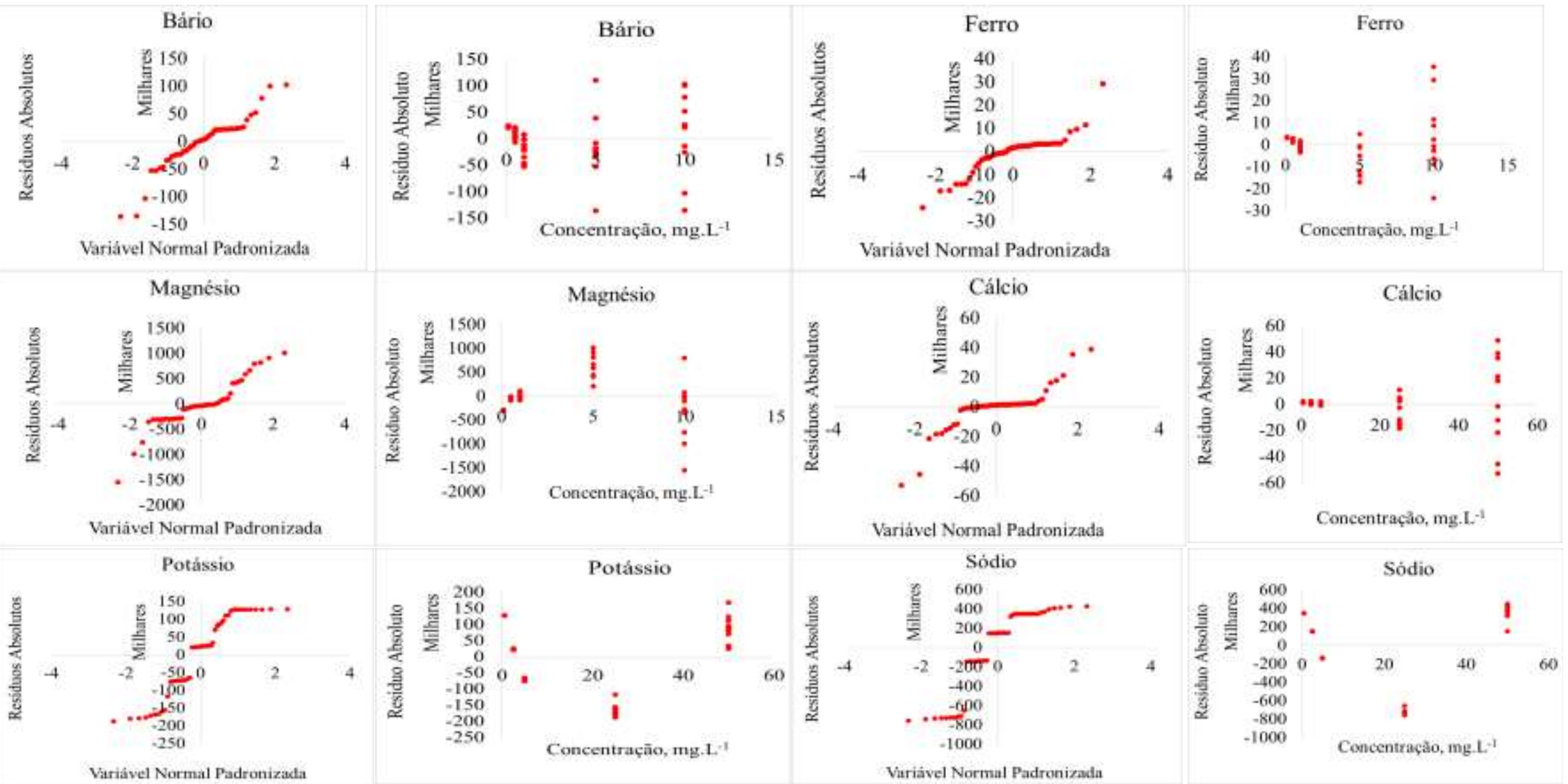

FIGURA 32 - Avaliação da normalidade e da linearidade dos dados da curva empregando a análise de resíduos - Sem matriz 
$\mathrm{Na}$ análise dos resíduos absolutos versus a concentração $\left(\mathrm{mg} . \mathrm{L}^{-1}\right)$, os gráficos apresentaram uma característica de heterocedasticidade, ou seja, a variância não é a mesma para cada ponto analisado. Conforme o aumento das concentrações há mais variações entre as replicatas de cada concentração. Contudo, analisando os gráficos de resíduos na FIG.31 pôde-se observar que os pontos de todos os elementos têm um comportamento distribuído semelhante a uma reta, na avaliação dos resíduos absolutos versus a variável normal, além de estarem distribuídos dentro da faixa entre $-2 \mathrm{a}+2$, significando que estão dentro de \pm dois desvios padrão (2s), isto é, com $95 \%$ de confiança.

A Análise de Variância (ANOVA) também foi utilizada para avaliar a linearidade e a exatidão, os resultados estão apresentados, resumidamente, na TAB.24, os resultados com detalhes podem ser observados no APÊNDICE A. Com o teste F de regressão é possível avaliar se o modelo de regressão é significativo, ou seja, se o modelo linear se ajusta ao conjunto de dados, levando em consideração os $95 \%$ de intervalo de confiança; o teste $\mathrm{F}$ de ajuste verifica o quanto o modelo se ajusta no conjunto de dados obtidos e no final foi realizada uma avaliação da porcentagem de variação explicada da porcentagem máxima de variação explicável, isto é, o quanto de variação pode ser explicada dentro da porcentagem explicável realizada pelo ajuste aplicado ao método.

TABELA 24 - Resumo dos resultados da análise de variância (ANOVA) para os elementos sem matriz

\begin{tabular}{ccccc} 
Elementos & Regressão & Ajuste & $\begin{array}{c}\text { \% de variação } \\
\text { explicada }\end{array}$ & $\begin{array}{c}\text { \% máxima de } \\
\text { variação } \\
\text { explicável }\end{array}$ \\
\cline { 2 - 4 } & $\mathrm{F}_{(1,8,95 \%)}=5,32$ & $\mathrm{~F}_{(3,5,95 \%)}=5,41$ & & 99,99 \\
Alumínio & 46872,66 & 0,39 & 99,98 & 99,98 \\
Cádmio & 21626,05 & 1,91 & 99,96 & 99,99 \\
Crômio & 60930,26 & 1,69 & 99,99 & 100,00 \\
Cobre & 61591,58 & 3,80 & 99,99 & 99,99 \\
Níquel & 25995,36 & 2,07 & 99,97 & 99,99 \\
Manganês & 46872,66 & 0,39 & 99,98 & 100,00 \\
Ferro & 172810,33 & 0,68 & 100,00 & 100,00 \\
Bário & 161330,83 & 0,18 & 100,00 & 99,99 \\
Cálcio & 102915,38 & 0,07 & 99,99 & 99,74 \\
Potássio & 1195,66 & 2,56 & 99,34 & 100,00 \\
Magnésio & 110397,24 & 1,73 & 99,99 & 99,88 \\
Sódio & 1270,45 & 6,80 & 99,37 & \\
\hline
\end{tabular}


Observando os dados obtidos na TAB.24 os valores do $\mathrm{F}_{\text {calculado }}$ para a regressão

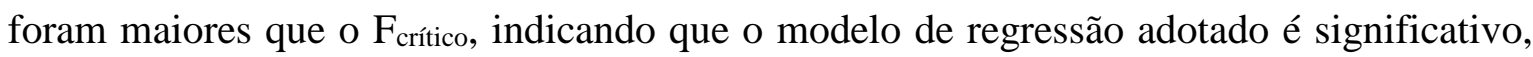
isto é, a equação da reta é adequada para os pares de pontos estudados e as variações foram explicadas satisfatoriamente pelos métodos lineares utilizados, evidenciado pelas equações das retas de cada elemento. Os resultados do teste de ajuste demonstraram que a falta de ajuste não é evidenciada ( $\mathrm{F}_{\text {calculado }}<\mathrm{F}_{\text {crítico}}$ ), ou seja, não ocorre dispersão dos pontos na curva analítica, para os elementos $\mathrm{Al}, \mathrm{Cd}, \mathrm{Cr}, \mathrm{Cu}, \mathrm{Ni}, \mathrm{Mn}, \mathrm{Ba}, \mathrm{Ca}, \mathrm{Fe}, \mathrm{K}$ e Mg. Porém o elemento $\mathrm{Na}$ apresentou um resultado acima do $\mathrm{F}_{\text {crítico, ou seja, demonstrando que há dispersões nos }}$ pontos na curva analítica, contudo, mesmo com essas dispersões a variável explicada e explicável ficaram dentro do limite aceitável, que é de 100\%, portanto a regressão analítica foi aceita para a quantificação desse elemento.

\subsection{Limite de detecção do Método (LDM) e quantificação do Método (LQM)}

O limite de detecção (LDM) e de quantificação (LQM) do método foi obtido para cada elemento, pois cada um possui uma sensibilidade diferente e foram determinados especificamente para essa metodologia. O LDM é a menor concentração do analito que pode ser detectada com certo limite de confiabilidade. O LQM é a quantidade mínima que um analito é quantificada com um nível aceitável de precisão e exatidão no método desenvolvido. Os valores para o LDM e o LQM estão apresentados na TAB.25.

TABELA 25- Limite de Detecção e Quantificação

\begin{tabular}{ccc}
\hline Elementos & LDM $\left(\mathbf{m g . L}^{-\mathbf{1}}\right)$ & LQM $\left(\mathbf{m g . L}^{-\mathbf{1}}\right)$ \\
\hline $\mathbf{A l}$ & 0,001 & 0,01 \\
$\mathbf{B a}$ & 0,001 & 0,01 \\
$\mathbf{C a}$ & 0,029 & 0,50 \\
$\mathbf{C d}$ & 0,001 & 0,01 \\
$\mathbf{C r}$ & 0,001 & 0,01 \\
$\mathbf{C u}$ & 0,002 & 0,01 \\
$\mathbf{F e}$ & 0,002 & 0,10 \\
$\mathbf{K}$ & 0,012 & 0,45 \\
$\mathbf{M g}$ & 0,003 & 0,02 \\
$\mathbf{M n}$ & 0,001 & 0,01 \\
$\mathbf{N a}$ & 0,068 & 0,42 \\
$\mathbf{N i}$ & 0,001 & 0,01 \\
\hline
\end{tabular}

\subsection{Tendência/Recuperação}


A recuperação foi realizada com adição padrão na matriz. Foi realizado em sete replicatas independes, com $n=10$. A faixa de aceitação foi baseada no método USEPA $6010 \mathrm{C}$, no qual especifica que o limite de recuperação deve ser $\pm 20 \%$, ou seja, entre 80 a $120 \%$ (US ENVIRONMETAL PROTECTION AGENCY, 2007). Para analisar a recuperação do método foi construído gráficos com a média de todos os elementos, apresentados na FIG.33, no qual pôde-se observar que todos os elementos estudados nesse trabalho estão dentro da faixa de aceitação proposta, variando entre 80 a 99\%, ou seja, todos os elementos se encontraram satisfatórios. Contudo foram construídos gráficos com as sete replicatas independentes para cada elemento, para que fosse possível observar as variações em cada replicada. Os dados são apresentados na FIG.34. Os elementos $\mathrm{Al}, \mathrm{Ba}, \mathrm{Cd}, \mathrm{Cr}, \mathrm{Cu}$, $\mathrm{Ni}, \mathrm{Fe}, \mathrm{Mg}, \mathrm{Mn}, \mathrm{Ca}$ e $\mathrm{Na}$ variaram dentro da faixa de aceitação, porém o elemento $\mathrm{K}$ apresentou recuperação de $79 \%$ em três dos sete pontos analisados, a principal causa desse resultado foi o erro na pipetagem da solução-padrão, uma vez que os outros pontos se encontraram dentro da faixa de aceitação.

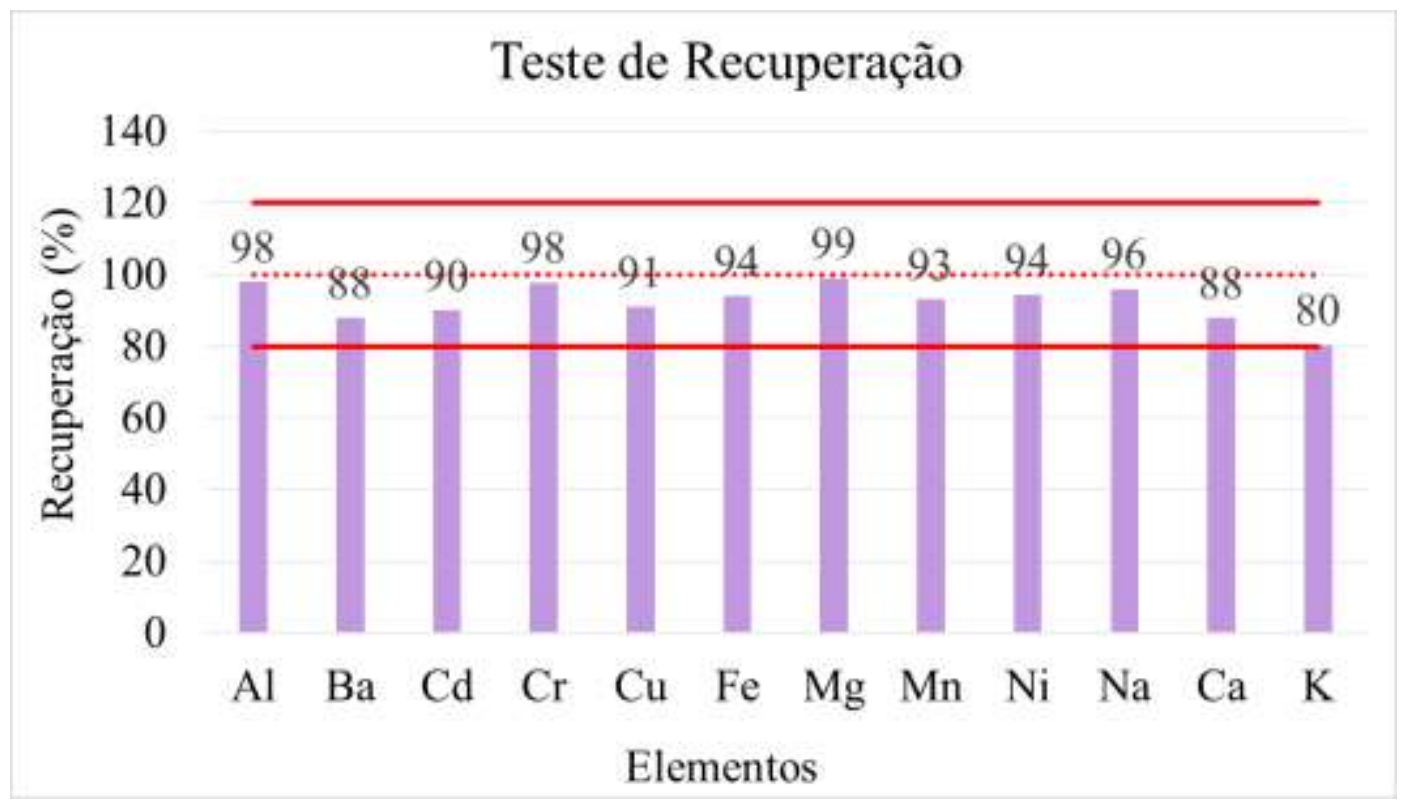

FIGURA 33 - Representação gráfica do teste de recuperação com os dados da média de recuperação de cada elemento para verificar a exatidão do método 

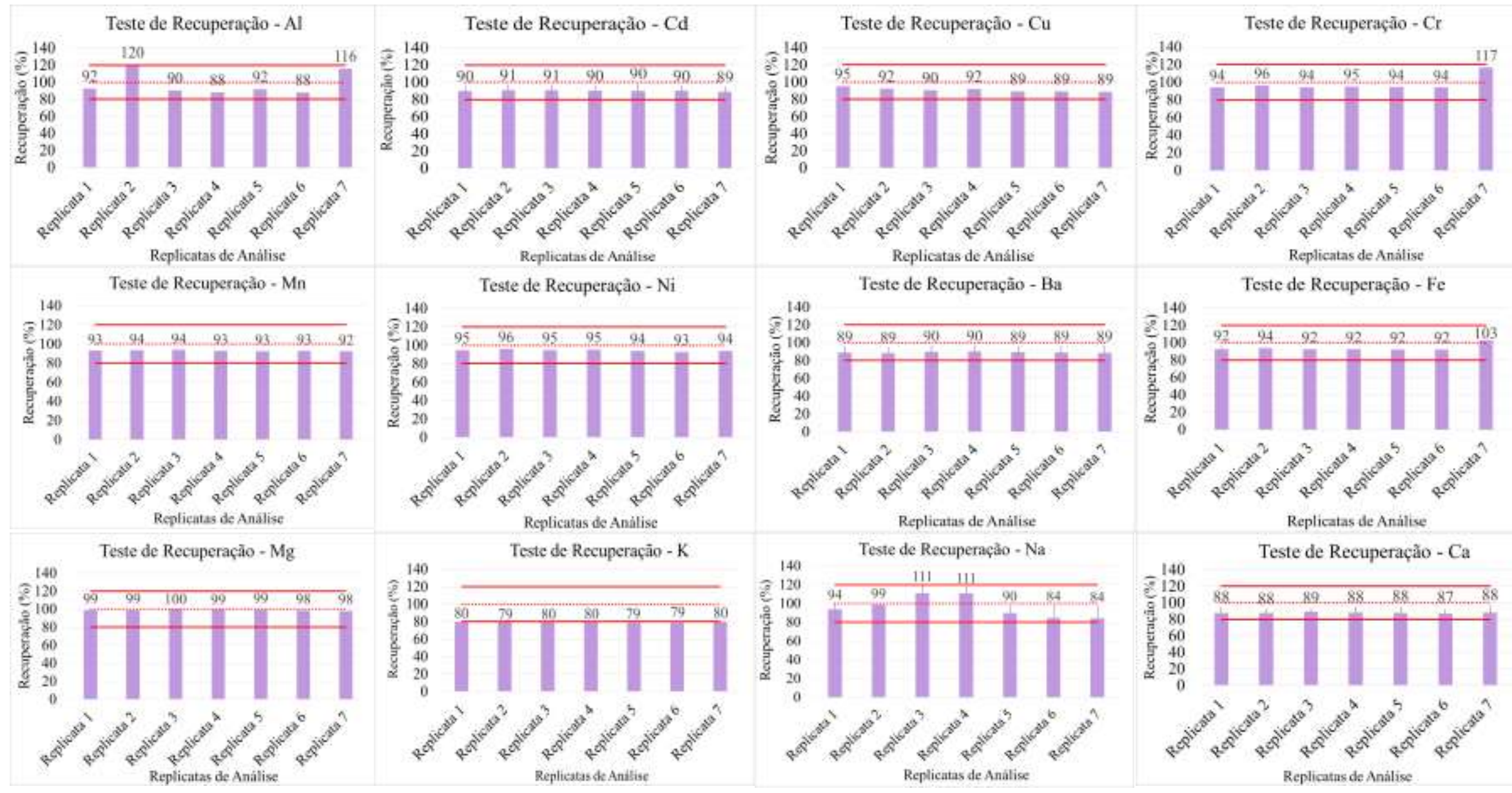

FIGURA 34 - Representação gráfica dos elementos com os dados de recuperação das sete replicatas para verificar a exatidão do método 


\subsection{Precisão}

Para a avaliação da precisão foi realizado o teste de repetitividade. O cálculo de repetitividade foi realizado a partir do cálculo do desvio padrão relativo (DPR\%), no qual para ser considerado satisfatório, segundo o valor de Horwitz, o valor de DPR\% necessita estar abaixo de $16 \%$. Os resultados de repetitividade deram todos satisfatórios para todos os elementos analisados. As análises foram feitas em um dia, com n igual a 10, utilizando as condições exigidas pelo guia do INMETRO (2011). Os resultados são apresentados FIG.35.

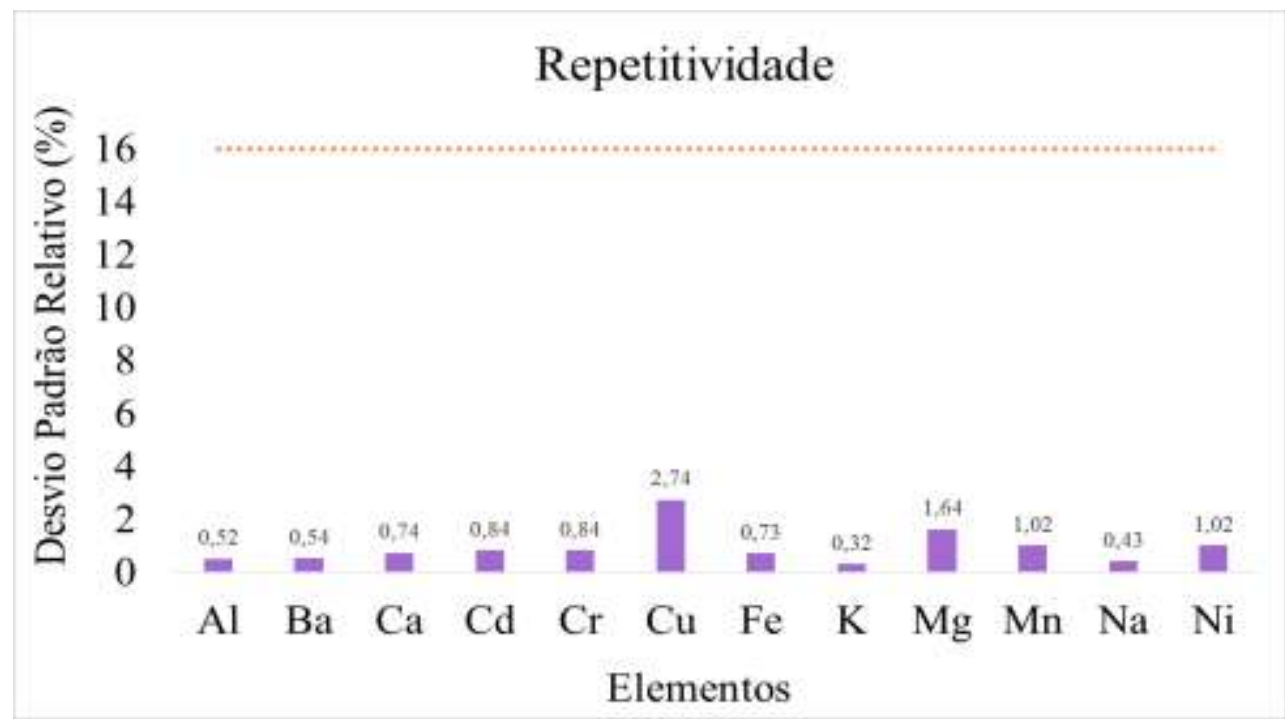

FIGURA 35 - Representação gráfica do cálculo do Desvio Padrão Relativo (DPR\%), para observar a precisão do método, utilizando o teste de repetitividade* $*(. .$.$) Limite do DPR (\%)=16$

\subsection{Robustez}

Para verificar o quanto se o método se comporta através de pequenas variações, como descrito no item 6.7.6, foram realizados teste de robustez para os elementos estudados nesse trabalho. Os resultados mostraram a influência que cada fator tem sobre o método desenvolvido. Foram atribuídos um intervalo de confiança de 95\% para os cálculos estatísticos e foi possível verificar se os efeitos são ou não significativos e se o método é ou não robusto nas condições selecionadas. Para melhor demonstrar os resultados, dos cálculos estatístico, foram elaborados três gráficos, sendo eles o de verificação de significância dos efeitos, apresentado nas FIG.39, os gráficos de probabilidade normal e Rankit, apresentado na FIG.36, FIG.37 e FIG.38. 


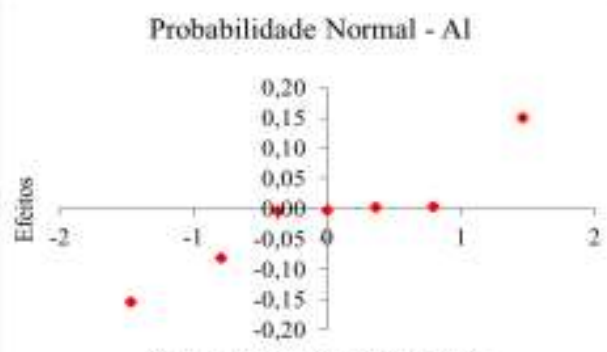

Valores Observados Nomalizados

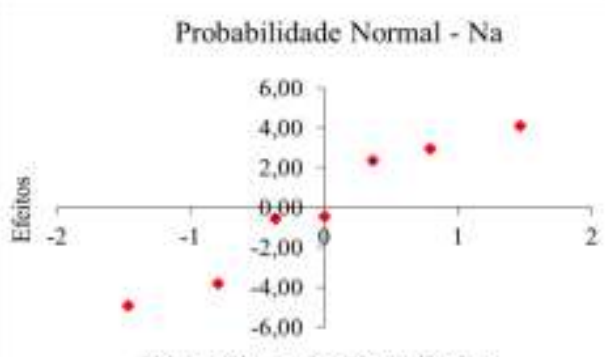

Valeres Observados Normalizados

Probabilidade Nomal - Mg

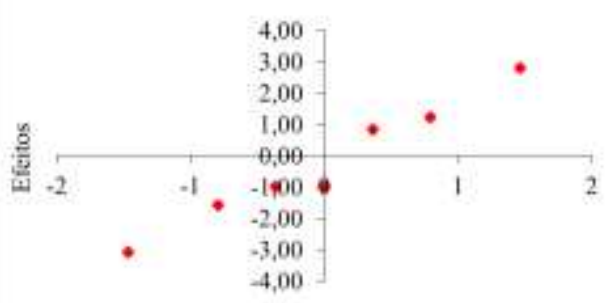

Valores Observados Normalizados

Probabilidade Normal - K

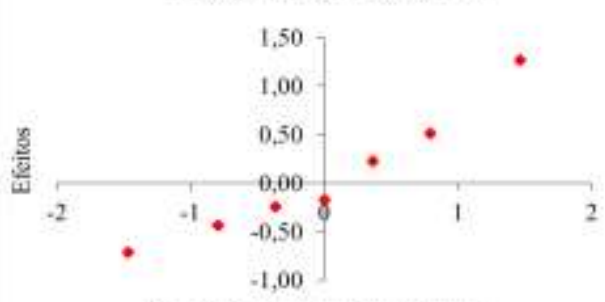

Valores Observados Normalizados

Probabilidade Normal - Cd

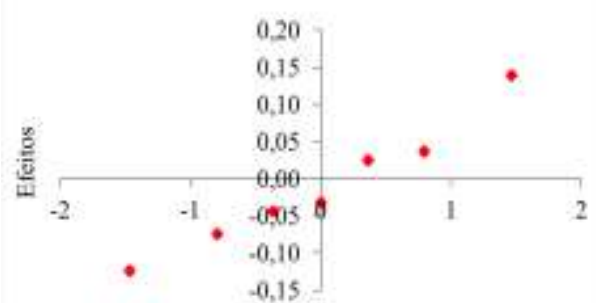

Valores Observados Normulizados
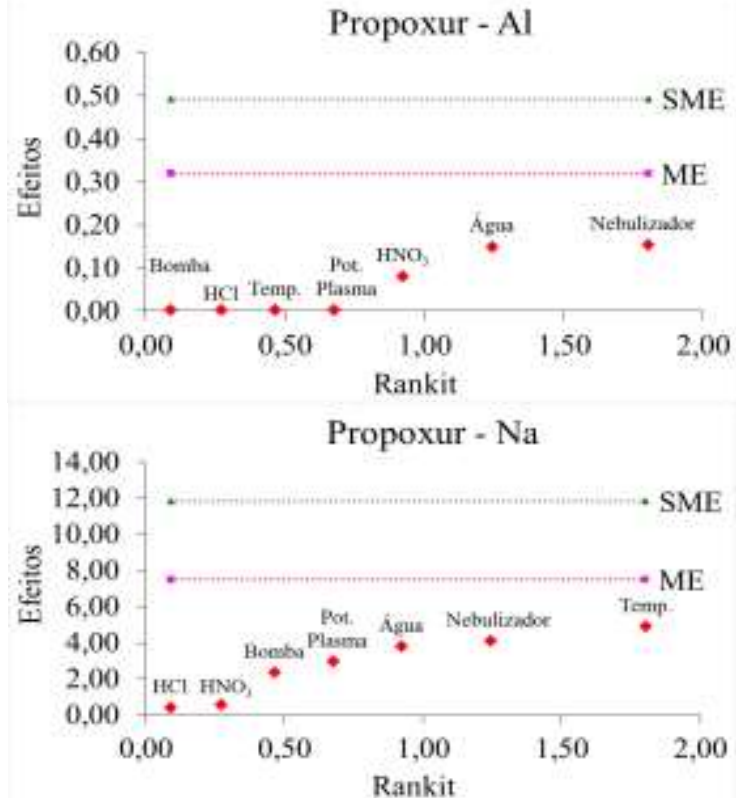

Propoxur - Mg

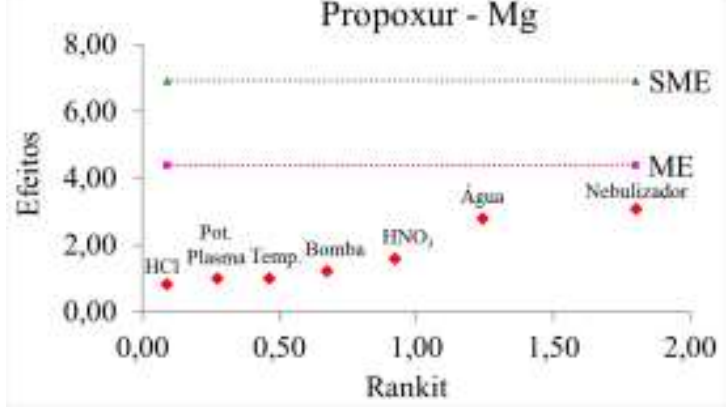

Propoxur - K

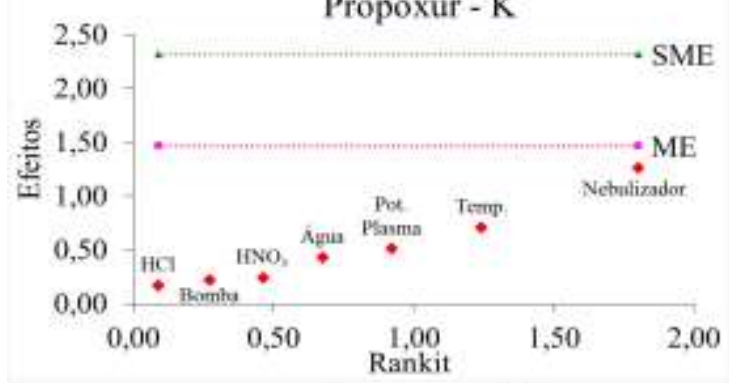

Propoxur - Cd

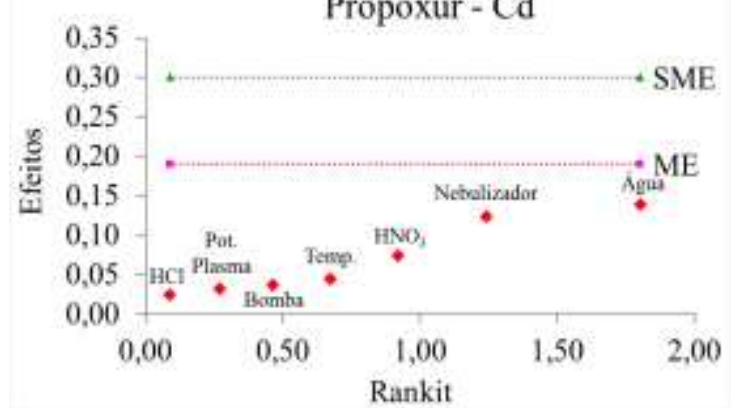

FIGURA 36 - Representação gráfica dos elementos alumínio, sódio, magnésio, potássio e cádmio com os dados de meia normal (Rankit) e probabilidade normal 


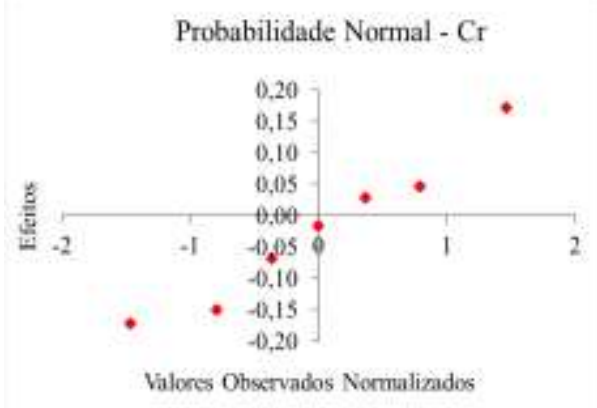

Probabilidade Normal - Mn

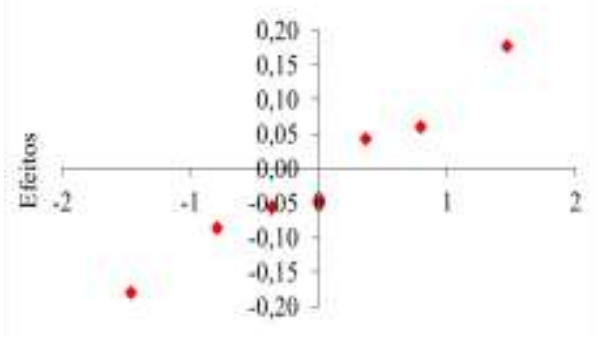

Valores Observados Normalizidos

Probabilidade Normal - Fe

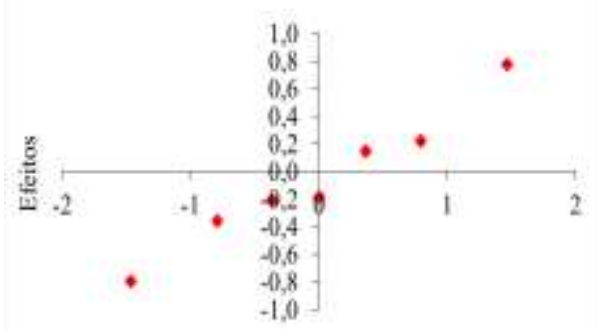

Válores Observados Nurmalizidos

Probabilidade Normal - Ni

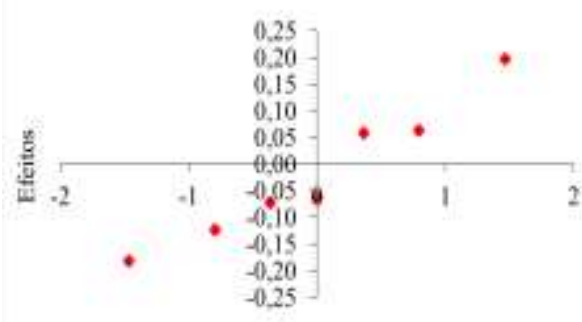

Valores Observados Normalizados

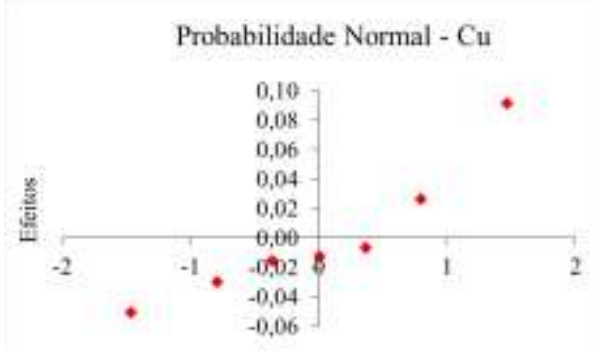

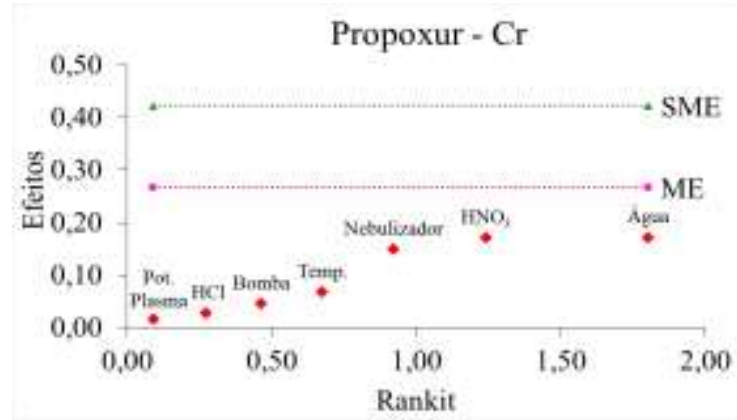
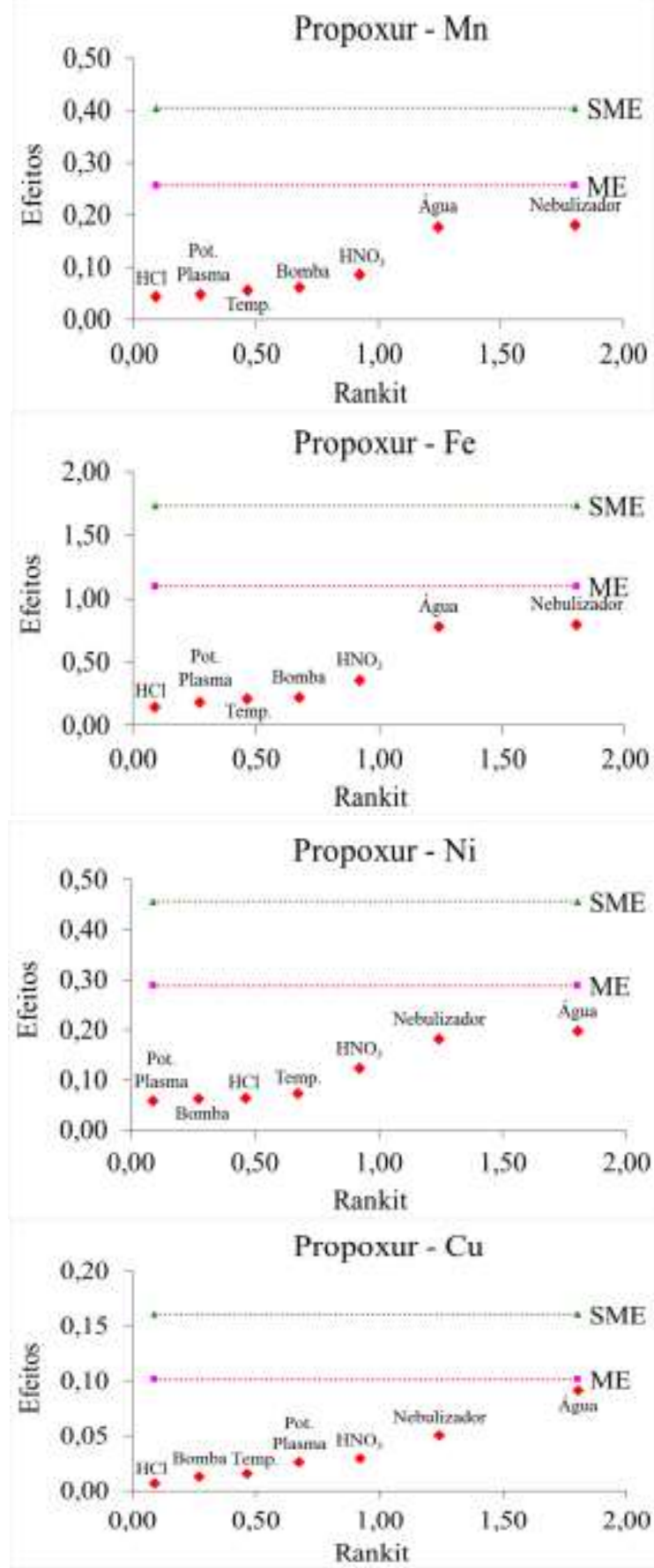

FIGURA 37 - Representação gráfica dos elementos crômio, manganês, ferro, níquel e cobre com os dados de meia normal (Rankit) e probabilidade normal 

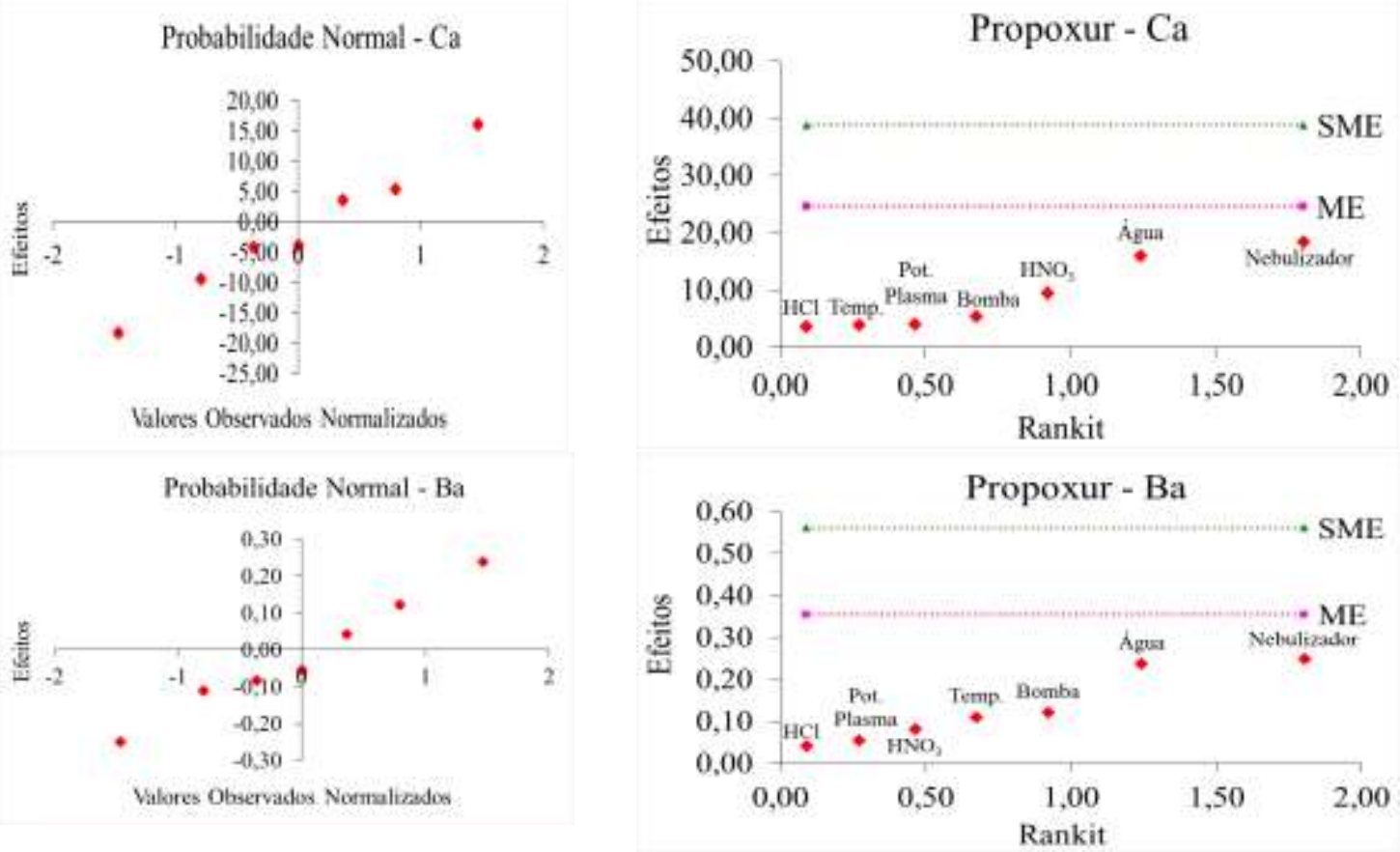

FIGURA 38 - Representação gráfica dos elementos cálcio e bário com os dados de meia normal (Rankit) e probabilidade normal

Na representação gráfica Rankit, apresentado nas FIG.35, FIG.36 e FIG.37, pôde se observar que os parâmetros selecionados não afetam significativamente os resultados, dado que os valores obtidos para todos os elementos se encontram abaixo do limite de Margin of Error (ME) e da Simultaneous Margin of Error (SME). O parâmetro que ultrapassar o ME pode, provavelmente, ter algum efeito sobre o processo. Se o parâmetro ultrapassar o SME, o parâmetro tem evidentemente um efeito sobre o processo. Porém esses dois limites não devem ser necessariamente reajustados.

A representação gráfica da probabilidade normal, apresentada na FIG.35, FIG.36 e FIG.37, demonstra que os valores estão entre \pm 2 , ou seja, distribuídos em \pm dois desvios padrões (2s) com a utilização de um intervalo de confiança de 95\%, significando que não há outliers, isto é, pontos com comportamentos diferentes.

Nas duas primeiras análises, Rankit e probabilidade normal, não demonstraram resultados discrepantes, mostrando que o método é robusto e não há necessidade de alteração desses parâmetros selecionados.

Para melhor observar os efeitos de cada parâmetro analisado, foram construídos gráficos de análise dos efeitos, apresentados na FIG.39 e FIG.40, onde 92\%, 83\%, 58\% e 
25\% dos elementos apresentaram efeitos positivos para as variações nos parâmetros velocidade da bomba, água, volume do ácido clorídrico $(\mathrm{HCl})$ e potência do plasma, respectivamente. Nesse caso, o estudo adotado sugere que os valores nominais desses parâmetros favorecem a análise dos elementos de interesse.

Os parâmetros temperatura, vazão do nebulizador e o volume do ácido nítrico $\left(\mathrm{HNO}_{3}\right)$, apresentaram respectivamente, $92 \%, 83 \%$ e $100 \%$, dos elementos com efeitos negativos, esse comportamento diante da mudança do valor nominal indica um favorecimento na determinação desses elementos em relação a alteração.

Após a análise dos efeitos, positivos e negativos, não foi necessário a mudança de nenhum parâmetro nominal pela variação, pois como já citado, as duas primeiras análises referentes a robustez não apresentaram qualquer alteração no método, porém é preciso sempre verificar a qualidade da água que está sendo utilizada para o preparo dos padrões de análise, a velocidade da bomba e o $\mathrm{HCl}$ adicionado na digestão ácida, que apresentaram valores altos nos efeitos positivos.

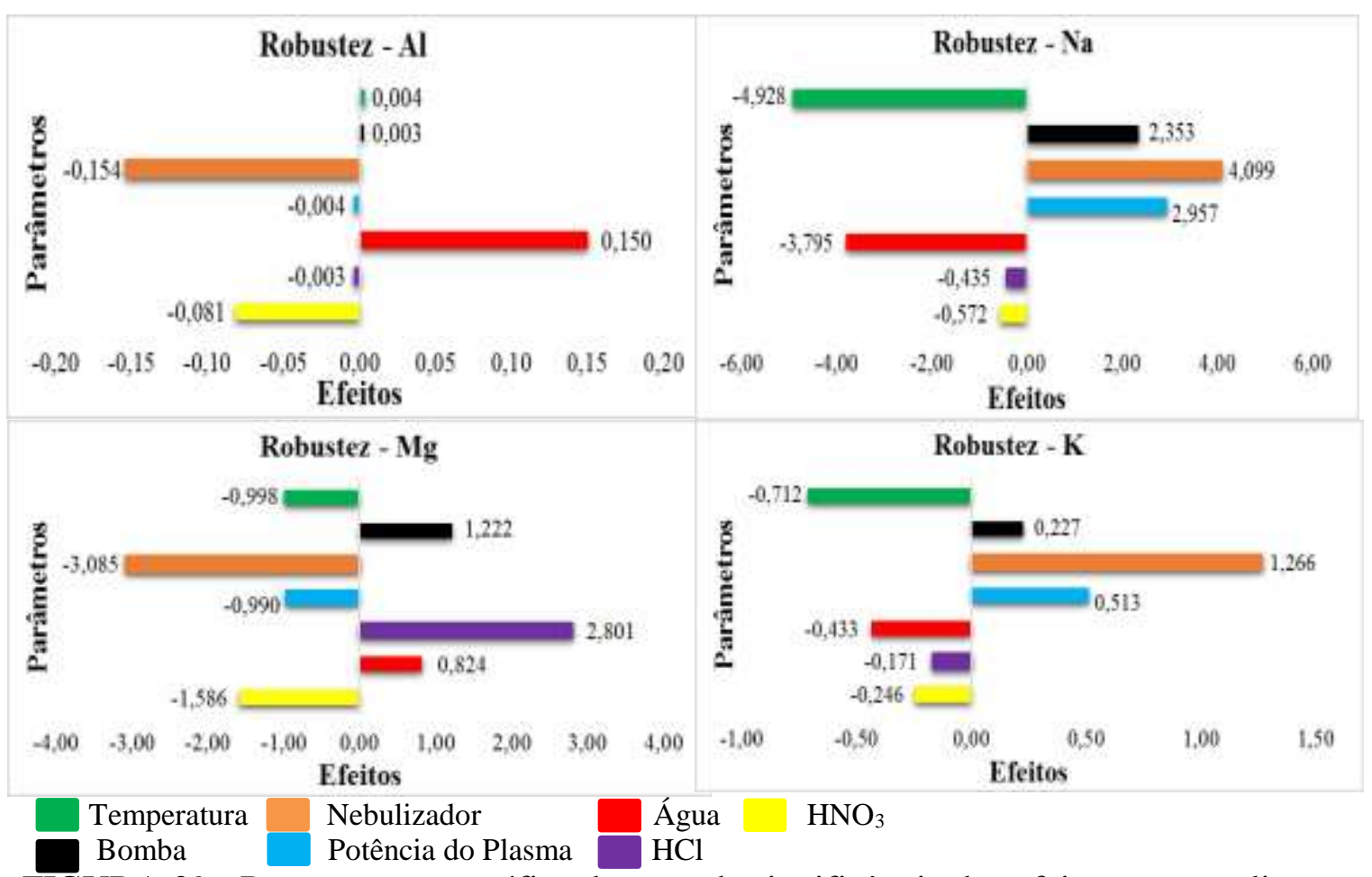

FIGURA 39 - Representação gráfica do teste de significância dos efeitos para avaliar o comportamento dos elementos alumínio, sódio, magnésio e potássio no ensaio de robustez 


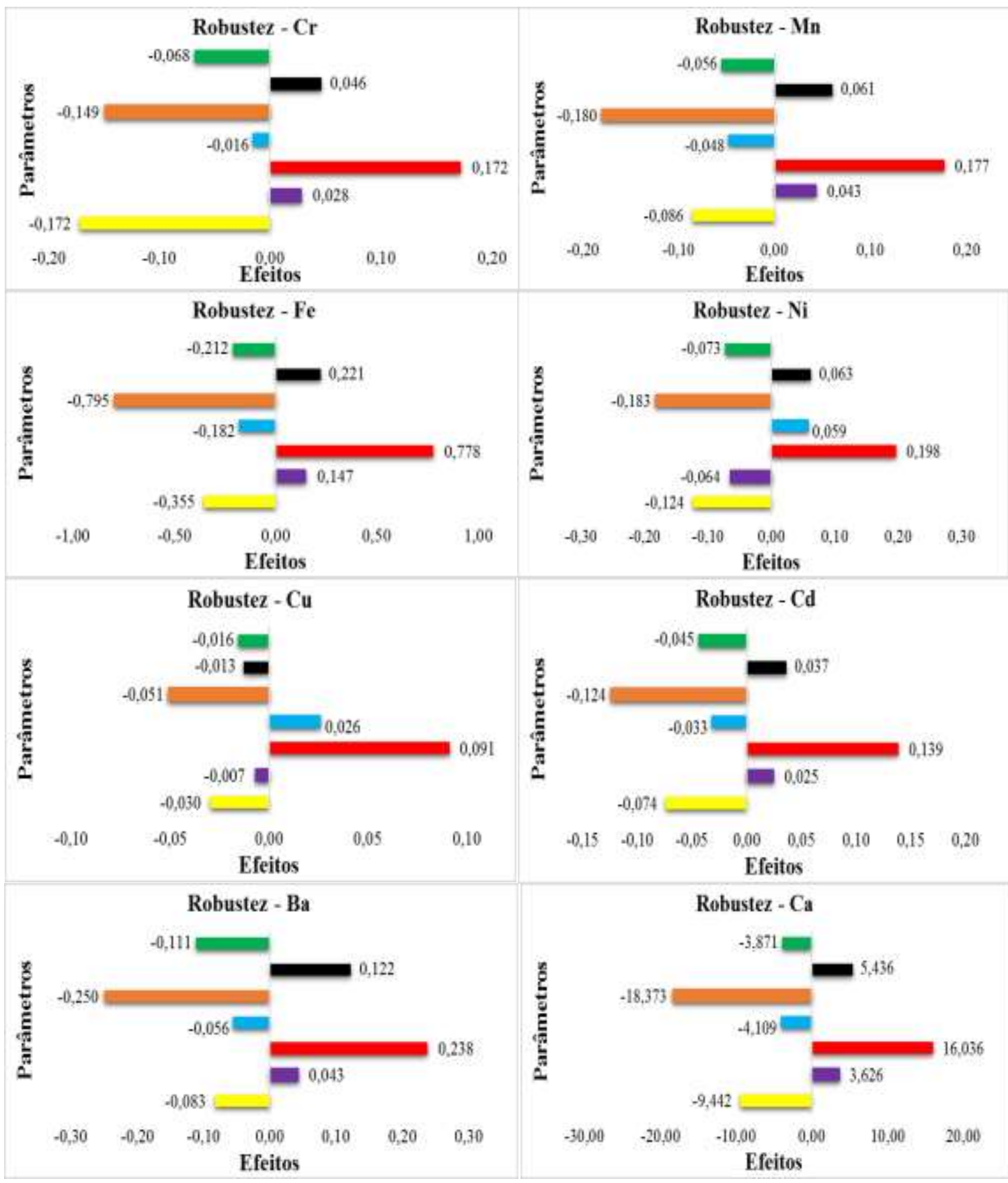

Legenda:

\begin{tabular}{lllll} 
Temperatura & $\begin{array}{l}\text { Nebulizador } \\
\text { Bomba }\end{array}$ & Potência do Plasma & $\mathrm{HNO}_{3}$ \\
\cline { 2 - 3 } & & $\mathrm{HCl}$ &
\end{tabular}

FIGURA 40 - Representação gráfica do teste de significância dos efeitos para avaliar o comportamento dos elementos crômio, manganês, ferro, níquel, cobre, cádmio, bário e cálcio no ensaio de robustez

\subsection{Estimativa de incerteza de medição}

A incerteza de medição realizada somente para os elementos quantificados e foi calculado conforme descrita no item 6.7.7, deste trabalho. 
Na TAB.27 estão apresentados a incerteza combinada $(\mu)$, calculada pela equação (30), e a incerteza expandida (U), calculada pela equação (31), além da incerteza de cada fonte dividido pela grandeza utilizada nos 12 elementos estudos nesse trabalho.

A grandeza utilizada no volume final da amostra, após da digestão, foi de $50 \mathrm{~mL}$ para todos os elementos; O resultado da média de recuperação, em porcentagem, foi obtido a partir dos testes de recuperação realizada nesse trabalho, apresentado no item 7.4; e a concentração utilizada foi da concentração média da curva analítica, o ponto P3. Os dados estão apresentados na TAB.26.

TABELA 26 - Grandeza utilizada na recuperação, na concentração da curva analítica e no volume final de amostra para a estimativa de incerteza de medição.

\begin{tabular}{cccc} 
& \multicolumn{3}{c}{ Grandeza } \\
\cline { 2 - 4 } Elementos & $\overline{R e c}(\%)$ & $\mathrm{C}_{\mathrm{o}}\left(\mathrm{mg} \cdot \mathrm{L}^{-1}\right)$ & $\mathrm{V}_{\mathrm{f}}(\mathrm{mL})$ \\
$\mathbf{C d}$ & 98 & 0,01 & 50 \\
$\mathbf{C r}$ & 98 & 0,09 & 50 \\
$\mathbf{C u}$ & 98 & 0,09 & 50 \\
$\mathbf{M n}$ & 93 & 0,09 & 50 \\
$\mathbf{N i}$ & 95 & 0,09 & 50 \\
$\mathbf{F e}$ & 94 & 0,92 & 50 \\
$\mathbf{B a}$ & 88 & 0,89 & 50 \\
$\mathbf{M g}$ & 99 & 0,99 & 50 \\
$\mathbf{C a}$ & 88 & 4,40 & 50 \\
$\mathbf{N a}$ & 96 & 4,80 & 50 \\
$\mathbf{K}$ & 80 & 4,40 & 50
\end{tabular}


TABELA 27 - Resultados do cálculo de estimativa de incerteza de medição para os 12 elementos avaliados

\begin{tabular}{|c|c|c|c|c|c|c|c|c|}
\hline \multirow{2}{*}{ Elementos } & \multicolumn{5}{|c|}{ Fontes de Incerteza } & \multirow{2}{*}{$\begin{array}{c}\mu \text { combinada } \\
\left(\mathrm{mg} \cdot \mathrm{L}^{-1}\right)\end{array}$} & \multicolumn{2}{|c|}{ Incerteza Expandida } \\
\hline & $\boldsymbol{\mu}\left(\mathbf{V}_{\mathbf{f}}\right)$ & $\mu\left(\mathbf{C}_{\mathbf{P C}}\right)$ & $\boldsymbol{\mu}\left(\mathbf{C}_{\mathbf{0}}\right)$ & $\mu(\operatorname{Rep})$ & $\mu(\operatorname{Rec})$ & & $\mathbf{U}\left(\mathbf{m g} . \mathbf{L}^{-1}\right)$ & $\mathrm{U}(\%)$ \\
\hline Al & 0,0012 & 0,014 & 0,027 & 0,00017 & 0,053 & 0,006 & $\pm 0,012$ & 12 \\
\hline Cd & 0,0012 & 0,014 & 0,022 & 0,00013 & 0,0029 & 0,002 & $\pm 0,005$ & 5 \\
\hline $\mathrm{Cr}$ & 0,0012 & 0,014 & 0,011 & 0,00013 & 0,00032 & 0,002 & $\pm 0,003$ & 4 \\
\hline $\mathbf{C u}$ & 0,0012 & 0,014 & 0,062 & 0,00043 & 0,010 & 0,006 & $\pm 0,012$ & 13 \\
\hline Mn & 0,0012 & 0,014 & 0,014 & 0,00016 & 0,0028 & 0,002 & $\pm 0,004$ & 4 \\
\hline $\mathbf{N i}$ & 0,0012 & 0,014 & 0,013 & 0,00016 & 0,0039 & 0,002 & $\pm 0,004$ & 4 \\
\hline $\mathbf{F e}$ & 0,0012 & 0,013 & 0,010 & 0,0012 & 0,017 & 0,022 & $\pm 0,043$ & 5 \\
\hline $\mathbf{B a}$ & 0,0012 & 0,00050 & 0,017 & 0,00015 & 0,0021 & 0,01 & $\pm 0,03$ & 3 \\
\hline Mg & 0,0012 & 0,013 & 0,036 & 0,0026 & 0,0026 & 0,038 & $\pm 0,076$ & 8 \\
\hline $\mathbf{C a}$ & 0,0012 & 0,00047 & 0,012 & 0,0012 & 0,0025 & 0,06 & $\pm 0,11$ & 3 \\
\hline $\mathbf{N a}$ & 0,0012 & 0,00051 & 0,086 & 0,00081 & 0,045 & 0,439 & $\pm 0,879$ & 18 \\
\hline $\mathbf{K}$ & 0,0012 & 0,00047 & 0,074 & 0,00054 & 0,0025 & 0,328 & $\pm 0,655$ & 15 \\
\hline
\end{tabular}


As contribuições das grandezas de entrada utilizadas foram: o volume final utilizado na digestão ácida da amostra $\left(\mathrm{V}_{\mathrm{f}}\right)$; concentração do preparo da curva analítica $\left(\mathrm{C}_{\mathrm{PC}}\right)$; concentração dos elementos na amostra analisada $\left(\mathrm{C}_{0}\right)$; a repetitividade do método (Rep); e a recuperação do método (Rec), as quais foram calculadas pelas equações (22), (26), (27), (28) e (29).

Utilizando um intervalo de confiança de 95\%, para o cálculo da incerteza expandida, foi utilizado um fator de abrangência k igual a 2 . A incerteza expandida estimada variou entre 3 e $18 \%$ da concentração encontrada. Esse valor de $18 \%$ encontrado no elemento sódio está associado a curva analítica, a qual possui uma alta concentração afetando a incerteza de medição.

As contribuições da incerteza combinada utilizada para o cálculo da incerteza expandida estão apresentadas nas FIG.41 e FIG.42 para cada elemento.

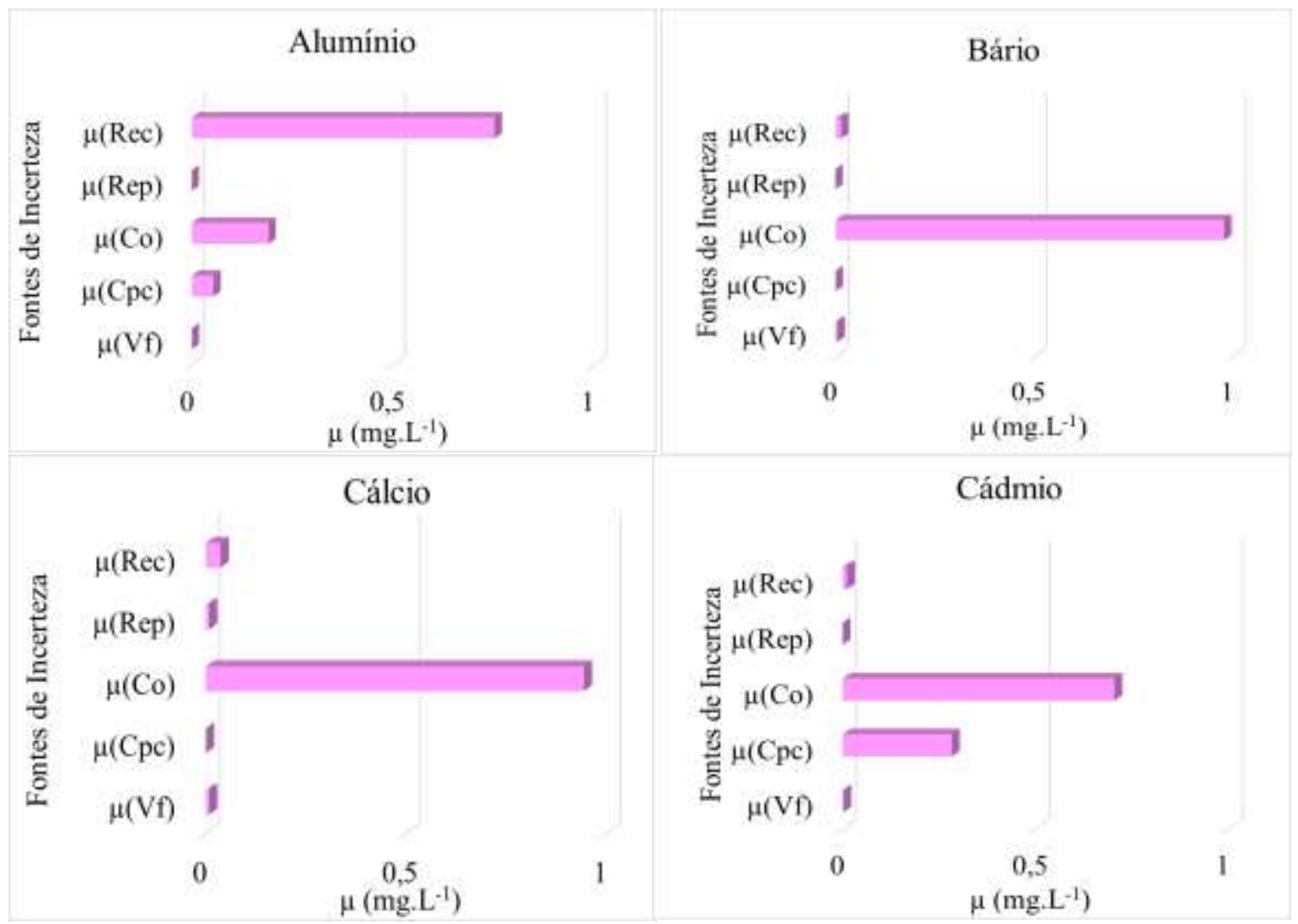

FIGURA 41 - Contribuição de cada fonte na estimativa da incerteza combinada para os elementos alumínio, bário, cálcio e cádmio 


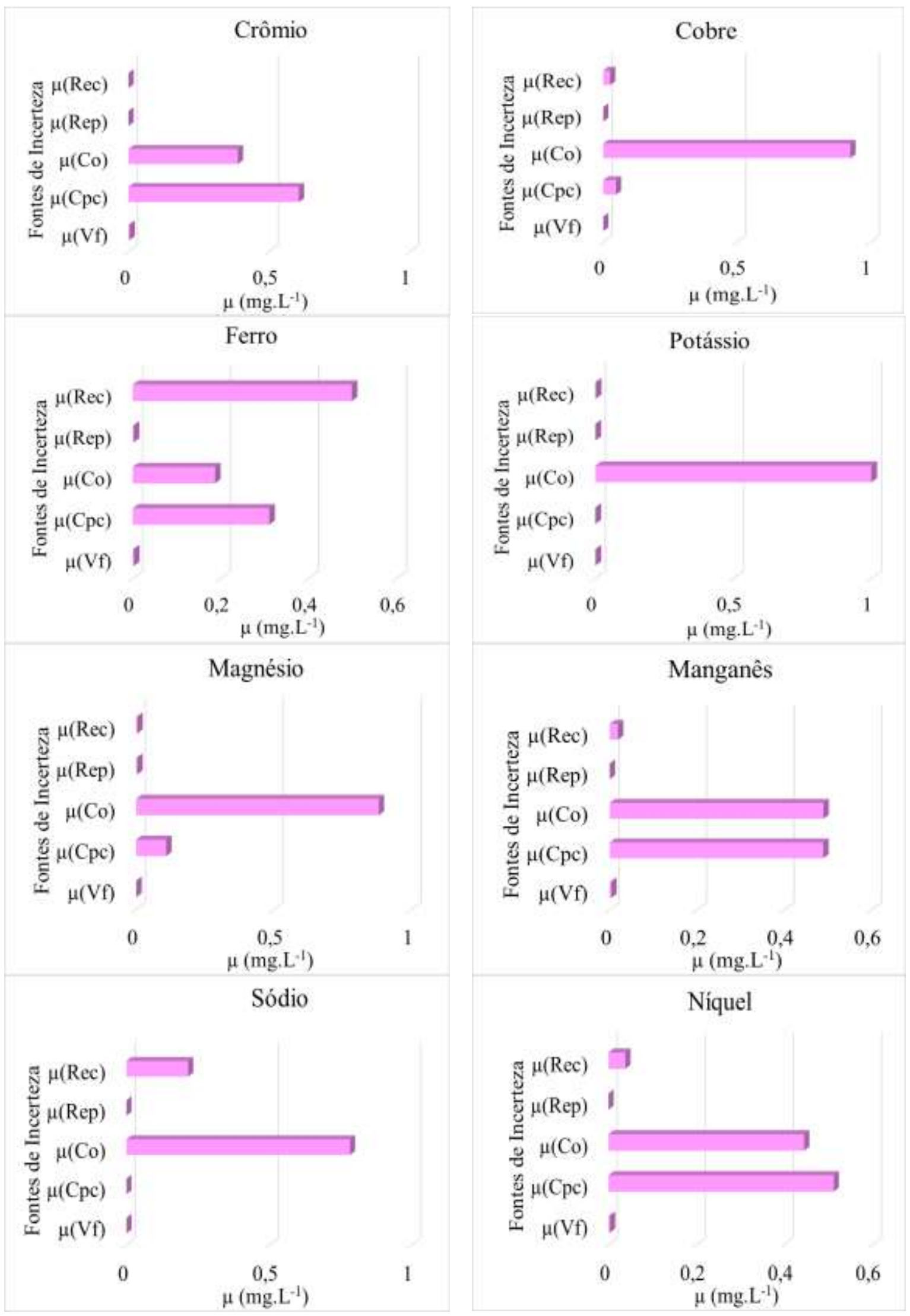

FIGURA 42 - Contribuição de cada fonte na estimativa da incerteza combinada para os elementos crômio, cobre, ferro, potássio, magnésio, manganês, sódio e níquel 
Analisando as FIG.40 e FIG.41, com exceção do Cr, os elementos Al, Ba, Ca, $\mathrm{Cd}, \mathrm{Cu}, \mathrm{Fe}, \mathrm{K}, \mathrm{Mg}, \mathrm{Mn}, \mathrm{Na}$ e Ni apresentaram valores de contribuições altas na incerteza associada a curva analítica $\mu\left(\mathrm{C}_{0}\right)$, pois estão relacionadas a concentração do elemento e a resposta do equipamento.

Alguns elementos, tais como $\mathrm{Na}, \mathrm{Ni}, \mathrm{Fe}$ e $\mathrm{Al}$ apresentaram valores altos na incerteza associada a recuperação $\mu(\operatorname{Rec})$, pois igual a curva analítica está relacionada a concentração elemento na amostra analisada e podem ter variações na concentração.

\subsection{Resultados dos metais na Represa Guarapiranga}

Com uma única coleta realizada nos dias 07 e 09 de outubro de 2014, as amostras de água da Represa Guarapiranga foram analisadas pelo método desenvolvido e validado.

Os resultados obtidos para os elementos sódio, cálcio, potássio e magnésio demonstraram presença predominante em todos os pontos coletados. Um dos motivos podem ser a característica da geológica da área, além disso, esses elementos tem alta predominância na crosta terrestre, como discutido nos itens 4.2.9, 4.2.10, 4.2.11 e 4.2.12. Os resultados com os valores estão apresentados na FIG.43.

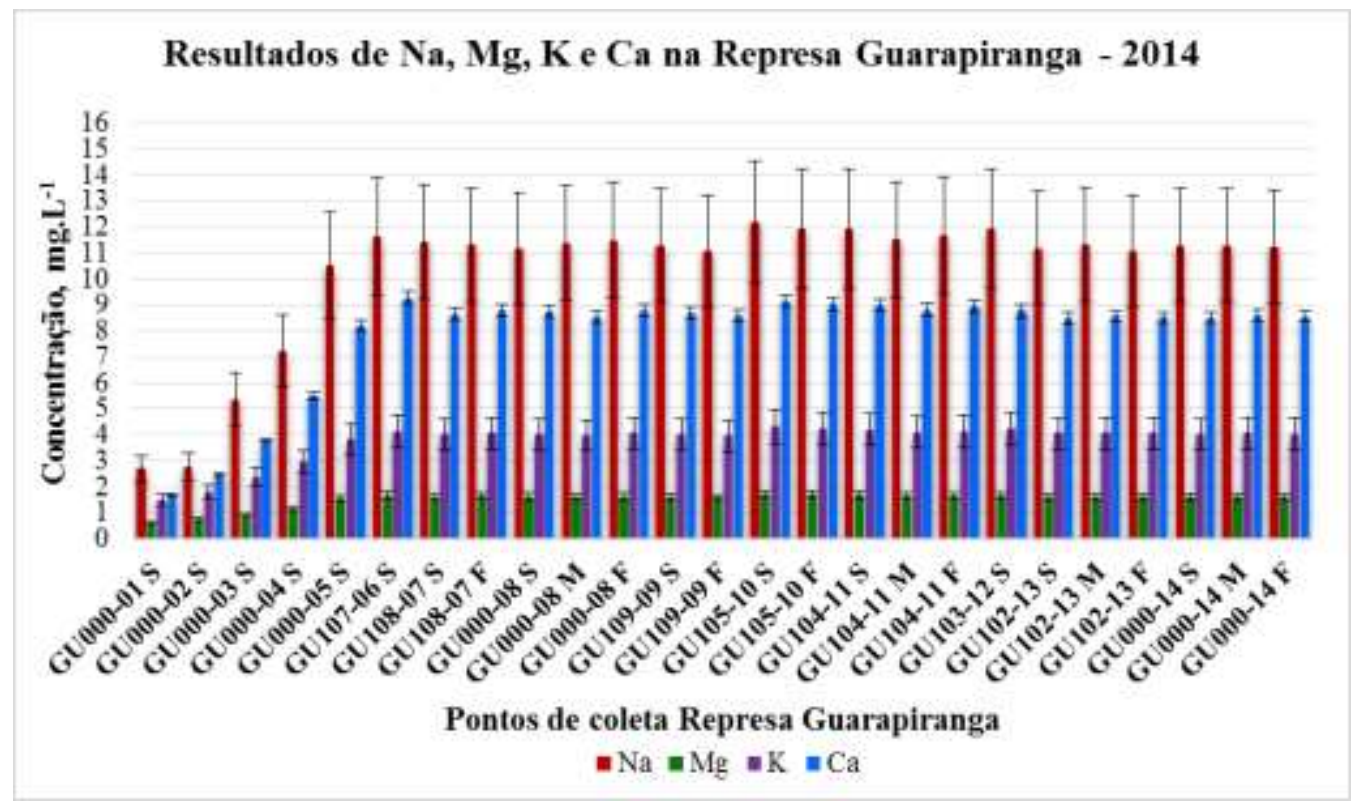

FIGURA 43 - Resultados de $\mathrm{Na}, \mathrm{Mg}, \mathrm{K}$ e Ca nas amostras de água, nas profundidades subsuperficie (S), zona média (M) e $1 \mathrm{~m}$ acima do fundo (F) na Represa Guarapiranga, nos dias 07 e 09 de outubro de 2014, com suas respectivas incertezas de medição. 
Os elementos alumínio e ferro apresentaram concentrações acima do permitido, pela Resolução Conama n³57/2005. O alumínio nos pontos GU000-01 (2346’49.6” S4647'22”0W), GU000-02 (2345'29.5”S-4646'18.7’W), GU000-03 (2344'52.2”S4646'13.6”W), GU103-12 (2341'88.5”S-4644'67.3”W) e GU000-14 (2340'78.2”S4643'55.0”W); e o ferro nos pontos GU000-01 (2346’49.6” S-4647'22”0W), GU000-02 $\left(23^{\circ} 45^{\prime} 29.5^{\prime \prime S}-46^{\circ} 46^{\prime} 18.7^{\prime \prime W}\right)$ e GU000-03 (2344'52.2”S-4646'13.6”W). Na FIG. 44 estão apresentados os valores de alumínio e ferro encontrados nas amostras de água da Represa Guarapiranga.

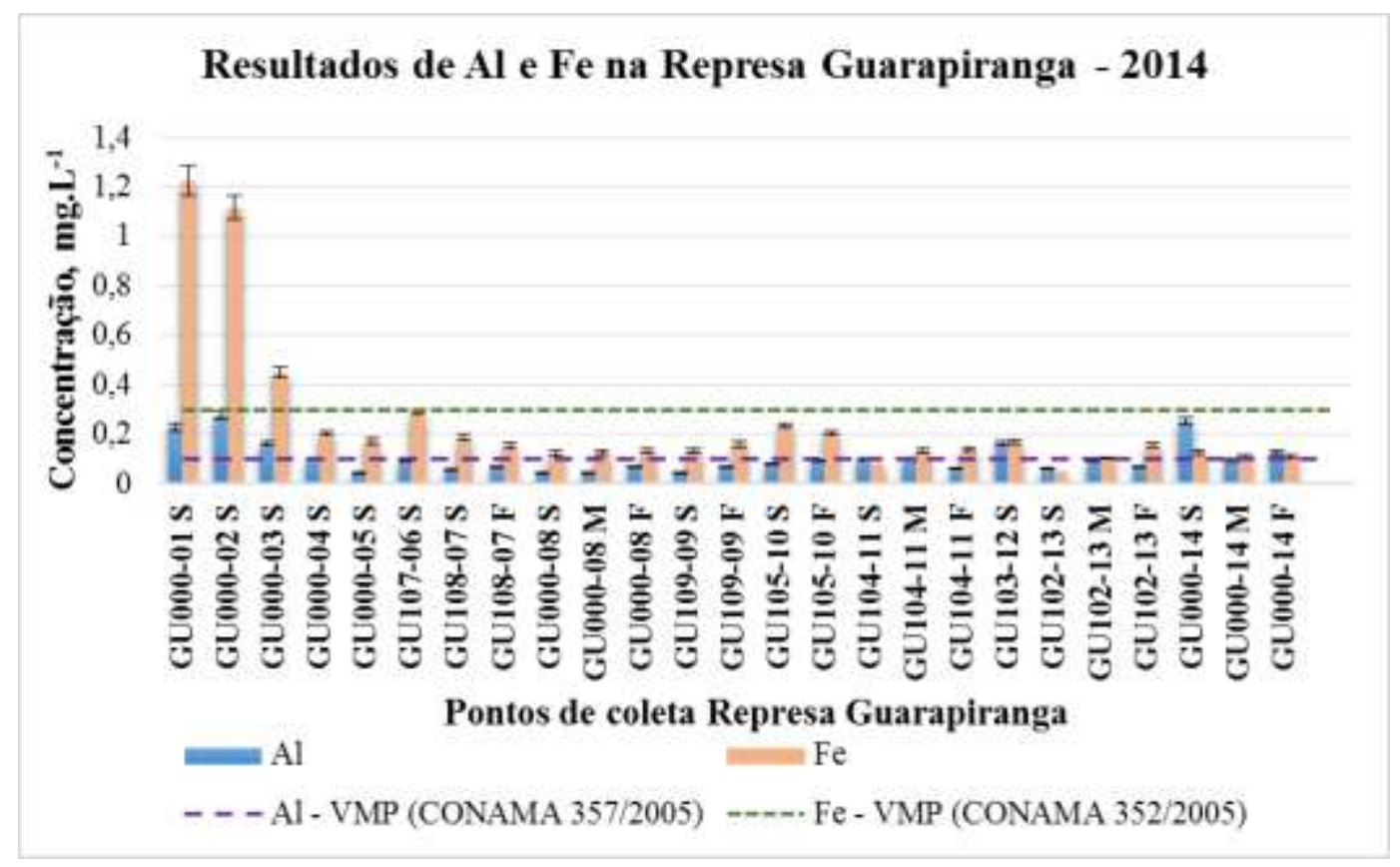

FIGURA 44 - Resultados de Al e Fe em água, nos pontos coletados, nas profundidades subsuperficie (S), zona média (M) e $1 \mathrm{~m}$ acima do fundo (F), da Represa Guarapiranga, nos dia 07 e 09 de outubro de 2014, com os VMP (Valores Máximos permitidos) pela Resolução CONAMA 357/2005 e suas respectivas incertezas de medição.

O motivo da presença elevada de concentração de alumínio pode estar associado a característica geológica da área, por ser o elemento mais abundante da crosta terrestres; a sua utilização na forma de sulfato de alumínio utilizado no tratamento de água da SABESP; e pelo nível de $\mathrm{pH}$ encontrado nesses pontos. O pH encontrado no ponto GU000-01 e GU000-02, apresentaram valores de 6,84 e 6,90, respectivamente, e como mencionado no item 4.2.1, o pH da água entre 5,5 - 6,0 pode contribuir para diminuição na solubilidade do alumínio. Já os pontos GU000-03, GU103-12 e GU000-14 apresentaram pH 8,62, 9,69 e 9,54 9 (média das três profundidades coletadas no ponto GU000-14), respectivamente. 
Devido a essa alcalinidade, o sulfato de alumínio, usando no tratamento de água, em contato com a água pode levar a formação de hidróxido de alumínio, e desta forma pode estar relacionado a sua presença nesses três pontos. $\mathrm{O}$ elemento ferro encontrado pode estar relacionado com a característica geológica da área; além de estar presente no coagulante utilizado em tratamento de água de abastecimento público, como mencionado no item 4.2.6; e pela a razão ferro:fósforo na represa, como discutido no item 3.2.

O elemento cobre está presente em todos os pontos da represa Guarapiranga, porém acima do VMP (Valor Máximo Permitido) pela Resolução CONAMA 357/2005, somente nos pontos, GU000-05 (2344'57.5”S-4645’24.2”W), GU107-06 (2345'01.2”S4643'61.5”W), GU108-07 (2343'64.7'S-4643'42.3”W), GU000-08 (2342'96.9”S4643'61.2”W), GU109-09 (2343'04.6”S-4643'34.0”W), GU105-10 (2342'89.9”S4644'68.7'W), GU108-11 (2342'53.4”S-4643'44.9'W), GU103-12 (2341'88.5”S4644'67.3”W), GU102-13 (2341'58.0”S-4643'57.3”W) e GU000-14 (2340'78.2”S46³3'55.0”'W). Esses valores estão associados a adição de sulfato de cobre na captação da Represa para o combate de blooms de algas na represa. Os valores estão apresentados na FIG. 45.

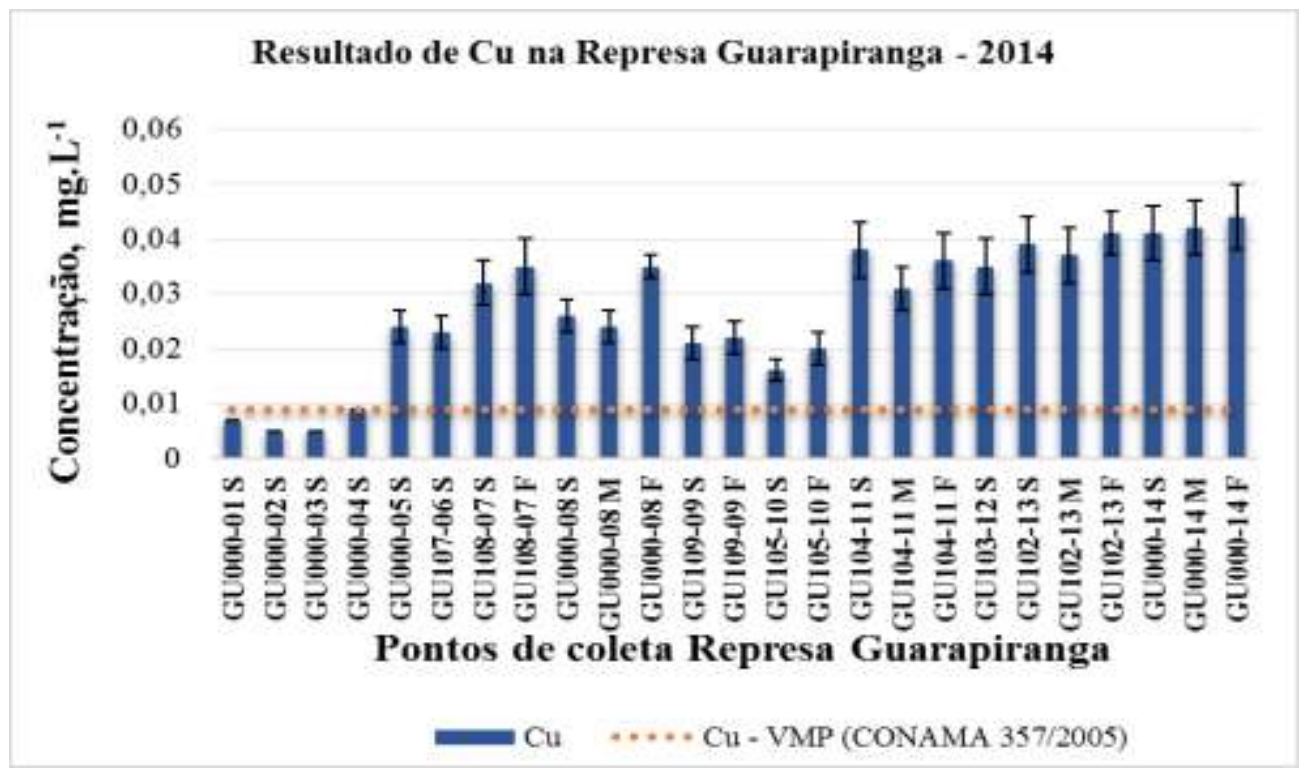

FIGURA 45 - Resultado de $\mathrm{Cu}$ em água, nos pontos coletados, nas profundidades subsuperficie (S), zona média (M) e $1 \mathrm{~m}$ acima do fundo (F) da Represa Guarapiranga, nos dia 07 e 09 de outubro de 2014, com os VMP (Valores Máximos permitidos) pela Resolução CONAMA 357/2005 e suas respectivas incertezas de medição. 
Os demais elementos estudos nesse trabalho, como cádmio, crômio, bário, manganês e níquel obtiveram concentrações baixas e todos abaixo da Resolução CONAMA $357 / 2005$.

No APÊNDICE B estão apresentados os valores de concentração dos 12 elementos estudos nesse trabalho, nos 14 pontos de coleta da represa Guarapiranga, com a estimativa de incerteza de medição calculada.

Uma análise das três profundidades, coletadas, de cada ponto também foi realizado. Os pontos que tiveram mais de uma profundidade coletada foram os pontos: GU108-07 (2343'64.7’S-4643'42.3”W), GU000-08 (2342'96.9”S-4643'61.2”W), GU109-09 (2343'04.6”S-4643'34.0”W), GU105-10 (2342'89.9'S-4644'68.7'W), GU108-11 (2342'53.4”S-4643'44.9”W), GU102-13 (2341'58.0”S-4643'57.3”W) e GU000-14 (2340'78.2”S-4643'55.0”W). Os elementos que apresentaram concentrações maiores que o LD e LQ foram agrupados por concentração para a melhor visualização de cada ponto analisado.

Os elementos $\mathrm{Na}, \mathrm{Mg}, \mathrm{K}$ e Ca, apresentaram concentrações acima de $1 \mathrm{mg} . \mathrm{L}^{-1}$, nas três profundidades coletadas. Analisando a FIG. 46, pôde-se observar que, com exceção do elemento $\mathrm{Na}$, os elementos Mg, K e Ca, nos pontos GU000-14, GU102-13, GU104-11 e GU000-08, os quais foram coletados todas as profundidades, os elementos na profundidade sub-superfície (S), zona média (M) e $1 \mathrm{~m}$ acima do fundo $(\mathrm{F})$ possuem características muito semelhantes, mostrando uma homogeneidade nesses pontos. $\mathrm{O}$ elemento $\mathrm{Na}$, por estar em abundância na crosta terrestre, possui maiores concentrações e algumas variações entre as profundidades. 


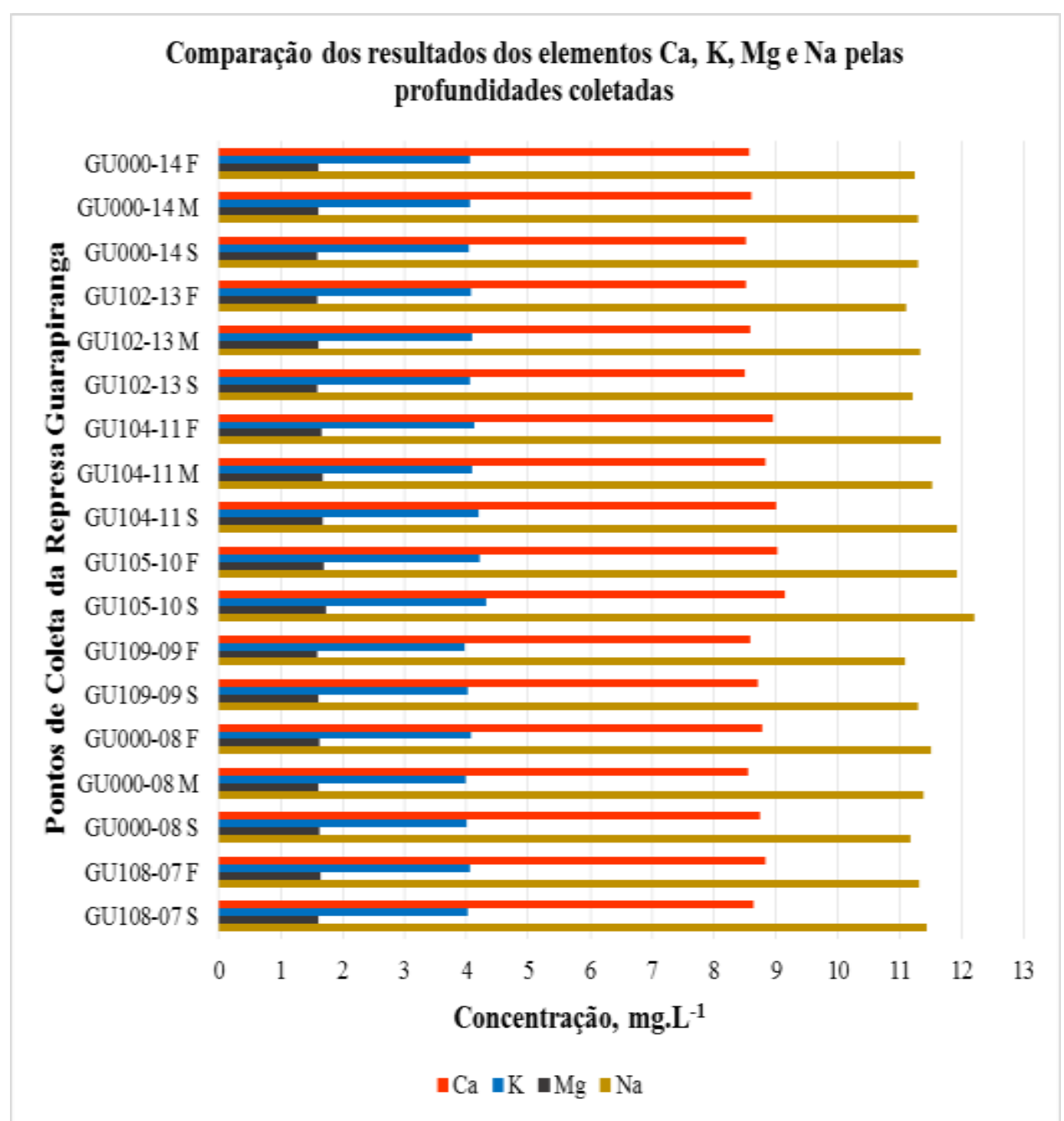

FIGURA 46 - Comparação dos resultados em função das profundidades coletadas - elementos $\mathrm{Ca}, \mathrm{K}, \mathrm{Mg}$ e $\mathrm{Na}$. 
$\mathrm{O}$ elemento $\mathrm{Ba}$ apresentou homogeneidade entre as três profundidades, nos pontos GU000-14, GU102-13, GU104-11 e GU000-08, além dos pontos que tiveram coletas na sub superfície e $1 \mathrm{~m}$ acima do fundo. $\mathrm{O}$ elemento $\mathrm{Cu}$ apresentou variações entre os pontos e nas profundidades analisadas, devido a seu uso, na forma de sulfato de cobre, na Represa Guarapiranga. O elemento Mn apresentou concentrações mais altas na profundidade $1 \mathrm{~m}$ acima do fundo, podendo estar associado ao sedimento de fundo que pode ter se deslocado para a água. Os dados estão apresentados na FIG. 47.

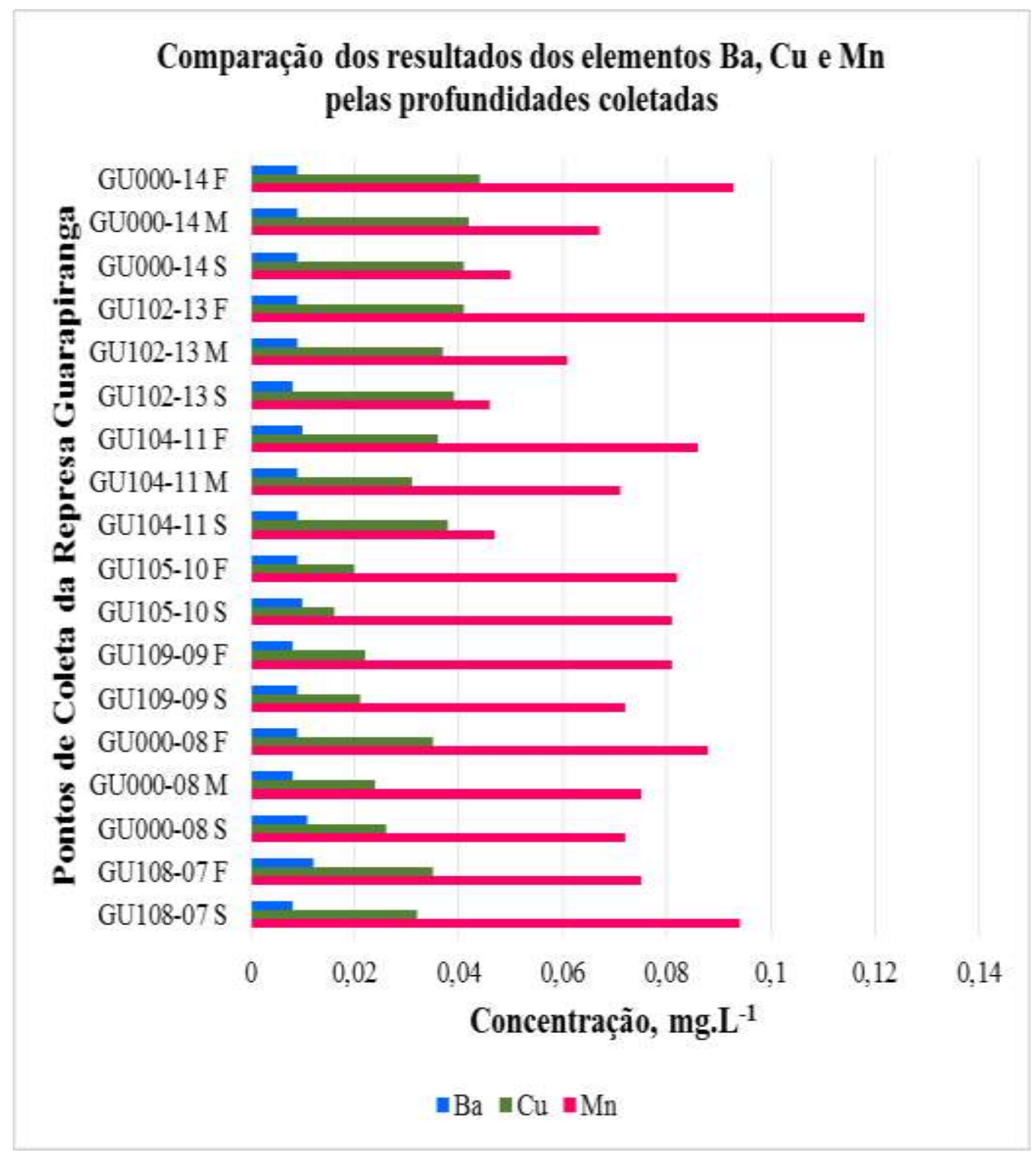

FIGURA 47 - Comparação dos resultados em função das profundidades coletadas - elementos Ba, Cu e Mn. 
O elemento $\mathrm{Fe}$, quando coletado nas profundidades na zona média e 1 $\mathrm{m}$ acima do fundo apresentou homogeneidade nos pontos GU000-14, GU102-13, GU104-11 e GU000-08. O elemento Al apresentou concentrações altas na profundidade $1 \mathrm{~m}$ acima do fundo, com exceção do ponto GU00014, no qual a coleta da sub-superfície apresentou valores mais altos. Os resultados estão apresentados na FIG. 48.

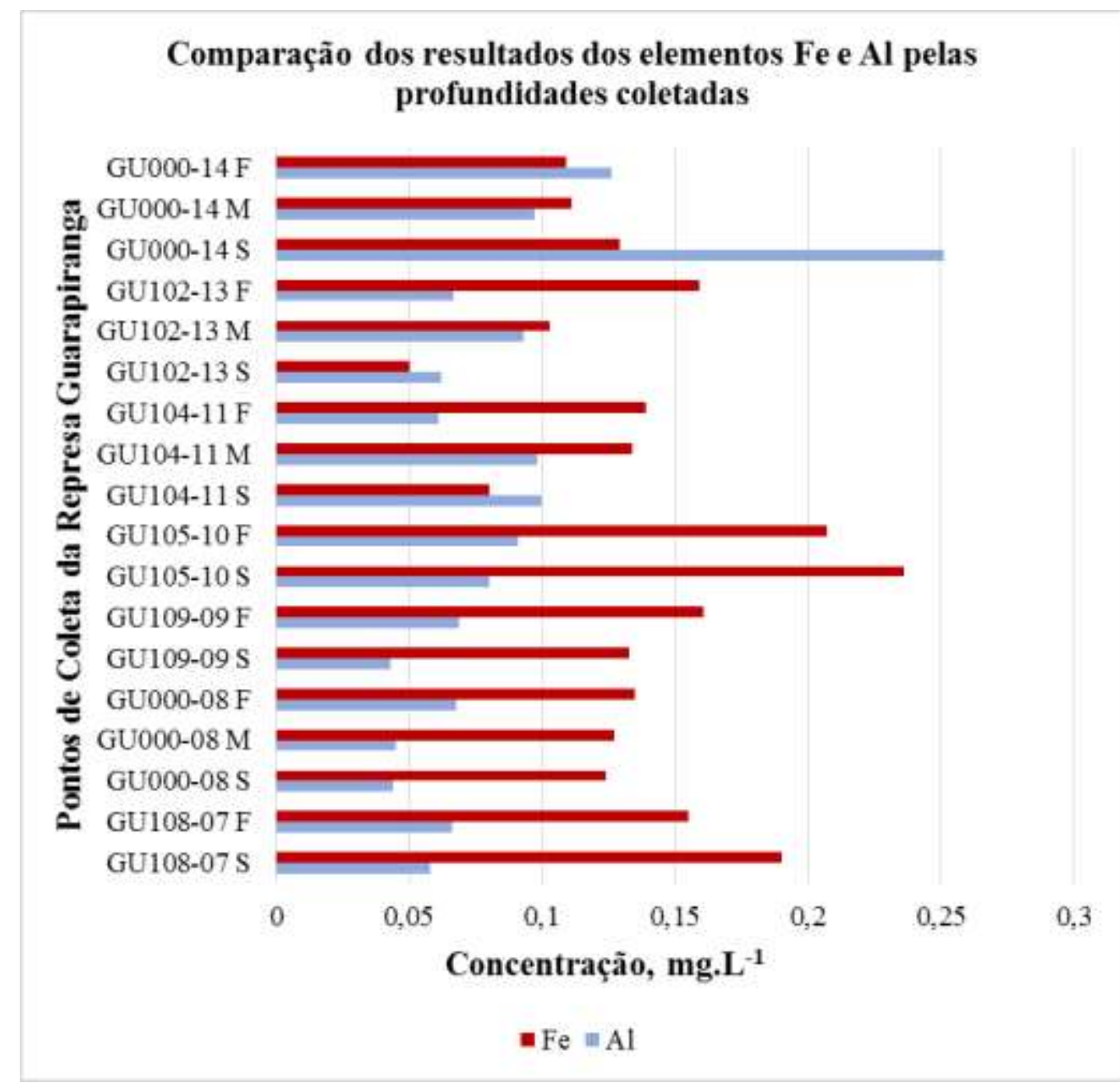

FIGURA 48 - Comparação dos resultados em função das profundidades coletadas - elementos Fe e Al. 


\section{CONCLUSÃO}

O estudo de validação realizado demonstrou que para a metodologia analítica desenvolvida, para os elementos químicos estudados, é seletiva, sensível, linear, precisa e robusta. A execução da validação da metodologia a partir dos parâmetros exigidos na norma do INMETRO (2011) permitiu assegurar a qualidade e a precisão dos resultados obtidos na matriz de interesse.

O método apresentou se seletivo para os elementos estudados. A matriz utilizada para os testes não mostrou nenhuma interferência para a determinação dos elementos, além de apresentar picos definidos nos espectros selecionados.

Os testes de linearidade demonstraram que o método é linear na faixa de trabalho desenvolvida, com um coeficiente de correlação (r) maior que 0,9965 e com os cálculos dos testes $t$ de Student foi possível comprovar matematicamente a linearidade do método. Portanto, foi possível determinar os resultados de intensidade em contagens por segundo (cps) proporcionais as concentrações dos analitos dentro de uma variação conhecida e aceitável.

Os limites de detecção e quantificação do método encontrados demonstraram-se apropriados, em relação aos valores máximos permitidos de concentrações em água nas legislações, como a Resolução CONAMA 357/05 para os metais estudados.

Os testes de precisão, com a utilização do teste de repetitividade foram satisfatórios, pois todos os elementos obtiveram um desvio padrão relativo (DPR\%) abaixo do limite permitido de $16 \%$.

A exatidão do método foi testada através dos testes de recuperação e todos os elementos obtiveram uma recuperação aceitável para os limites selecionados, entre 80 a 99\%. E o método se apresentou robusto, através dos testes realizados.

Foi possível estimar uma incerteza do método a partir das fontes de incerteza e pelo modelo matemático utilizado. A incerteza expandida estimada variou entre 3 e $18 \%$ da concentração encontrada. 
Com o método desenvolvido e validado foi possível analisar as amostras de água, dos 14 pontos coletados, na represa Guarapiranga. A partir da análise das amostras foi possível demonstrar que os elementos sódio, cálcio, potássio e magnésio tem concentrações altas em todos os pontos coletados, evidenciando que esses elementos estão associados a característica geológica da área.

Os elementos ferro, alumínio e cobre apresentaram valores acima da Resolução CONAMA 357/2005. O ferro está associado a característica geológica da área; o alumínio está associado à sua utilização, como sulfato de alumínio, para o tratamento de água, pois a represa Guarapiranga é utilizada como abastecimento público; e o cobre é utilizado, como sulfato de cobre, para o combate dos blooms de algas que estão cada vez mais frequentes na região.

Os outros elementos avaliados, cádmio, crômio, bário, manganês e níquel, apresentaram valores abaixo do permitido pela legislação, sendo considerados satisfatórios. 


\section{APÊNDICE A}

\section{ANALISE DE VARIÂNCIA (ANOVA)}

Conforme apresentado nas TAB. 26 a 37, a regressão é significativa para pra todos os elementos estudados, ou seja, a equação da reta é adequada para os pares de pontos analisados, visto que o valor de $\mathrm{F}_{(1,8,95 \%)}$ calculado de todos os elementos é maior que o $\mathrm{F}_{(1,8,95 \%)}$ crítico.

A falta de ajuste não é evidenciada para os elementos $\mathrm{Al}, \mathrm{Ba}, \mathrm{Ca}, \mathrm{Cd}, \mathrm{Cr}, \mathrm{Cu}, \mathrm{Fe}$, $\mathrm{K}, \mathrm{Mg}, \mathrm{Mn}$, e Ni, porém o $\mathrm{Na}$ foi o único elemento que a falta de ajuste é evidenciada, apresentando um $\mathrm{F}_{(3,4,95 \%)}$ calculado maior que o $\mathrm{F}_{(3,4,95 \%)}$ crítico, indicando que há dispersão nos pontos da curva analítica, contudo observando a porcentagem explicada $(99,37 \%$ explicada em 99,88\% explicável), essa dispersão não compromete o ajuste aplicado e o uso da curva analítica para a quantificação do elemento.

TABELA 28 - Análise de variância (ANOVA) para o alumínio, sem matriz.

\begin{tabular}{|c|c|c|c|c|c|}
\hline $\begin{array}{l}\text { Fonte de } \\
\text { Variação }\end{array}$ & Soma Quadrática & $\begin{array}{l}\text { Graus de } \\
\text { liberdade }\end{array}$ & Média Quadrática & \multicolumn{2}{|c|}{ Teste F } \\
\hline Regressão & 1444392960529,56 & 1 & 1444392960529,56 & $\mathrm{~F}_{(1,8,95 \%)}$ & 46872,66 \\
\hline Resíduos & 246522029,33 & 8 & 30815253,67 & $\mathrm{~F}_{(3,5,95 \%)}$ & 0,39 \\
\hline Falta de Ajuste & 46961372,50 & 3 & 15653790,83 & & \\
\hline Erro Puro & 199560656,83 & 5 & 39912131,37 & & \\
\hline Total & 1444639482558,89 & 9 & & & \\
\hline $\begin{array}{c}\text { \% de variação } \\
\text { explicada }\end{array}$ & 99,98 & & & & \\
\hline \% máxima de & 9999 & $\begin{array}{l}\text { Faixa de } \\
\text { trabalho }\end{array}$ & 0,01 - 1 mg.L. ${ }^{-1}$ & $\begin{array}{c}\mathbf{F}_{\text {tabelado }} \\
(\mathbf{1 , 8 , 9 5 \% )})\end{array}$ & 5,32 \\
\hline explicável & & $\begin{array}{c}\text { Modelo } \\
\text { linear }\end{array}$ & $\begin{array}{c}y=1007502,98 x- \\
3570,26\end{array}$ & $\begin{array}{c}\mathbf{F} \text { tabelado } \\
(\mathbf{3 , 5 , 9 5 \% )}\end{array}$ & 5,41 \\
\hline
\end{tabular}

TABELA 29 - Análise de variância (ANOVA) para o cádmio, sem matriz.

\begin{tabular}{|c|c|c|c|c|c|}
\hline $\begin{array}{l}\text { Fonte de } \\
\text { Variação }\end{array}$ & Soma Quadrática & $\begin{array}{l}\text { Graus de } \\
\text { liberdade }\end{array}$ & Média Quadrática & \multicolumn{2}{|c|}{ Teste F } \\
\hline Regressão & 758862010399,53 & 1 & 758862010399,53 & $\mathrm{~F}_{(1,8,95 \%)}$ & 21626,05 \\
\hline Resíduos & 280721395,79 & 8 & 35090174,47 & $\mathrm{~F}_{(3,5,95 \%)}$ & 1,91 \\
\hline Falta de Ajuste & 149734232,04 & 3 & 49911410,68 & & \\
\hline Erro Puro & 130987163,75 & 5 & 26197432,75 & & \\
\hline Total & 759142731795,32 & 9 & & & \\
\hline $\begin{array}{c}\% \text { de variação } \\
\text { explicada }\end{array}$ & 99,96 & & & & \\
\hline \% máxima de & 000 & $\begin{array}{l}\text { Faixa de } \\
\text { trabalho }\end{array}$ & $0,01-1$ mg.L-1 & $\begin{array}{c}\text { F tabelado } \\
(1,8,95 \%)\end{array}$ & 5,32 \\
\hline $\begin{array}{l}\text { varraçao } \\
\text { explicável }\end{array}$ & 99,98 & & $\begin{array}{c}\mathrm{y}=730272,69 \mathrm{x}- \\
3936,50\end{array}$ & $\begin{array}{c}\text { F tabelado } \\
(3,5,95 \%)\end{array}$ & 5,41 \\
\hline
\end{tabular}


TABELA 30 - Análise de variância (ANOVA) para o crômio, sem matriz.

\begin{tabular}{|c|c|c|c|c|c|}
\hline $\begin{array}{l}\text { Fonte de } \\
\text { Variação }\end{array}$ & Soma Quadrática & $\begin{array}{l}\text { Graus de } \\
\text { liberdade }\end{array}$ & Média Quadrática & \multicolumn{2}{|c|}{ Teste F } \\
\hline Regressão & 43618249270,29 & 1 & 43618249270,29 & $\mathrm{~F}_{(1,8,95 \%)}$ & 60930,26 \\
\hline Resíduos & 5726973,96 & 8 & 715871,74 & $\mathrm{~F}_{(3,5,95 \%)}$ & 1,69 \\
\hline Falta de Ajuste & 2886308,43 & 3 & 962102,81 & & \\
\hline Erro Puro & 2840665,53 & 5 & 568133,11 & & \\
\hline Total & 43623976244,25 & 9 & & & \\
\hline $\begin{array}{c}\text { \% de variação } \\
\text { explicada }\end{array}$ & 99,99 & & & & \\
\hline \% máxima de & 9999 & $\begin{array}{l}\text { Faixa de } \\
\text { trabalho }\end{array}$ & 0,01 - 1 mg.L ${ }^{-1}$ & $\begin{array}{c}\mathrm{F}_{\text {tabelado }} \\
(\mathbf{1 , 8 , 9 5 \% )})\end{array}$ & 5,32 \\
\hline explicável & & Modelo linear & $\begin{array}{c}y=175080,50 x- \\
468,55\end{array}$ & $\begin{array}{c}\text { F tabelado } \\
(3,5,95 \%)\end{array}$ & 5,41 \\
\hline
\end{tabular}

TABELA 31 - Análise de variância (ANOVA) para o cobre, sem matriz.

\begin{tabular}{|c|c|c|c|c|c|}
\hline $\begin{array}{l}\text { Fonte de } \\
\text { Variação }\end{array}$ & Soma Quadrática & $\begin{array}{l}\text { Graus de } \\
\text { liberdade }\end{array}$ & Média Quadrática & \multicolumn{2}{|c|}{ Teste F } \\
\hline Regressão & 4176990586,22 & 1 & 4176990586,22 & $\mathrm{~F}_{(1,8,95 \%)}$ & 61591,58 \\
\hline Resíduos & 542540,50 & 8 & 67817,56 & $\mathrm{~F}_{(3,5,95 \%)}$ & 3,80 \\
\hline Falta de Ajuste & 377153,81 & 3 & 125717,94 & & \\
\hline Erro Puro & 165386,70 & 5 & 33077,34 & & \\
\hline Total & 4177533126,73 & 9 & & & \\
\hline $\begin{array}{c}\text { \% de variação } \\
\text { explicada }\end{array}$ & 99,99 & & & & \\
\hline $\begin{array}{l}\text { \% máxima de } \\
\text { variação } \\
\text { explicável }\end{array}$ & 100 & $\begin{array}{c}\begin{array}{c}\text { Faixa de } \\
\text { trabalho }\end{array} \\
\text { Modelo linear }\end{array}$ & $\begin{array}{c}0,01-1 \mathrm{mg} . \mathrm{L}^{-1} \\
y=54179,55 x-175,49\end{array}$ & $\begin{array}{c}\mathbf{F}_{\text {tabelado }} \\
(\mathbf{1 , 8 , 9 5 \% )} \\
\mathbf{F}_{\text {tabelado }} \\
(\mathbf{3 , 5 , 9 5 \% )}\end{array}$ & $\begin{array}{r}5,32 \\
5,41\end{array}$ \\
\hline
\end{tabular}

TABELA 32 - Análise de variância (ANOVA) para o manganês, sem matriz.

\begin{tabular}{|c|c|c|c|c|c|}
\hline $\begin{array}{l}\text { Fonte de } \\
\text { Variação }\end{array}$ & Soma Quadrática & $\begin{array}{l}\text { Graus de } \\
\text { liberdade }\end{array}$ & Média Quadrática & \multicolumn{2}{|c|}{ Teste F } \\
\hline Regressão & 1444392960529,56 & 1 & 1444392960529,56 & $\mathrm{~F}_{(1,8,95 \%)}$ & 46872,66 \\
\hline Resíduos & 246522029,33 & 8 & 30815253,67 & $\mathrm{~F}_{(3,5,95 \%)}$ & 0,39 \\
\hline Falta de Ajuste & 46961372,50 & 3 & 15653790,83 & & \\
\hline Erro Puro & 199560656,83 & 5 & 39912131,37 & & \\
\hline Total & 1444639482558,89 & 9 & & & \\
\hline $\begin{array}{c}\% \text { de variação } \\
\text { explicada }\end{array}$ & 99,98 & & & & \\
\hline \% máxima de & 9999 & $\begin{array}{l}\text { Faixa de } \\
\text { trabalho }\end{array}$ & 0,01 - 1 mg.L.'-1 & $\begin{array}{c}F_{\text {tabelado }} \\
(1,8,95 \%)\end{array}$ & 5,32 \\
\hline explicável & נ,ענו & $\begin{array}{c}\text { Modelo } \\
\text { linear }\end{array}$ & $\begin{array}{c}y=1007502,97 x- \\
3570,26\end{array}$ & $\begin{array}{c}\mathbf{F}_{\text {tabelado }} \\
(\mathbf{3 , 5 , 9 5 \% )}\end{array}$ & 5,41 \\
\hline
\end{tabular}


TABELA 33 - Análise de variância (ANOVA) para o níquel, sem matriz.

\begin{tabular}{|c|c|c|c|c|c|}
\hline $\begin{array}{l}\text { Fonte de } \\
\text { Variação }\end{array}$ & Soma Quadrática & $\begin{array}{l}\text { Graus de } \\
\text { liberdade }\end{array}$ & Média Quadrática & \multicolumn{2}{|c|}{ Teste F } \\
\hline Regressão & 29795315404,21 & 1 & 29795315404,21 & $\mathrm{F}_{(1,8,95 \%)}$ & 25995,36 \\
\hline Resíduos & 9169427,02 & 8 & 1146178,38 & $\mathrm{~F}_{(3,5,95 \%)}$ & 2,07 \\
\hline Falta de Ajuste & 5082233,11 & 3 & 1694077,70 & & \\
\hline Erro Puro & 4087193,91 & 5 & 817438,78 & & \\
\hline Total & 29804484831,22 & 9 & & & \\
\hline $\begin{array}{c}\% \text { de variação } \\
\text { explicada }\end{array}$ & 99,97 & & & & \\
\hline \% máxima de & 0090 & $\begin{array}{l}\text { Faixa de } \\
\text { trabalho }\end{array}$ & 0,01 - 1 mg.L. ${ }^{-1}$ & $\begin{array}{c}\mathbf{F}_{\text {tabelado }} \\
(1,8,95 \%)\end{array}$ & 5,32 \\
\hline explicável & ני,עינו & $\begin{array}{l}\text { Modelo } \\
\text { linear }\end{array}$ & $\begin{array}{c}y=144703,04 x- \\
1050,56\end{array}$ & $\begin{array}{c}\text { F tabelado } \\
(\mathbf{3 , 5 , 9 5 \% )}\end{array}$ & 5,41 \\
\hline
\end{tabular}

TABELA 34 - Análise de variância (ANOVA) para o bário, sem matriz.

\begin{tabular}{|c|c|c|c|c|c|}
\hline $\begin{array}{l}\text { Fonte de } \\
\text { Variação }\end{array}$ & Soma Quadrática & $\begin{array}{l}\text { Graus de } \\
\text { liberdade }\end{array}$ & Média Quadrática & \multicolumn{2}{|c|}{ Teste F } \\
\hline Regressão & 876234545740319 & 1 & 876234545740319 & $\mathrm{~F}_{(1,8,95 \%)}$ & 161330,83 \\
\hline Resíduos & 43450320605,12 & 8 & 5431290075,64 & $\mathrm{~F}_{(3,5,95 \%)}$ & 0,18 \\
\hline Falta de Ajuste & 4191718014,62 & 3 & 1397239338,21 & & \\
\hline Erro Puro & 39258602590,50 & 5 & 7851720518,10 & & \\
\hline Total & 876277996060924 & 9 & & & \\
\hline $\begin{array}{c}\text { \% de variação } \\
\text { explicada }\end{array}$ & 100 & & & & \\
\hline $\begin{array}{l}\text { \% máxima de } \\
\text { variação } \\
\text { explicável }\end{array}$ & 100 & $\begin{array}{c}\text { Faixa de } \\
\text { trabalho } \\
\text { Modelo } \\
\text { linear }\end{array}$ & $\begin{array}{c}\text { 0,1 - } 10 \mathrm{mg} . \mathrm{L}^{-1} \\
\mathrm{y}=\underset{2481497,49 x}{ } \\
23544,95\end{array}$ & $\begin{array}{c}F_{\text {tabelado }} \\
(1,8,95 \%) \\
F_{\text {tabelado }} \\
(3,5,95 \%)\end{array}$ & $\begin{array}{r}5,32 \\
5,41\end{array}$ \\
\hline
\end{tabular}

TABELA 35 - Análise de variância (ANOVA) para o ferro, sem matriz.

\begin{tabular}{|c|c|c|c|c|c|}
\hline $\begin{array}{l}\text { Fonte de } \\
\text { Variação }\end{array}$ & Soma Quadrática & $\begin{array}{l}\text { Graus de } \\
\text { liberdade }\end{array}$ & Média Quadrática & \multicolumn{2}{|c|}{ Teste F } \\
\hline Regressão & 14011993624618,40 & 1 & 14011993624618,40 & $\mathrm{~F}_{(1,8,95 \%)}$ & $\begin{array}{c}172810 \\
, 33\end{array}$ \\
\hline Resíduos & 648664627,40 & 8 & 81083078,43 & $\mathrm{~F}_{(3,5,95 \%)}$ & 0,68 \\
\hline Falta de Ajuste & 187396811,22 & 3 & 62465603,74 & & \\
\hline Erro Puro & 461267816,18 & 5 & 92253563,24 & & \\
\hline Total & 14012642289245,80 & 9 & & & \\
\hline $\begin{array}{c}\text { \% de variação } \\
\text { explicada }\end{array}$ & 100 & & & & \\
\hline \% máxima de & 100 & $\begin{array}{l}\text { Faixa de } \\
\text { trabalho }\end{array}$ & 0,1 - 10 mg.L -1 $^{-1}$ & $\begin{array}{c}\mathbf{F}_{\text {tabelado }} \\
(\mathbf{1 , 8 , 9 5 \% )}\end{array}$ & 5,32 \\
\hline $\begin{array}{l}\text { varraçao } \\
\text { explicável }\end{array}$ & 100 & $\begin{array}{c}\text { Modelo } \\
\text { linear }\end{array}$ & $\begin{aligned} y= & 313800,49 x \\
& 3990,252\end{aligned}$ & $\begin{array}{c}\text { F tabelado } \\
(\mathbf{3 , 5}, \mathbf{9 5 \%})\end{array}$ & 5,41 \\
\hline
\end{tabular}


TABELA 36 - Análise de variância (ANOVA) para o magnésio, sem matriz.

\begin{tabular}{|c|c|c|c|c|c|}
\hline $\begin{array}{l}\text { Fonte de } \\
\text { Variação }\end{array}$ & Soma Quadrática & $\begin{array}{l}\text { Graus de } \\
\text { liberdade }\end{array}$ & Média Quadrática & \multicolumn{2}{|c|}{ Teste F } \\
\hline Regressão & 13576981314346800 & 1 & 13576981314346800 & $\mathrm{~F}_{(1,8,95 \%)}$ & 110397,24 \\
\hline Resíduos & 983863820629,17 & 8 & 122982977578,65 & $\mathrm{~F}_{(3,5,95 \%)}$ & 1,73 \\
\hline Falta de Ajuste & 500716345629,17 & 3 & 166905448543,06 & & \\
\hline Erro Puro & 483147475000 & 5 & 96629495000 & & \\
\hline Total & 13577965178167400 & 9 & & & \\
\hline $\begin{array}{c}\text { \% de variação } \\
\text { explicada }\end{array}$ & 99,99 & & & & \\
\hline \% máxima de & 100 & $\begin{array}{l}\text { Faixa de } \\
\text { trabalho }\end{array}$ & 0,1 - 10 mg.L L $^{-1}$ & $\begin{array}{c}F_{\text {tabelado }} \\
(1,8,95 \%)\end{array}$ & 5,32 \\
\hline explicável & & $\begin{array}{c}\text { Modelo } \\
\text { linear }\end{array}$ & $\begin{aligned} y= & 9767991,30 x- \\
& 350170,12\end{aligned}$ & $\begin{array}{c}\mathbf{F} \text { tabelado } \\
(\mathbf{3 , 5 , 9 5 \% )}\end{array}$ & 5,41 \\
\hline
\end{tabular}

TABELA 37 - Análise de variância (ANOVA) para o cálcio, sem matriz.

\begin{tabular}{|c|c|c|c|c|c|}
\hline $\begin{array}{l}\text { Fonte de } \\
\text { Variação }\end{array}$ & Soma Quadrática & $\begin{array}{l}\text { Graus de } \\
\text { liberdade }\end{array}$ & Média Quadrática & \multicolumn{2}{|c|}{ Teste F } \\
\hline Regressão & 30096799126153,40 & 1 & 30096799126153,40 & $\mathrm{~F}_{(1,8,95 \%)}$ & 102915,38 \\
\hline Resíduos & 2339537606,17 & 8 & 292442200,77 & $\mathrm{~F}_{(3,5,95 \%)}$ & 0,07 \\
\hline Falta de Ajuste & 99313112,17 & 3 & 33104370,72 & & \\
\hline Erro Puro & 2240224494 & 5 & 448044898,80 & & \\
\hline Total & 30099138663759,60 & 9 & & & \\
\hline $\begin{array}{c}\text { \% de variação } \\
\text { explicada }\end{array}$ & 99,99 & & & & \\
\hline $\begin{array}{l}\text { \% máxima de } \\
\text { variação } \\
\text { explicável }\end{array}$ & 99,99 & $\begin{array}{c}\text { Faixa de } \\
\text { trabalho } \\
\text { Modelo } \\
\text { linear }\end{array}$ & $\begin{array}{c}0,5-50 \mathrm{mg} \cdot \mathrm{L}^{-1} \\
\mathbf{y}=91980,08 x-2923,01\end{array}$ & $\begin{array}{c}\mathbf{F}_{\text {tabelado }} \\
(\mathbf{1 , 8 , 9 5 \% )} \\
\mathbf{F}_{\text {tabelado }} \\
(\mathbf{3 , 5 , 9 5 \% )}\end{array}$ & $\begin{array}{l}5,32 \\
5,41\end{array}$ \\
\hline
\end{tabular}

TABELA 38 - Análise de variância (ANOVA) para o potássio, sem matriz.

\begin{tabular}{|c|c|c|c|c|c|}
\hline $\begin{array}{l}\text { Fonte de } \\
\text { Variação }\end{array}$ & Soma Quadrática & $\begin{array}{l}\text { Graus de } \\
\text { liberdade }\end{array}$ & Média Quadrática & \multicolumn{2}{|c|}{ Teste $\mathbf{F}$} \\
\hline Regressão & 30646723077387,90 & 1 & 30646723077387,90 & $\mathrm{~F}_{(1,8,95 \%)}$ & 1195,66 \\
\hline Resíduos & 205053605810 & 8 & 25631700726,25 & $\mathrm{~F}_{(3,5,95 \%)}$ & 2,56 \\
\hline Falta de Ajuste & 124176126702,96 & 3 & 41392042234,32 & & \\
\hline Erro Puro & 80877479107,05 & 5 & 16175495821,41 & & \\
\hline Total & 30851776683197,90 & 9 & & & \\
\hline $\begin{array}{c}\text { \% de variação } \\
\text { explicada }\end{array}$ & 99,34 & & & & \\
\hline \% máxima de & 0074 & $\begin{array}{l}\text { Faixa de } \\
\text { trabalho }\end{array}$ & 0,5 - 50 mg.L $\mathrm{L}^{-1}$ & $\begin{array}{c}\mathbf{F}_{\text {tabelado }} \\
(\mathbf{1 , 8 , 9 5 \% )}\end{array}$ & 5,32 \\
\hline explicável & 99,14 & $\begin{array}{c}\text { Modelo } \\
\text { linear }\end{array}$ & $\begin{array}{c}y=92816,60 x- \\
138624,96\end{array}$ & $\begin{array}{c}\mathbf{F} \text { tabelado } \\
(3,5,95 \%)\end{array}$ & 5,41 \\
\hline
\end{tabular}


TABELA 39 - Análise de variância (ANOVA) para o sódio, sem matriz.

\begin{tabular}{|c|c|c|c|c|c|}
\hline $\begin{array}{l}\text { Fonte de } \\
\text { Variação }\end{array}$ & Soma Quadrática & $\begin{array}{l}\text { Graus de } \\
\text { liberdade }\end{array}$ & Média Quadrática & \multicolumn{2}{|c|}{ Teste F } \\
\hline Regressão & 5356889092698610 & 1 & 5356889092698610 & $\mathrm{~F}_{(1,8,95 \%)}$ & 1270,45 \\
\hline Resíduos & 33732208586586,10 & 8 & 4216526073323,26 & $\mathrm{~F}_{(3,5,95 \%)}$ & 6,80 \\
\hline Falta de Ajuste & 27089252209886,10 & 3 & 9029750736628,69 & & \\
\hline Erro Puro & 6642956376700 & 5 & 1328591275340 & & \\
\hline Total & 5390621301285200 & 9 & & & \\
\hline $\begin{array}{c}\text { \% de variação } \\
\text { explicada }\end{array}$ & 99,37 & & & & \\
\hline \% máxima de & 0988 & $\begin{array}{l}\text { Faixa de } \\
\text { trabalho }\end{array}$ & 0,5 - 50 mg.L $\mathrm{L}^{-1}$ & $\begin{array}{c}F_{\text {tabelado }} \\
(1,8,95 \%)\end{array}$ & 5,32 \\
\hline explicável & 99,00 & $\begin{array}{c}\text { Modelo } \\
\text { linear }\end{array}$ & $\begin{array}{c}y=1227128,32 x- \\
1867225,12\end{array}$ & $\begin{array}{c}\mathbf{F} \text { tabelado } \\
(3,5,95 \%)\end{array}$ & 5,41 \\
\hline
\end{tabular}




\section{APÊNDICE B}

Na TABELA 40 estão apresentados os resultados de análise, dos metais estudados nesse trabalho, nos pontos coletados da represa Guarapiranga com suas respectivas incertezas de medição.

TABELA 40 - Resultado da concentração dos 12 elementos avaliados nesse trabalho em cada ponto analisado da represa Guarapiranga

\begin{tabular}{|c|c|c|c|c|c|c|c|c|c|c|c|c|}
\hline \multirow{2}{*}{$\begin{array}{l}\text { Pontos de } \\
\text { coleta }\end{array}$} & \multicolumn{12}{|c|}{ Concentração dos elementos $\left(\mathrm{mg} \mathrm{L}^{-1}\right)$} \\
\hline & $\mathbf{N a}$ & Mg & $\mathbf{K}$ & $\mathbf{C a}$ & Al & $\mathrm{Cr}$ & Mn & $\mathbf{F e}$ & $\mathbf{N i}$ & $\mathbf{C u}$ & Cd & $\mathbf{B a}$ \\
\hline G000-01 S & $2,70 \pm 0,52$ & $0,61 \pm 0,05$ & $1,49 \pm 0,22$ & $1,70 \pm 0,04$ & $0,23 \pm 0,014$ & $<\mathrm{LQ}$ & $0,044 \pm 0,002$ & $1,23 \pm 0,06$ & $<\mathrm{LQ}$ & $<\mathrm{LQ}$ & $<\mathrm{LQ}$ & $<\mathrm{LQ}$ \\
\hline G000-02 S & $2,75 \pm 0,53$ & $0,74 \pm 0,06$ & $1,82 \pm 0,27$ & $2,47 \pm 0,06$ & $0,28 \pm 0,017$ & $<\mathrm{LQ}$ & $0,037 \pm 0,002$ & $1,12 \pm 0,05$ & $<\mathrm{LQ}$ & $<\mathrm{LQ}$ & $<\mathrm{LQ}$ & $<\mathrm{LD}$ \\
\hline G000-03 S & $5,37 \pm 1,04$ & $0,92 \pm 0,07$ & $2,37 \pm 0,35$ & $3,78 \pm 0,10$ & $0,16 \pm 0,010$ & $<\mathrm{LQ}$ & $0,029 \pm 0,001$ & $0,45 \pm 0,02$ & $<\mathrm{LQ}$ & $<\mathrm{LQ}$ & $<\mathrm{LQ}$ & $<\mathrm{LD}$ \\
\hline G000-04 S & $7,24 \pm 1,40$ & $1,16 \pm 0,09$ & $2,96 \pm 0,44$ & $5,49 \pm 0,14$ & $0,10 \pm 0,006$ & $<\mathrm{LQ}$ & $0,039 \pm 0,002$ & $0,21 \pm 0,01$ & $<\mathrm{LQ}$ & $<\mathrm{LQ}$ & $<\mathrm{LQ}$ & $<\mathrm{LQ}$ \\
\hline G000-05 S & $10,52 \pm 2,04$ & $1,56 \pm 0,12$ & $3,83 \pm 0,57$ & $8,20 \pm 0,21$ & $0,04 \pm 0,003$ & $<\mathrm{LQ}$ & $0,075 \pm 0,003$ & $0,17 \pm 0,01$ & $<\mathrm{LQ}$ & $0,024 \pm 0,003$ & $<\mathrm{LQ}$ & $<\mathrm{LQ}$ \\
\hline G107-06 S & $11,62 \pm 2,25$ & $1,68 \pm 0,13$ & $4,13 \pm 0,62$ & $9,28 \pm 0,24$ & $0,09 \pm 0,006$ & $<\mathrm{LQ}$ & $0,092 \pm 0,004$ & $0,29 \pm 0,01$ & $<\mathrm{LQ}$ & $0,023 \pm 0,003$ & $<\mathrm{LQ}$ & $<\mathrm{LQ}$ \\
\hline G108-07 S & $11,44 \pm 2,21$ & $1,61 \pm 0,12$ & $4,02 \pm 0,60$ & $8,64 \pm 0,22$ & $0,058 \pm 0,004$ & $<\mathrm{LQ}$ & $0,094 \pm 0,004$ & $0,19 \pm 0,01$ & $<\mathrm{LQ}$ & $0,032 \pm 0,004$ & $<\mathrm{LQ}$ & $<\mathrm{LQ}$ \\
\hline G108-07 F & $11,32 \pm 2,19$ & $1,64 \pm 0,13$ & $4,06 \pm 0,61$ & $8,82 \pm 0,23$ & $0,066 \pm 0,004$ & $<\mathrm{LQ}$ & $0,075 \pm 0,003$ & $0,16 \pm 0,01$ & $<\mathrm{LQ}$ & $0,035 \pm 0,005$ & $<\mathrm{LQ}$ & $0,011 \pm 0,031$ \\
\hline G000-08 S & $11,17 \pm 2,16$ & $1,63 \pm 0,13$ & $4,01 \pm 0,60$ & $8,75 \pm 0,23$ & $0,044 \pm 0,003$ & $<\mathrm{LQ}$ & $0,072 \pm 0,003$ & $0,12 \pm 0,01$ & $<\mathrm{LQ}$ & $0,026 \pm 0,003$ & $<\mathrm{LQ}$ & $0,012 \pm 0,032$ \\
\hline G000-08 M & $11,39 \pm 2,20$ & $1,61 \pm 0,12$ & $3,99 \pm 0,59$ & $8,56 \pm 0,22$ & $0,045 \pm 0,003$ & $<\mathrm{LQ}$ & $0,075 \pm 0,003$ & $0,13 \pm 0,01$ & $<\mathrm{LQ}$ & $0,024 \pm 0,003$ & $<\mathrm{LQ}$ & $<\mathrm{LQ}$ \\
\hline G000-08 F & $11,50 \pm 2,23$ & $1,63 \pm 0,13$ & $4,08 \pm 0,61$ & $8,78 \pm 0,23$ & $0,068 \pm 0,004$ & $<\mathrm{LQ}$ & $0,088 \pm 0,004$ & $0,14 \pm 0,01$ & $<\mathrm{LQ}$ & $0,035 \pm 0,002$ & $<\mathrm{LQ}$ & $<\mathrm{LQ}$ \\
\hline G109-09 S & $11,30 \pm 2,19$ & $1,61 \pm 0,12$ & $4,02 \pm 0,60$ & $8,70 \pm 0,22$ & $0,043 \pm 0,003$ & $<\mathrm{LQ}$ & $0,072 \pm 0,003$ & $0,13 \pm 0,01$ & $<\mathrm{LQ}$ & $0,021 \pm 0,003$ & $<\mathrm{LQ}$ & $<\mathrm{LQ}$ \\
\hline G109-09 F & $11,09 \pm 2,15$ & $1,59 \pm 0,12$ & $3,96 \pm 0,59$ & $8,58 \pm 0,22$ & $0,069 \pm 0,003$ & $<\mathrm{LQ}$ & $0,081 \pm 0,003$ & $0,16 \pm 0,01$ & $<\mathrm{LQ}$ & $0,022 \pm 0,003$ & $<\mathrm{LQ}$ & $<\mathrm{LQ}$ \\
\hline G105-10 S & $12,20 \pm 2,36$ & $1,73 \pm 0,13$ & $4,32 \pm 0,64$ & $9,14 \pm 0,23$ & $0,08 \pm 0,003$ & $<\mathrm{LQ}$ & $0,081 \pm 0,003$ & $0,24 \pm 0,01$ & $<\mathrm{LQ}$ & $0,016 \pm 0,002$ & $<\mathrm{LQ}$ & $0,01 \pm 0,03$ \\
\hline G105-10 F & $11,92 \pm 2,31$ & $1,69 \pm 0,13$ & $4,22 \pm 0,63$ & $9,03 \pm 0,23$ & $0,091 \pm 0,003$ & $<\mathrm{LQ}$ & $0,082 \pm 0,003$ & $0,21 \pm 0,01$ & $<\mathrm{LQ}$ & $0,020 \pm 0,003$ & $<\mathrm{LQ}$ & $<\mathrm{LQ}$ \\
\hline G104-11 S & $11,92 \pm 2,31$ & $1,68 \pm 0,13$ & $4,20 \pm 0,61$ & $9,01 \pm 0,23$ & $0,10 \pm 0,002$ & $<\mathrm{LQ}$ & $0,047 \pm 0,002$ & $<\mathrm{LQ}$ & $<\mathrm{LQ}$ & $0,038 \pm 0,005$ & $<\mathrm{LQ}$ & $<\mathrm{LQ}$ \\
\hline G104-11 M & $11,53 \pm 2,23$ & $1,67 \pm 0,13$ & $4,10 \pm 0,61$ & $8,82 \pm 0,23$ & $0,098 \pm 0,003$ & $<\mathrm{LQ}$ & $0,071 \pm 0,003$ & $0,13 \pm 0,01$ & $<\mathrm{LQ}$ & $0,031 \pm 0,004$ & $<\mathrm{LQ}$ & $<\mathrm{LQ}$ \\
\hline G104-11 F & $11,67 \pm 2,26$ & $1,66 \pm 0,13$ & $4,13 \pm 0,62$ & $8,95 \pm 0,23$ & $0,061 \pm 0,003$ & $<\mathrm{LQ}$ & $0,086 \pm 0,003$ & $0,14 \pm 0,01$ & $<\mathrm{LQ}$ & $0,036 \pm 0,005$ & $<\mathrm{LQ}$ & $0,01 \pm 0,03$ \\
\hline G103-12 S & $11,92 \pm 2,31$ & $1,64 \pm 0,13$ & $4,23 \pm 0,63$ & $8,78 \pm 0,23$ & $0,016 \pm 0,002$ & $<\mathrm{LQ}$ & $0,055 \pm 0,002$ & $0,17 \pm 0,01$ & $<\mathrm{LQ}$ & $0,035 \pm 0,005$ & $<\mathrm{LQ}$ & $0,01 \pm 0,03$ \\
\hline G102-13 S & $11,20 \pm 2,17$ & $1,60 \pm 0,12$ & $4,06 \pm 0,61$ & $8,50 \pm 0,22$ & $0,062 \pm 0,002$ & $<\mathrm{LQ}$ & $0,046 \pm 0,002$ & $<\mathrm{LQ}$ & $<\mathrm{LQ}$ & $0,039 \pm 0,005$ & $<\mathrm{LQ}$ & $<\mathrm{LQ}$ \\
\hline G102-13 M & $11,33 \pm 2,19$ & $1,60 \pm 0,12$ & $4,08 \pm 0,61$ & $8,58 \pm 0,22$ & $0,093 \pm 0,002$ & $<\mathrm{LQ}$ & $0,061 \pm 0,002$ & $0,10 \pm 0,005$ & $<\mathrm{LQ}$ & $0,037 \pm 0,005$ & $<\mathrm{LQ}$ & $<\mathrm{LQ}$ \\
\hline G102-13 F & $11,10 \pm 2,15$ & $1,59 \pm 0,12$ & $4,07 \pm 0,61$ & $8,52 \pm 0,22$ & $0,067 \pm 0,005$ & $<\mathrm{LQ}$ & $0,118 \pm 0,005$ & $0,16 \pm 0,01$ & $<\mathrm{LQ}$ & $0,041 \pm 0,004$ & $<\mathrm{LQ}$ & $<\mathrm{LQ}$ \\
\hline G000-14 S & $11,30 \pm 2,19$ & $1,59 \pm 0,12$ & $4,03 \pm 0,60$ & $8,52 \pm 0,22$ & $0,25 \pm 0,002$ & $<\mathrm{LQ}$ & $0,050 \pm 0,002$ & $0,13 \pm 0,01$ & $<\mathrm{LQ}$ & $0,041 \pm 0,005$ & $<\mathrm{LQ}$ & $<\mathrm{LQ}$ \\
\hline G000-14 M & $11,30 \pm 2,19$ & $1,61 \pm 0,12$ & $4,07 \pm 0,61$ & $8,60 \pm 0,22$ & $0,097 \pm 0,003$ & $<\mathrm{LQ}$ & $0,067 \pm 0,003$ & $0,11 \pm 0,01$ & $<\mathrm{LQ}$ & $0,042 \pm 0,005$ & $<\mathrm{LQ}$ & $<\mathrm{LQ}$ \\
\hline G000-14 F & $11,24 \pm 2,18$ & $1,60 \pm 0,12$ & $4,06 \pm 0,60$ & $8,57 \pm 0,22$ & $0,126 \pm 0,004$ & $<\mathrm{LQ}$ & $0,093 \pm 0,004$ & $0,11 \pm 0,01$ & $<\mathrm{LQ}$ & $0,044 \pm 0,006$ & $<\mathrm{LQ}$ & $<\mathrm{LQ}$ \\
\hline
\end{tabular}




\section{APÊNDICE C}

TABELA 41 - Controle de qualidade dos grupos de análises da digestão ácida em micro-ondas das águas na Represa Guarapiranga

\begin{tabular}{|c|c|c|c|c|c|c|c|c|c|c|c|c|}
\hline PONTOS DE AMOSTRAGEM & $\mathbf{N a}$ & Mg & $\mathbf{K}$ & Ca & Al & $\mathrm{Cr}$ & Mn & $\mathbf{F e}$ & $\mathbf{N i}$ & $\mathbf{C u}$ & Cd & Ba \\
\hline $\begin{array}{c}\text { Branco } \\
(\mathrm{G} 000-01 \mathrm{~S}, \mathrm{G} 000-02 \mathrm{~S}, \mathrm{G} 000-03 \mathrm{~S} \\
\text { G000-04S, G000-05S) }\end{array}$ & $<0,42$ & $<0,02$ & 1,12 & $<0,5$ & 0,02 & $<0,01$ & $<0,01$ & $<0,01$ & $<0,001$ & $<0,01$ & $<0,001$ & $<0,01$ \\
\hline Recuperação, \% & 118 & 57 & 74 & 85 & 180 & 100 & 80 & 241 & 20 & 80 & 80 & 70 \\
\hline $\begin{array}{c}\text { Branco } \\
\text { (G107-06S, G108-07S, G108-07F, } \\
\text { G000-08S) }\end{array}$ & $<0,42$ & $<0,02$ & 0,73 & $<0,5$ & 0,02 & 0,05 & $<0,01$ & $<0,01$ & $<0,001$ & $<0,01$ & $<0,001$ & $<0,01$ \\
\hline Recuperação, \% & 47 & 105 & 91 & 83 & 89 & 130 & 70 & 92 & 60 & 80 & 100 & 93 \\
\hline $\begin{array}{c}\text { Branco (G000-08M, G000-08F, } \\
\text { G109-09S, G109-09F) }\end{array}$ & $<0,42$ & $<0,02$ & 0,076 & $<0,5$ & 0,011 & $<0,01$ & $<0,01$ & $<0,01$ & $<0,001$ & $<0,01$ & $<0,001$ & $<0,01$ \\
\hline Recuperação, \% & 118 & 23 & 167 & 166 & 124 & 124 & 124 & 118 & 124 & 131 & 135 & 127 \\
\hline $\begin{array}{c}\text { Branco (G105-10S, G105-10F, } \\
\text { G104-11S, G104-11M, G104-11F) }\end{array}$ & $<0,42$ & $<0,02$ & 0,77 & $<0,5$ & 0,023 & $<0,01$ & $<0,01$ & $<0,01$ & $<0,001$ & $<0,01$ & $<0,001$ & $<0,01$ \\
\hline Recuperação, $\%$ & 97 & 60 & 127,8 & 50 & 90 & 95 & 96 & 87 & 98 & 105 & 106 & 97 \\
\hline $\begin{array}{c}\text { Branco (G103-12S, G102-13S, } \\
\text { G102-13M, G102-13F }\end{array}$ & $<0,42$ & $<0,02$ & 0,77 & $<0,5$ & 0,023 & $<0,01$ & $<0,01$ & $<0,01$ & $<0,001$ & $<0,01$ & $<0,001$ & $<0,01$ \\
\hline Recuperação, \% & 131 & 60 & 128 & 50 & 90 & 95 & 96 & 87 & 98 & 105 & 106 & 97 \\
\hline $\begin{array}{c}\text { Branco (G000-14S, G000-14M, } \\
\text { G000-14F) }\end{array}$ & $<0,42$ & $<0,02$ & 0,76 & $<0,5$ & 0,06 & $<0,01$ & $<0,01$ & $<0,01$ & $<0,001$ & $<0,01$ & $<0,001$ & $<0,01$ \\
\hline Recuperação, \% & 101 & 61 & 141 & 64 & 101 & 95 & 99 & 78 & 97 & 108 & 109 & 101 \\
\hline
\end{tabular}




\section{REFERÊNCIAS BIBLIOGRÁFICAS}

ACQUASED. Reconstrução palolimnológica da Represa Guarapiranga e diagnóstico da qualidade atual da água e dos sedmentos de mananciais da RMSP com vistas ao gerenciamento do abastecimento. IPEN - Instituto de Pesquisa Energéticas e Nucleares/ Instituto Botânico. São Paulo : s.n., 2012. Projeto Temático - FAPESP - Segundo Relatório. 2009/53898-9.

AGÊNCIA NACIONAL DAS ÁGUAS; CIA SANEAMENTO DO ESTADO DE SÃO PAULO. Guia nacional de coleta e preservação de amostras: água, sedimento, comunidades aquáticas e efluentes líquidos. 2011. Disponível em: < http://www.cetesb.sp.gov.br/userfiles/file/laboratorios/publicacoes/guia-nacional-coleta2012.pdf >. Acesso: 23 de jul. 2015.

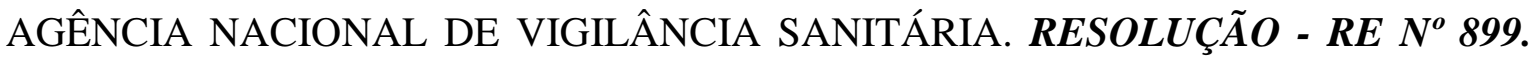
Guia para validação de métodos analíticos e bioanalíticos. BRASIL: ANVISA - Agência Nacional de Vigilância Sanitária, 2003.

APHA AWWA WPCF. American Public Health Association American Water Works Association \& Water Pollution Control Federation. Standard Methods for the examination of water and wastewater. Washington : s.n., 21. 2005.

AVILA-CAMPOS, Mario Julio; NAKANO, Viviane. Metais Pesados: Um Perigo Eminente. São Paulo: Departamento de Microbiologia da Universidade de São Paulo. 2015. Disponível em: <http://www.icb.usp.br/bmm/mariojac/index.php?option=com_content\&view=article\&id= 33\&Itemid=56\&lang=br> $>$. Acesso em: 14 de nov. 2015.

BAIRD, Colin. 2002. Química Ambiental. Porto Alegre : Artmed Editora S.A., 2002.

BALTRUSIS, Nelson; ANCONA, Ana Lúcia. Recuperação Ambiental e Saúde Pública. O programa Guarapiranga. São Paulo : Saúde e Sociedade. Vol. 15, pp. 9 - 21, 2006.

BOMFIM, Vinícius Oliveira Faria. Gestão de Recursos Hídricos e a Contribuição da Ciência Econômica: $O$ caso da conrança pelo uso da pagua para a captação e emissão de 
poluentes. Instituto de Economia (IE)/ UNIVERSIDADE ESTADUAL DE CAMPINAS UNICAMP. $2011 . \quad$ Disponível em: <http://www.prp.unicamp.br/pibic/congressos/xixcongresso/paineis/046930.pdf>. Acesso: 23 de jul. 2015.

BOSS, Charles B; FREDEEN, Kenneth J. Concepts, Instrumentation and Techniques in Inductively Coupled Plasma Optical Emission Spectrometry.1997. Disponível em: < http://www.atoomspectrometrie.nl/Icpconceptsbook.pdf >. Acesso: 08 de agos. de 2015.

BRAGA, Benetid; HESPANHOL, Ivanildo; CONEJO, João G. Lotufo; MIERZWA, José Carlos; BARROS, Mario Thadeu L. de; SPENCER, Milton; PORTO, Monica; NUCCI, Nelson; JULIANO, Neusa; EIGER, Sérgio. Introdução à Engenharia Ambiental. São Paulo : Prentice Hall, 2005.

BRASIL. Mananciais. Ministério do Meio Ambiente, 2015. Disponível em: < http://www.mma.gov.br/cidades-sustentaveis/aguas-urbanas/mananciais $>$. Acesso: 29 de jun. de 2015.

BRASIL. CONAMA - CONSELHO NACIONAL DO MEIO AMBIENTE - RESOLUÇÃO 357/2005. Ministério do Meio Ambiente. 17 de Março de 2005. Disponível em: < http://www.mma.gov.br/port/conama/res/res05/res35705.pdf $>$. Acesso: 15 de jun. de 2015.

BRASIL. Manual de Impactos Ambientais - Orientações Básicas sobre Aspectos Ambientais Produtivas. Ministério do Meio Ambiente. 2013. Disponível em: 〈http://www.mma.gov.br/estruturas/sqa_pnla/_arquivos/manual_bnb.pdf $>$. Acesso: 15 jan. 2015

CENTRO DE INFORMAÇÃO METAL MECÂNICA. Sulfato de alumínio: eficaz e barato para tratar água. CIMM - Centro de Informação Metal Mecânica. 02 de Dezembro de 2008. Disponivel em: <http://www.cimm.com.br/portal/noticia/exibir_noticia/4592-sulfato-dealuminio-eficaz-e-barato-para-tratar-agua $>$. Acesso: 21 de jul. de 2015.

CIA SANEAMENTO BÁSICO DO ESTADO DE SÃO PAULO. DOSSI $\hat{\boldsymbol{E}}$ - Sistema Guarapiranga. Espaço das Águas. São Paulo : Fundação Patrimônio Histórico da Energia 
e Saneamento Companhia de Saneamento Básico do Estado de São Paulo - SABESP, 2008.

CIA SANEAMENTO BÁSICO DO ESTAdO DE SÃO PAULO. Água no Planeta. SABESP - CIA SANEAMENTO BÁSICO DO ESTADO DE SÃO PAULO. 2015. Disponível em: <http://site.sabesp.com.br/site/interna/Default.aspx?secaoId=97>. Acesso: 06 de fev. 2015.

CIA SANEAMENTO BÁSICO DO ESTADO DE SÃO PAULO. CHESS - Crise Hídrica, Estratégica e Soluções da SABESP, para Região Metropolitana de São Paulo. SABESP CIA SANEAMENTO BÁSICO DO ESTADO DE SÃO PAULO. 2015. Disponível em: < http://site.sabesp.com.br/site/uploads/file/crisehidrica/chess_crise_hidrica.pdf>. Acesso: 14 de nov. 2015.

COELHO, Gustavo Ferreira; GONÇALVES Jr., Affonso Celso; TARLEY, Ricardo Teixeira; CASARIN, Juliana; NACKE, Herbert; FRANCZISKOWSKI, Marcio André. Removal of metal ions $\mathrm{Cd}$ (II), Pb (II), and Cr (III) from water by the cashew nut shell Anacardium occidentale L. Ecological Engineering. 2014.

COMPANHIA AMBIENTAL DO ESTADO DE SÃO PAULO. FIT - Ficha de Informação Toxicológica - Crômio e seus compostos. CETESB - Companhia de Tecnologia de Saneamento Ambiental. Janeiro de 2012. Disponível em: <http://www.cetesb.sp.gov.br/userfiles/file/laboratorios/fit/cromio.pdf $>$. Acesso: $16 \mathrm{de} \mathrm{dez.}$ de 2014.

COMPANHIA AMBIENTAL DO ESTADO DE SÃO PAULO. FIT - Ficha de Informação Toxicológica - Bário. CETESB - Companhia de Tecnologia de Saneamento Ambiental do Estado de São Paulo. Janeiro de 2012. Disponível em: $\langle$ http://www.cetesb.sp.gov.br/userfiles/file/laboratorios/fit/bario.pdf $>$. Acesso: $07 \mathrm{de} \mathrm{dez.}$ 2014

COMPANHIA AMBIENTAL DO ESTADO DE SÃO PAULO. FIT - Ficha de informação toxicológica - Cádmio. CETESB - Companhia de Tecnologia de Saneamento Ambiental do Estado de São Paulo. Janeiro de 2012. Disponível em: $\langle$ http://www.cetesb.sp.gov.br/userfiles/file/laboratorios/fit/cadmio.pdf $>$. Acesso: $15 \mathrm{dez}$. 
COMPANHIA AMBIENTAL DO ESTADO DE SÃO PAULO. FIT - Ficha de Informação Toxicológica - Manganês. CETESB - Companhia de Tecnologia de Saneamento Ambiental do Estado de São Paulo. Janeiro de 2012. Disponível em: <http://www.cetesb.sp.gov.br/userfiles/file/laboratorios/fit/manganes.pdf $>$. Acesso: $07 \mathrm{de}$ dez. 2014.

COMPANHIA AMBIENTAL DO ESTADO DE SÃO PAULO. FIT - Ficha de Informação Toxicológica - Níquel e seus compostos. CETESB - Companhia de Tecnologia de Saneamento Ambiental do Estado de São Paulo. Janeiro de 2012. Disponível em: 〈http://www.cetesb.sp.gov.br/userfiles/file/laboratorios/fit/niquel.pdf>. Acesso: $26 \mathrm{dez}$. 2014.

COMPANHIA AMBIENTAL DO ESTADO DE SÃO PAULO. FIT - Ficha de Informação Toxixológica - Potássio. CETESB - Companhia de Tecnologia de Saneamento Ambiental do Estado de São Paulo. Julho de 2012. Disponível em: 〈http://www.cetesb.sp.gov.br/userfiles/file/laboratorios/fit/potassio.pdf $>$. Acesso: $25 \mathrm{dez}$. 2014.

COMPANHIA AMBIENTAL DO ESTADO DE SÃO PAULO. Significado Ambiental $\boldsymbol{e}$ Sanitário das Variáveis de Qualidade das Águas e dos Sedimentos e Metodologias Analíticas e de Amostragem. CETESB - Comapanhia Ambiental do Estado de São Paulo. 2009. Disponível em: 〈http://www.cetesb.sp.gov.br/userfiles/file/agua/aguassuperficiais/variaveis.pdf>. Acesso: 25 de set. 2015.

CORNELIS, Rita; CARUSO, Joe; CREWS, Helen; HEUMANN, Klaus. Handbook of Elemental Speciation II - Species $i$ the Envitonment, Food, Medicine and Occupational Health. West Sussex : Wiley, 2005.

CUNHA, Davi Gasparini Fernandes; CALIJURI, Maria do Carmo; LAMPARELLI, Marta Condé; MANEGON Jr., Nelson. 2013. Resolução CONAMA 357/2005: análise espacial e temporal de não conformidades em rios e reservatóriosdo estado de São Paulo de acordo com seus enquadramentos (2005-2009). 2013. Disponivel em: < 
http://www.scielo.br/pdf/esa/v18n2/a08v18n2.pdf>. Acesso em: 23 de jul 2015.

DO CANTO, Eduardo Leite. Minerais, minérios, metais - De onde vêm?, Para onde vão? São Paulo : Moderna, 2006.

DUFFUS, John H. “Heavy Metals”-A Meaningless Term?. Vol. 74, 5, pp. 793-807. 2002.

ESCAP. A. Role of various environment-related measures: Command and control instruments (CAC). Economica and Social Commission for Asia and the Pacif. UNESCAP, 2003. Disponível em: 〈http://www.unescap.org/drpad/vc/orientation/M5_2.htm>. Acesso em: 30 de set. 2013.

EURACHEM/CITAC Guide. Quantifying Uncertainty in Analytical Measurentent. United Kingdom : s.n., Third Edition. 2012.

FLORIANO, Eduardo Pagel. Politcas de Gestão Ambiental. SANTA MARIA : Biblioteca Virtual de Desarrollo Sostenible y Salud Ambiental, 2005.

FURUSAWA, Hélio A. Estimativa de incerteza em análise química. [Fonte eletrônica excel]. Documento Interno IPEN. São Paulo : IPEN, 2007.

FURUSAWA, Hélio A. Validação de Ensaios Químicos. Adaptação eletrônica baseada no documento DOQ-CGCRE-008 de 01/03/2003 do INMETRO. Documento Interno IPEN. São Paulo : IPEN-CNEN-SP, 2007.

GARCIA, Solange Cristina, GIODA, Adriana; NASCIMENTO, Denise Bohrer do. $\boldsymbol{O}$ Problema da Contaminação na Determinação de Traços de Alumínio. Santa Maria, Rio Grande do Sul : Quimica Nova, Quimica Nova, 1996.

GINÉ ROSIAS, Maria Fernanda. Espectrometria de emissão atômica com plasma acoplado indutivamente - ICP-AES. Piracicaba - SP : CENA - Centro de Energia Nuclear na Agricultura/ USP - Universidade de São Paulo, 1998.

HARRIS, Daniel C. Análise Química Quantitativa. Rio de Janeiro : LTC, 2007. 
HOU, Xiandeng; JONES, Brandley T. Inductively Coupled Plasma/Optical Emission Spectrometry. Encyclopedia of Analytical Chemistry. Winston-Salem, USA : R.A. Meyers, 2000.

INMETRO/CICMA/SEPIN. Avaliação de dados de medição: Guia para a expressão de incerteza de medição - GUM 2008. INSTITUTO NACIONAL DE METROLOGIA, NORMALIZAÇÃO E QUALIDADE INDUSTRIAL; 2012. Traduzido de: Evaluation of measurement data: Guide to the expression of uncertainty in measurement - GUM 2008. 2008.

INSTITUTO BRASILEIRO DE GEOGRAFIA E ESTATÍSTICA. Cidades. IBGE Instituto Brasileiro de Geografia e Estatística. 2015. Disponível em: <http://cidades.ibge.gov.br/xtras/uf.php?lang=\&coduf=35\&search=sao-paulo $>$. Acesso: 17 de fev. 2015.

INSTITUTO NACIONAL DE METROLOGIA, NORMALIZAÇÃO E QUALIDADE INDUSTRIAL. Orientação sobre a validação de métodos analíticos. Rio de Janeiro : INMETRO - Instituto Nacional de Metrologia, Normalização e Qualidade Industrial. Vol. Julho, Revisão 4. 2011.

INSTITUTO NACIONAL DE METROLOGIA, NORMALIZAÇÃO E QUALIDADE INDUSTRIAL. Orietação sobre validação de métodos de ensaios químicos - DOCCGCRE-008. Rio de Janeiro : INMETRO - Instituto Nacional de Metrologia, Normalização e Qualidade Industrial. DOC-CGCRE-008, Vol. Revisão 2, 2007.

ITALIANI, Rafael; LEITE, Fabio. Guarapiranga e Cantareira quase igualam captação. Estadão - O Estado de São Paulo, 18 de Dezembro de 2014. [Disponível em: <http://saopaulo.estadao.com.br/noticias/geral,guarapiranga-e-cantareira-quase-igualamcaptacao,1608874>. Acesso em: 19 de jul. 2015.

KUBICEK, Andreas; JOPP, Fred; BRECKLING, Broder; LANGE, Christoph; REUTER, Hauke. Context-oriented model validation of individual-based models in ecology: A hierarchically structured approach to validate qualitative, compositional and quantitative characteristics. Ecological Complexity. Vol. 22, pp. 178-191. 2015. 
LEMES, M J L. Avaliação de metais e elementos-traço em águas e sedimentos das bacias hidrográficas dos rios Mogi - Guaçu e Pardo. Dissertação (Mestrado). São Paulo : IPEN/USP, 2001.

MEDEIROS, Miguel de Araújo. Elemento Químico - Ferro. 12 de Março de 2010. Disponível em <http://qnesc.sbq.org.br/online/qnesc32_3/11-EQ-6809.pdf $>$. Acesso em: 25 de dez. 2014.

MORTATTI, Jefferson; PROBST, Jean-Luc. Characteristics of heavy metals and their evaluation in suspended sediments from Piracicaba river basin (São Paulo, Brazil). São Paulo : Rev Brasileira de Geociências. Vol. 40, pp. 375-379. Setembro de 2010.

MOZETO, A. A; SILVÉRIO, P. F.; DE PAUlA, F. C. F.; BEVIlACQUA, J. E.; PATELLA, E.; JARDIM, W. F. Weakly-bound metals and total nutrient concetrations of bulk sediments from some water reservoirs in São Paulo state SE Brazil. Sediment Quality Assesment and Manegement. Burlington, Canadá : M. Munawar, pp. 221-339. 2003.

PEIXOTO, Eduardo Motta Alves. Elemento Químico - Cálcio. Quimica Nova na Escola. 20, Novembro de 2004. Disponivel em: http://qnesc.sbq.org.br/online/qnesc20/v20a12.pdf>. Acesso: 25 de set. 2015.

PEIXOTO, Eduardo Motta Alves. Magnésio. Química Nova na Escola. 12, Novembro de 2000. Disponivel em: 〈http://qnesc.sbq.org.br/online/qnesc12/v12a11.pdf>. Acesso: 25 de set. 2015.

PEIXOTO, Eduardo Motta Alves. Elemento Químico - Alumínio. Química Nova na Escola. 13, Maio de 2001. Disponivel em: <http://qnesc.sbq.org.br/online/qnesc13/13aluminio.pdf>. Acesso: 25 de set. 2015.

PEIXOTO, Eduardo Motta Alves. Elemento Químico - Sódio. Química Nova na Escola. 10, Novembro de $1999 . \quad$ Disponivel em: http://qnesc.sbq.org.br/online/qnesc10/elemento.pdf>. Acesso: 25 de set. 2015.

PEREIRA, Andréia Mara; LIMA, Divina Aparecida Leonel Lunas; REYDON, Bastiaan Philip. As políticas de comando e controle são a melhor alternativa para o conhecimento 
tradicional?. VII Encontro da Sociedade Brasileira de Economia Ecológica. Este estudo faz parte da pesquisa realizada para dissertação de mestrado da autora, intitulada: Condicionantes. Fortaleza : s.n., 2007.

RIBANI, Marcelo; BOTTOLLI, Carla Beatriz Grespan; COLLINS, Carol H.; JARDIM, Isabel Cristina Sales Fontes; MELO, Lúcio Flávio Costa . Validação em métodos cromatográficos e eletroforéticos. Quím. Nova Vol. 27, $n^{\circ}$ 5. São Paulo: Scielo. 2004. Disponível em: < http://www.scielo.br/scielo.php?script=sci_arttext\&pid=S0100-

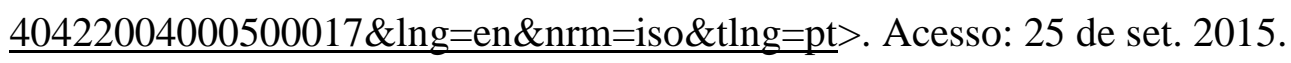

RICHTER, Eduardo M.; FORNARO, Adalgiza; LAGO, Claudimir L. do; ANGNES, Lúcio. Avaliação da Composição química de águas do sistema Guarapiranga: Estudo de Caso nos anos 2002 e 2003. 5 s.l. : Rev Quím Nova, Vol. 30, pp. 1147 - 1152. 2007.

ROCHA, Julio César, ROSA, André Henrique e CARDOSO, Arnaldo Alves. Introdução à Química Ambiental. São Paulo : Artmed Editora S.A., 2009.

RODRIGUES, Mônica Aparecida, SILVA, Priscila Pereira e GUERRA, Wendell. 2012. Elemento Químico - Cobre. Química Nova na Escola. Vol. 34, n 3, Agosto de 2012. Disponível em: 〈http://qnesc.sbq.org.br/online/qnesc34_3/10-EQ-37-10.pdf>. Acesso: 25 set. 2015.

SANTORO, Paula Freire, FERRARA, Luciana Nicolau e WHATELEY, Marussia. Mananciais: diagnóstico e políticas habitacionais. São Paulo : Instituto Socioambiental, 2009. Disponível em: 〈http://www.socioambiental.org/banco_imagens/pdfs/10368.> . Acesso: 25 de set. 2015.

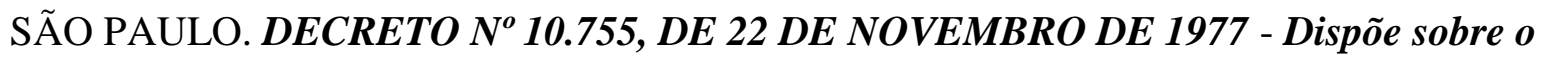
enquadramento dos corpos de água receptores na classificação prevista no Decreto $\boldsymbol{n}^{o}$ 8.468, de 8 de setembro de 1976, e dá providências correlatas. São Paulo : s.n., 1977.

SÃO PAULO. História da Represa Guarapiranga. Prefeitura do Estado de São Paulo. 2013. Disponível em: 〈http://ww2.prefeitura.sp.gov.br/guarapiranga/historia_02.asp >. Acesso em: 17 de fev. 2013. 
SÃO PAULO. Lei $n^{\circ}$ 12.233. Sistema Ambiental Paulista. Governo do Estado de São Paulo, 16 de Janeiro de 2006. Disponível em: < http://www.sigam.ambiente.sp.gov.br/sigam2/repositorio/259/documentos/12233_2006.pdf >. Acesso em: 17 de fev. 2013.

SHIHOMATSU, Helena Miho. Desenvolvimento e validação de metodologia SPE-LCMS/MS para a determinação de fármacos e droga de abuso nas águas da represa Guarapiranga-São Paulo/SP, Brasil. São Paulo : Instituto de Pesquisas Energéticas e Nucleares (IPEN). Tese de doutorado em ciências na área de tecnologia nuclear - materias. 2015.

SILVA, Andréia de Paulo; ALVES, Miriam C. Carvalho. Como iniciar a validação de métodos analíticos. São Paulo : ENQUALAB-2006 - Congresso e Feira da Qualidade em Metrologia, 2006.

SILVA, Douglas B.; MONTEIRO, Lucilena R.; FAUSTINO, Mainara Generoso; BICUDO, Carlos; BICUDO, Denise; COTRIM, Marycel E. B.; PIRES, Maria Aparecida F. 2013. Estudo sobre ferro e fósforo nas águas e sedimentos da represa Guarapiranga São Paulo - Brasil. XX SIMPÓSIO BRASILEIRO DE RECURSOS HÍDRICOS. Rio Grande do Sul, Bento Gonçalves, Brasil : s.n., 2013.

SKOOG, Douglas A, HOLLER, F James; NIEMAN, Timothy A. Principles of Instrumental Analysis. Orlando : Harcount Brace \& Company, pp. 796-829. Vol. Fifth Edition, 1998

SMA/CEA. Caderno Ambiental Guarapiranga. Secretaria do Meio Ambiente / Secretaria da Educação, Governo do Estado de São Paulo. São Paulo : Secretaria do Meio Ambiente/Coordenadoria de Educação Ambiental, 2008. São Paulo : SMA/CEA, 2008.

UMBUZEIRO, Gisela de Aragão; LORENZETTI, Maria de Lourdes. Fundamentos da Gestão da Qualidade das Águas Superficiais - Resolução CONAMA 357/2005. São Paulo, Limeira : Biblioteca da Unicamp/CPEA, 2009.

US ENVIRONMETAL PROTECTION AGENCY. Method 6010c - inductively coupled plasma-atomic emission spectrometry. 2007. Disponível em: < 
http://www.epa.gov/osw/hazard/testmethods/sw846/pdfs/6010c.pdf>. Acesso em: 04 de maio de 2015.

US ENVIRONMETAL PROTECTION AGENCY. Microwave assisted acid digestion of aqueous samples and extracts - Method 3015a. Fevereiro de 2007. Disponível em: < http://www.epa.gov/osw/hazard/testmethods/sw846/pdfs/3015a.pdf $>$. Acesso em: 10 de Dezembro de 2014.

VARELA, Carmen Augusta. Instrumentos de políticas ambientais, casos de aplicação e seus impactos. Relatório de Pesquisa No 62/2001 . São Paulo : EAESP/FGV/NPP NÚCLEO DE PESQUISAS E PUBLICAÇÕES , 2001.

VIEIRA, Maria Cristina Ribeiro. Absorção de metais pesados nas partículas em suepensão nas águas naturais. Influência das características físico-químicas das superfícies. Porto : Universidade do Porto - Faculdade de Engenharia, Tese, 2000.

VOCABULÁRIO INTERNACIONAL DE METROLOGIA. VIM - Vocabulário Internacional de Metrologia. Duque de Caxias : INMETRO, 3 edição. Traduzido por grupo de trabalho luso-brasileiro. 2012.

WEINER, Eugene R. Applications of Environmental Aquatic Chemistry: A Pratical Guide. 2007. Disponível em: <http://faculty.ksu.edu.sa/Almutaz/Documents/ChE438/Applications\%20of\%20Environmental\%20Aquatic\%20Chemistry.pdf>. Acesso em: 15 de jan. 2015.

WHATEly, Marussia; CUNHA, Pilar Machado. 2006. Guarapiranga 2005 - Como e porque São Paulo está perdendo este manancial. São Paulo : Instituto Socioambiental ISA, 2006.

WHATEly, Marussia; CUNHA, Pilar Machado. Seminário Guarapiranga: Proposição de ações prioritárias para garantir água de boa qualidade para abastecimento. São Paulo : Instituto Socioambiental, 2006. 
